\title{
Frantz FANON
}

Psychiatre et militant de l'indépendance algérienne dans le FLN

\section{(1952)}

\section{PEAU NOIRE MASQUES BLANCS}

Un document produit en version numérique par Émilie Tremblay, bénévole, Doctorante en sociologie à l'Université de Montréal Courriel: emiliet82@yahoo.fr Page web dans Les Classiques des sciences sociales.

Dans le cadre de: "Les classiques des sciences sociales" Une bibliothèque numérique fondée et dirigée par Jean-Marie Tremblay, professeur de sociologie au Cégep de Chicoutimi

Site web: http://classiques.uqac.ca/

Une collection développée en collaboration avec la Bibliothèque Paul-Émile-Boulet de l'Université du Québec à Chicoutimi

Site web: http://bibliotheque.uqac.ca/ 


\section{Politique d'utilisation de la bibliothèque des Classiques}

Toute reproduction et rediffusion de nos fichiers est interdite, même avec la mention de leur provenance, sans l'autorisation formelle, écrite, du fondateur des Classiques des sciences sociales, Jean-Marie Tremblay, sociologue.

Les fichiers des Classiques des sciences sociales ne peuvent sans autorisation formelle:

- être hébergés (en fichier ou page web, en totalité ou en partie) sur un serveur autre que celui des Classiques.

- servir de base de travail à un autre fichier modifié ensuite par tout autre moyen (couleur, police, mise en page, extraits, support, etc...),

Les fichiers (.html, .doc, .pdf, .rtf, .jpg, .gif) disponibles sur le site Les Classiques des sciences sociales sont la propriété des Classiques des sciences sociales, un organisme à but non lucratif composé exclusivement de bénévoles.

Ils sont disponibles pour une utilisation intellectuelle et personnelle et, en aucun cas, commerciale. Toute utilisation à des fins commerciales des fichiers sur ce site est strictement interdite et toute rediffusion est également strictement interdite.

L'accès à notre travail est libre et gratuit à tous les utilisateurs. C'est notre mission.

Jean-Marie Tremblay, sociologue

Fondateur et Président-directeur général, LES CLASSIQUES DES SCIENCES SOCIALES. 


\section{REMARQUE}

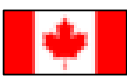

Ce livre est du domaine public au Canada parce qu'une œuvre passe au domaine public 50 ans après la mort de l'auteur(e).

Cette œuvre n'est pas dans le domaine public dans les pays où il faut attendre 70 ans après la mort de l'auteur(e).

Respectez la loi des droits d'auteur de votre pays. 
Du même auteur

Peau noire, masques blancs, Seuil, 1952 ; rééd. Seuil, coll. «Point/Essais », 1971.

Sociologie d'une révolution. L'An $V$ de la révolution algérienne, Librairie François Maspero, coll. « Cahiers libres », 1959 ; rééd. La Découverte, coll. « Redécouverte», 2001.

Pour la révolution africaine, Librairie François Maspero, coll. « Cahiers libres», 1964 ; rééd. La Découverte, coll. « Redécouverte», 2001. 
Cette édition électronique a été réalisée par Émilie Tremblay, bénévole, doctorante en sociologie à l'Université de Montréal

Courriel : emiliet82@yahoo.fr

à partir de :

Frantz FANON

PEAU NOIRE, MASQUES BLANCS.

Préface (1952) et Postface (1965) de Francis Jeanson. Paris: Les Éditions du Seuil, 1952, 239 pp. Collection : La condition humaine.

Polices de caractères utilisée:

Pour le texte: Comic Sans, 12 points.

Pour les citations : Comic Sans, 12 points.

Pour les notes de bas de page : Comic Sans, 10 points.

Édition électronique réalisée avec le traitement de textes Microsoft Word 2008 pour Macintosh.

Mise en page sur papier format : LETTRE US, $8.5^{\prime \prime} \times 11^{\prime \prime}$ )

Édition numérique réalisée le 6 décembre 2011 à Chicoutimi, Ville de Saguenay, Québec. 


\section{Frantz FANON}

Psychiatre, intellectuel antillais

et militant de l'indépendance algérienne dans le FLN

\section{PEAU NOIRE, MASQUES BLANCS}

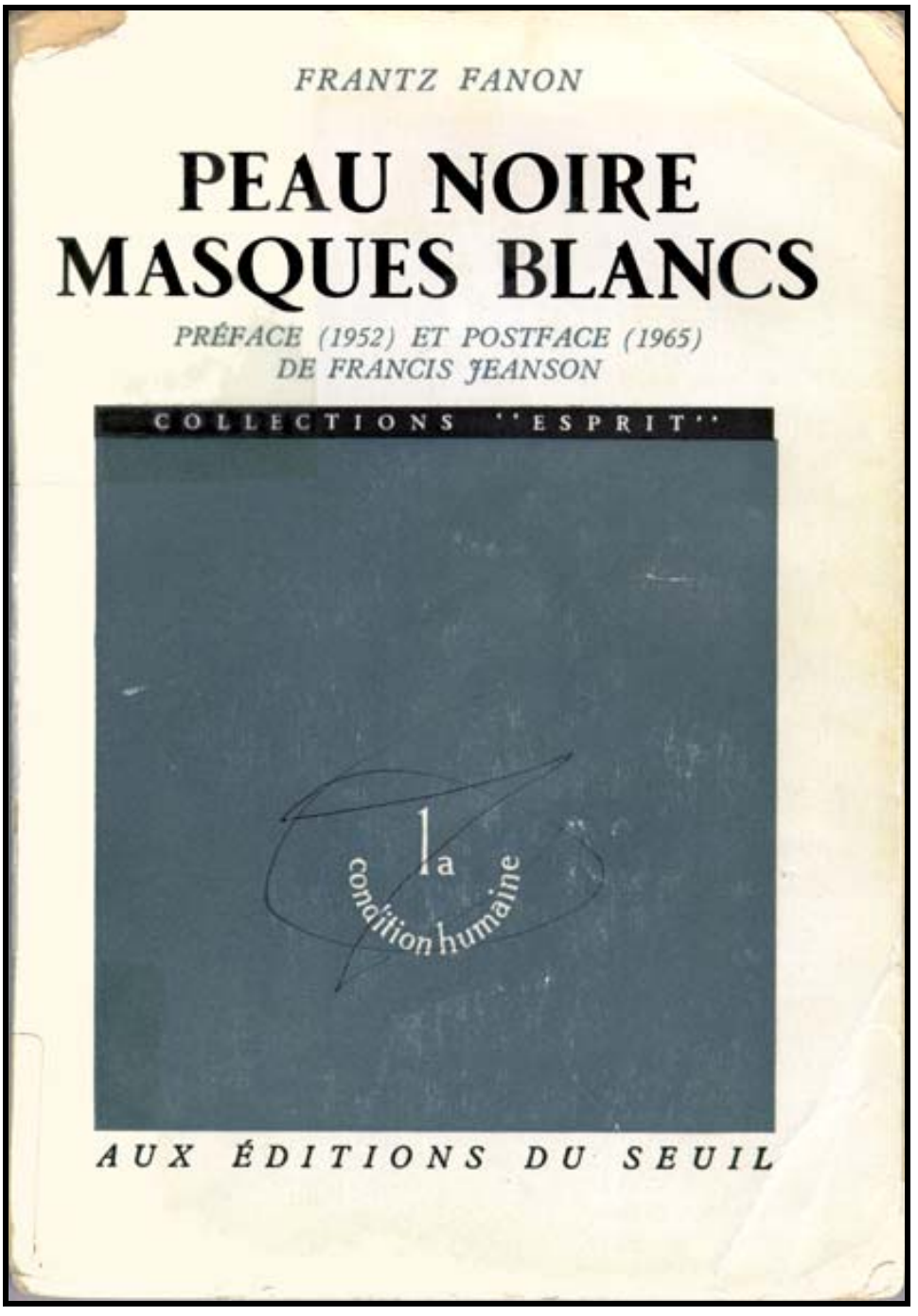

Préface (1952) et Postface (1965) de Francis Jeanson. Paris : Les Éditions du Seuil, 1952, 239 pp. Collection : La condition humaine. 
[239]

\section{Table des matières}

Quatrième de couverture

Préface

Introduction

Chapitre I. Le Noir et le langage

Chapitre II. La femme de couleur et le Blanc

Chapitre III. L'homme de couleur et la Blanche

Chapitre IV. Du prétendu complexe de dépendance du colonisé

Chapitre V. L'expérience vécue du Noir

Chapitre VI. Le Nègre et la psychopathologie

Chapitre VII. Le Nègre et la reconnaissance

En quise de conclusion

Reconnaissance de Fanon 
PEAU NOIRE. MASQUES BLANCS.

\section{QUATRIÈME DE COUVERTURE}

\section{Retour à la table des matières}

Le premier livre de Frantz Fanon n'est pas seulement un extraordinaire document psychologique et historique sur la révolte du colonisé. Après la guerre d'Algérie, après la décolonisation - qui a laissé de côté les Antilles, première patrie de l'auteur - "Peau noire, masques blancs" garde toute sa valeur prophétique, car le racisme, malgré les horreurs dont il a comblé le monde, reste un problème d'avenir. Il est ici abordé et combattu de front, avec toutes les ressources des sciences de l'homme, et avec la passion brûlante de celui qui allait devenir un pionnier de la révolution algérienne et un maître à penser pour beaucoup d'intellectuels des peuples sous-développés. Mais, à travers la lutte des consciences, c'est vers la dignité de soi et la liberté de tous que s'élève Frantz Fanon dans une conclusion qui est un cri inoubliable.

Francis Jeanson qui, en 1952, avait préfacé, la première édition, donne, dans une postface, un témoignage de fidélité à celui qui consacra sa courte vie de penseur et de militant à "lâcher l'homme". 


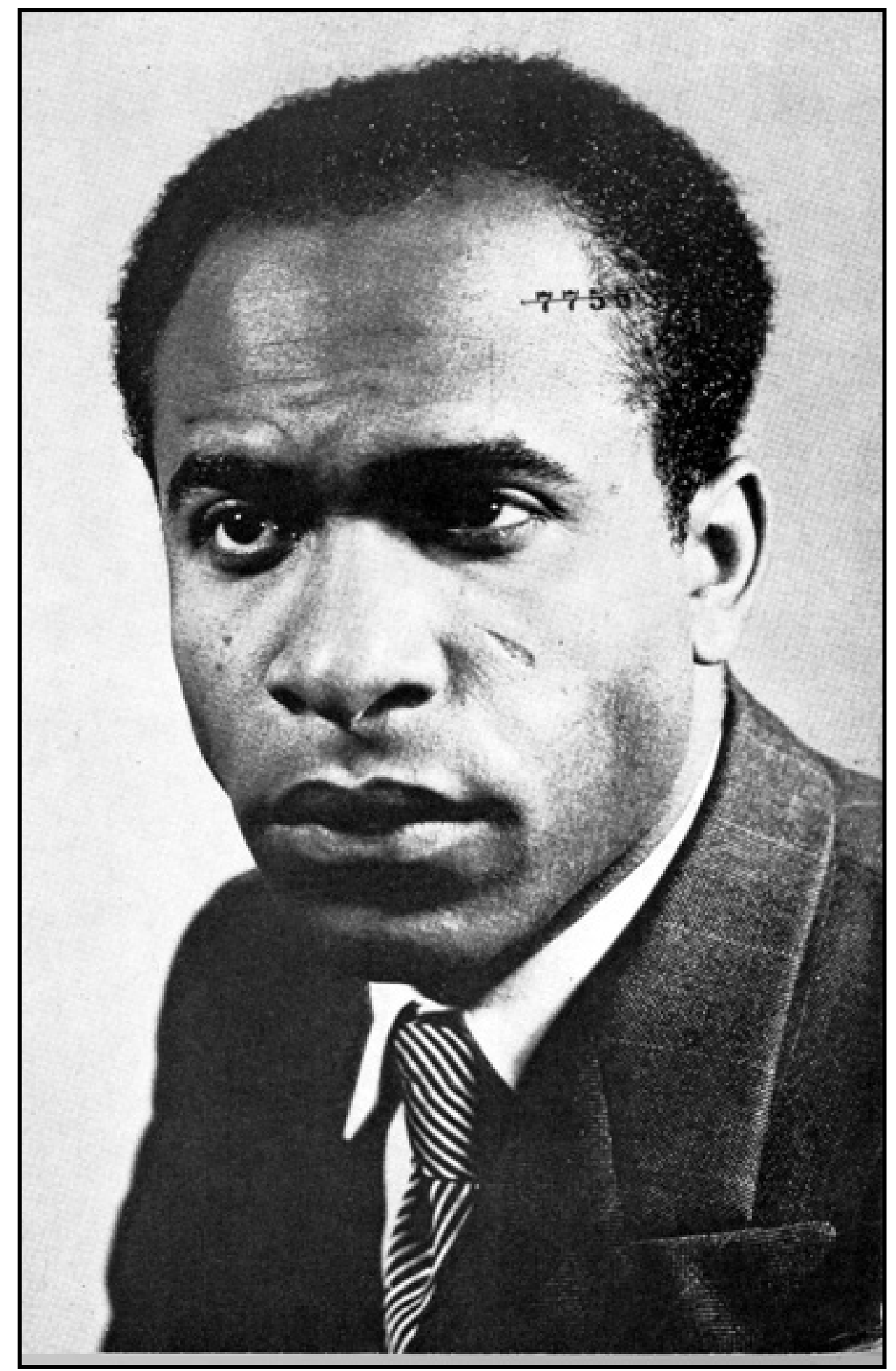


PEAU NOIRE. MASQUES BLANCS.

Préface [1952]

Par Francis Jeanson

\section{Retour à la table des matières}

Né en 1925 à Fort-de-France, docteur en médecine, Frantz Fanon, qui a entrepris de se spécialiser dans l'exercice de la psychiatrie, se trouve, par ailleurs, être un Noir. Naturellement, certaines de ces caractéristiques sont accidentelles, et sans doute aurait-il pu se produire - tout aussi bien qu'il naquît jaune ou blanc, à Tchoung-King ou à Cherbourg, un peu plus tard ou un peu plus tôt. Mais enfin c'est ainsi : Fanon a vingt-sept ans, il est Martiniquais et il a la peau noire. Et si j'insiste en particulier sur ce dernier point, c'est qu'il constitue justement le thème de son livre... «Quoi! sa propre noirceur? » Oui : son expérience d'homme noir plongé dans un monde blanc.

Mais les bons esprits voient d'un mauvais œil ces sortes de descriptions concrètes, qui touchent à la chair même des consciences et compromettent le sang-froid des idées dans la trouble épaisseur du vécu. On imagine ici quelques-unes de leurs protestations. "Qu'importe, diront-ils, que votre auteur soit lui-même noir ou blanc? Ces questions, désormais, peuvent être posées par n'importe qui. Le problème noir, d'ailleurs, est un problème blanc: sa solution aussi est blanche. Sans 
doute les protestations des Noirs n'en sont-elles pas moins émouvantes, mais elles ne peuvent plus rien nous apprendre... Et c'est bien tout de même à la science occidentale qu'on doit la véritable dénonciation objective du mythe raciste! Quel honnête homme, au reste, pourrait encore ignorer qu'on ne conclut pas d'une différence de pigmentation à une différence de valeur humaine, et que la couleur de la peau ne révèle rien sur les ressources de la conscience? L'UNESCO, justetent, [8] diffuse à ce sujet de très remarquables brochures, où les plus grands savants et ethnologues démontrent de la façon la plus irréfutable... » Bon. Mais Fanon les a lues... Et s'il vous dit que malgré tout ça compte, pour lui, d'avoir la peau noire, et que ce fait - en lui-même privé de sens - retombe cependant sur lui, comme sur ses frères noirs, chargé d'une très lourde et insupportable signification? «Ainsi, ce docteur en médecine, ce psychiatre, trébucherait sur un simple préjugé ? Sa culture et son titre ne lui prouvent-ils pas assez qu'il est maintenant un homme comme nous, et qu'il n'y a plus pour lui de monde «blanc», puisque ce monde est devenu le sien? N'est-il pas désormais, quant à l'essentiel, un Blanc parmi les Blancs? 》

Bien sûr, bien sûr... Mais, au fait, pourquoi ne voulez-vous point qu'il soit noir ? Pourquoi tenez-vous tellement à omettre ce détail ? Ne serait-ce pas que, d'une certaine façon, vous en demeurez gêné pour lui ? Vous pensez qu'il devrait lui-même faire abstraction de sa couleur: donner l'exemple, en quelque sorte... Mais peut-être a-t-il précisément tenté d'y parvenir! Et si le monde, alors, pour prix de son audace, l'a rejeté, condamné à sa noirceur, identifié à elle au point de le séparer presque de lui-même et de le réduire à pousser jusqu'au bout, sans espoir, cette séparation? On aurait tort, je crois, de se méprendre sur la façon discrète dont il évoque ce moment de sa vie: «Il y a trois ans que ce livre aurait dû être écrit... Mais alors les vérités nous brûlaient. Aujourd'hui, elles peuvent être dites sans fièvre. "Voici d'ailleurs le cruel itinéraire de son expérience vécue:

... Et puis il nous fut donné d'affronter le regard blanc... 
« Tiens, un nègre! » C'était vrai. Je m'amusai.

«Tiens, un nègre! » Le cercle peu à peu se resserrait. Je m'amusai ouvertement.

«Maman, regarde le nègre, j'ai peur!» Peur! Peur! Voilà qu'on se mettait à me craindre. Je voulus m'amuser jusqu'à m'étouffer, mais cela m'était devenu impossible.

Je ne pouvais plus, car je savais déjà qu'existaient des légendes, des histoires, l'histoire...

... Je promenai sur moi un regard objectif, découvris ma noirceur, mes caractères ethniques, - et me défoncèrent [9] le tympan, l'anthropophagie, l'arriération mentale, le fétichisme, les tares raciales, les négriers, et surtout, et surtout : « $Y$ a bon banania »...

... Qu'était-ce pour moi, sinon un décollement, un arrachement, une hémorragie qui caillait du sang noir sur tout mon corps?

On l'aura noté : ce n'est encore ici que la première phase, la première «station», mais déjà le Noir s'est vu délogé de son précaire équilibre. Déjà, l'on a requis de lui plus que le simple assentiment à ce fait brutal, et plus que le simple constat de sa traduction en langage blanc: «Tiens, un nègre!»... Il était un « nègre», et il l'admettait. «C'était vrai », dit-il. Oui, seulement ça ne suffisait pas, et l'on attendait de lui davantage encore. Bien sûr, c'était « vrai »! Mais il fallait en plus qu'il reconnût que c'était mal. Il fallait qu'il en fît l'aveu : il avait tort d'être noir: aux lumières du monde, ce fait devenait une malédiction, ce « donné » un destin, cette noirceur contingente une tare essentielle.

Allait-il se laisser condamner, paralyser, réduire à son être-noir simple objet, mais coupable pourtant d'être cet objet? «Je voulais tout simplement être un homme parmi d'autres hommes... être homme, rien qu'homme. D'aucuns me reliaient aux ancêtres miens, esclavagisés, lynchés: je décidai d'assumer... J'étais petit-fils d'esclaves au même titre que le président Lebrun l'était de paysans corvéables et taillables. Au fond, l'alerte se dissipait rapidement. » Pas pour longtemps... 
Responsable? Quelle prétention! Non, le Noir est et demeure coupable: coupable de n'être pas blanc. Et peut-être, ici ou là, le lui pardonne-t-on, mais le malheur est que justement on ne cesse pas de le lui pardonner, - ce qui montre bien qu'il est indéfiniment coupable: en faute, en défaut, et, dans tous les cas, marqué à jamais.

Quand on maime, on me dit que c'est malgré ma couleur. Quand on me déteste, on ajoute que ce n'est pas à cause de ma couleur...

- Regarde, il est beau ce nègre...

- Voyez-vous, monsieur, je suis l'un des plus négrophiles de Lyon...

... Le linge du nègre sent le nègre - les dents du nègre [10] sont blanches - les pieds du nègre sont grands - la large poitrine du nègre...

« Nous avons un professeur d'histoire sénégalais. Il est très intelligent... Notre médecin est un Noir. Il est très doux... »

... Je sens, je vois dans ces regards blancs que ce n'est pas un nouvel homme qui entre, mais un nouveau type d'homme, un nouveau genre. Un nègre, quoi!

Prisonnier de ce cercle infernal, si le Noir se révolte au nom de la raison et de la science, il se heurte à l'irrationnel, à la passion et peutêtre à la haine. "Je réclamai, j'exigeai des explications. Doucement, comme on parle à un enfant, on me révéla l'existence d'une certaine opinion qu'adoptaient certaines personnes, mais, ajoutait-on, « il fallait en espérer la rapide disparition ». Qu'était-ce? Le préjugé de couleur... Je voulus rationaliser le monde, montrer au Blanc qu'il était dans l'erreur... Les scientifiques, après beaucoup de réticences, avaient admis que le nègre était un être humain; in vivo et in vitro le nègre s'était révélé analogue au Blanc: même morphologie, même histologie. La raison s'assurait la victoire sur tous les plans... Mais je dus déchanter... 
Car les victoires de la raison ne résolvent pas les problèmes d'existence. Certes, le nègre, rationnellement, est devenu un homme: le nègre idéal est un être humain. Mais le nègre réel est demeuré, avec sa peau noire, parmi des Blancs réels... Et les problèmes - résolus par la science blanche - n'ont pas cessé de se poser à vif, en pleine chair nègre.

«Ne seront-ils donc jamais contents? Quoi qu'on fasse pour eux, et quoi qu'on leur dise, ils le prennent toujours en mauvaise part! Si vous les aimez, ils croient que vous avez pitié d'eux parce qu'ils sont noirs; si vous leur faites un reproche, c'est encore à leur noirceur que vous aurez l'air de vous en prendre... Et les plus exigeants sont toujours les plus évolués, ceux qui partagent notre vie et participent à toutes nos activités, ceux précisément à qui nous avons déjà tout accordé ! À tout moment, même quand nous n'y pensons plus, ce sont eux qui nous rappellent qu'ils sont noirs, - comme s'ils voulaient nous en [11] faire porter la faute. Bientôt, c'est nous qui serons les coupables! »

Un comble, évidemment.

Et je crois bien, en effet, qu'il y a dans le livre de Fanon quelque obstination intolérable aux esprits distingués, une véhémence fort propre à dresser contre lui (outre la très banale espèce des trafiquants du racisme) le front commun des hommes de bon sens, des honnêtes gens, des spiritualistes, des rationalistes, des idéologues objectifs, dialecticiens brevetés, instructeurs diplômés, responsables au recrutement, fonctionnaires de l'Histoire et autres belles âmes, tous installés dans leur rôle, bien calés dans leur personnage, sachant ce qui doit être su, détenant les vraies réponses, assurés enfin contre l'incertitude du présent par leur fixation au Passé, leurs relations avec l'Éternel, ou leur connaissance de l'Avenir...

Il faut, dit Fanon, lâcher l'homme. Une telle formule, on le voit bien, ne peut qu'être absolument subversive. Si c'est une réclamation, elle manifeste une ignorance totale des usages administratifs, puisqu'on ne pourrait même jamais savoir, l'ayant par distraction prise au 
sérieux, à quel moment on la devrait tenir pour satisfaite. Et si c'est un mot d'ordre, il est clair que seul en peut surgir le désordre le plus radical : car il ne repose sur aucune doctrine, sur aucune science, il défie toute juridiction, conteste toute autorité, ne détermine aucun programme et ne se prête à aucune planification. En un mot, cette formule révèle chez son auteur une déplorable tendance à l'anarchisme, - dont ne sauraient s'accommoder ni les réactionnairesen-place, ni les révolutionnaires-à-l'alignement, ni les satisfaits-depeu, ni les profiteurs-de-n'importe-quoi. Osons le dire, enfin: en s'exprimant de la sorte, Fanon présente une exigence qui n'est pas «présentable», une exigence qui n'a pas pris le temps de s'habiller, de se farder ni de se donner une contenance pour venir figurer dans le monde. Une exigence toute nue, brute, et qui se refuse à jouer le jeu, - quelque jeu que ce soit. Un scandale.

Pas «sortable», inconvenante, inadaptée, presque indicible, nonobjectivable, telle est la revendication maîtresse qui parcourt d'un ample et constant frémissement les [12] pages qu'on va lire. De là, très souvent, ce surgissement brutal, inattendu, d'un mode d'expression quasi poétique, et qui va du cri le plus spontané, si quelque image ou quelque mot vient raviver les brûlures anciennes, jusqu'à la tentative consciente pour atteindre le lecteur malgré tous ses systèmes défensifs, au défaut de chacune de ses cuirasses pour lui communiquer en deçà des idées la plus incommunicable part d'une expérience qui ne sera jamais la sienne.

Ayant un jour écrit à Fanon afin d'obtenir quelques précisions sur un passage qui, dans son texte, mavait semblé un peu obscur, je m'aperçus en lisant sa réponse, fort détaillée, que le passage en question me l'avait déjà totalement fournie, comme en contrebande, - bien qu'il fût en effet obscur si, refusant de s'abandonner à son mouvement, on commettait l'erreur d'y chercher un système de concepts. $\grave{A}$ la suite de son explication, d'ailleurs, Fanon ajoutait lui-même: "Cette phrase est inexplicable. Je cherche, quand j'écris de telles choses, à toucher affectivement mon lecteur... c'est-à-dire irrationnellement, 
presque sensuellement. » Plus loin, il avouait aussi combien il est luimême sensible à la magie des mots, et quelle sorte de ressource ultime constitue pour lui le langage, une fois libéré de ses conventions et de cette exsangue sagesse qui est besoin de se tranquilliser, terreur de se trouver soudain face à face avec soi-même: «Les mots ont pour moi une charge. Je me sens incapable d'échapper à la morsure d'un mot, au vertige d'un point d'interrogation. » Faisant allusion à Césaire, il souhaitait également pouvoir «couler, comme lui, s'il le fallait, sous la lave ahurissante des mots couleur de chair trépidante ».

C'est que la parole - créatrice d'équivoques, dissimulatrice, mystificatrice, et d'autant plus, sans doute, qu'elle prétend à une plus parfaite transparence - peut aussi devenir un moyen de provoquer autrui et de se provoquer soi-même à d'authentiques surgissements. L'expérience vécue par le Noir est une expérience-limite; s'il tente de la ressaisir pour en dégager le sens, il lui faut avant tout en reproduire, d'une manière ou d'une autre, la phase de désintégration: passage par le néant, descente aux véritables [14] Enfers. Ainsi arrive-t-il que Fanon jette soudain au cour d'une idée, en plein milieu d'une argumentation, cette charge des mots, cette dynamite qui se révèle en eux dès qu'ils ne sont plus neutralisés par leur sage enrôlement dans un discours suivi. À ces moments où il fait exploser le contexte, Fanon désorganise d'un coup nos assurances intellectuelles et reproduit en nous, magiquement, l'explosion même à laquelle il fut soumis pour s'être trop brutalement cogné à l'absurde, télescopé aux limites de la condition humaine. Ainsi, parvient-il assez fréquemment à nous faire quitter l'étage réflexif, à nous précipiter de cette hauteur illusoire d'où nous pensions être en mesure de considérer la question, de nous «pencher» sur le cas du Noir: nous voici alors contraints d'aborder l'expérience d'un homme au niveau même où elle est effectivement vécue et soufferte avant d'être objective, désincarnée, stérilisée.

Cela ne signifie point que Fanon se cantonne dans la pure subjectivité. Il n'imagine aucunement que tout se passe «à l'intérieur» et qu'un simple malentendu, un simple défaut de compréhension entre 
Blancs et Noirs, constitue la racine de ce Mal d'être un Noir. Cette question est même assez importante à ses yeux pour que soient centrées sur elle la plupart des critiques qu'il adresse à l'ouvrage de Mannoni, Psychologie de la colonisation. Ces critiques, d'ailleurs, ne me semblent pas absolument décisives, dans la mesure où elles considèrent la thèse soutenue par l'auteur comme une explication totale, alors que cette thèse se donne elle-même pour une description relative et partielle, visant à éclairer la question sous un angle inusité. Mais, quoi qu'il en soit de leur portée immédiate, les remarques formulées par Fanon à cette occasion sont précieuses dans la mesure où elles permettent de rejeter toute interprétation subjectiviste de son attitude. «Les conséquences de (l')irruption européenne à Madagascar, écrit-il, ne sont pas seulement psychologiques, puisque, tout le monde l'a dit, il y a des rapports internes entre la conscience et le contexte social. »-Étudiant sur le plan psychanalytique le cas d'un malade nègre qui rêve qu'il devient blanc, il conclut que ce rêve réalise un désir [14] inconscient, dont on doit libérer le malade pour lui éviter une dissolution de sa structure psychique: mais il ajoute aussitôt que « si ce nègre se trouve à ce point submergé par le désir d'être blanc, c'est qu'il vit dans une société qui rend possible son complexe d'infériorité, dans une société qui tire sa consistance du maintien de ce complexe, dans une société qui affirme la supériorité d'une race: c'est dans l'exacte mesure où cette société lui fait des difficultés, qu'il se trouve placé dans une situation névrotique. Ce qui apparaît alors, c'est la nécessité d'une action couplée sur l'individu et sur le groupe. En tant que psychanalyste, je dois aider mon client à « conscienciser » son inconscient, à ne plus tenter une lactification hallucinatoire, mais bien à agir dans le sens d'un changement des structures sociales». Un peu plus loin, il observe qu' «à certains moments le « socius» est plus important que l'homme », et cite un passage de Psychologie, marxisme, matérialisme, où Pierre Naville énonce que «ce sont les conditions économiques et sociales des luttes de classe qui expliquent et déterminent les conditions réelles dans lesquelles s'exprime la sexualité individuelle». 
L'attitude de Frantz Fanon n'est donc pas subjectiviste. Elle n'est pas davantage anarchiste ou «révoltée». C'est une attitude révolutionnaire, et dont le rapport à l'actuelle orthodoxie semble devoir impliquer non point un état de rupture et d'hostilité mais la plus féconde des tensions. Bien sûr, il n'est pas très orthodoxe, après avoir rejeté tout idéalisme, - «Nous ne poussons pas la naïveté jusqu'à croire que les appels à la raison ou au respect de l'homme puissent changer le réel. Pour le nègre qui travaille dans les plantations de canne du Robert, il n'y a qu'une solution : la lutte... », - de préciser aussitôt : «... Cette lutte, il l'entreprendra non pas après une analyse marxiste ou idéaliste, mais parce que, tout simplement, il ne pourra concevoir son existence que sous les espèces d'un combat mené contre l'exploitation, la misère et la faim. » Et peut-être y a-t-il quelque hérésie à estimer que « seule une interprétation psychanalytique du problème noir peut révéler » la morbidité psychique et les anomalies affectives qui enferment le Blanc dans sa blancheur, le Noir dans sa noirceur, et les rendent l'un [15] comme l'autre incapable de tout passage à l'universel.

Et cependant... De quoi s'agit-il donc pour lui, sinon justement d'aboutir à cette même société, sans distinctions de classes ni de races, que la conscience communiste se propose comme but suprême dans son entreprise révolutionnaire? En pareil cas, il est vrai, les communistes - qui ont d'assez bonnes raisons de se montrer sceptiques peuvent aisément protester qu'il ne suffit pas d'invoquer ce but, et d'en rêver, comme n'importe qui est en mesure de le faire. Mais, d'abord, il n'est pas du tout sûr, précisément, que n'importe qui soit en mesure de le faire: à vrai dire, on serait même tenté de tenir le contraire pour une évidence, - et pas seulement en milieu blanc, et pas seulement en milieu bourgeois. Or, s'il est manifeste que les rêves des hommes ne suffisent pas à transformer le monde, sans doute serait-il malgré tout préférable que ces rêves fussent à tendance humaine plutôt qu'inhumaine. En d'autres termes, sans doute serait-il préférable que toutes les consciences noires, par exemple, conçoivent et désirent l'établissement d'un rapport de reconnaissance entre elles et les consciences blanches: bien qu'un tel désir soit par lui-même inca- 
pable de détruire les structures objectives d'oppression et d'exploitation, du moins mettrait-il ces consciences en meilleure posture pour contribuer tôt ou tard, de façon valable, à cette destruction.

«Le Noir, constate Fanon, n'est pas un homme... le Noir est un homme noir »; dans de trop nombreux cas, en effet, il s'est laissé prendre au piège, il a implicitement admis la valorisation des différences de fait et l'essentielle blessure qu'elle maintient au cœur de ce monde. C'est alors qu'il adopte une attitude tout entière négative, soit qu'il mette son ambition à devenir blanc, soit qu'il s'efforce au contraire d'exalter sa «négritude » et de démontrer, dans le refus total de la civilisation blanche, la suprématie des valeurs noires. Ces deux voies sont également sans issue. Mais il n'est pas indifférent de distinguer pour chacune les raisons particulières qui font d'elle une impasse.

Nier sa noirceur, ou tout au moins en faire abstraction, la mettre entre parenthèses, est pour le Noir, dans le [16] monde actuel, une entreprise insensée. Car il ne peut oublier sa noirceur qu'au prix d'ignorer que les autres la voient et qu'elle est encore pour beaucoup d'entre eux le signe d'une infériorité, d'un mal, de quelque indéfinissable défaut d'humanité : et comment y parviendrait-il sans fausser radicalement son rapport à autrui, sans avoir à réfugier dans la plus dérisoire abstraction sa propre présence à lui-même, sans condamner toute son existence au porte-à-faux, au refoulement, à la fuite? Ce cas est, à vrai dire, celui du Noir vivant en milieu blanc : pour lui, note Fanon, « l'aliénation est de nature presque intellectuelle. C'est en tant qu'il conçoit la culture européenne comme moyen de se déprendre de sa race, qu'il se pose comme aliéné ». Mais la tentative devient cette fois tout à fait impensable dans le cas du nègre qui travaille à la construction du port d'Abidjan. L'aliénation, ici, n'est certes pas du tout intellectuelle: d'ordre essentiellement économique, la violence qui est faite à ce nègre se trouve de surcroît garantie par la constante éventualité d'une violence policière. Il est donc bien vrai que la lutte cons- 
titue son unique recours, et que cette lutte, menée contre tout un système d'exploitation et contre tout un appareil de répression, n'a aucune chance d'aboutir si elle n'est largement collective. Or, comment le deviendrait-elle, sinon par la prise de conscience d'un destin commun: celui d'un groupe d'hommes si commodément désignables par la couleur de leur peau, et qui sont exploités par le Blanc dans le cadre de la colonisation, à titre de Noirs, en tant que race «inférieure»? En d'autres termes, la prise de conscience de l'aliénation économique se confond ici plus ou moins, dans la phase actuelle, avec une prise de conscience de l'aliénation raciale; la lutte libératrice implique pour le travailleur noir des pays colonisés la conscience de son être-nègre. Seuls, par suite, des Noirs privilégiés peuvent, en se ralliant aux oppresseurs de leurs frères, tenter de se prendre eux-mêmes pour des Blancs : mais il est clair que leur cas s'identifie dès lors à celui du Noir vivant en milieu blanc, et que leur tentative est d'emblée promise à la même sorte d'échec.

L'exaltation de la négritude, à l'inverse, ne semble pas devoir conduire à de meilleurs résultats. Et Fanon se [17] montre assez impitoyable pour les Noirs qui, esclaves de leur passé d'esclaves, ne pensent pas pouvoir se libérer autrement qu'en se perdant à la recherche d'un plus ancien passé : un passé de grandeur, qui leur appartiendrait en propre: une véritable civilisation nègre, comparable ou supérieure aux civilisations blanches. Le Noir, dit-il, croit avoir « un passé à valoriser, une revanche à prendre ; en face du Noir, le Blanc contemporain ressent la nécessité de rappeler la période anthropophagique... Je suis un homme, et c'est tout le passé du monde que j'ai à reprendre. En aucune façon je ne dois tirer du passé des peuples de couleur ma vocation originelle. En aucune façon je ne dois mattacher à faire revivre une civilisation nègre injustement méconnue... Je ne veux pas chanter le passé aux dépens de mon présent et de mon avenir... Je ne veux pas être victime de la Ruse d'un monde noir. Ma vie ne doit pas être consacrée à faire le bilan des valeurs nègres... »

Il y a eu, dans l'expérience de Fanon, un moment - dont son livre rend compte - au cours duquel cette «culture» de la négritude lui 
apparut cependant comme l'unique solution qui lui restât possible. Il a subi, lui aussi, le vertige du « grand trou noir». Et il en a quelque peu voulu à Sartre de l'avoir désillusionné en lui faisant apparaître la négritude, dans Orphée noir, comme un « passage», un «moyen», un «moment négatif», « le temps faible d'une progression dialectique», un «mythe», « un absolu qui se sait transitoire » : n'était-ce pas, justement, retirer au Noir toute possibilité d'y recourir? Lorsque Sartre écrivait : « ce moment négatif [posé comme valeur antithétique contre l'affirmation de la suprématie blanche] n'a pas de suffisance par luimême, et les Noirs qui en usent le savent fort bien; ils savent qu'il vise à préparer la synthèse ou réalisation de l'humain dans une société sans races... », - ne se débarrassait-il pas un peu légèrement des questions qu'il venait lui-même de se poser, une page plus haut: «Est-ce une conquête de la réflexion? Ou si la réflexion l'empoisonne? Si elle n'est jamais authentique que dans l'irréfléchi et dans l'immédiat? » C'est, en tout cas, le reproche que Fanon lui adressait alors, avec une insistance émouvante: Sartre avait oublié [18] que la négativité dialectique, ruse de l'Esprit pour parvenir à soi, doit être historiquement vécue en tant que positivité par les consciences individuelles. Dès lors que le Noir cessait de croire à la négritude comme à un absolu, dès lors qu'elle devenait à ses yeux relative et transitoire, dès lors enfin qu'elle se présentait à sa réflexion comme une ruse, il ne pouvait plus se perdre en elle, se faire posséder par elle, elle lui devenait inaccessible, étrangère et peut-être hostile.

Car la recherche de la négritude, c'est en quelque façon, pour le Noir, la tentative de faire l'amour avec sa race. "J'avais besoin de me perdre dans la négritude absolument... » Et Fanon se plaint d'avoir été, «au paroxysme du vécu et de la fureur, expulsé »... de lui-même : ce qui n'est pas sans évoquer l'espèce de traumatisme et le sentiment de mutilation que peut éprouver l'homme, de façon plus ou moins vive, avec une conscience plus ou moins claire, à l'issue de son union charnelle avec la femme, - lorsqu'il lui faut sans transition réassumer sa solitude subjective et son autonomie corporelle, et qu'il se découvre soudain 
frustré, chassé, exposé aux rigueurs du monde, jeté à vif à quelque châtiment...

En réalité, Fanon n'avait pas été expulsé de lui-même, mais renvoyé, rendu à lui-même. Expulsé, il ne l'avait été que d'un rêve, - celui d'une irréalisable communion, d'une sorte d'annihilation de soi que ses propres exigences et son entraînement réflexif le condamnaient d'avance à tenir pour fictive. Tel était le véritable sens de sa protestation: il avait cru pouvoir fuir et se fuir, oublier le monde réel, s'oublier luimême, s'abandonner dans une extase mystique, - mais voici qu'on le réveillait, qu'on lui rappelait ce que déjà lui-même il savait bien, voici qu'on le contraignait de nouveau à exister dans ce monde, à en affronter les tensions, à s'y frayer, parmi tant d'embûches et de pièges, un chemin de liberté. "Pas encore blanc, plus tout à fait noir, j'étais un damné... » Damné, certes pas: mais condamné - oui, sans doute - à demeurer conscient de soi, présent à soi, présent aux autres, au centre même de son drame et du leur.

"Mais on a oublié, ajoutait Fanon dans un dernier sursaut de révolte, la constance de mon amour. » Non, on ne [19] l'avait pas oubliée, et Sartre moins que tout autre: "La négritude n'est pas un état, elle est pur dépassement d'elle-même, elle est amour. C'est au moment où elle se renonce qu'elle se trouve: c'est au moment où elle accepte de perdre qu'elle a gagné : à l'homme de couleur et à lui seul il peut être demandé de renoncer à la fierté de sa couleur. »

Fanon, d'ailleurs, - passé le moment de la pire détresse, - ne tarda pas à comprendre que cet amour lui-même n'est rien s'il n'est un amour militant, soucieux de se réaliser dans le monde, et qu'il ne peut s'incarner de la sorte qu'au prix de se faire toujours plus conscient de ses propres ressources et des conditions effectives de la lutte. Or ce qu'il y a peut-être de plus remarquable dans ce livre, c'est justement le soin mis par l'auteur à n'y point trahir la réalité humaine, à ne lui infliger aucune mutilation, à lui maintenir sa valeur de totalité, - quels que soient les points de vue particuliers qu'il faut bien tour à tour qu'elle 
adopte sur elle-même pour parvenir à se connaître. "L'analyse que nous entreprenons est psychologique. Il demeure toutefois évident que, pour nous, la véritable désaliénation du Noir implique une prise de conscience abrupte des réalités économiques et sociales... L'aliénation du Noir n'est pas une question individuelle. A côté de la phylogénie et de l'ontogénie, il y a la sociogénie... Disons qu'il s'agit ici d'un sociodiagnostic... La réalité, pour une fois, réclame une compréhension totale. » D'où cette conclusion d'ordre pratique: "Sur le plan objectif comme sur le plan subjectif, une solution doit être apportée... Le Noir doit mener la lutte sur les deux plans: attendu que, historiquement, ils se conditionnent, toute libération unilatérale est imparfaite, et la pire erreur serait de croire en leur dépendance mécanique. »

Pourquoi dès lors Fanon a-t-il choisi de mettre l'accent, tout au long de son livre, sur l'aspect psychologique du problème? Il me semble découvrir à ce choix une assez profonde et complexe raison, - que je veux tenter de dégager en terminant.

Dès la seconde page, on trouve cette importante notation: «Nous ne tendons à rien de moins qu'à libérer [20] l'homme de couleur de luimême. "Ainsi Fanon nous suggère-t-il d'emblée que le Noir s'aliène dans le temps même où il est aliéné : selon l'expression de Sartre, «à moitié victime, à moitié complice, comme tout le monde», - il s'établit, «à la faveur d'une série d'aberrations affectives, au sein d'un univers d'où il faudra bien le sortir ». Autrement dit, si les structures sociales créent les conditions de la névrose, elles ne suffisent à expliquer ni son apparition ni son mode de développement: « Le destin du névrosé demeure entre ses mains. »Fanon vise donc à la destruction d'un «complexus psycho-existentiel»: «Cet ouvrage est une étude clinique. Ceux qui s'y reconnaîtront auront, je crois, avancé d'un pas. Je veux vraiment amener mon frère, Noir ou Blanc, à secouer le plus énergiquement la lamentable livrée édifiée par des siècles d'incompréhension. »

Or il semble assez normal de craindre que l'individu névrosé ne constitue un mauvais appoint pour une entreprise collective de libération, et qu'il ne soit chimérique de prétendre édifier un monde humain 
avec des hommes perpétuellement en fuite vis-à-vis d'eux-mêmes: pour entreprendre de se libérer, il faut déjà, d'une certaine manière, être libre. Chez le "sauvage de la brousse», collectivement et anonymement exploité, cette liberté première demeure en général intacte: les rapports avec le Blanc étant nuls ou très rudimentaires, elle n'a pas été réduite à se renier, elle est seulement assoupie. Mais chez le Noir qui vit en milieu blanc, il est fréquent qu'elle s'emploie contre ellemême et cause sa propre impuissance, en se précipitant par désespoir dans les plus impraticables bourbiers. "J'ai constamment essayé de révéler au Noir qu'en un sens il s'anormalise... Avant de s'engager dans la voie positive, il y a pour la liberté un effort de désaliénation. »

Je ne crois pas cependant que le souci principal de Fanon, lorsqu'il propose au Noir de devenir un homme psychiquement « sain», «normal», équilibré, soit d'alimenter les forces révolutionnaires en combattants de la meilleure qualité possible. Et s'il lui importe tant que la conscience de leur aliénation objective n'entraîne pas chez ses frères de couleur le sacrifice de leurs exigences et de [21] leurs ressources humaines, c'est avant tout, me semble-t-il, parce qu'il aime trop profondément les hommes pour se sentir apaisé par les certitudes que lui propose, quant à l'avenir, l'optimisme d'une philosophie marxiste de I'histoire. Je ne dis point que Fanon se moque de l'avenir : la structure temporelle de l'existence est bien trop fondamentale pour lui. "L'architecture du présent travail se situe dans la temporalité. Tout problème humain demande à être considéré à partir du temps. » Mais si la liberté consiste à ne pas se faire victime du passé afin de pouvoir construire un avenir, c'est dans le présent seul que cette liberté peut s'exercer, et cet avenir risque de perdre toute signification réelle dès qu'il cesse d'être à l'échelle d'une existence humaine: «... Cet avenir n'est pas celui du cosmos, mais bien celui de mon siècle, de mon pays, de mon existence. En aucune façon, je ne dois me proposer de préparer le monde qui suivra. J'appartiens irréductiblement à mon époque. Et c'est pour elle que je dois vivre. » 
Car l'homme, ce n'est jamais l'Homme, I'histoire, ce n'est jamais l'Histoire: je puis former ces deux grands concepts, mais non pas oublier qu'ils désignent tous deux une limite inaccessible, et qu'il serait absurde, au nom même de l'idéal qu'on se propose, d'en différer toujours, d'en rejeter à jamais toute réalisation partielle. La postulation d'un salut futur des sociétés humaines n'apporte aucun remède aux malheurs des hommes de ce temps. Que l'humanité doive un jour parvenir à se réaliser, c'est une piètre consolation pour celui qui crève, aujourd'hui, de ce qu'elle n'y est point encore parvenue : le salut éternel que peut lui offrir la foi le concerne après tout bien davantage: car la foi lui assure l'éternité, mais ce triomphe purement terrestre ne sera jamais pour lui. L'homme qu'il s'agit de sauver, ce n'est pas cette abstraction de nulle époque, dont on livre volontiers le destin à l'accomplissement d'une dialectique indéfinie: c'est ce nègre arraché à son village, traité comme un forçat, battu et méprisé : c'est ce jeune gynécologue noir incapable d'exercer sa profession pour avoir un jour, à l'hôpital, reçu en pleine chair cette exclamation d'une consultante [22] blanche: "S'il me touche, je le gifle. Avec eux, on ne sait jamais... »; c'est ce tirailleur sénégalais contraint de se battre au VietNam dans un conflit qui lui demeure étranger: c'est ce détenu politique malgache: ce sont toutes ces existences actuellement en question, et dont chacune est unique, irremplaçable, vécue sans espoir de retour...

C'est Pour eux que parle Fanon, pour tous ses frères réels, pour toutes ses scurs vivantes, - comme pour tous ceux qui, les méconnaissant et contestant leur appartenance à l'humanité, du même coup se méconnaissent et s'excluent eux aussi de l'humain. En est-il moins révolutionnaire? J'avouerai qu'il me paraît l'être, au contraire, d'autant plus véritablement. Ecoutez-le: «Moi, l'homme de couleur, je ne veux qu'une chose: que cesse à jamais l'asservissement de l'homme par l'homme. C'est-à-dire de moi par un autre... » Il n'ignore point que la lutte doit aussi être collective, il en désigne expressément la fin dernière: mais ce terme irréel n'a pas cessé pour lui d'être un thème vivant, et Fanon avoue - il proclame - que sa propre existence est en 
jeu en même temps que celle de ses contemporains. Sa revendication en faveur de l'humain est d'emblée totale, parce qu'elle le concerne luimême autant qu'elle concerne les autres, et parce qu'il n'a, comme tous les autres, que cette vie pour se rejoindre ou pour se perdre. Supprimez cette protestation absolue au cœur du révolutionnaire, supprimez en lui cette exigence totale et totalement irréductible à l'Histoire, ce déraisonnable besoin d'une réussite immédiate, ici et maintenant, - et vous ne tiendrez plus qu'un dérisoire mannequin, vainement agité par une cause dont on a égaré le sens.

L'entreprise révolutionnaire n'atteindra peut-être jamais son but, mais la seule chance qu'elle ait de tendre réellement vers lui réside dans ces hommes trop impatients pour se contenter du rythme de l'Histoire, trop exigeants pour admettre qu'il n'y ait rien d'autre à faire dans ce monde - par hasard le leur - que d'y préparer, dans la résignation à leur propre échec, le triomphe de quelque lointaine humanité. Si la reconnaissance réciproque des consciences est le véritable but, c'est tout de suite qu'elle doit être tentée, c'est dans le cours même de la lutte pour [23] édifier les structures qui lui seront le plus favorables, et si grande soit la résistance que lui opposent les structures actuelles. Sans cette impatience, la lutte se dégrade en vaine rhétorique, et chaque génération se sacrifie pour rien, - ayant cessé d'éprouver en elle-même l'appel de cette liberté qu'elle prétend élaborer pour les générations suivantes.

Ainsi la démarche de Fanon est-elle d'un homme qui sait que le terme de sa route est à la fois très loin, de l'autre côté du monde, à l'autre bout du temps, et tout près de lui, comme indiscernable de luimême. Ainsi a-t-il entrepris de nous affronter, Noirs ou Blancs, à la simple générosité d'une conscience qui se refuse à toute haine et ne s'en prend qu'aux ténèbres de l'âme: «Il faudra bien que le soleil que je transhume éclaire les moindres recoins... Celui qui cherchera dans mes yeux autre chose qu'une interrogation perpétuelle devra perdre la vue... » 
Comment ne pas reconnaître dans cette ardente et tenace et capitale interrogation, à travers toutes ces pages bousculées, sous ces paroles véhémentes et fraternelles, une exigence sans égale, - qui nous concerne tous?

FRANCIS JEANSON.

1952. 
[25]

PEAU NOIRE. MASQUES BLANCS.

\section{INTRODUCTION}

Je parle de millions d'hommes à qui on a inculqué savamment la peur, le complexe d'infériorité, le tremblement, l'agenouillement, le désespoir, le larbinisme.

(A. Césaire, Discours sur le Colonialisme.)

\section{Retour à la table des matières}

L'explosion n'aura pas lieu aujourd'hui. Il est trop tôt... ou trop tard.

Je n'arrive point armé de vérités décisives.

Ma conscience n'est pas traversée de fulgurances essentielles.

Cependant, en toute sérénité, je pense qu'il serait bon que certaines choses soient dites.

Ces choses, je vais les dire, non les crier. Car depuis longtemps le cri est sorti de ma vie.

Et c'est tellement loin...

Pourquoi écrire cet ouvrage? Personne ne m'en a prié.

Surtout pas à ceux à qui il s'adresse. 
Alors? Alors, calmement, je réponds qu'il y a trop d'imbéciles sur cette terre. Et puisque je le dis, il s'agit de le prouver.

Vers un nouvel humanisme...

La compréhension des hommes...

Nos frères de couleur...

Je crois en toi, Homme...

Le préjugé de race...

Comprendre et aimer...

De partout massaillent et tentent de s'imposer à moi des dizaines et des centaines de pages. Pourtant, une seule ligne suffirait. Une seule réponse à fournir et le problème noir se dépouille de son sérieux.

[26]

Que veut l'homme?

Que veut l'homme noir?

Dussé-je encourir le ressentiment de mes frères de couleur, je dirai que le Noir n'est pas un homme.

Il y a une zone de non-être, une région extraordinairement stérile et aride, une rampe essentiellement dépouillée, d'où un authentique surgissement peut prendre naissance. Dans la majorité des cas, le Noir n'a pas le bénéfice de réaliser cette descente aux véritables Enfers.

L'homme n'est pas seulement possibilité de reprise, de négation. S'il est vrai que la conscience est activité de transcendance, nous devons savoir aussi que cette transcendance est hantée par le problème de l'amour et de la compréhension. L'homme est un OUI vibrant aux harmonies cosmiques. Arraché, dispersé, confondu, condamné à voir se dissoudre les unes après les autres les vérités par lui élaborées, il doit 
cesser de projeter dans le monde une antinomie qui lui est coexistante.

Le Noir est un homme noir : c'est-à-dire qu'à la faveur d'une série d'aberrations affectives, il s'est établi au sein d'un univers d'où il faudra bien le sortir.

Le problème est d'importance. Nous ne tendons à rien de moins qu'à libérer l'homme de couleur de lui-même. Nous irons très lentement, car il y a deux camps : le blanc et le noir.

Tenacement, nous interrogerons les deux métaphysiques et nous verrons qu'elles sont fréquemment fort dissolvantes.

Nous n'aurons aucune pitié pour les anciens gouverneurs, pour les anciens missionnaires. Pour nous, celui qui adore les nègres est aussi «malade» que celui qui les exècre.

Inversement, le Noir qui veut blanchir sa race est aussi malheureux que celui qui prêche la haine du Blanc.

Dans l'absolu, le Noir n'est pas plus aimable que le Tchèque, et véritablement il s'agit de lâcher l'homme.

Il y a trois ans que ce livre aurait dû être écrit... Mais alors les vérités nous brûlaient. Aujourd'hui elles peuvent être dites sans fièvre. Ces vérités-là n'ont pas besoin d'être jetées à la face des hommes. Elles ne veulent pas enthousiasmer. Nous nous méfions de l'enthousiasme.

[27]

Chaque fois qu'on l'a vu éclore quelque part, il annonçait le feu, la famine, la misère... Aussi, le mépris de l'homme.

L'enthousiasme est par excellence l'arme des impuissants.

Ceux qui chauffent le fer pour le battre immédiatement. Nous voudrions chauffer la carcasse de l'homme et partir. Peut-être arriverions-nous à ce résultat: l'Homme entretenant ce feu par autocombustion. 
L'Homme libéré du tremplin que constitue la résistance d'autrui et creusant dans sa chair pour se trouver un sens.

Seuls quelques-uns de ceux qui nous liront devineront les difficultés que nous avons rencontrées dans la rédaction de cet ouvrage.

Dans une période où le doute sceptique s'est installé dans le monde, où, aux dires d'une bande de salauds, il n'est plus possible de discerner le sens du non-sens, il devient ardu de descendre à un niveau où les catégories de sens et de non-sens ne sont pas encore employées.

Le Noir veut être Blanc. Le Blanc s'acharne à réaliser une condition d'homme.

Nous verrons au cours de cet ouvrage s'élaborer un essai de compréhension du rapport Noir-Blanc.

Le Blanc est enfermé dans sa blancheur.

Le Noir dans sa noirceur.

Nous essaierons de déterminer les tendances de ce double narcissisme et les motivations auxquelles il renvoie.

Au début de nos réflexions, il nous avait paru inopportun d'expliciter les conclusions qu'on va lire.

Le souci de mettre fin à un cercle vicieux a seul guidé nos efforts.

C'est un fait : des Blancs s'estiment supérieurs aux Noirs.

C'est encore un fait : des Noirs veulent démontrer aux Blancs coûte que coûte la richesse de leur pensée, l'égale puissance de leur esprit.

Comment s'en sortir?

Nous avons employé tout à l'heure le terme de narcissisme. En effet, nous pensons que seule une interprétation psychanalytique du problème noir peut révéler les anomalies [28] affectives responsables de l'édifice complexuel. Nous travaillons à une lyse totale de cet univers morbide. Nous estimons qu'un individu doit tendre à assumer l'universalisme inhérent à la condition humaine. Et quand nous avançons ceci, nous pensons indifféremment à des hommes comme Gobineau ou à 
des femmes comme Mayotte Capécia. Mais, pour parvenir à cette saisie, il est urgent de se débarrasser d'une série de tares, séquelles de la période enfantine.

Le malheur de l'homme, disait Nietzsche, est d'avoir été enfant. Toutefois, nous ne saurions oublier, comme le laisse entendre Charles Odier, que le destin du névrosé demeure entre ses mains.

Aussi pénible que puisse être pour nous cette constatation, nous sommes obligé de la faire : pour le Noir, il n'y a qu'un destin. Et il est blanc.

Avant d'ouvrir le procès, nous tenons à dire certaines choses. L'analyse que nous entreprenons est psychologique. Il demeure toutefois évident que pour nous la véritable désaliénation du Noir implique une prise de conscience abrupte des réalités économiques et sociales. S'il y a complexe d'infériorité, c'est à la suite d'un double processus :

- économique d'abord:

- par intériorisation ou, mieux, épidermisation de cette infériorité, ensuite.

Réagissant contre la tendance constitutionnaliste de la fin du XIX siècle, Freud, par la psychanalyse, demanda qu'on tînt compte du facteur individuel. A une thèse phylogénétique, il substituait la perspective ontogénétique. On verra que l'aliénation du Noir n'est pas une question individuelle. A côté de la phylogénie et de l'ontogénie, il y a la sociogénie. En un sens, pour répondre au vœu de Leconte et Damey ${ }^{1}$, disons qu'il s'agit ici d'un sociodiagnostic.

Quel est le pronostic?

Mais la Société, au contraire des processus bio-chimiques, n'échappe pas à l'influence humaine. L'homme est [29] ce par quoi la

1 M. Leconte et A. Damey, Essai critique des nosographies psychiatriques actuelles. 
Société parvient à l'être. Le pronostic est entre les mains de ceux qui voudront bien secouer les racines vermoulues de l'édifice.

Le Noir doit mener la lutte sur les deux plans : attendu que, historiquement, ils se conditionnent, toute libération unilatérale est imparfaite, et la pire erreur serait de croire en leur dépendance mécanique. D'ailleurs, les faits s'opposent à une pareille inclination systématique. Nous le montrerons.

La réalité, pour une fois, réclame une compréhension totale. Sur le plan objectif comme sur le plan subjectif, une solution doit être apportée.

Et ce n'est pas la peine de venir, avec des airs de « crabe-c'est-mafaute», proclamer qu'il s'agit de sauver l'âme.

Il n'y aura d'authentique désaliénation que dans la mesure où les choses, au sens le plus matérialiste, auront repris leur place.

Il est de bon ton de faire précéder un ouvrage de psychologie d'un point de vue méthodologique. Nous faillirons à l'usage. Nous laissons les méthodes aux botanistes et aux mathématiciens. Il y a un point où les méthodes se résorbent.

Nous voudrions nous y placer. Nous essaierons de découvrir les différentes positions qu'adopte le nègre en face de la civilisation blanche.

Le « sauvage de la brousse » n'est pas envisagé ici. C'est que, pour lui, certains éléments n'ont pas encore de poids.

Nous estimons qu'il y a, du fait de la mise en présence des races blanche et noire, prise en masse d'un complexus psycho-existentiel. En l'analysant, nous visons à sa destruction.

Beaucoup de nègres ne se retrouveront pas dans les lignes qui vont suivre.

Pareillement beaucoup de Blancs.

Mais le fait, pour moi, de me sentir étranger au monde du schizophrène ou à celui de l'impuissant sexuel n'attaque en rien leur réalité. 
Les attitudes que je me propose de décrire sont vraies. Je les ai retrouvées un nombre incalculable de fois.

Chez les étudiants, chez les ouvriers, chez les souteneurs [30] de Pigalle ou de Marseille, j'identifiai la même composante d'agressivité et de passivité.

Cet ouvrage est une étude clinique. Ceux qui s'y reconnaîtront auront, je crois, avancé d'un pas. Je veux vraiment amener mon frère, Noir ou Blanc, à secouer le plus énergiquement la lamentable livrée édifiée par des siècles d'incompréhension.

L'architecture du présent travail se situe dans la temporalité. Tout problème humain demande à être considéré à partir du temps. L'idéal étant que toujours le présent serve à construire l'avenir.

Et cet avenir n'est pas celui du cosmos, mais bien celui de mon siècle, de mon pays, de mon existence. En aucune façon je ne dois me proposer de préparer le monde qui me suivra. J'appartiens irréductiblement à mon époque.

Et c'est pour elle que je dois vivre. L'avenir doit être une construction soutenue de l'homme existant. Cette édification se rattache au présent, dans la mesure où je pose ce dernier comme chose à dépasser.

Les trois premiers chapitres s'occupent du nègre moderne. Je prends le Noir actuel et j'essaie de déterminer ses attitudes dans le monde blanc. Les deux derniers sont consacrés à une tentative d'explication psychopathologique et philosophique de l'exister du nègre.

L'analyse est surtout régressive.

Les quatrième et cinquième chapitres se situent sur un plan essentiellement différent.

Au quatrième chapitre, je critique un travail 2 qui, à mon avis, est dangereux. L'auteur, M. Mannoni, est d'ailleurs conscient de l'ambiguiité

2 Psychologie de la colonisation, par O. Mannoni (Ed. du Seuil, 1950). 
de sa position. C'est peut-être là un des mérites de son témoignage. Il a essayé de rendre compte d'une situation. Nous avons le droit de nous déclarer insatisfait. Nous avons le devoir de montrer à l'auteur en quoi nous nous écartons de lui.

Le cinquième chapitre, que j'ai intitulé «L'expérience vécue du Noir », est important à plus d'un titre. Il montre le nègre en face de sa race. On s'apercevra qu'il n'y a rien de commun entre le nègre de ce chapitre et celui qui cherche à coucher avec la Blanche. On retrouvait chez ce [31] dernier un désir d'être Blanc. Une soif de vengeance, en tout cas. - Ici, au contraire, nous assistons aux efforts désespérés d'un nègre qui s'acharne à découvrir le sens de l'identité noire. La civilisation blanche, la culture européenne ont imposé au Noir une déviation existentielle. Nous montrerons ailleurs que souvent ce qu'on appelle l'âme noire est une construction du Blanc.

Le Noir évolué, esclave du mythe nègre, spontané, cosmique, sent à un moment donné que sa race ne le comprend plus.

Ou qu'il ne la comprend plus.

Alors il s'en félicite et, développant cette différence, cette incompréhension, cette désharmonie, il y trouve le sens de sa véritable humanité. Ou plus rarement il veut être à son peuple. Et c'est la rage aux lèvres, le vertige au cœur, qu'il s'enfonce dans le grand trou noir. Nous verrons que cette attitude si absolument belle rejette l'actualité et l'avenir au nom d'un passé mystique.

Etant Antillais d'origine, nos observations et nos conclusions ne valent que pour les Antilles, - tout au moins en ce qui concerne le Noir chez lui. Il y aurait une étude à consacrer à l'explication des divergences qui existent entre Antillais et Africains. Peut-être la ferons-nous un jour. Peut-être aussi sera-t-elle rendue inutile, ce dont nous ne pourrons que nous féliciter. 
PEAU NOIRE. MASQUES BLANCS.

\section{Chapitre I}

\section{LE NOIR ET LE LANGAGE}

\section{Retour à la table des matières}

Nous attachons une importance fondamentale au phénomène du langage. C'est pourquoi nous estimons nécessaire cette étude qui doit pouvoir nous livrer un des éléments de compréhension de la dimension pour-autrui de l'homme de couleur. Etant entendu que parler, c'est exister absolument pour l'autre.

Le Noir a deux dimensions. L'une avec son congénère, l'autre avec le Blanc. Un Noir se comporte différemment avec un Blanc et avec un autre Noir. Que cette scissiparité soit la conséquence directe de l'aventure colonialiste, nul doute... Qu'elle nourrisse sa veine principale au cour des différentes théories qui ont voulu faire du Noir le lent acheminement du singe à l'homme, personne ne songe à le contester. Ce sont des évidences objectives, qui expriment la réalité.

Mais quand on a rendu compte de cette situation, quand on l'a comprise, on tient que la tâche est terminée... Comment ne pas réentendre alors, dégringolant les marches de l'Histoire, cette voix «Il ne s'agit plus de connaître le monde, mais de le transformer. » 
Il est effroyablement question de cela dans notre vie.

Parler, c'est être à même d'employer une certaine syntaxe, posséder la morphologie de telle ou telle langue, mais c'est surtout assumer une culture, supporter le poids d'une civilisation.

La situation n'étant pas à sens unique, l'exposé doit s'en ressentir. On voudra bien nous accorder certains points qui, pour inacceptables qu'ils puissent paraître au début, sauront trouver dans les faits le critère de leur exactitude.

[34]

Le problème que nous envisageons dans ce chapitre est le suivant: le Noir Antillais sera d'autant plus blanc, c'est-à-dire se rapprochera d'autant plus du véritable homme, qu'il aura fait sienne la langue française. Nous n'ignorons pas que c'est là une des attitudes de l'homme en face de l'Etre. Un homme qui possède le langage possède par contrecoup le monde exprimé et impliqué par ce langage. On voit où nous voulons en venir: il y a dans la possession du langage une extraordinaire puissance. Paul Valéry le savait, qui faisait du langage

«le dieu dans la chair égaré 3 »

Dans un ouvrage en préparation ${ }^{4}$, nous nous proposons d'étudier ce phénomène.

Pour l'instant, nous voudrions montrer pourquoi le Noir antillais, quel qu'il soit, a toujours à se situer en face du langage. Davantage, nous élargissons le secteur de notre description, et par-delà l'Antillais nous visons tout homme colonisé.

Tout peuple colonisé - c'est-à-dire tout peuple au sein duquel a pris naissance un complexe d'infériorité, du fait de la mise au tombeau

3 Charmes, La Pythie.

$4 \quad$ Le langage et l'agressivité. 
de l'originalité culturelle locale - se situe vis-à-vis du langage de la nation civilisatrice, c'est-à-dire de la culture métropolitaine. Le colonisé se sera d'autant plus échappé de sa brousse qu'il aura fait siennes les valeurs culturelles de la métropole. Il sera d'autant plus blanc qu'il aura rejeté sa noirceur, sa brousse. Dans l'armée coloniale, et plus spécialement dans les régiments de tirailleurs sénégalais, les officiers indigènes sont avant tout des interprètes. Ils servent à transmettre à leurs congénères les ordres du maître, et ils jouissent eux aussi d'une certaine honorabilité.

Il y a la ville, il y a la campagne. Il y a la capitale, il y a la province. Apparemment, le problème est le même. Prenons un Lyonnais à Paris ; il vantera le calme de sa ville, la beauté enivrante des quais du Rhône, la splendeur des platanes, et tant d'autres choses que chantent les gens [35] qui n'ont rien à faire. Si vous le rencontrez à son retour de Paris, et surtout si vous ne connaissez pas la capitale, alors il ne tarira pas d'éloges: Paris-ville-lumière, la Seine, les guinguettes, connaître Paris et mourir...

Le processus se répète dans le cas du Martiniquais. D'abord dans son île: Basse-Pointe, Marigot, Gros-Morne et, en face, l'imposant Fort-de-France. Ensuite, et c'est là le point essentiel, hors de son île. Le Noir qui connaît la métropole est un demi-dieu. Je rapporte à ce sujet un fait qui a dû frapper mes compatriotes. Beaucoup d'Antillais, après un séjour plus ou moins long dans la métropole, reviennent se faire consacrer. Avec eux l'indigène, celui-qui-n'est-jamais-sorti-deson-trou, le «bitaco», adopte la forme la plus éloquente de l'ambivalence. Le Noir qui pendant quelque temps a vécu en France revient radicalement transformé. Pour nous exprimer génétiquement, nous dirons que son phéno-type subit une mue définitive, absolue ${ }^{5}$. Dès avant son départ, on sent, à l'allure presque aérienne de sa démarche, que des forces nouvelles se sont mises en branle. Quand il ren-

5 Nous voulons dire par là que les Noirs qui reviennent près des leurs, donnent l'impression d'avoir achevé un cycle, de s'être ajouté quelque chose qui leur manquait. Ils reviennent littéralement pleins d'eux-mêmes. 
contre un ami ou un camarade, ce n'est plus le large geste huméral qui l'annonce: discrètement, notre «futur» s'incline. La voix, rauque d'habitude, laisse deviner un mouvement interne fait de bruissements. Car le Noir sait que là-bas, en France, il y a une idée de lui qui l'agrippera au Havre ou à Marseille: « Je suis Matiniquais, c'est la pemiè fois que je viens en Fance »; il sait que ce que les poètes appellent « roucoulement divin» (entendez le créole) n'est qu'un moyen terme entre le petit-nègre et le français. La bourgeoisie aux Antilles n'emploie pas le créole, sauf dans ses rapports avec les domestiques. $\grave{A}$ l'école, le jeune Martiniquais apprend à mépriser le patois. On parle de créolismes. Certaines familles interdisent l'usage du créole et les mamans traitent leurs enfants de «tibandes » quand ils l'emploient.

«Ma mère voulant un fils mémorandum si votre leçon d'histoire n'est pas sue

[36]

vous n'irez pas à la messe dimanche avec vos effets de dimanche cet enfant sera la honte de notre nom cet enfant sera notre nom de Dieu taisez-vous vous ai-je dit qu'il vous fallait parler français le français de France le français du Français le français français ${ }^{6}$.

Oui il faut que je me surveille dans mon élocution, car c'est un peu à travers elle qu'on me jugera... On dira de moi, avec beaucoup de mépris : il ne sait même pas parler le français.

6 Léon-G. Damas, Hoquet(Pigments). 
Dans un groupe de jeunes Antillais, celui qui s'exprime bien, qui possède la maîtrise de la langue, est excessivement craint ; il faut faire attention à lui, c'est un quasi-Blanc. En France, on dit : parler comme un livre. En Martinique : parler comme un Blanc.

Le Noir entrant en France va réagir contre le mythe du Martiniquais qui-mange-les- $R$. Il va s'en saisir, et véritablement entrera en conflit ouvert avec lui. Il s'appliquera non seulement à rouler les $R$, mais à les ourler. Epiant les moindres réactions des autres, s'écoutant parler, se méfiant de la langue, organe malheureusement paresseux, il s'enfermera dans sa chambre et lira pendant des heures - s'acharnant à se faire diction.

Dernièrement, un camarade nous racontait cette histoire. Un Martiniquais arrivant au Havre entre dans un café. Avec une parfaite assurance, il lance: «Garrrçon! un vè de biè. » Nous assistons là à une véritable intoxication. Soucieux de ne pas répondre à l'image du nègremangeant-les- $R$, il en avait fait une bonne provision, mais il n'a pas su répartir son effort.

Il y a un phénomène psychologique qui consiste à croire en une ouverture du monde dans la mesure où les frontières se brisent. Le Noir, prisonnier dans son île, perdu dans une atmosphère sans le moindre débouché, ressent comme une trouée d'air cet appel de l'Europe. Parce que, [37] il faut le dire, Césaire fut magnanime - dans son Cahier d'un retour au pays natal. Cette ville, Fort-de-France, est véritablement plate, échouée. Là-bas, aux flancs de ce soleil, « cette ville plate, étalée, trébuchée de son bon sens, inerte, essoufflée sous son fardeau géométrique de croix éternellement recommençantes, indocile à son sort, muette, contrariée de toute façon, incapable de croître selon le suc de cette terre, embarrassée, rognée, réduite, en rupture de faune et de flore 7 ».

La description qu'en donne Césaire n'est nullement poétique. On comprend alors que le Noir, à l'annonce de son entrée en France (com- 
me on dit de quelqu'un qui fait son «entrée dans le monde »), jubile et décide de changer. D'ailleurs, il n'y a pas thématisation, il change de structure indépendamment de toute démarche réflexive. Il existe aux Etats-Unis un centre dirigé par Pearce et Williamson; c'est le centre de Peckam. Les auteurs ont prouvé qu'il y avait chez les gens mariés un remaniement bio-chimique, et, paraît-il, ils auraient décelé la présence de certaines hormones chez l'époux d'une femme gestante. Il serait aussi intéressant, il s'en trouvera d'ailleurs pour le faire, de rechercher les bouleversements humoraux des Noirs à leur arrivée en France. Ou simplement d'étudier par des tests les modifications de leur psychisme avant leur départ et un mois après leur installation en France.

Il y a un drame dans ce qu'il est convenu d'appeler les sciences de l'homme. Doit-on postuler une réalité humaine type et en décrire les modalités psychiques, ne tenant compte que des imperfections, ou bien ne doit-on pas tenter sans relâche une compréhension concrète et toujours nouvelle de l'homme?

Quand nous lisons qu'à partir de vingt-neuf ans l'homme ne peut plus aimer, qu'il lui faut attendre quarante-neuf ans pour que réapparaisse son affectivité, nous sentons le sol se dérober. On ne s'en sortira qu'à la condition expresse de bien poser le problème, car toutes ces découvertes, toutes ces recherches ne tendent qu'à une chose: faire admettre à l'homme qu'il n'est rien, absolument rien, [38] - et qu'il lui faut en finir avec ce narcissisme selon lequel il s'imagine différent des autres « animaux».

Il y a là ni plus ni moins capitulation de l'homme.

$\grave{A}$ tout prendre, je saisis mon narcissisme à pleines mains et je repousse l'abjection de ceux qui veulent faire de l'homme une mécanique. Si le débat ne peut pas s'ouvrir sur le plan philosophique, c'est-à-dire de l'exigence fondamentale de la réalité humaine, je consens à le mener sur celui de la psychanalyse, c'est-à-dire des « ratés », au sens où l'on dit qu'un moteur a des ratés. 
Le Noir qui entre en France change parce que pour lui la métropole représente le Tabernacle; il change non seulement parce que c'est de là que lui sont venus Montesquieu, Rousseau et Voltaire, mais parce que c'est de là que lui viennent les médecins, les chefs de service, les innombrables petits potentats - depuis le sergent-chef «quinze ans de service » jusqu'au gendarme originaire de Panissières. Il y a une sorte d'envoûtement à distance, et celui qui part dans une semaine à destination de la Métropole crée autour de lui un cercle magique où les mots Paris, Marseille, la Sorbonne, Pigalle représentent les clés de voûte. Il part et l'amputation de son être disparaît à mesure que le profil du paquebot se précise. Il lit sa puissance, sa mutation, dans les yeux de ceux qui l'ont accompagné. " Adieu madras, adieu foulard... »

Maintenant que nous l'avons conduit au port, laissons-le voguer, nous le retrouverons. Pour l'instant, allons à la rencontre de l'un d'entre eux qui revient. Le «débarqué », dès son premier contact, s'affirme; il ne répond qu'en français et souvent ne comprend plus le créole. A ce propos, le folklore nous fournit une illustration. Après quelques mois passés en France, un paysan retourne près des siens. Apercevant un instrument aratoire, il interroge son père, vieux campagnard à-qui-on-ne-la-fait-pas : « Comment s'appelle cet engin ? » Pour toute réponse, son père le lui lâche sur les pieds, et l'amnésie disparaît. Singulière thérapeutique.

Voici donc un débarqué. Il n'entend plus le patois, parle de l'Opéra, qu'il n'a peut-être aperçu que de loin, mais surtout adopte une attitude critique à l'égard de ses compatriotes. En présence du moindre événement, il se comporte [39] en original. Il est celui qui sait. Il se révèle par son langage. A la Savane, où se réunissent les jeunes gens de Fortde-France, le spectacle est significatif: la parole est tout de suite donnée au débarqué. - Dès la sortie du lycée et des écoles, ils se réunissent sur la Savane. Il paraît qu'il y a une poésie de cette Savane. Imaginez un espace de deux cents mètres de long sur quarante de large, limité latéralement par des tamariniers vermoulus, en haut par l'immense monument aux morts, la patrie reconnaissante à ses enfants, en bas par le Central-Hôtel; un espace torturé de pavés inégaux, des 
cailloux qui roulent sous les pieds, et, enfermés dans tout cela, montant et descendant, trois ou quatre cents jeunes gens qui s'accostent, se prennent, non ne se prennent jamais, se quittent.

- Ça va?

- Ça va. Et toi?

- Ca va.

Et l'on va comme ça pendant cinquante ans. Oui, cette ville est lamentablement échouée. Cette vie aussi.

Ils se retrouvent et parlent. Et si le débarqué obtient rapidement la parole, c'est qu'on l'attend. D'abord dans la forme: la moindre faute est saisie, dépouillée, et en moins de quarante-huit heures tout Fortde-France la connaît. On ne pardonne pas, à celui qui affiche une supériorité, de faillir au devoir. Qu'il dise, par exemple: «Il ne m'a pas été donné de voir en France des gendarmes à chevaux», et le voilà perdu. Il ne lui reste qu'une alternative: se débarrasser de son parisianisme ou mourir au pilori. Car on n'oubliera point: marié, sa femme saura qu'elle épouse une histoire, et ses enfants auront une anecdote à affronter et à vaincre.

D'où provient cette altération de la personnalité ? D'où provient ce nouveau mode d'être? Tout idiome est une façon de penser, disaient Damourette et Pichon. Et le fait, pour le Noir récemment débarqué, d'adopter un langage différent de celui de la collectivité qui l'a vu nâ̂tre, manifeste un décalage, un clivage. Le professeur Westermann, dans The African to-day, écrit qu'il existe un sentiment d'infériorité des Noirs qu'éprouvent surtout les évolués et qu'ils s'efforcent sans cesse de dominer. La manière employée pour cela, ajoute-t-il, est souvent naïve: «Porter des [40] vêtements européens ou des guenilles à la dernière mode, adopter les choses dont l'Européen fait usage, ses formes extérieures de civilité, fleurir le langage indigène d'expressions européennes, user de phrases ampoulées en parlant ou 
en écrivant dans une langue européenne, tout cela est mis en œuvre pour tenter de parvenir à un sentiment d'égalité avec l'Européen et son mode d'existence. »

Nous voudrions, nous référant à d'autres travaux et à nos observations personnelles, essayer de montrer pourquoi le Noir se situe de façon caractéristique en face du langage européen. Nous rappelons encore une fois que les conclusions auxquelles nous aboutirons valent pour les Antilles françaises: nous n'ignorons pas toutefois que ces mêmes comportements se retrouvent au sein de toute race ayant été colonisée.

Nous avons connu, et malheureusement nous connaissons encore, des camarades originaires du Dahomey ou du Congo qui se disent Antillais: nous avons connu et nous connaissons encore des Antillais qui se vexent quand on les soupçonne d'être Sénégalais. C'est que l'Antillais est plus « évolué » que le Noir d'Afrique : entendez qu'il est plus près du Blanc; et cette différence existe non seulement dans la rue et sur les boulevards, mais aussi dans les administrations, dans l'armée. Tout Antillais ayant fait son service militaire dans un régiment de tirailleurs connaît cette bouleversante situation: d'un côté les Européens, vieilles colonies ou originaires, de l'autre les tirailleurs. Il nous souvient de certain jour où, en pleine action, la question se trouva posée d'anéantir un nid de mitrailleuses. Par trois fois les Sénégalais furent lancés, par trois fois ils furent rejetés. Alors, l'un des leurs demanda pourquoi les toubabs n'y allaient pas. Dans ces moments-là, on arrive à ne plus savoir qui l'on est, toubab ou indigène. Cependant pour beaucoup d'Antillais cette situation n'est pas ressentie comme bouleversante, mais au contraire comme tout à fait normale. Il ne manquerait plus que ça, nous assimiler à des nègres! Les originaires méprisent les tirailleurs et l'Antillais règne sur toute cette négraille en maître incontesté. À l'extrême d'ailleurs, je rapporte un fait qui est pour le moins comique: dernièrement, je mientretenais avec un Martiniquais qui m'apprit, courroucé, [41] que certains Guadeloupéens se faisaient passer pour nôtres. Mais, ajoutait-il, on s'aperçoit rapidement de l'erreur, ils sont plus sauvages que nous; entendez encore: ils sont plus éloi- 
gnés du Blanc. On dit que le Noir aime les palabres; et quand pour ma part je prononce "palabres», je vois un groupe d'enfants jubilant, lançant vers le monde des appels inexpressifs, des raucités; des enfants en plein jeu, dans la mesure où le jeu peut être conçu comme initiation à la vie. Le Noir aime les palabres, et le chemin n'est pas long qui conduit à cette nouvelle proposition : le Noir n'est qu'un enfant. Les psychanalystes ici ont beau jeu, et le terme d'oralité est vite lâché.

Mais nous devons aller plus loin. Le problème du langage est trop capital pour espérer le poser intégralement ici. Les remarquables études de Piaget nous ont appris à distinguer des stades dans son apparition, et celles de Gelb et Goldstein nous ont montré que la fonction du langage se distribue en paliers, en degrés. Ici c'est l'homme noir en face de la langue française qui nous intéresse. Nous voulons comprendre pourquoi l'Antillais aime bien parler le français.

Jean-Paul Sartre, dans son Introduction à l'Anthologie de la poésie nègre et malgache, nous dit que le poète noir se retournera contre la langue française, mais cela est faux quant aux poètes antillais. Nous sommes en cela d'ailleurs de l'avis de M. Michel Leiris, qui, il y a peu de temps, pouvait écrire à propos du créole:

«Actuellement encore, langue populaire que tous connaissent plus ou moins, mais que les seuls illettrés parlent à l'exclusion du français, le créole paraît d'ores et déjà promis à passer tôt ou tard au rang de survivance quand l'instruction (si lents soient ses progrès, entravés par le nombre partout trop restreint des établissements scolaires, la pénurie en matière de lecture publique et le niveau souvent trop bas de la vie matérielle) se sera diffusée assez généralement dans les couches déshéritées de la population.» - Et, ajoute l'auteur, «pour les poètes dont je parle ici, il ne s'agit nullement de se faire «Antillais» - sur le plan du pittoresque de félibrige - en usant d'un langage d'emprunt et, qui plus est, dénué de [42] rayonnement extérieur quelles que puissent être ses qualités intrinsèques, mais d'affirmer, face à 
des Blancs imbus des pires préjugés raciaux et dont l'orgueil de plus en plus clairement s'avère injustifié, l'intégrité de leur personne 8 ».

S'il existe un Gilbert Gratiant pour écrire en patois, il faut avouer que la chose est rare. Ajoutons d'ailleurs que la valeur poétique de ces créations est fort douteuse. Au contraire, il y a de véritables ouvrages traduits du ouolof ou du peuhl et nous suivons avec beaucoup d'intérêt les études de linguistique de Cheik Anta Diop.

Aux Antilles, rien de pareil. La langue officiellement parlée est le français: les instituteurs surveillent étroitement les enfants pour que le créole ne soit pas utilisé. Nous passons sous silence les raisons invoquées. Donc, apparemment, le problème pourrait être le suivant : aux Antilles comme en Bretagne, il y a un dialecte et il y a la langue française. Mais c'est faux, car les Bretons ne s'estiment pas inférieurs aux Français. Les Bretons n'ont pas été civilisés par le Blanc.

Refusant de multiplier les éléments, nous risquons de ne pas délimiter le foyer : or, il est important de dire au Noir que l'attitude de rupture n'a jamais sauvé personne; et s'il est vrai que je dois me libérer de celui qui m'étouffe parce que véritablement je ne puis pas respirer, il demeure entendu que sur la base physiologique : difficulté mécanique de respiration, il devient malsain de greffer un élément psychologique : impossibilité d'expansion.

Qu'est-ce à dire? Tout simplement ceci : lorsqu'un Antillais licencié en philosophie déclare ne pas présenter l'agrégation, alléguant sa couleur, je dis que la philosophie n'a jamais sauvé personne. Quand un autre s'acharne à me prouver que les Noirs sont aussi intelligents que les Blancs, je dis: l'intelligence non plus n'a jamais sauvé personne, et cela est vrai, car si c'est au nom de l'intelligence et de la philosophie que l'on proclame l'égalité des hommes, c'est en leur nom aussi qu'on décide leur extermination.

[43] 
Avant de continuer, il nous semble nécessaire de dire certaines choses. Je parle ici, d'une part, de Noirs aliénés (mystifiés), et d'autre part de Blancs non moins aliénés (mystificateurs et mystifiés). S'il se trouve un Sartre ou un Verdier, le cardinal, pour dire que le scandale du problème noir n'a que trop duré, on ne peut que conclure à la normalité de leur attitude. Nous aussi pourrions multiplier références et citations et montrer qu'effectivement le «préjugé de couleur» est une idiotie, une iniquité qu'il s'agit d'anéantir.

Sartre commence ainsi son Orphée noir: "Qu'est-ce donc que vous espériez quand vous ôtiez le bâillon qui fermait ces bouches noires? Qu'elles allaient entonner vos louanges? Ces têtes que nos pères avaient courbées jusqu'à terre par la force, pensiez-vous, quand elles se relèveraient, lire l'adoration dans leurs yeux ${ }^{9}$ ? $\gg \mathrm{Je}$ ne sais pas, mais je dis que celui qui cherchera dans mes yeux autre chose qu'une interrogation perpétuelle devra perdre la vue: ni reconnaissance ni haine. Et si je pousse un grand cri, il ne sera point nègre. Non, dans la perspective adoptée ici, il n'y a pas de problème noir. Ou du moins, s'il y en a un, les Blancs n'y sont intéressés que par hasard. C'est une histoire qui se passe dans l'obscurité, et il faudra bien que le soleil que je transhume éclaire les moindres recoins.

Le $D^{r} H .-L$. Gordon, médecin de l'hôpital de psychopathie Mathari à Nairobi, écrit dans un article de la Presse médicale de l'Est-Africain: "L'observation poussée au plus haut point d'une série de cent cerveaux d'indigènes normaux établit à l'œil nu une absence de cerveaux nouveaux, caractérisés, comme on sait, par des cellules au dernier stade de développement. Et, ajoute-t-il, cette infériorité représente quantitativement 14,8\%. » (Cité par sir Alan Burns ${ }^{10}$.)

On a dit que le nègre reliait le singe à l'homme, l'homme blanc bien entendu; et ce n'est qu'à la cent vingtième page que sir Alan Burns conclut: «Nous ne pouvons donc considérer comme scientifiquement établie la théorie [44] selon laquelle l'homme noir serait inferieur à

9 J.-P. Sartre, Préface à l'Anthologie de la poésie nègre et malgache.

10 Le Préjugé de race et de couleur, p. 112. 
I'homme blanc ou proviendrait d'une souche différente. » Il nous serait facile, ajoutons-nous, de montrer l'absurdité de propositions telles que: «Aux termes de l'Écriture, la séparation des races blanches et noires se prolongera au ciel comme sur la terre, et les indigènes qui seront accueillis au Royaume des Cieux se trouveront séparément dirigés sur certaines de ces maisons du Père dont le Nouveau Testament contient la mention. » Ou encore: « Nous sommes le peuple élu, regarde la teinte de nos peaux, d'autres sont noirs ou jaunes, c'est à cause de leurs péchés. »

Oui, comme on le voit, en faisant appel à l'humanité, au sentiment de la dignité, à l'amour, à la charité, il nous serait facile de prouver ou de faire admettre que le Noir est l'égal du Blanc. Mais notre but est tout autre: ce que nous voulons, c'est aider le Noir à se libérer de l'arsenal complexuel qui a germé au sein de la situation coloniale. M. Achille, professeur au lycée du Parc à Lyon, dans une conférence citait une aventure personnelle. Cette aventure est universellement connue. Rares sont les Noirs résidant en France qui ne l'ont pas vécue. Etant catholique, il se rendait à un pèlerinage d'étudiants. Un prêtre, avisant ce bronzé dans sa troupe, lui dit : « Toi quitté grande Savane pourquoi et venir avec nous? » L'interpellé répondit très courtoisement et le gêné de l'histoire ne fut pas le jeune déserteur des Savanes. On rit de ce quiproquo et le pèlerinage continua. Mais si nous nous y arrêtions, nous verrions que le fait pour le prêtre de s'adresser en petit-nègre appelle diverses remarques:

1. «Les Noirs, je les connais; il faut s'adresser à eux gentiment, leur parler de leur pays ; savoir leur parler, telle est la question. Voyez plutôt... » Nous n'exagérons pas: un Blanc s'adressant à un nègre se comporte exactement comme un adulte avec un gamin, et l'on s'en va minaudant, susurrant, gentillonnant, calinotant. Ce n'est pas un Blanc que nous avons observé, mais des centaines; et nos observations n'ont pas porté sur telle ou telle catégorie, mais, nous prévalant d'une attitude essentiellement objective, nous avons voulu étudier ce fait chez les médecins, les agents de police, les entrepreneurs sur les chantiers. 
[45] L'on nous dira, oubliant en cela notre but, que nous aurions pu porter notre attention ailleurs, qu'il existe des Blancs n'entrant pas dans notre description.

Nous répondrons à ces objecteurs que nous faisons ici le procès des mystifiés et des mystificateurs, des aliénés, et que, s'il existe des Blancs à se comporter sainement en face d'un Noir, c'est justement le cas que nous n'avons pas à retenir. Ce n'est pas parce que le foie de mon malade fonctionne bien que je dirai : les reins sont sains. Le foie étant reconnu normal, je l'abandonne à sa normalité, qui est normale, et je me tourne vers les reins; en l'occurrence, les reins sont malades. Ce qui veut dire qu'à côté des gens normaux qui se comportent sainement selon une psychologie humaine, il en est à se comporter pathologiquement selon une psychologie inhumaine. Et il se trouve que l'existence de ce genre d'hommes a déterminé un certain nombre de réalités à la liquidation desquelles nous voulons ici contribuer.

Parler aux nègres de cette façon, c'est aller à eux, c'est les mettre à leur aise, c'est vouloir se faire comprendre d'eux, c'est les rassurer...

Les médecins des salles de consultation le savent. Vingt malades européens se succèdent: «Asseyez-vous, monsieur... Pourquoi venezvous ?... De quoi souffrez-vous ?...» - Arrive un nègre ou un Arabe: «Assieds-toi, mon brave... Qu'est-ce que tu as ?... Où as-tu mal ?»Quand ce n'est pas : «Quoi toi y en a ?... »

2. Parler petit-nègre à un nègre, c'est le vexer, car il est celui-quiparle-petit-nègre. Pourtant, nous dira-t-on, il n'y a pas intention, volonté de vexer. Nous l'accordons, mais c'est justement cette absence de volonté, cette désinvolture, cette nonchalance, cette facilité avec laquelle on le fixe, avec laquelle on l'emprisonne, on le primitivise, l'anticivilise, qui est vexante.

Si celui qui s'adresse en petit-nègre à un homme de couleur ou à un Arabe ne reconnaît pas dans ce comportement une tare, un vice, c'est qu'il n'a jamais réfléchi. Personnellement, il nous arrive, en interrogeant certains malades, de sentir à quel moment nous glissons... 
En face de cette vieille paysanne de soixante-treize ans, débile mentale, en plein processus démentiel, je sens tout [46] à coup s'effondrer les antennes avec lesquelles je touche et par lesquelles je suis touché. Le fait pour moi d'adopter un langage approprié à la démence, à la débilité mentale; le fait pour moi de me «pencher» sur cette pauvre vieille de soixante-treize ans; le fait pour moi d'aller à elle, à la recherche d'un diagnostic, est le stigmate d'un fléchissement dans mes relations humaines.

C'est un idéaliste, dira-t-on. Mais non, ce sont les autres qui sont des salauds. Pour ma part, je madresse toujours aux «bicots» en français correct, et j'ai toujours été compris. Ils me répondent comme ils peuvent, mais je me refuse à toute compréhension paternaliste.

- Bonjour, mon z'ami! Où y a mal ? Hé ? Dis voir un peu ? le ventre? le cœur?

... Avec le petit accent que les hypos des salles de consultation connaissent bien.

On a bonne conscience quand la réponse arrive sur le même mode. « Vous voyez, on ne vous raconte pas de blagues. Ils sont comme ça. »

Dans le cas contraire, il faudra rappeler ses pseudopodes et se comporter en homme. Tout l'édifice s'écroule. Un Noir qui vous dit: «Monsieur, je ne suis nullement votre brave... » Du nouveau dans le monde.

Mais il faut aller plus bas. Vous êtes au café, à Rouen ou à Strasbourg, un vieil ivrogne par malheur vous aperçoit. Vite, il s'assied à votre table: «Toi Africain? Dakar, Rufisque, bordels, femmes, café, mangues, bananes... » Vous vous levez et vous partez; vous êtes salué d'une bordée de jurons: "Sale nègre, tu ne faisais pas tant l'important dans ta brousse! » 
M. Mannoni a décrit ce qu'il appelle le complexe de Prospéro. Nous reviendrons sur ces découvertes, qui nous permettront de comprendre la psychologie du colonialisme. Mais déjà nous pouvons dire:

Parler petit-nègre, c'est exprimer cette idée: «Toi, reste où tu es. »

Je rencontre un Allemand ou un Russe parlant mal le français. Par gestes, j'essaie de lui donner le renseignement qu'il réclame, mais ce faisant je n'ai garde d'oublier qu'il a une langue propre, un pays, et qu'il est peut-être avocat ou ingénieur dans sa culture. En tout cas, il est [47] étranger à mon groupe, et ses normes doivent être différentes.

Dans le cas du Noir, rien de pareil. Il n'a pas de culture, pas de civilisation, pas ce «long passé d'histoire».

On retrouve peut-être là l'origine des efforts des Noirs contemporains : coûte que coûte prouver au monde blanc l'existence d'une civilisation nègre.

Le nègre doit, qu'il le veuille ou non, endosser la livrée que lui a faite le Blanc. Regardez les illustrés pour enfants, les nègres ont tous à la bouche le « oui Missié » rituel. Au cinéma, l'histoire est plus extraordinaire. La plupart des films américains synchronisés en France reproduisent des nègres type : « $Y$ a bon banania. » Dans un de ces films récents, Requins d'acier, on voyait un nègre, naviguant dans un sousmarin, parler le jargon le plus classique qui soit. D'ailleurs, il était bien nègre, marchant derrière, tremblant au moindre mouvement de colère du quartier-maître, et finalement tué dans l'aventure. Je suis pourtant persuadé que la version originale ne comportait pas cette modalité d'expression. Et quand bien même elle aurait existé, je ne vois pas pourquoi en France démocratique, où soixante millions de citoyens sont de couleur, l'on synchroniserait jusqu'aux imbécillités d'outreAtlantique. C'est que le nègre doit se présenter d'une certaine manière, et depuis le Noir de Sans Pitié - « Moi bon ouvrier, jamais mentir, jamais voler » jusqu'à la servante de Duel au soleil, on retrouve cette stéréotypie. 
Oui, au Noir on demande d'être bon négro; ceci posé, le reste vient tout seul. Le faire parler petit-nègre, c'est l'attacher à son image, l'engluer, l'emprisonner, victime éternelle d'une essence, d'un apparaître dont il n'est pas le responsable. Et naturellement, de même qu'un Juif qui dépense de l'argent sans compter est suspect, le Noir qui cite Montesquieu doit être surveillé. Qu'on nous comprenne: surveillé, dans la mesure où avec lui commence quelque chose. Et, certes, je ne prétends pas que l'étudiant noir soit suspect à ses camarades ou à ses professeurs. Mais en dehors des milieux universitaires subsiste une armée d'imbéciles : il importe non pas de les éduquer, mais d'amener le Noir à ne pas être l'esclave de leurs archétypes.

[48]

Que ces imbéciles soient le produit d'une structure économicopsychologique, nous l'accordons: seulement nous n'en sommes pas plus avancé.

Quand un nègre parle de Marx, la première réaction est la suivante: «On vous a élevés et maintenant vous vous retournez contre vos bienfaiteurs. Ingrats! Décidément, on ne peut rien attendre de vous. " Et puis il y a aussi cet argument-massue du planteur en Afrique : notre ennemi, c'est l'instituteur.

Ce que nous affirmons, c'est que l'Européen a une idée définie du Noir, et il n'y a rien de plus exaspérant que de s'entendre dire: «Depuis quand êtes-vous en France? Vous parlez bien le français. »

On pourrait me répondre que cela est dû au fait que beaucoup de Noirs s'expriment en petit-nègre. Mais ce serait trop facile. Vous êtes dans le train, vous demandez:

- Pardon, monsieur, voudriez-vous m'indiquer le wagon-restaurant, s'il vous plaît.

- Oui, mon z'ami, toi y en a prendre couloir tout droit, un, deux, trois, c'est là. 
Non, parler petit-nègre, c'est enfermer le Noir, c'est perpétuer une situation conflictuelle où le Blanc infeste le Noir de corps étrangers extrêmement toxiques. Rien de plus sensationnel qu'un Noir s'exprimant correctement, car, vraiment, il assume le monde blanc. Il nous arrive de nous entretenir avec des étudiants d'origine étrangère. Ils parlent mal le français le petit Crusoë, alias Prospéro, se trouve alors à son aise. Il explique, renseigne, commente, leur prend leurs cours. Avec le Noir, l'ahurissement est à son comble; lui, il s'est mis à la page. Avec lui, le jeu n'est plus possible, il est une pure réplique du Blanc. Il faut s'incliner 11.

On comprend, après tout ce qui vient d'être dit, que [49] la première réaction du Noir soit de dire non à ceux qui tentent de le définir. On comprend que la première action du Noir soit une réaction, et puisque le Noir est apprécié en référence à son degré d'assimilation, on comprend aussi que le débarqué ne s'exprime qu'en français. C'est qu'il tend à souligner la rupture qui s'est désormais produite. Il réalise un nouveau type d'homme qu'il impose à ses camarades, à ses parents. Et à sa vieille mère qui ne comprend plus, il parle de ses liquettes, de la bicoque en désordre, de la baraque... Tout cela agrémenté de l'accent qui convient.

Dans tous les pays du monde, il y a des arrivistes: « ceux qui ne se sentent plus», et il y $a$, en face d'eux, « ceux qui gardent la notion de leur origine». L'Antillais qui revient de la métropole s'exprime en patois s'il veut signifier que rien n'a changé. On le sent au débarcadère, où parents et amis l'attendent. L'attendent non seulement parce qu'il arrive, mais dans le sens où l'on dit: je l'attends au tournant. Il leur

11 « J'ai connu des nègres à la Faculté de médecine... en un mot ils étaient décevants : le teint de leur peau devait leur permettre de nous donner l'opportunité d'être charitables, magnanimes, ou scientifiquement amicaux. Ils avaient failli à ce devoir, à cette exigence de notre bon vouloir. Toute notre larmoyante tendresse, toute notre sollicitude roublarde nous restait sur les bras. Nous n'avions pas de nègres à cajoler, nous n'avions pas de quoi les haïr non plus: ils pesaient, à peu de chose près, notre propre poids dans la balance des petits travaux et des maigres tricheries quotidiennes.» - Michel Salomon, " D'un juif à des nègres », Présence africaine, $n^{\circ} 5$, p. 776. 
faut une minute pour établir le diagnostic. Si à ses camarades le débarqué dit: « Je suis très heureux de me retrouver parmi vous. Mon Dieu, qu'il fait chaud dans ce pays, je ne saurais y demeurer longtemps», on est prévenu : c'est un Européen qui arrive.

Dans un ordre plus particulier, quand à Paris des étudiants antillais se rencontrent, deux possibilités s'offrent à eux :

- ou soutenir le monde blanc, c'est-à-dire le véritable monde, et, le français alors employé, il leur demeure possible d'envisager quelques problèmes et de tendre dans leurs conclusions à un certain degré d'universalisme:

- ou rejeter l'Europe, «Yo»12, et se rejoindre par le patois, en s'installant bien confortablement dans ce que nous appellerons l'umwelt martiniquais: nous voulons dire par là - et cela s'adresse surtout à nos frères antillais - que lorsqu'un de nos camarades, à Paris ou dans quelque autre ville de Facultés, s'essaie à considérer sérieusement un problème, on l'accuse de faire l'important, et le meilleur moyen de le désarmer est de s'infléchir [50] vers le monde antillais en brandissant le créole. Il faut trouver là une des raisons pour lesquelles tant d'amitiés s'écroulent après quelque temps de vie européenne.

Notre propos étant la désaliénation des Noirs, nous voudrions qu'ils sentent que chaque fois qu'il y a incompréhension entre eux en face du Blanc, il y a absence de discernement.

Un Sénégalais apprend le créole afin de se faire passer pour antillais : je dis qu'il y a aliénation.

Les Antillais qui le savent multiplient leurs railleries je dis qu'il y a absence de discernement.

Comme on le voit, nous n'avions pas tort de penser qu'une étude du langage chez l'Antillais pouvait nous révéler quelques traits de son

12 Façon de désigner les autres pris génériquement, et plus spécialement les Européens. 
monde. Nous l'avons dit au début, il y a un rapport de soutènement entre la langue et la collectivité.

Parler une langue, c'est assumer un monde, une culture. L'Antillais qui veut être blanc le sera d'autant plus qu'il aura fait sien l'instrument culturel qu'est le langage. Je me souviens, il y a un peu plus d'un an, à Lyon, après une conférence où j'avais tracé un parallèle entre la poésie noire et la poésie européenne, de ce camarade métropolitain me disant chaleureusement : « Au fond, tu es un Blanc. » Le fait pour moi d'avoir étudié à travers la langue du Blanc un problème aussi intéressant me donnait droit de cité.

Historiquement, il faut comprendre que le Noir veut parler le français, car c'est la clef susceptible d'ouvrir les portes qui, il y a cinquante ans encore, lui étaient interdites. Nous retrouvons chez les Antillais entrant dans le cadre de notre description une recherche des subtilités, des raretés du langage, - autant de moyens de se prouver à euxmêmes une adéquation à la culture ${ }^{13}$. On a dit: les orateurs antillais ont une puissance d'expression qui laisserait pantelants les Européens. Il me revient un fait [51] significatif : en 1945, lors des campagnes électorales, Aimé Césaire, candidat à la députation, parlait à l'école des garçons de Fort-de-France devant un auditoire nombreux. Au milieu de la conférence, une femme s'évanouit. Le lendemain, un camarade, relatant l'affaire, la commentait de la sorte: «Français a té tellement chaud que la femme là tombé malcadi ${ }^{14}$. » Puissance du langage!

Quelques autres faits méritent de retenir notre attention: par exemple M. Charles-André Julien présentant Aimé Césaire : « un poète noir agrégé de l'Université... », ou encore, tout simplement, le terme de « grand poète noir».

13 Voir par exemple le nombre presque incroyable des anecdotes auxquelles a donné naissance l'élection à la députation de tel candidat. Une ordure de journal, du nom de Canard déchaîné, n'a eu de cesse qu'il n'ait enveloppé M. B... de créolismes éviscérants. C'est en effet l'arme-massue aux Antilles : ne sait pas s'exprimer en français.

14 Le français (l'élégance de la forme) était tellement chaud que la femme est tombée en transes. 
Il y a dans ces phrases toutes faites, et qui semblent répondre à une urgence de bon sens, - car enfin Aimé Césaire est noir et il est poète, - une subtilité qui se cache, un nœud qui persiste. J'ignore qui est Jean Paulhan, sinon qu'il écrit des ouvrages fort intéressants: j'ignore quel peut être l'âge de Caillois, ne retenant que les manifestations de son existence dont il raye le ciel de temps à autre. Et que l'on ne nous accuse point d'anaphylaxie affective; ce que nous voulons dire, c'est qu'il n'y a pas de raison pour que M. Breton dise de Césaire : «Et c'est un Noir qui manie la langue française comme il n'est pas aujourd'hui un Blanc pour la manier ${ }^{15}$. »

Et quand bien même $M$. Breton exprimerait la vérité, je ne vois pas en quoi résiderait le paradoxe, en quoi résiderait la chose à souligner, car enfin M. Aimé Césaire est martiniquais et agrégé de l'Université.

Encore une fois nous retrouvons M. Michel Leiris : "S'il y a chez les écrivains antillais volonté de rupture avec les formes littéraires liées à l'enseignement officiel, cette volonté, tendue vers un avenir plus aéré, ne saurait revêtir une allure folklorisante. Désireux avant tout, littérairement, de formuler le message qui leur appartient en propre et quant à quelques-uns tout au moins d'être les porte-parole d'une vraie race aux possibilités méconnues, ils dédaignent l'artifice que représenterait pour eux, dont [52] la formation intellectuelle s'est opérée à travers le français de façon presque exclusive, le recours à un parler qu'ils ne pourraient plus guère employer que comme une chose apprise ${ }^{16}$.»

Mais, me rétorqueront les Noirs, c'est un honneur pour nous qu'un Blanc comme Breton écrive pareilles choses.

Continuons...

15 Introduction au Cahier d'un retour au pays natal, p. 14.

16 Michel Leiris, art. cit. 
[53]

PEAU NOIRE. MASQUES BLANCS.

\section{Chapitre II}

\section{LA FEMME DE COULEUR \\ ET LE BLANC}

\section{Retour à la table des matières}

L'homme est mouvement vers le monde et vers son semblable. Mouvement d'agressivité, qui engendre l'asservissement ou la conquête: mouvement d'amour, don de soi, terme final de ce qu'il est convenu d'appeler l'orientation éthique. Toute conscience semble pouvoir manifester, simultanément ou alternativement, ces deux composantes. Energétiquement, l'être aimé m'épaulera dans l'assomption de ma virilité, tandis que le souci de mériter l'admiration ou l'amour d'autrui tissera tout le long de ma vision du monde une superstructure valorisante.

Dans la compréhension des phénomènes de cet ordre, le travail de l'analyste et du phénoménologue se révèle suffisamment ardu. Et s'il s'est trouvé un Sartre pour réaliser une description de l'amour-échec, l'Etre et le Néant n'étant que l'analyse de la mauvaise foi et le l'inauthenticité, il demeure que l'amour vrai, réel, - vouloir pour les autres ce que l'on postule pour soi, quand cette postulation intègre les 
valeurs permanentes de la réalité humaine, - requiert la mobilisation d'instances psychiques fondamentalement libérées des conflits inconscients.

Loin, loin derrière, se sont évanouies les ultimes séquelles d'une lutte gigantesque menée contre l'autre. Aujourd'hui nous croyons en la possibilité de l'amour, c'est pourquoi nous nous efforçons d'en détecter les imperfections, les perversions.

Il s'agit, pour nous, dans ce chapitre consacré aux rapports de la femme de couleur et de l'Européen, de déterminer dans quelle mesure l'amour authentique demeurera impossible tant que ne seront pas expulsés ce sentiment d'infériorité ou cette exaltation adlérienne, cette surcompensation, [54] qui semblent être l'indicatif de la Weltanschauung noire.

Parce qu'enfin, quand nous lisons dans Je suis Martiniquaise: «J'aurais voulu me marier, mais avec un Blanc. Seulement une femme de couleur n'est jamais tout à fait respectable aux yeux d'un Blanc. Même s'il l'aime. Je le savais $17 »$, nous sommes en droit d'être inquiet. Ce passage, qui sert en un sens de conclusion à une énorme mystification, nous incite à réfléchir. Un jour, une femme du nom de Mayotte Capécia, obéissant à un motif dont nous apercevons mal les tenants, a écrit deux cent deux pages - sa vie - où se multipliaient à loisir les propositions les plus absurdes. L'accueil enthousiaste qui a été réservé à cet ouvrage dans certains milieux nous fait un devoir de l'analyser. Pour nous, aucune équivoque n'est possible: Je suis Martiniquaise est un ouvrage au rabais, prônant un comportement malsain.

Mayotte aime un Blanc dont elle accepte tout. C'est le seigneur. Elle ne réclame rien, n'exige rien, sinon un peu de blancheur dans sa vie. Et quand, se posant la question de savoir s'il est beau ou laid, l'amoureuse dira: "Tout ce que je sais, c'est qu'il avait les yeux bleus, les cheveux blonds, le teint pâle, et que je l'aimais», - il est facile de voir, en remettant les termes à leur place, qu'on obtient à peu près ceci : « Je

17 Mayotte Capécia (Corrêa éd., p. 202). 
l'aimais parce qu'il avait les yeux bleus, les cheveux blonds et le teint pâle. » Et nous qui sommes Antillais, nous ne le savons que trop : le nègre craint les yeux bleus, répète-t-on là-bas.

Quand nous disions dans notre introduction que l'infériorité avait été historiquement ressentie comme économique, nous ne nous trompions guère.

«Certains soirs, hélas! il devait me quitter, pour remplir ses obligations mondaines. Il allait à Didier, le quartier chic de Fort-deFrance où vivent les «békès Martinique ", qui ne sont peut-être pas de race très pure, mais sont souvent très riches (il est admis qu'on est blanc à partir d'un certain nombre de millions), et les «békès France», pour la plupart fonctionnaires ou officiers.

«Parmi les camarades d'André, qui, comme lui, se trouvaient [55] bloqués par la guerre aux Antilles, certains avaient réussi à faire venir leurs femmes. Je comprenais qu'André ne pouvait rester toujours à l'écart. J'acceptais aussi de ne pas être admise dans ce cercle, puisque j'étais une femme de couleur: mais je ne pouvais m'empêcher d'être jalouse. Il avait beau m'expliquer que sa vie intime était une chose qui lui appartenait en propre et sa vie sociale et militaire une autre dont il n'était pas le maître, j'insistai tant qu'un jour il m'emmena à Didier. Nous passâmes la soirée dans une de ces petites villas que j'admirais depuis mon enfance, avec deux officiers et leurs femmes. Celles-ci me regardaient avec une indulgence qui me fut insupportable. Je sentais que je m'étais trop fardée, que je n'étais pas habillée comme il le fallait, que je ne faisais pas honneur à André, peut-être simplement à cause de la couleur de ma peau, enfin je passai une soirée si désagréable que je décidai de ne plus jamais demander à André de l'accompagner ${ }^{18}$.»

C'est à Didier, boulevard des richissimes Martiniquais, que vont les désirs de la belle. Et c'est elle qui le dit : on est blanc à partir d'un certain nombre de millions. Les villas du quartier ont depuis longtemps 
fasciné les yeux de l'auteur. D'ailleurs, nous avons l'impression que Mayotte Capécia nous en fait accroire : elle nous dit avoir connu Fortde-France très tard, vers dix-huit ans; pourtant, les villas de Didier avaient charmé son enfance. Il y a dans ce fait une inconséquence que l'on comprend si l'on situe l'action. Il est habituel en effet, en Martinique, de rêver à une forme de salut qui consiste à se blanchir magiquement. Une villa à Didier, son insertion dans la société de là-haut (la colline de Didier domine la ville), et voici réalisée la certitude subjective de Hegel. Et l'on voit assez bien, par ailleurs, la place qu'occuperait dans la description de ce comportement la dialectique de l'être et de l'avoir ${ }^{19}$. Tel n'est cependant pas encore le cas de Mayotte. On lui «fait la tête». Les choses commencent leur ronde... C'est parce qu'elle est une femme de couleur qu'on ne la tolère pas dans ces cercles. C'est à partir de sa facticité [56] que s'élaborera le ressentiment. Nous verrons pourquoi l'amour est interdit aux Mayotte Capécia de tous les pays. Car l'autre ne doit pas me permettre de réaliser des phantasmes infantiles: il doit au contraire maider à les dépasser. Nous retrouvons dans l'enfance de Mayotte Capécia un certain nombre de traits qui illustrent la ligne d'orientation de l'auteur. Et chaque fois qu'il y aura un mouvement, un ébranlement, ce sera toujours en rapport direct avec ce but. Il semble en effet que pour elle le Blanc et le Noir représentent les deux pôles d'un monde, pôles en lutte perpétuelle: véritable conception manichéiste du monde: le mot est jeté, il faut s'en souvenir - Blanc ou Noir, telle est la question.

Je suis Blanc, c'est-à-dire que j'ai pour moi la beauté et la vertu, qui n'ont jamais été noires. Je suis de la couleur du jour...

Je suis Noir, je réalise une fusion totale avec le monde, une compréhension sympathique de la terre, une perte de mon moi au cœur du cosmos, et le Blanc, quelque intelligent qu'il soit, ne saurait comprendre Armstrong et les chants du Congo. Si je suis Noir, ce n'est pas à la suite d'une malédiction, mais c'est parce que, ayant tendu ma peau, j'ai pu 
capter tous les effluves cosmiques. Je suis véritablement une goutte de soleil sous la terre...

Et l'on va dans un corps à corps avec sa noirceur ou avec sa blancheur, en plein drame narcissiste, enfermé chacun dans sa particularité, avec de temps à autre, il est vrai, quelques lueurs, menacées toutefois à leur source.

Tout d'abord, c'est ainsi que le problème se pose à Mayotte - à l'âge de cinq ans et à la troisième page de son livre: «Elle sortait son encrier du pupitre et lui flanquait une douche sur la tête. » C'était sa façon à elle de transformer les Blancs en Noirs. Mais elle s'est aperçue assez tôt de la vanité de ses efforts; et puis il y a Loulouze et sa mère, qui lui ont dit que la vie pour une femme de couleur était difficile. Alors, ne pouvant plus noircir, ne pouvant plus négrifier le monde, elle va tenter dans son corps et dans sa pensée de le blanchir. D'abord, elle se fera blanchisseuse: "Je me faisais payer cher, plus cher qu'ailleurs, mais je travaillais mieux, et comme les gens de Fort-deFrance aiment le linge propre, ils [57] venaient chez moi. Finalement, ils étaient fiers de se faire blanchir chez Mayotte ${ }^{20}$. »

Nous regrettons que Mayotte Capécia ne nous ait point fait part de ses rêves. Le contact avec son inconscient en eût été facilité. Au lieu de se découvrir noire absolument, elle va accidentaliser ce fait. Elle apprend que sa grand-mère est blanche: « Je m'en trouvais fière. Certes, je n'étais pas la seule à avoir du sang blanc, mais une grand-mère blanche, c'était moins banal qu'un grand-père blanc ${ }^{21}$. Et ma mère

Je suis Martiniquaise, p. 131.

21 Le Blanc étant le maître, et plus simplement le mâle, peut se payer le luxe de coucher avec beaucoup de femmes. Cela est vrai dans tous les pays et davantage aux colonies. Mais une Blanche qui accepte un Noir, cela prend automatiquement un aspect romantique. Il y a don et non pas viol. Aux colonies, en effet, sans qu'il y ait mariage ou co-habitation entre Blancs et Noires, le nombre de métis est extraordinaire. C'est que les Blancs couchent avec leurs servantes noires. - Ce qui n'autorise pas pour autant ce passage de Mannoni : « Ainsi une partie de nos tendances nous pousseraient assez naturellement vers les types les plus étrangers. Ce n'est pas seulement un mirage littéraire. Ce n'était pas littérature, et le mirage était sans doute mince quand les soldats de Gallieni se 
était donc une métisse? J'aurais dû m'en douter en voyant son teint pâle. Je la trouvais plus jolie que jamais, et plus fine et plus distinguée. Si elle avait épousé un Blanc, peut-être aurais-je été tout à fait blanche ?... Et que la vie aurait été moins difficile pour moi ?... Je songeais à cette grand-mère que je n'avais pas connue et qui était morte parce qu'elle avait aimé un homme de couleur martiniquais... Comment une Canadienne pouvait-elle aimer un Martiniquais? Moi qui pensais [58] toujours à $M$. le Curé, je décidai que je ne pourrais aimer qu'un Blanc, un blond avec des yeux bleus, un Français 22. »

Nous sommes avertis, c'est vers la lactification que tend Mayotte. Car enfin il faut blanchir la race: cela, toutes les Martiniquaises le savent, le disent, le répètent. Blanchir la race, sauver la race, mais non dans le sens qu'on pourrait supposer : non pas préserver «l'originalité de la portion du monde au sein duquel elles ont grandi », mais assurer sa blancheur. Chaque fois que nous avons voulu analyser certains comportements, nous n'avons pu éviter l'apparition de phénomènes nauséeux. Le nombre de phrases, de proverbes, de petites lignes de conduite qui régissent le choix d'un amoureux est extraordinaire aux Antilles. Il s'agit de ne pas sombrer de nouveau dans la négraille, et toute Antillaise s'efforcera, dans ses flirts ou dans ses liaisons, de choisir le moins noir. Quelquefois elle est obligée, pour excuser un

choisissaient des compagnes plus ou moins temporaires parmi les jeunes Ramatoa. En fait ces premiers contacts ne présentaient aucune difficulté. Cela tenait en partie à ce qu'était la vie sexuelle des Malgaches, saine et à peu près sans manifestations complexuelles. Mais cela prouve aussi que les conflits raciaux s'élaborent peu à peu et ne naissent pas spontanément. » (Psychologie de la colonisation, p. 110). N'exagérons rien. Quand un soldat des troupes conquérantes couchait avec une jeune Malgache, il n'y avait sans doute de sa part aucun respect de l'altérité. Les conflits raciaux ne sont pas venus après, ils ont coexisté. Le fait que des colons algériens couchent avec leur petite bonne de quatorze ans ne prouve aucunement l'absence de conflits raciaux en Algérie. Non, le problème est plus compliqué. - Et Mayotte Capécia a raison : c'est un honneur d'être la fille d'une femme blanche. Cela montre qu'elle n'est pas une fille « en bas feuille ». (On réserve ce terme à tous les rejetons des békès de la Martinique : on sait qu'ils sont fort nombreux : Aubery, par exemple, est réputé en avoir eu près de cinquante.)

22 Je suis Martiniquaise, p. 59. 
mauvais investissement, de faire appel à des arguments comme le suivant: "X est noir, mais la misère est plus noire que lui. » Nous connaissons beaucoup de compatriotes, étudiantes en France, qui nous avouent avec candeur, une candeur toute blanche, qu'elles ne sauraient épouser un Noir. (S'être échappée et y revenir volontairement? Ah! non, merci.) D'ailleurs, ajoutent-elles, ce n'est pas que nous contestions aux Noirs toute valeur, mais vous savez, il vaut mieux être blanc. Dernièrement, nous nous entretenions avec l'une d'entre elles. A bout de souffle, elle nous jeta à la face: "D'ailleurs, si Césaire revendique tant sa couleur noire, c'est parce qu'il ressent bien une malédiction. Est-ce que les Blancs revendiquent la leur? En chacun de nous il y a une potentialité blanche, certains veulent l'ignorer ou plus simplement l'inversent. Pour ma part, pour rien au monde je n'accepterais d'épouser un nègre. " De telles attitudes ne sont pas rares, et nous avouons notre inquiétude, car cette jeune Martiniquaise, dans peu d'années, sera licenciée et ira enseigner dans quelque établissement aux Antilles. On devine aisément ce qu'il en adviendra.

Un travail colossal attend l'Antillais qui préalablement [59] aura passé au crible de l'objectivité les préjugés en cours chez lui. Quand nous avons commencé cet ouvrage, parvenu au terme de nos études médicales, nous nous proposions de le soutenir en tant que thèse. Et puis la dialectique exigea de nous des prises de position redoublées. Bien qu'en quelque sorte nous nous fussions attaqué à l'aliénation psychique du Noir, nous ne pouvions passer sous silence certains éléments qui, pour psychologiques qu'ils aient pu être, engendraient des effets ressortissant à d'autres sciences.

Toute expérience, surtout si elle se révèle inféconde, doit entrer dans la composition du réel et, par-là, occuper une place dans la restructuration de ce réel. C'est-à-dire qu'avec ses tares, avec ses ratés, avec ses vices, la famille européenne, patriarcale, en rapport étroit avec la société que l'on sait, produit environ trois dixièmes de névrosés. Il s'agit, en s'appuyant sur les données psychanalytiques, sociologiques, politiques, d'édifier un nouveau milieu parental susceptible 
de diminuer sinon d'annuler la part de déchets, au sens asocial du terme.

Autrement dit, il s'agit de savoir si la basic personality est une donnée ou une variable.

Toutes ces femmes de couleur échevelées, en quête du Blanc, attendent. Et certainement un de ces jours elles se surprendront à ne pas vouloir se retourner, elles penseront « à une nuit merveilleuse, à un amant merveilleux, un Blanc». Elles aussi peut-être s'apercevront un jour «que les Blancs n'épousent pas une femme noire». Mais ce risque, elles ont accepté de le courir, ce qu'il leur faut, c'est de la blancheur à tout prix. Pour quelle raison? Rien de plus facile. Voici un conte qui satisfait l'esprit :

« Un jour, saint Pierre voit arriver à la porte du paradis trois hommes: un Blanc, un mulâtre, un nègre.

$»-$ Que désires-tu? demande-t-il au Blanc.

$\gg-$ De l'argent.

$»-$ Et toi ? dit-il au mulâtre.

$»-$ La gloire.

»Et comme il se tourne vers le Noir, celui-ci lui déclare avec un large sourire 23 :

23 Le sourire du Noir, le grin, semble avoir retenu l'attention de beaucoup d'écrivains. Voici ce qu'en dit Bernard Wolfe: «Nous nous plaisons à représenter le Noir souriant de toutes ses dents à notre adresse. Et son sourire, tel que nous le voyons, - tel que nous le créons, - toujours signifie un don... »

Dons sans fin, tout au long des affiches, des écrans de cinéma, des étiquettes de produits alimentaires... Le Noir donne à Madame les nouvelles « teintes créole sombre » pour ses purs nylons, grâce à la maison de Vigny, ses flacons « grotesques», «tortillés», d'eau de Cologne de Golliwogg et de parfums. Cirage des chaussures, linge blanc comme neige, couchettes basses, confortables, transport rapide des bagages: jazz jitterbug, jive, comédies, et les contes merveilleux de BrerRabbitt (Frère Lapin) pour la joie des toutpetits. Le service avec le sourire toujours... « Les Noirs, écrit un anthropolo- 
[60]

$»-$ Je suis venu porter la malle de ces messieurs. »

Tout récemment, Etiemble, parlant d'une de ses déconvenues : «Ma stupeur, adolescent, quand une amie, et qui me connaissait, se leva outragée de m'entendre lui dire en une circonstance où c'était le mot propre et le seul qui convînt : "Toi qui es une négresse. - Moi ? une négresse? ne vois-tu pas que je suis presque blanche? Je déteste les nègres. Ils puent, les nègres. Ils sont sales, paresseux. Ne me parle jamais de nègres ${ }^{24}$. 》

Nous en connaissions une autre qui avait une liste des dancings parisiens où-l'on-ne-risque-pas-de-rencontrer-des-nègres.

Il s'agit de savoir s'il est possible au Noir de dépasser son sentiment de diminution, d'expulser de sa vie le caractère compulsionnel qui l'apparente tant au comportement du phobique. Chez le nègre, il y a une exacerbation affective, une rage de se sentir petit, une incapacité à toute communion humaine qui le confinent dans une insularité intolérable.

Décrivant le phénomène de la rétraction du moi, Anna Freud écrit: «Il consiste dans une défense de ce moi contre les excitations extérieures: cette rétraction, en tant que méthode d'évitement de déplaisir, n'appartient pas à la psychologie des névroses : elle constitue seulement [61] dans l'évolution du moi un stade normal. Pour un jeune moi malléable, tout mécompte subi dans un domaine se trouve parfois compensé par des réussites parfaites dans d'autres. Mais quand le moi est devenu rigide ou qu'il ne tolère plus le déplaisir et s'en tient compul-

giste (a), sont maintenus dans leur attitude obséquieuse par les sanctions extrêmes de la crainte et de la force, et ceci est bien connu des Blancs et des Noirs tout à la fois. Néanmoins les Blancs exigent que les Noirs se montrent souriants, empressés et amicaux dans tous leurs rapports avec eux... " L'oncle Rémus et son lapin, Bernard Wolfe, Les Temps Modernes, $n^{\circ}$ 43, p. 888.

(a) Geoffrey Gorer, The American Spirit : A study in national character.

24 «Sur le Martinique de lyfichel Cournot», Les Temps Modernes, février 1950. 
sionnellement à la réaction de fuite, la formation du moi en subit les fâcheuses conséquences, le moi, ayant abandonné un trop grand nombre de ses positions, devient unilatéral, perd trop de ses intérêts et voit ses activités perdre de leur valeur ${ }^{25}$. »

Nous comprenons maintenant pourquoi le Noir ne peut se complaire dans son insularité. Pour lui il n'existe qu'une porte de sortie et elle donne sur le monde blanc. D'où cette préoccupation permanente d'attirer l'attention du Blanc, ce souci d'être puissant comme le Blanc, cette volonté déterminée d'acquérir les propriétés de revêtement, c'est-à-dire la partie d'être ou d'avoir qui entre dans la constitution d'un moi. Comme nous le disions tout à l'heure, c'est par l'intérieur que le Noir va essayer de rejoindre le sanctuaire blanc. L'attitude renvoie à l'intention.

La rétraction du moi en tant que processus de défense réussi est impossible au Noir. Il lui faut une sanction blanche.

En pleine euphorie mystique, psalmodiant un cantique ravissant, il semble à Mayotte Capécia qu'elle est un ange et qu'elle s'envole " toute rose et blanche ». Il y a toutefois ce film, Verts Pâturages, où anges et Dieu sont noirs, mais cela a terriblement choqué notre auteur: «Comment imaginer Dieu sous les traits d'un nègre? Ce n'est pas ainsi que je me représente le paradis. Mais, après tout, il ne s'agissait que d'un film américain 26 . »

Non, vraiment, le Dieu bon et miséricordieux ne peut pas être noir, c'est un Blanc qui a des joues bien roses. Du noir au blanc, telle est la ligne de mutation. On est blanc comme on est riche, comme on est beau, comme on est intelligent.

[62]

Cependant, André est parti vers d'autres cieux porter le Message blanc à d'autres Mayottes: délicieux petits gènes aux yeux bleus, pé-

25 A. Freud, Le moi et les mécanismes de défense, traduit par Anne Berman, pp. 91-92.

26 Je suis Martiniquaise, p. 65. 
dalant le long des couloirs chromosomiaux. Mais en bon Blanc, il a laissé des instructions. Il a parlé de leur enfant: « Tu l'élèveras, tu lui parleras de moi, tu lui diras : c'était un homme supérieur. Il faut que tu travailles pour être digne de lui 27 . »

Et la dignité ? Il n'avait plus à l'acquérir, elle était maintenant tissée dans le labyrinthe de ses artères, enfoncée dans ses petits ongles roses, bien calée, bien blanche.

Et le père? Voici ce qu'en dit Etiemble: « Un beau spécimen du genre ; il parlait de la famille, du travail, de la patrie, du bon Pétain et du bon Dieu, ce qui lui permettait de l'engrosser selon les règles. Dieu s'est servi de nous, disait le beau salaud, le beau Blanc, le bel officier. Après quoi, que je te la plaque selon les mêmes règles pétainistes et bondieusardes. »

Avant d'en finir avec celle dont le Seigneur blanc est « comme mort » et qui se fait escorter par des morts dans un livre où s'étalent des choses lamentablement mortes, nous voudrions demander à l'Afrique de nous déléguer un messager 28.

Je suis Martiniquaise, p. 185.

28 Depuis Je suis Martiniquaise, Mayotte Capécia a écrit un autre ouvrage: La négresse blanche. Elle a dû s'apercevoir des erreurs commises, puisqu'on assiste à une tentative de revalorisation du nègre. Mais Mayotte Capécia a compté sans son inconscient. Dès que la romancière laisse un peu de liberté à ses personnages, c'est toujours pour accabler le nègre. Tous les nègres qu'elle décrit sont en quelque sorte des crapules ou des « Y'a bon Banania».

De plus, et nous augurons déjà de l'avenir, nous pouvons affirmer que Mayotte Capécia s'est définitivement écartée de son pays. Dans ses deux ouvrages une seule attitude est laissée à son héroïne: partir. Ce pays de nègres est décidément maudit. Il y a en effet une malédiction qui flotte autour de Mayotte Capécia. Mais elle est centrifuge. Mayotte Capécia s'est interdite.

Qu'elle n'enfle plus le procès du poids de ses imbécillités.

Partez en paix, ô éclaboussante romancière... Mais sachez que, au-delà de vos cinq cents pages anémiées, on saura toujours retrouver le chemin honnête qui mène au coeur.

$\mathrm{Ce}$, malgré vous. 
Elle ne nous fait pas attendre: c'est Abdoulaye Sadji qui, avec Ni$n i^{29}$, nous donne une description de ce que [63] peut être le comportement des Noirs en face des Européens. Nous l'avons dit, il existe des négrophobes. Ce n'est d'ailleurs pas la haine du Noir qui les anime; ils n'en ont pas le courage, ou ne l'ont plus. La haine n'est pas donnée, elle a à se conquérir à tout instant, à se hisser à l'être, en conflit avec des complexes de culpabilité plus ou moins avoués. La haine demande à exister, et celui qui hait doit manifester cette haine par des actes, un comportement approprié ; en un sens, il doit se faire haine. C'est pourquoi les Américains ont substitué la discrimination au lynchage. Chacun de son côté. Aussi ne sommes-nous pas surpris qu'il y ait, dans les villes de l'Afrique noire (française?), un quartier européen. L'ouvrage de Mounier: L'éveil de l'Afrique noire, avait déjà attiré notre attention, mais nous attendions, impatient, une voix africaine. Grâce à la revue d'Alioune Diop, nous avons pu coordonner les motivations psychologiques qui meuvent les hommes de couleur.

Il y a un étonnement, au sens le plus religieux du terme, dans ce passage: «M. Campian est le seul Blanc de Saint-Louis qui fréquente le Saint-Louisien Club 30, homme d'une certaine position sociale, puisqu'il est ingénieur des Ponts et Chaussées et sous-directeur des Travaux publics au Sénégal. On le croit très négrophile, plus négrophile que M. Roddin, professeur au lycée Faidherbe, qui a donné en plein Saint-Louisien Club une conférence sur l'égalité des races. La bonté de l'un ou de l'autre est un perpétuel sujet de discussions enflammées. En tout cas, M. Campian est plus fréquent au cercle, où il a eu l'occasion de connaître des indigènes très corrects et déférents vis-à-vis de lui : qui l'aiment et s'honorent de sa présence parmi eux ${ }^{31}$. 》

L'auteur, qui est instituteur en Afrique noire, est redevable à $M$. Roddin de cette conférence sur l'égalité des races. Nous appelons cet-

29 Présence Africaine, I-2-3.

30 Cercle où se réunit la jeunesse indigène. En face existe le cercle civil, exclusivement européen.

31 «ini », Présence Africaine, 2, p. 280. 
te situation un scandale. On comprend les doléances que présentaient à Mounier les jeunes indigènes qu'il avait l'occasion de rencontrer: «Ce [64] sont des Européens comme vous qu'il nous faudrait ici. » On sent à tout instant que le fait pour le Noir de rencontrer un toubab 32 compréhensif représente un nouvel espoir d'entente.

Analysant quelques passages du roman de M. Abdoulaye Sadji, nous essaierons de saisir sur le vif les réactions de la femme de couleur en face de l'Européen. D'abord il y a la négresse et la mulâtresse. La première n'a qu'une possibilité et un souci : blanchir. La deuxième non seulement veut blanchir, mais éviter de régresser. Qu'y a-t-il de plus illogique, en effet, qu'une mulâtresse qui épouse un Noir? Car, il faut le comprendre une fois pour toutes, il s'agit de sauver la race.

De là le trouble extrême de Nini : un nègre ne s'est-il pas enhardi jusqu'à la demander en mariage? Un nègre n'est-il pas allé jusqu'à lui écrire: «L'amour que je vous offre est pur et robuste, il n'a point le caractère d'une tendresse intempestive faite pour vous bercer de mensonges et d'illusions... Je voudrais vous voir heureuse, tout à fait heureuse dans un milieu qui cadre bien avec vos charmes que je crois savoir apprécier... Je considère comme un honneur insigne et comme le bonheur le plus vaste de vous avoir dans ma maison et de me dévouer à vous corps et âme. Vos grâces rayonneraient dans mon foyer et mettraient de la lumière dans les coins d'ombre... Par ailleurs, je vous crois trop évoluée et suffisamment délicate pour décliner avec brutalité les offres d'un amour loyal uniquement préoccupé de faire votre bonheur ${ }^{33}$.»

Cette dernière phrase ne doit pas nous étonner. Normalement, la mulâtresse doit rejeter impitoyablement le nègre prétentieux. Mais comme elle est évoluée, elle évitera de voir la couleur de l'amant pour n'attacher d'importance qu'à sa loyauté. Décrivant Mactar, Abdoulaye Sadji écrit : « Idéaliste et partisan convaincu d'une évolution à outran-

\footnotetext{
32 Européen.

33 «ini », Présence Africaine, p. 286.
} 
ce, il croit encore en la sincérité des hommes, en leur loyauté, et il suppose volontiers qu'en tout, le mérite seul doit triompher ${ }^{34}$. »

[65]

Qui est Mactar? C'est un bachelier, comptable aux Entreprises fluviales, et il s'adresse à une petite dactylographe, toute bête, mais qui possède la valeur la moins discutée : elle est presque blanche. Alors on s'excusera de la liberté que l'on prend d'écrire une lettre: «La grande audace, la première peut-être qu'un nègre ait osé commettre ${ }^{35}$. »

On s'excusera d'oser proposer un amour noir à une âme blanche. Cela, nous le retrouverons chez René Maran : cette crainte, cette timidité, cette humilité du Noir dans ses rapports avec la Blanche, ou en tout cas avec une plus blanche que lui. De même que Mayotte Capécia accepte tout du seigneur André, Mactar se fait esclave de Nini la mulâtresse. Prêt à vendre son âme. Mais c'est une fin de non-recevoir qui attend cet impudent. La mulâtresse trouve que cette lettre est une insulte, un outrage fait à son honneur de « fille blanche ». Ce nègre est un imbécile, un bandit, un malappris qui a besoin d'une leçon. Elle la lui donnera, cette leçon: elle lui apprendra à être plus décent et moins hardi ; elle lui fera comprendre que les «peaux blanches» ne sont pas pour «Bougnouls» 36 .

En l'occurrence, la mulâtraille fera chorus à son indignation. On parle d'envoyer l'affaire en justice, de faire comparaître le Noir en Cour d'assises. "On va écrire au chef du service des Travaux publics, au gouverneur de la Colonie, pour leur signaler la conduite du Noir et obtenir son licenciement comme réparation du dégât moral qu'il a commis 37 . »

Ibid., pp. 281-282.

35 «ini », Présence Africaine, p. 281.

36 Ibid., p. 287.

37 Ibid., p. 288. 
Un pareil manquement aux principes devrait être puni de castration. Et c'est à la police qu'en définitive on demandera d'admonester Mactar. Car s'il « recommence ses insanités morbides, on le fera dresser par M. Dru, inspecteur de police, que ses pareils ont surnommé le Blanc très-méchant 38 ».

Nous venons de voir comment réagit une fille de couleur à une déclaration d'amour venant d'un de ses congénères. Demandons-nous maintenant ce qui se produit avec le [66] Blanc. C'est encore à Sadji que nous faisons appel. L'étude fort longue qu'il consacre aux réactions que provoque le mariage d'un Blanc et d'une mulâtresse nous servira d'excipient.

«Depuis quelque temps un bruit court par toute la ville de Saint-Louis... C'est d'abord un petit chuchotement qui va d'oreille en oreille, fait dilater les figures ridées des vieilles « signaras », ranime leur regard éteint ; puis les jeunes, ouvrant de grands yeux blancs et arrondissant une bouche épaisse, se transmettent bruyamment la nouvelle qui ébranle des: Oh! pas possible ... Comment le sais-tu? Est-ce possible... C'est charmant ... Ce que c'est tordant... La nouvelle qui court depuis un mois dans tout Saint-Louis est agréable, plus agréable que toutes les promesses du monde. Elle couronne un certain rêve de grandeur, de distinction, qui fait que toutes les mulâtressses, les Ninis, les Nanas et les Nénettes vivent hors des conditions naturelles de leur pays. Le grand rêve qui les hante est celui d'être épousées par un Blanc d'Europe, On pourrait dire que tous leurs efforts tendent vers ce but, qui n'est presque jamais atteint. Leur besoin de gesticulation, leur amour de la parade ridicule, leurs attitudes calculées, théâtrales, écœurantes, sont autant d'effets d'une même manie des grandeurs, il leur faut un homme blanc, tout blanc, et rien que cela. Presques toutes attendent, leur vie durant, cette bonne fortune qui n'est rien moins que probable. Et c'est dans cette attente que la vieillesse 
les surprend et les accule au fond des sombres retraites où le rêve finalement se change en hautaine résignation...

» Une nouvelle très agréable... M. Darrivey, européen tout blanc et adjoint des Services civils, demande la main de Dédée, mulâtresse de demi-teinte. Pas possible ${ }^{39}$. »

Le jour où le Blanc a dit son amour à la mulâtresse, quelque chose d'extraordinaire a dû se passer. Il y eut reconnaissance, intégration dans une collectivité qui semblait hermétique. La moins-value psychologique, ce sentiment de diminution et son corollaire, l'impossibilité d'accéder à la limpidité, disparaissaient totalement. Du [67] jour au lendemain, la mulâtresse passait du rang des esclaves à celui des maîtres...

Elle était reconnue dans son comportement sur-compensateur. Elle n'était plus celle qui avait voulu être blanche, elle était blanche. Elle entrait dans le monde blanc.

Dans Magie noire, Paul Morand nous décrivait pareil phénomène, mais nous avons appris par la suite à nous méfier de Paul Morand. Du point de vue psychologique, il peut être intéressant de poser le problème suivant. La mulâtresse instruite, l'étudiante en particulier, a un comportement doublement équivoque. Elle dit: « Je n'aime pas le Nègre, parce qu'il est sauvage. Pas sauvage au sens cannibale, mais parce qu'il manque de finesse. " Point de vue abstrait. Et quand on lui objecte que des Noirs peuvent lui être supérieurs sur ce plan, elle allègue leur laideur. Point de vue de la facticité. Devant les preuves d'une réelle esthétique noire, elle dit ne pas la comprendre; on essaie alors de lui en révéler le canon : battement des ailes du nez, un arrêt en apnée de la respiration, « elle est libre de choisir son mari ». Appel, en dernier ressort, à la subjectivité. Si, comme le dit Anna Freud, on accule le moi en l'amputant de tout processus de défense, «si on en rend conscientes les activités inconscientes, on révèle et par-là on rend inopérants

39 « Nini », Présence Africaine, p. 489. 
ses processus de défense, l'affaiblissant davantage et favorisant le processus morbide 40 ».

Mais ici le moi n'a pas à se défendre, puisque ses revendications sont homologuées: Dédée épouse un Blanc. Toutefois chaque médaille a son revers; des familles entières ont été bafouées. À trois ou quatre mulâtresses on a adjoint des cavaliers mulâtres, or toutes leurs camarades avaient des Blancs. "Cela fut regardé spécialement comme une offense faite à leur famille entière; offense qui exigeait d'ailleurs une réparation 41 . „ Car ces familles étaient humiliées dans leurs aspirations les plus légitimes, la mutilation qu'elles subissaient portait sur le mouvement même de leur vie... sur la tension de leur existence...

[68]

Elles voulaient, en référence à un profond désir, se changer, « évoluer ». On leur déniait ce droit. En tout cas, on le leur disputait.

Que dire, au terme de ces descriptions?

Qu'il se soit agi de Mayotte Capécia la Martiniquaise ou de Nini la Saint-Louisienne, le même processus s'est retrouvé. Processus bilatéral, tentative de recouvrement - par intériorisation - de valeurs originellement interdites. C'est parce que la négresse se sent inférieure qu'elle aspire à se faire admettre dans le monde blanc. Elle s'aidera, dans cette tentative, d'un phénomène que nous appellerons éréthisme affectif.

Ce travail vient clore sept ans d'expériences et d'observations: quel que soit le domaine par nous considéré, une chose nous a frappé : le nègre esclave de son infériorité, le Blanc esclave de sa supériorité, se comportent tous deux selon une ligne d'orientation névrotique. Aussi avons-nous été amené à envisager leur aliénation en référence aux descriptions psychanalytiques. Le nègre dans son comportement s'apparente à un type névrotique obsessionnel ou, si l'on préfère, il se place en pleine névrose situationnelle. Il y a chez l'homme de couleur

\footnotetext{
40 Anna Freud, op. cit., p. 58.

$41 \ll$ Nini », p. 498.
} 
tentative de fuir son individualité, de néantiser son être-là. Chaque fois qu'un homme de couleur proteste, il y a aliénation. Chaque fois qu'un homme de couleur réprouve, il y a aliénation. Nous verrons plus loin, au chapitre VI, que le nègre infériorisé va de l'insécurité humiliante à l'auto-accusation ressentie jusqu'au désespoir. Souvent, l'attitude du Noir en face du Blanc, ou en face de son congénère, reproduit presque intégralement une constellation délirante, qui touche au domaine pathologique.

On nous objectera qu'il n'y a rien de psychotique chez les Noirs dont il est question ici. Toutefois, nous voudrions citer deux traits hautement significatifs. Il y a quelques années, nous avons connu un Noir, étudiant en médecine. Il avait l'impression infernale de n'être pas estimé selon sa valeur, non pas sur le plan universitaire mais, disait-il, humainement. Il avait l'impression infernale que jamais il n'arriverait à se faire reconnaître en tant que confrère par les Blancs et en tant que docteur par les malades européens. À ces moments d'intuition [69] délirante 42 , les moments féconds 43 de la psychose, il s'enivrait. Et puis, un jour, il s'engagea dans l'armée comme médecin auxiliaire; et, ajoutait-il, pour rien au monde je n'accepte d'aller aux colonies ou d'être affecté à une unité coloniale. Il voulait avoir sous ses ordres des Blancs. C'était un chef ; comme tel, il devait être craint ou respecté. C'est en fait ce qu'il voulait, ce qu'il recherchait : amener les Blancs à avoir avec lui une attitude de Noirs. Ainsi se vengeait-il de l'imago qui l'avait de tout temps obsédé : le nègre effrayé, tremblant, humilié devant le seigneur blanc.

Nous avons connu un camarade, inspecteur des douanes dans un port de la métropole, qui était extrêmement dur aux visites des touristes ou des transitaires. «Car, nous disait-il, si tu n'es pas vache, ils te prennent pour un couillon. Comme je suis nègre, tu penses bien que les deux termes s'appellent... »

\footnotetext{
42 Dublineau, L'intuition délirante.

43 Lacan.
} 
Dans Connaissance de l'homme, Adler écrit: «Pour inventorier la conception du monde d'un homme, il convient de procéder à des investigations comme si, à partir d'une impression d'enfance jusqu'à l'état de choses actuel une ligne était tirée. En beaucoup de cas, on réussira de la sorte à tracer effectivement la voie où chemina jusqu'alors un sujet. C'est la courbe, la ligne d'orientation sur laquelle la vie de l'individu depuis son enfance se dessine schématiquement... Car ce qui agit véritablement, c'est toujours la ligne d'orientation de l'individu, ligne dont la configuration subit bien certaines modifications, mais dont le contenu principal, l'énergie et le sens même subsistent, implantés et sans changement depuis l'enfance, non sans une connexion avec l'entourage de l'enfance, qui plus tard se détachera du milieu plus vaste inhérent à la société humaine ${ }^{44}$. »

Nous anticipons, et déjà on aperçoit que la psychologie caractérielle d'Adler nous aidera à comprendre la conception du monde de l'homme de couleur. Comme le Noir est un ancien esclave, nous ferons aussi appel à Hegel: [70] et, pour terminer, Freud doit pouvoir concourir à notre étude.

Nini, Mayotte Capécia : deux comportements qui nous invitent à réfléchir.

N'y a-t-il pas d'autres possibilités?

Mais ce sont là des pseudo-questions que nous n'envisagerons pas. Nous dirons d'ailleurs que toute critique de l'existant implique une solution, si tant est qu'on puisse proposer une solution à son semblable, c'est-à-dire à une liberté.

Ce que nous affirmons, c'est que la tare doit être expulsée une fois pour toutes.

44 A. Adler, Connaissance de l'Homme, pp. 57-58 (Payot). [Livre disponible dans Les Classiques des sciences sociales. JMT.] 
PEAU NOIRE. MASQUES BLANCS.

\section{Chapitre III}

L'HOMME DE COULEUR

ET LA BLANCHE

\section{Retour à la table des matières}

De la partie la plus noire de mon âme, à travers la zone hachurée me monte ce désir d'être tout à coup blanc.

Je ne veux pas être reconnu comme Noir, mais comme Blanc.

Or - et c'est là une reconnaissance que Hegel n'a pas décrite - qui peut le faire, sinon la Blanche? En m'aimant, elle me prouve que je suis digne d'un amour blanc. On m'aime comme un Blanc.

Je suis un Blanc.

Son amour m'ouvre l'illustre couloir qui mène à la prégnance totale...

J'épouse la culture blanche, la beauté blanche, la blancheur blanche.

Dans ces seins blancs que mes mains ubiquitaires caressent, c'est la civilisation et la dignité blanches que je fais miennes. 
Il y a une trentaine d'années, un Noir du plus beau teint, en plein coït avec une blonde « incendiaire», au moment de l'orgasme s'écria: «Vive Schœlcher!» Quand on saura que Schœlcher est celui qui a fait adopter par la III $^{e}$ République le décret d'abolition de l'esclavage, on comprendra qu'il faille s'appesantir quelque peu sur les relations possibles entre le Noir et la Blanche.

On nous objectera que cette anecdote n'est pas authentique: mais le fait qu'elle ait pu prendre corps et se maintenir à travers les âges est un indice: il ne trompe pas. C'est que cette anecdote agite un conflit explicite ou latent, mais réel. Sa permanence souligne l'adhésion du monde noir. Autrement dit, quand une histoire se maintient au [72] sein du folklore, c'est qu'elle exprime en quelque façon une région de «l'âme locale ».

Avec l'analyse de Je suis Martiniquaise et de Nini, nous avons vu comment se comportait la négresse vis-à-vis du Blanc. Avec un roman de René Maran, - autobiographie, semble-t-il, de l'auteur, - tâchons de comprendre ce qui se passe dans le cas des Noirs.

Le problème est magnifiquement posé, car Jean Veneuse nous permettra d'approfondir davantage l'attitude du Noir. De quoi s'agit-il ? Jean Veneuse est un nègre. D'origine antillaise, il habite Bordeaux depuis longtemps ; donc c'est un Européen. Mais il est noir ; donc c'est un nègre. Voilà le drame. Il ne comprend pas sa race, et les Blancs ne le comprennent pas. Et, dit-il, « l'Européen en général, le Français en particulier, non contents d'ignorer le nègre de leurs colonies, méconnaissent celui qu'ils ont formé à leur image 45 . »

La personnalité de l'auteur ne se livre pas aussi facilement qu'on le voudrait. Orphelin, pensionnaire dans un lycée de province, il est condamné pendant les vacances à demeurer à l'internat. Ses amis et camarades, au moindre prétexte, s'éparpillent à travers la France, tandis que le petit nègre prend l'habitude de la rumination, en sorte que ses meilleurs amis seront ses livres. A l'extrême, je dirai qu'il y a 
une certaine récrimination, un certain ressentiment, une agressivité difficilement retenue, dans la longue, trop longue liste de «compagnons de route» que nous communique l'auteur: je dis à l'extrême, mais justement il s'agit d'y aller.

Incapable de s'intégrer, incapable de passer inaperçu, il va converser avec les morts, ou du moins avec les absents. Et sa conversation, à l'inverse de sa vie, survolera les siècles et les océans. Marc-Aurèle, Joinville, Pascal, Perez Galdos, Rabindranath Tagore... S'il nous fallait donner coûte que coûte une épithète à Jean Veneuse, nous en ferions un introverti, d'autres diraient un sensible, mais un sensible qui se réserve la possibilité de gagner sur le plan de l'idée et de la connaissance. C'est un fait, ses camarades et amis l'estiment beaucoup : "Quel rêveur [73] incorrigible, c'est un type, vous savez, que mon vieil ami Veneuse! Il ne sort de ses bouquins que pour couvrir de griffonnages son carnet de route ${ }^{46}$. »

Mais un sensible qui chante en espagnol et traduit en anglais coup sur coup. Un timide, mais aussi un inquiet : «Et pendant que je m'éloigne, j'entends Divrande lui dire: un bon garçon, ce Veneuse, volontiers chagrin et taciturne, mais très serviable. Vous pouvez vous fier à lui. Vous verrez. C'est un nègre comme on voudrait qu'il y eût beaucoup de Blancs 47 . »

Oui, certainement, un inquiet. Un inquiet collé à son corps. Nous savons par ailleurs que M. René Maran cultive un amour pour André Gide. Nous pensions trouver à Un homme pareil aux autres une fin rappelant celle de La Porte étroite. Ce départ, ce ton de souffrance affective, d'impossibilité morale, semblaient faire écho à l'aventure de Jérôme et d'Alissa.

Mais il y a le fait que Veneuse est noir. C'est un ours qui aime la solitude. C'est un penseur. Et quand une femme veut entreprendre un flirt avec lui : « Vous êtes venue trouver l'ours que je suis! Prenez

\footnotetext{
46 R. Maran, op. cit., p. 87.

47 Ibid., pp. 18-19.
} 
garde, petite madame. C'est beau d'avoir du courage, mais vous allez vous compromettre si vous continuez à vous afficher de la sorte! Un nègre. Fi donc! ça ne compte pas. C'est déchoir que frayer avec quelque individu que ce soit de cette race ${ }^{48}$. »

Avant tout, il veut prouver aux autres qu'il est un homme, qu'il est leur semblable. Mais ne nous y trompons point, Jean Veneuse est I'homme à convaincre. C'est au cœur de son âme, aussi compliquée que celle des Européens, que réside l'incertitude. Qu'on nous pardonne le mot : Jean Veneuse est l'homme à abattre. Nous nous y efforcerons.

Après avoir cité Stendhal et le phénomène de la «cristallisation », il constate "qu'il aime moralement Andrée dans Madame Coulanges et physiquement avec Clarisse. C'est insensé. Mais il en est ainsi, j'aime Clarisse, j'aime Madame [74] Coulanges, bien que je ne pense vraiment ni à l'une ni à l'autre. Elles ne sont pour moi qu'un alibi me permettant de me donner à moi-même le change. J'étudie Andrée en elles et apprends à la connaître par cœur... Je ne sais pas. Je ne sais plus. Je ne veux pas chercher à savoir quoi que ce soit, ou plutôt je ne sais plus qu'une chose, c'est que le nègre est un homme pareil aux autres, un homme comme les autres, et que son cœur, qui ne paraît simple qu'aux ignorants, est aussi compliqué que peut l'être celui du plus compliqué des Européens 49 ».

Car la simplicité nègre est un mythe forgé par des observateurs superficiels. "J'aime Clarisse, j'aime Madame Coulanges, et c'est Andrée Marielle que j'aime. Elle seule, pas une autre ${ }^{50}$.»

Qui est Andrée Marielle? Vous savez, la fille du poète Louis Marielle! Mais voilà, ce nègre, « qui par son intelligence et son travail assidu s'est élevé à la réflexion et à la culture de l'Europe 51 », est incapable de s'évader de sa race.

Ibid., pp. 45-46.

49 R. Maran, op. cit., p. 83.

50 Ibid.

51 P. 36. 
Andrée Marielle est blanche, toute solution semble impossible. Pourtant la fréquentation de Payot, Gide, Moréas et Voltaire avait semblé anéantir tout cela. De bonne foi, Jean Veneuse « a cru à cette culture et s'est mis à aimer ce nouveau monde découvert et conquis à son usage. Quelle erreur était la sienne! Il a suffi qu'il prenne de l'âge et qu'il aille servir sa patrie adoptive au pays de ses ancêtres pour qu'il en arrive à se demander s'il n'était pas trahi par tout ce qui l'entourait, le peuple blanc ne le reconnaissant pas pour sien, le noir le reniant presque $52 »$.

Jean Veneuse, se sentant incapable d'exister sans amour, va le rêver. Il va le rêver et ce sont des poèmes:

«Quand on aime il ne faut rien dire, Il vaut bien mieux s'en cacher même. »

Andrée Marielle lui a écrit son amour, mais Jean [75] Veneuse a besoin d'une autorisation. Il faut qu'un Blanc lui dise : prends ma scur. A son ami Coulanges, Veneuse a posé un certain nombre de questions. Voici, presque in extenso, la réponse de Coulanges:

« Old boy,

«Tu me consultes derechef sur ton cas, je vais te donner mon avis une fois de plus et une fois pour toutes. Procédons par ordre. Ta situation telle que tu me l'exposes est des plus nettes. Permets-moi néanmoins de déblayer le terrain devant moi. Ce sera pour toi tout profit.

»Quel âge avais-tu donc quand tu as quitté ton pays pour la France? Trois ou quatre ans, je crois. Tu n'as depuis jamais revu ton île natale et ne tiens pas du tout à la revoir. Depuis tu as 
toujours vécu à Bordeaux. C'est à Bordeaux, depuis que tu es fonctionnaire colonial, que tu passes la majeure partie de tes congés administratifs. Bref, tu es vraiment de chez nous. Peutêtre ne t'en rends-tu pas très bien compte. Sache en ce cas que tu es un Français de Bordeaux. Enfonce ça dans ta caboche. Tu ne sais rien des Antillais tes compatriotes. Je serais même étonné que tu parvinsses à t'entendre avec eux. Ceux d'ailleurs que je connais ne te ressemblent en rien.

»En fait tu es comme nous, tu es «nous». Tes réflexions sont nôtres. Tu agis comme nous agissons, comme nous agirions. Tu te crois - et on te croit - nègre? Erreur! Tu n'en as que l'apparence. Pour le reste, tu penses en Européen. D'où il est naturel que tu aimes comme l'Européen. L'Européen n'aimant que l'Européenne, tu ne peux guère épouser qu'une femme du pays où tu as toujours vécu, une fille du bon pays de France, ton vrai, ton seul pays. Ceci étant, passons à ce qui fait l'objet de ta dernière lettre. D'un côté, il y a un nommé Jean Veneuse qui te ressemble comme un frère, de l'autre Mademoiselle Andrée Marielle. Andrée Marielle, qui est blanche de peau, aime Jean Veneuse, qui est excessivement brun et adore Andrée Marielle. Cela ne t'empêche pas de me demander ce qu'il faut faire. Délicieux crétin !...

»De retour en France, précipite-toi chez le père de celle qui en esprit déjà t'appartient et crie-lui en te frappant le cœur avec un bruit sauvage: "Je l'aime. Elle m'aime. [76] Nous nous aimons. Il faut qu'elle devienne ma femme. Sinon je me tue à vos pieds 53 . $\gg$

Sollicité, le Blanc accepte donc de lui donner sa scur, - mais à une condition: tu n'as rien de commun avec les véritables nègres. Tu n'es pas noir, tu es « excessivement brun».

53 R. Maran, op. cit., pp. 152-153-154. 
Ce processus est bien connu des étudiants de couleur en France. On refuse de les considérer comme d'authentiques nègres. Le nègre c'est le sauvage, tandis que l'étudiant est un évolué. Tu es «nous», lui dit Coulanges, et si on te croit nègre c'est par erreur, tu n'en as que l'apparence. Mais Jean Veneuse ne veut pas. Il ne peut pas, car il sait.

Il sait qu'« enragés de cet humiliant ostracisme, mulâtres du commun et nègres n'ont qu'une pensée dès qu'ils sont en Europe : assouvir l'appétit qu'ils ont de la femme blanche.

» La plupart d'entre eux, et parmi eux ceux qui, plus clairs de teint, vont souvent jusqu'à renier et leur pays et leur mère, $y$ font moins des mariages d'inclination que des mariages où la satisfaction de dominer l'Européenne est pimentée d'un certain goût d'orgueilleuse revanche.

»Alors je me demande s'il n'en est pas de moi comme de tous et si en me mariant avec vous qui êtes une Européenne, je n'aurai pas l'air de proclamer que non seulement je dédaigne les femmes de ma race, mais qu'attiré par le désir de la chair blanche, qui nous est défendue à nous autres nègres depuis que les hommes blancs règnent sur le monde, je m'efforce obscurément de me venger sur une Européenne de tout ce que ses ancêtres ont fait subir aux miens au long des siècles 54 ».

Que d'efforts pour se débarrasser d'une urgence subjective. Je suis un Blanc, je suis né en Europe, tous mes amis sont blancs. Il n'y avait pas huit nègres dans la ville que j'habitais. Je pense en français, ma religion est la France. M'entendez-vous, je suis Européen, je ne suis pas un nègre, et pour vous le prouver je m'en vais, en tant [77] que commis civil, montrer aux véritables nègres la différence qui existe entre eux et moi. Et en effet, relisez attentivement l'ouvrage, vous serez convaincu: 
«Qui frappe à la porte? Ah! c'est vrai.

$»-C^{\prime} e s t$ toi, Soua?

$»-$ Oui, commandant.

$\gg-$ Que me veux-tu?

$»-$ L'appel. Cinq gardes dehors. Dix-sept prisonniers - manque personne.

»-A part ça, rien de neuf ? Pas de nouvelles du courrier?

$»-$ Non, mon commandant 55 .»

M. Veneuse a des porteurs. Il a une jeune négresse dans sa case. Et aux nègres qui semblent regretter son départ, il sent que la seule chose à dire serait: «Allez-vous-en, allez-vous-en! Voyez... je suis malheureux de vous quitter. Allez-vous-en! Je ne vous oublierai pas. Je ne m'éloigne de vous que parce que ce pays n'est pas le mien et parce que je m'y sens trop seul, trop vide, trop privé de tout ce confort qui m'est nécessaire et dont vous n'avez pas besoin encore, heureusement pour vous 56 . »

Quand nous lisons de telles phrases, nous ne pouvons nous empêcher de penser à Félix Eboué, d'un noir incontestable, qui dans les mêmes conditions comprit son devoir d'une toute autre façon. Jean Veneuse n'est pas un nègre, ne veut pas être un nègre. Pourtant, à son insu, il s'est produit un hiatus. Il y a quelque chose d'indéfinissable, d'irréversible, véritablement le that within de Harold Rosenberg 57.

Louis-T. Achille, dans sa communication aux Rencontres interraciales de 1949, disait:

55 R. Maran, op. cit., p. 162.

56 P. 213.

57 «Du Jeu au Je, Esquisse d'une géographie de l'action», Les Temps Modernes, 1948. 
«Pour ce qui est du mariage proprement inter-racial, on peut se demander dans quelle mesure il n'est pas quelquefois pour le conjoint coloré une sorte de consécration subjective de l'extermination en lui-même et à ses propres yeux du préjugé de couleur dont il a longtemps souffert. Il serait intéressant d'étudier cela dans un certain [78] nombre de cas et peut-être de chercher dans ce mobile confus la raison de certains mariages inter-raciaux réalisés en dehors des conditions normales des ménages heureux. Certains hommes ou certaines femmes épousent en effet dans une autre race des personnes d'une condition ou d'une culture inférieures à la leur, qu'ils n'auraient pas souhaitées comme conjoints dans leur propre race et dont le principal atout semble être une garantie de dépaysement et de « déracialisation » (I'horrible mot) pour le conjoint. Chez certaines personnes de couleur, le fait d'épouser une personne de race blanche semble avoir primé toute autre considération. Elles y trouvent l'accession à une égalité totale avec cette race illustre, maîtresse du monde, dominatrice des peuples de couleur 58 ... »

Historiquement, nous savons que le nègre coupable d'avoir couché avec une Blanche est castré. Le nègre qui a possédé une Blanche est fait tabou par ses congénères. C'est une facilité pour l'esprit de faire exact ce drame d'une préoccupation sexuelle. Et c'est bien ce à quoi tend l'archétype de l'oncle Rémus : Frère Lapin, qui représente le Noir. Arrivera-t-il ou non à coucher avec les deux filles de $M^{\text {me }}$ Meadows? Il y a des hauts et des bas, tout cela conté par un nègre riant, bonhomme, jovial; un nègre qui offre en souriant.

Alors que nous nous éveillions très lentement à l'ébranlement pubertaire, il nous fut donné d'admirer un de nos camarades revenant de la métropole, qui avait tenu une jeune Parisienne dans ses bras. Dans un chapitre spécial, nous essaierons d'analyser ce problème. 
Nous entretenant récemment avec quelques Antillais, nous apprîmes que le souci le plus constant de ceux qui arrivaient en France était de coucher avec une Blanche. À peine au Havre, ils se dirigent vers les maisons closes. Une fois accompli ce rite d'initiation à l' « authentique » virilité, ils prennent le train pour Paris.

Mais ce qui importe ici, c'est d'interroger Jean Veneuse. Pour ce, nous ferons largement appel à l'ouvrage de Germaine Guex, La névrose d'abandon 59.

[79]

Opposant la névrose dite d'abandon, de nature pré-oedipienne, aux véritables conflits post-oedipiens décrits par l'orthodoxie freudienne, l'auteur analyse deux types dont le premier semble illustrer la situation de Jean Veneuse :

« C'est sur ce trépied de l'angoisse qu'éveille tout abandon, de l'agressivité qu'il fait naître et de la non-valorisation de soimême qui en découle, que s'édifie toute la symptomatologie de cette névrose 60 . »

Nous faisions de Jean Veneuse un introverti. Nous savons caractérologiquement, ou mieux phénoménologiquement, qu'on peut faire dépendre la pensée autistique d'une introversion primaire 61.

«Chez le sujet du type négatif agressif, l'obsession du passé, avec ses frustrations, ses vides, ses échecs, paralyse l'élan vers la vie. Généralement plus introverti que le positif aimant, il a tendance à ressasser ses déceptions passées et présentes, développant en lui une zone plus ou moins secrète de pensées et

\footnotetext{
59 Presses Universitaires de France, 1950.

60 G. Guex, La Névrose d'abandon, p. 13.

61 Minkowski, La Schizophrénie, 1927.
} 
de ressentiments amers et désabusés, qui constitue souvent une sorte d'autisme. Mais contrairement à l'autiste véritable, l'abandonnique a conscience de cette zone secrète qu'il cultive et défend contre toute intrusion. Plus égocentriste que le névrosé du second type (le positif aimant), il rapporte tout à lui même. Il a peu de capacité oblative, son agressivité, un constant besoin de vengeance retiennent ses élans. Son repliement sur lui-même ne lui permet de faire aucune expérience positive qui compenserait son passé. Aussi l'absence de valorisation et, partant, de sécurité affective est chez lui presque complète; de là un très fort sentiment d'impuissance en face de la vie et des êtres, et le rejet total du sentiment de la responsabilité. Les autres l'ont trahi et frustré, et c'est pourtant des autres seuls qu'il attend une amélioration de son sort ${ }^{62}$. »

Merveilleuse description où vient s'encastrer le personnage de Jean Veneuse. Car, nous dit-il, « il a suffi que je prenne de l'âge et que j'aille servir ma patrie adoptive au pays de mes ancêtres pour que j'en arrive à me [80] demander si je n'étais pas trahi 63 par tout ce qui m'entourait, le peuple blanc ne me reconnaissant pas pour sien, le noir me reniant presque. Telle est mon exacte situation $64 »$.

Attitude de récrimination envers le passé, non-valorisation de soi, impossibilité d'être compris comme il le voudrait. Ecoutez Jean Veneuse :

«Qui dira le désespoir des petits pays-chauds que leurs parents implantent en France trop tôt dans le dessein d'en faire de vrais Français! Ils les internent du jour au lendemain dans un lycée, eux si libres et si vivants, « pour leur bien», disent-ils en pleurant.
62 Pp. 27-28.
63 Souligné par nous.
64 G. Guex, op. cit., p. 36. 
» J'ai été de ces orphelins intermittents et souffrirai toute ma vie de l'avoir été. A sept ans, on a confié mon enfance scolaire à un grand lycée triste situé en pleine campagne... Mais les mille jeux de l'adolescence n'ont jamais pu me faire oublier combien la mienne fut douloureuse. Mon caractère lui doit cette mélancolie intime et cette crainte de la vie de société qui réprime aujourd'hui jusqu'à mes moindres élans 65 ... »

Pourtant il aurait voulu être entouré, enchapé. Il n'aurait pas voulu être abandonné. Aux vacances, tout le monde partait, et seul, retenez le terme, seul dans le grand lycée blanc...

«Ah! ces larmes d'enfant qui n'a personne pour le consoler... Il n'oubliera jamais qu'on l'a mis de bonne heure à l'apprentissage de la solitude... Existence cloîtrée, existence repliée et recluse où j'ai appris trop tôt à méditer et à réfléchir. Vie solitaire qui à la longue s'émeut longuement d'un rien - à cause de vous sensible en dedans, incapable d'extérioriser ma joie ou ma douleur, je repousse tout ce que j'aime et me détourne malgré moi de tout ce qui mattire 66. »

De quoi s'agit-il? Deux processus: je ne veux pas qu'on m'aime. Pourquoi ? Parce qu'un jour, il y a de cela très longtemps, j'ai esquissé une relation objectale et j'ai été abandonné. Je n'ai jamais pardonné à ma mère. Ayant été [81] abandonné, je ferai souffrir l'autre, et l'abandonner sera l'expression directe de mon besoin de revanche. C'est en Afrique que je pars: je ne veux pas être aimé et je fuis l'objet. Cela s'appelle, dit Germaine Guex, «mettre à l'épreuve pour faire la preuve». Je ne veux pas être aimé, j'adopte une position de
65 P. 227.
66 P. 228. 
défense. Et si l'objet persiste, je déclarerai : je ne veux pas qu'on maime.

Non-valorisation? Oui, certainement. " Cette non-valorisation de lui-même en tant qu'objet digne d'amour est grave de conséquence. D'une part, elle maintient l'individu dans un état d'insécurité intérieure profond, de ce fait elle inhibe ou fausse toute relation avec autrui. C'est en tant qu'objet propre à susciter la sympathie ou l'amour que l'individu doute de lui-même. La non-valorisation affective s'observe uniquement chez des êtres ayant souffert d'une carence d'amour et de compréhension durant leur petite enfance 67. "

Jean Veneuse voudrait être un homme pareil aux autres, mais il sait que cette situation est fausse. C'est un quêteur. Il cherche la tranquillité, la permission dans les yeux du Blanc. Car lui, c'est «l'Autre». «La non-valorisation affective amène toujours l'abandonnique à un sentiment extrêmement pénible et obsédant d'exclusion, de n'avoir nulle part sa place, d'être de trop partout, affectivement parlant... Etre «l'Autre » est une expression que j'ai rencontrée à plusieurs reprises dans le langage des abandonniques. Etre "l'Autre», c'est se sentir toujours en position instable, demeurer sur le quivive, prêt à être répudié et... faisant inconsciemment tout ce qu'il faut pour que la catastrophe prévue se produise.

»On ne saurait assez tenir compte de l'intensité de souffrance qui accompagne de tels états d'abandon, souffrance qui se rattache d'une part aux premières expériences d'exclusion de l'enfance et en fait revivre toute l'acuité 68 ... »

L'abandonnique réclame des preuves. Il ne se contente plus d'affirmations isolées. Il n'a pas confiance. Avant de nouer une relation objective, il exige du partenaire [82] des preuves réitérées. Le sens de son attitude est de "ne pas aimer pour ne pas être abandonné ». L'abandonnique est un exigeant. C'est qu'il a droit à toutes les répara-

$\begin{array}{ll}67 & \text { G. Guex, op. cit., pp. 31-32. } \\ 68 & \text { Pp. 35-36. }\end{array}$ 
tions. Il veut être aimé totalement, absolument et pour toujours. Ecoutez:

«Mon Jean bien-aimé,

» Je ne reçois qu'aujourd'hui votre lettre de juillet dernier. Elle est parfaitement déraisonnable. Pourquoi me tourmenter ainsi ? Vous êtes - vous en rendez-vous bien compte? - d'une cruauté dont rien n'approche. Vous me donnez un bonheur mêlé d'inquiétude. Vous faites que je suis en même temps la plus heureuse et la plus malheureuse des créatures. Combien de fois me faudra-t-il redire que je vous aime, que je suis à vous, que je vous attends. Venez ${ }^{69}$.

Enfin l'abandonnique a abandonné. On le réclame. On a besoin de lui. Il est aimé. Pourtant, que de fantasmes! M'aime-t-elle vraiment? Me voit-elle objectivement?

« Un jour, un monsieur, un grand ami de papa Ned, arriva, que n'avait jamais vu Pontaponte. Il venait de Bordeaux. Mais, Dieu! qu'il était sale, Dieu! qu'il était laid ce monsieur grand ami de papa Ned! Il avait un vilain visage noir, tout noir, preuve qu'il ne devait pas se laver souvent 70 . $\gg$

Jean Veneuse, soucieux de trouver à l'extérieur des raisons à son complexe de Cendrillon, projette chez le gosse de trois ou quatre ans l'arsenal stéréotypique raciste. Et à Andrée il dira : 
«Dites, Andrée chérie...., malgré ma couleur, consentiriezvous à devenir ma femme, si je vous le demandais 71 ? »

Il doute terriblement. Voici ce qu'en dit G. Guex :

«La première caractéristique semble être la peur de se montrer tel qu'on est. C'est ici un vaste domaine de craintes diverses: pour de décevoir, de déplaire, d'ennuyer, [83] de lasser... et par conséquent de manquer une possibilité de créer avec autrui un lien de sympathie, ou, s'il existe, de porter atteinte à ce lien. L'abandonnique doute qu'on puisse l'aimer tel qu'il est, car il a fait la cruelle expérience de l'abandon alors qu'il se proposait à la tendresse des autres, tout petit, donc sans artifice ${ }^{72}$.

Pourtant Jean Veneuse n'a pas une vie dépourvue de compensations. Il taquine la muse. Ses lectures sont imposantes, son étude sur Suarès est fort intelligente. Cela aussi est analysé par G. Guex: «Prisonnier de lui-même, confiné dans son quant-à-soi, le négatif-agressif grossit son sentiment d'irréparable de tout ce qu'il continue à perdre ou que sa passivité lui fait manquer... Aussi, exception faite de secteurs privilégiés comme sa vie intellectuelle ou sa profession 73 , conserve-t-il un profond sentiment de non-valeur ${ }^{74}$. $\gg$

À quoi tend cette analyse? I rien de moins qu'à démontrer à Jean Veneuse qu'effectivement il n'est pas pareil aux autres. Faire honte aux gens de leur existence, disait Jean-Paul Sartre. Oui : les amener à prendre conscience des possibilités qu'ils se sont interdites, de la passivité dont ils ont fait montre dans des situations où justement il fal-

\footnotetext{
71 Pp. 247-248.

72 G. Guex, op. cit., p. 39.

73 Souligné par nous.

74 P. 44.
} 
lait, telle une écharde, s'agripper au cour du monde forcer s'il le fallait le rythme du cœur du monde, déplacer s'il le fallait le système de commande, mais en tout cas, mais certainement, faire face au monde.

Jean Veneuse est le croisé de la vie intérieure. Quand il retrouve Andrée, placé en face de cette femme qu'il désire depuis de longs mois, il se réfugie dans le silence... le silence si éloquent de ceux qui « connaissent l'artificialité de la parole ou du geste ».

Jean Veneuse est un névrosé et sa couleur n'est qu'une tentative d'explication d'une structure psychique. N'eût-elle pas existé, cette différence objective, qu'il l'eût créée de toutes pièces.

Jean Veneuse est un de ces intellectuels qui veulent se placer uniquement sur le plan de l'idée. Incapable de [84] réaliser le contact concret avec son semblable. Est-on bienveillant avec lui, gentil, humain? C'est parce qu'il a surpris des secrets de concierge. Il « les connaît» et se tient sur ses gardes. "Ma vigilance, si l'on peut s'exprimer ainsi, est un cran d'arrêt. J'accueille avec politesse et naïveté les avances que l'on nous fait. Accepte et rends les apéritifs que l'on nous offre, participe aux petits jeux de société qu'on organise sur le pont, mais ne me laisse pas prendre à la bienveillance qu'on nous témoigne, méfiant que je suis de cette sociabilité excessive qui a remplacé un peu trop vite l'hostilité au milieu de laquelle on a essayé naguère de nous isoler 75 . »

Il accepte les apéritifs, mais les rend. Il ne veut rien devoir à personne. Car s'il ne les rend pas, il est un nègre, ingrat comme tous les autres.

Est-on méchant? Justement c'est parce qu'il est nègre. Car on ne peut pas ne pas le détester. Or nous le disons, Jean Veneuse, alias René Maran, n'est ni plus ni moins qu'un abandonnique noir. Et on le remet à sa place, à sa juste place. C'est un névrosé qui a besoin d'être délivré de ses fantasmes infantiles. Et nous disons que Jean Veneuse ne représente pas une expérience des rapports noir-blanc, mais une certai- 
ne façon pour un névrosé, accidentellement noir, de se comporter. Et l'objet de notre étude se précise : permettre à l'homme de couleur de comprendre, à l'aide d'exemples précis, les tenants psychologiques qui peuvent aliéner ses congénères. Nous y insisterons davantage dans le chapitre réservé à la description phénoménologique, mais, rappelons-le, notre but est de rendre possible pour le Noir et le Blanc une saine rencontre.

Jean Veneuse est laid. Il est noir. Que faut-il d'autre? Qu'on relise les quelques observations de Guex, et l'on se convaincra de cette évidence: Un homme pareil aux autres est une imposture, un essai de faire dépendre le contact entre deux races d'une morbidité constitutionnelle. Il faut en convenir: sur le plan de la psychanalyse comme sur celui de la philosophie, la constitution n'est mythe que pour celui qui la dépasse. Si d'un point de vue heuristique [85] on doit dénier toute existence à la constitution, il demeure, nous n'y pouvons rien, que des individus s'efforcent d'entrer dans des cadres préétablis. Ou du moins, si : nous y pouvons quelque chose.

Nous parlions tout à l'heure de Jacques Lacan : ce n'était pas un hasard. En 1932, il a, dans sa thèse, fait une critique violente de la notion de constitution. Apparemment, nous nous écartons de ses conclusions, mais l'on comprendra notre dissidence quand on se rappellera qu'à la notion de constitution au sens où l'entendait l'école française, nous substituons celle de structure, - « englobant la vie psychique inconsciente telle que nous pouvons partiellement la connaître, en particulier sous la forme de refoulé et de refoulant, en tant que ces éléments participent activement à l'organisation propre de chaque individualité psychique $76 »$.

Nous l'avons vu, Jean Veneuse révèle à l'examen une structure d'abandonnique du type négatif-agressif. On peut tenter d'expliquer cela réactionnellement, c'est-à-dire par l'interaction milieu-individu, et prescrire par exemple un changement de milieu, « un changement d'air». Justement, on s'est aperçu que dans ce cas la structure de-

76 G. Guex, La névrose d'abandon, p. 54. 
meurait. Le changement d'air que s'est imposé Jean Veneuse n'était pas dans le but de se situer en tant qu'homme; il n'avait pas pour fin une saine mise en forme du monde; il ne recherchait point cette prégnance caractéristique de l'équilibre psycho-social, mais bien une confirmation de sa névrose externisante.

La structure névrotique d'un individu sera justement l'élaboration, la formation, l'éclosion dans le moi de nœuds conflictuels provenant d'une part du milieu, d'autre part de la façon toute personnelle dont cet individu réagit à ces influences.

De même qu'il y avait une tentative de mystification à vouloir inférer du comportement de Nini et de Mayotte Capécia une loi générale du comportement de la Noire vis-à-vis du Blanc, il y aurait, affirmonsnous, manquement à l'objectivité dans l'extension de l'attitude de Veneuse à l'homme de couleur en tant que tel. Et nous [86] voudrions avoir découragé toute tentative en vue de ramener les échecs d'un Jean Veneuse à la plus ou moins grande concentration en mélanine de son épiderme.

Il faut que ce mythe sexuel - recherche de la chair blanche - ne vienne plus, transité par des consciences aliénées, gêner une compréhension active.

En aucune façon ma couleur ne doit être ressentie comme une tare. À partir du moment où le nègre accepte le clivage imposé par l'Européen, il n'a plus de répit et, « dès lors, n'est-il pas compréhensible qu'il essaie de s'élever jusqu'au Blanc? S'élever dans la gamme des couleurs auxquelles il assigne une sorte de hiérarchie 77 ? »

Nous verrons qu'une autre solution est possible. Elle implique une restructuration du monde.

77 Claude Nordey, L'homme de couleur, Coll. «Présences », Plon, éd., 1939. 
PEAU NOIRE. MASQUES BLANCS.

\section{Chapitre IV}

\section{DU PRÉTENDU COMPLEXE DE DÉPENDANCE DU COLONISÉ}

Il n'y a pas dans le monde un paurre type lynché, un pauvre homme torturé, en qui je ne sois assassiné et humilié. (Aimé Césaire, Et les chiens se taisaient.)

\section{Retour à la table des matières}

Lorsque nous avons commencé ce travail, nous ne possédions que quelques études de M. Mannoni parues dans la revue Psyché. Nous nous proposions d'écrire à l'auteur pour le prier de nous communiquer les conclusions auxquelles il était parvenu. Depuis, nous avons su qu'un ouvrage allait paraître qui réunirait ses réflexions. Cet ouvrage est paru : Psychologie de la colonisation. Nous allons l'étudier.

Avant d'entrer dans le détail, disons que la pensée analytique est honnête. Ayant vécu à l'extrême l'ambivalence inhérente à la situation coloniale, M. Mannoni est parvenu à une saisie malheureusement trop exhaustive des phénomènes psychologiques qui régissent les rapports indigène-colonisateur. 
La caractéristique fondamentale de la recherche psychologique actuelle semble consister dans la réalisation d'une certaine exhaustivité. Mais on ne doit pas perdre de vue le réel.

Nous montrerons que M. Mannoni, bien qu'ayant consacré deux cent vingt-cinq pages à l'étude de la situation coloniale, n'en a pas saisi les véritables coordonnées.

Quand on aborde un problème aussi important que l'inventaire des possibilités de compréhension de deux peuples différents, on doit redoubler d'attention.

[88]

Nous sommes redevable à $M$. Mannoni d'avoir introduit dans la procédure deux éléments dont l'importance ne saurait plus échapper à personne.

Une analyse rapide avait semblé écarter la subjectivité de ce domaine. L'étude de M. Mannoni est une recherche sincère, car elle se propose de montrer qu'on ne saurait expliquer l'homme en dehors de cette possibilité qu'il a d'assumer ou de nier une situation donnée. Le problème de la colonisation comporte ainsi non seulement l'intersection de conditions objectives et historiques, mais aussi l'attitude de l'homme à l'égard de ces conditions.

Pareillement, nous ne pouvons qu'adhérer à cette partie du travail de M. Mannoni qui tend à pathologiciser le conflit, c'est-à-dire à démontrer que le Blanc colonisateur n'est mû que par son désir de mettre fin à une insatisfaction, sur le plan de la sur-compensation adlérienne.

Toutefois, nous nous découvrons en opposition avec lui quand nous lisons cette phrase: "Le fait qu'un Malgache adulte isolé dans un autre milieu peut devenir sensible à l'infériorité de type classique prouve de façon à peu près irréfutable que, depuis son enfance, il existait en lui un germe d'infériorité 78 . »

78 O. Mannoni, Psychologie de la colonisation, p. 32. (Ed. du Seuil). 
À la lecture de ce passage, nous sentons chavirer quelque chose, et l'« objectivité » de l'auteur risque de nous induire en erreur.

Avec ferveur cependant, nous avons essayé de retrouver la ligne d'orientation, le thème fondamental du livre: «L'idée centrale est que la mise en présence des «civilisés» et des «primitifs» crée une situation particulière - la situation coloniale - faisant apparaître un ensemble d'illusions et de malentendus que seule l'analyse psychologique peut situer et définir ${ }^{79}$. »

Or, puisque tel est le point de départ de M. Mannoni, pourquoi veutil faire du complexe d'infériorité quelque chose de préexistant à la colonisation? Nous reconnaissons là le mécanisme d'explication qui, en psychiatrie, donnerait: il y a des formes latentes de la psychose qui deviennent manifestes à la suite d'un traumatisme. Et en [89] chirurgie: l'apparition de varices chez un individu ne provient pas de l'obligation pour lui de rester dix heures debout, mais bien d'une fragilité constitutionnelle de la paroi veineuse: le mode de travail n'est qu'une condition favorisante, et le sur-expert requis décrète très limitée la responsabilité de l'employeur.

Avant d'aborder dans le détail les conclusions de M. Mannoni, nous voudrions préciser notre position. Une fois pour toutes, nous posons ce principe: une société est raciste ou ne l'est pas. Tant qu'on n'aura pas saisi cette évidence, on laissera de côté un grand nombre de problèmes. Dire, par exemple, que le nord de la France est plus raciste que le sud, que le racisme est l'œuvre des subalternes, donc n'engage nullement l'élite, que la France est le pays le moins raciste du monde, est le fait d'hommes incapables de réfléchir correctement.

Pour nous prouver que le racisme ne reproduit pas la situation économique, l'auteur nous rappelle qu'« en Afrique du Sud les ouvriers blancs se montrent autant et parfois plus racistes que les dirigeants et les employeurs 80 ».

\footnotetext{
79 Cf. p. II de la couverture. - C'est nous qui soulignons.

80 O. Mannoni, op. cit., p. 16.
} 
Nous nous excusons, mais nous voudrions que ceux qui se chargent de décrire la colonisation se rappellent une chose : c'est qu'il est utopique de rechercher en quoi un comportement inhumain se différencie d'un autre comportement inhumain. Nous ne voulons nullement enfler le monde de nos problèmes, mais nous voudrions bonnement demander à M. Mannoni s'il ne pense pas que pour un Juif les différences entre l'antisémitisme de Maurras et celui de Goebbels sont impalpables.

À la fin d'une représentation de La Putain respectueuse en Afrique du Nord, un général disait à Sartre: «Il serait bon que votre pièce fût jouée en Afrique noire. Elle montre bien à quel point le Noir en pays français est plus heureux que son congénère américain. »

Je crois sincèrement qu'une expérience subjective peut être comprise par autrui ; et il ne me plaît nullement de venir en disant : le problème noir est mon problème, moi seul, puis de me mettre à l'étudier. Mais il me semble [90] que M. Mannoni n'a pas essayé de ressentir par le dedans le désespoir de l'homme de couleur en face du Blanc. Je me suis attaché dans cette étude à toucher la misère du Noir. Tactilement et affectivement. Je n'ai pas voulu être objectif. D'ailleurs, c'est faux : il ne m'a pas été possible d'être objectif.

En vérité, y a-t-il donc une différence entre un racisme et un autre? Ne retrouve-t-on pas la même chute, la même faillite de l'homme?

M. Mannoni estime que le pauvre blanc d'Afrique du Sud déteste le Noir indépendamment de tout processus économique. Outre qu'on peut comprendre cette attitude en évoquant la mentalité antisémite « aussi nommerais-je volontiers l'antisémitisme un snobisme du pauvre. Il semble en effet que la plupart des riches utilisent 81 cette passion plutôt qu'ils ne s'y abandonnent, ils ont mieux à faire. Elle se propage à l'ordinaire dans les classes moyennes, précisément parce qu'elles ne possèdent ni terre ni château, ni maison! En traitant le Juif comme un être inférieur et pernicieux, j'affirme du même coup que je suis d'une 
élite $82 »-$, nous pourrions rétorquer que ce déplacement de l'agressivité du prolétariat blanc sur le prolétariat noir est fondamentalement une conséquence de la structure économique de l'Afrique du Sud.

Qu'est-ce que l'Afrique du Sud? Une chaudière où 2530300 Blancs matraquent et parquent 13000000 de Noirs. Si les pauvres Blancs haïssent les nègres, ce n'est pas, comme le laisserait entendre M. Mannoni, parce que « le racisme est l'œuvre de petits commerçants et de petits colons qui ont beaucoup trimé sans grand succès $83 »$. Non, c'est parce que la structure de l'Afrique du Sud est une structure raciste: «Négrophilie et philanthropie sont des injures en Afrique du Sud... on propose de séparer les indigènes des Européens, territorialement, économiquement et sur le terrain politique, et de leur permettre d'édifier leur propre civilisation sous la direction et l'autorité de Blancs, mais avec un minimum de contact entre [91] les races. On propose de réserver aux indigènes des territoires et d'obliger le plus grand nombre à y habiter... La compétition économique serait supprimée et un chemin préparé pour la réhabilitation des «pauvres Blancs» qui forment $50 \%$ de la population européenne...

»Il n'est pas exagéré de dire que la plupart des Sud-Africains éprouvent une répugnance presque physique vis-à-vis de tout ce qui met un indigène ou une personne de couleur à leur niveau ${ }^{84}$.

Pour en finir avec l'argument de M. Mannoni, rappelons que « la barrière économique vient entre autres causes de la crainte de la concurrence et du désir de protéger les classes des Blancs pauvres qui forment la moitié de la population européenne et de les empêcher de tomber plus bas».

M. Mannoni continue: "L'exploitation coloniale ne se confond pas avec les autres formes d'exploitation, le racisme colonial diffère des

82 J.-P. Sartre, Réflexions sur la question juive, p. 32.

83 Mannoni, op. cit., p. 16.

84 R. P. Oswin, Magrath du couvent dominicain de Saint-Nicolas, Stallenbosch, Afrique Australe Anglaise, L'homme de couleur, p. 140. - Souligné par nous. 
autres racismes 85 ... » L'auteur parle de phénoménologie, de psychanalyse, d'unité humaine, mais nous voudrions que ces termes revêtent chez lui un caractère plus concret. Toutes les formes d'exploitation se ressemblent. Elles vont toutes chercher leur nécessité dans quelque décret d'ordre biblique. Toutes les formes d'exploitation sont identiques, car elles s'appliquent toutes à un même «objet»: I'homme. A vouloir considérer sur le plan de l'abstraction la structure de telle exploitation ou de telle autre, on se masque le problème capital, fondamental, qui est de remettre l'homme à sa place.

Le racisme colonial ne diffère pas des autres racismes.

L'antisémitisme me touche en pleine chair, je m'émeus, une contestation effroyable manémie, on me refuse la possibilité d'être un homme. Je ne puis me désolidariser du sort réservé à mon frère. Chacun de mes actes engage l'homme. Chacune de mes réticences, chacune de mes lâchetés manifeste l'homme ${ }^{86}$. Il nous semble encore [92] enten-

85 Mannoni, op. cit., p. 19.

86 En écrivant ceci, nous pensons à la culpabilité métaphysique de Jaspers : «Il existe entre les hommes, du fait qu'ils sont des hommes, une solidarité en vertu de laquelle chacun se trouve co-responsable de toute injustice et de tout mal commis dans le monde, et en particulier de crimes commis en sa présence, ou sans qu'il les ignore. Si je ne fais pas ce que je peux pour les empêcher, je suis complice. Si je n'ai pas risqué ma vie pour empêcher l'assassinat d'autres hommes, si je me suis tenu coi, je me sens coupable en un sens qui ne peut être compris de façon adéquate ni juridiquement, ni politiquement, ni moralement... Que je vive encore après que de telles choses se soient passées pèse sur moi comme une culpabilité inexpiable.

»Quelque part dans la profondeur des rapports humains s'impose une exigence absolue: en cas d'attaque criminelle ou de conditions de vie menaçant l'être physique, n'accepter de vivre que tous ensemble ou pas du tout » (Karl Jaspers, La culpabilité allemande, traduit par Jeanne Hersch, pp. 60-61).

Jaspers déclare que l'instance compétente est Dieu. Il est facile de voir que Dieu n'a rien à faire ici. À moins qu'on ne veuille expliciter cette obligation pour la réalité humaine de se sentir responsable de son semblable. Responsable en ce sens que le moindre de mes actes engage l'humanité. Chaque acte est réponse ou question. Les deux peut-être. En exprimant une certaine façon pour mon être de se dépasser j'affirme la valeur de mon acte pour autrui. Inversement la passivité observée aux heures troublantes de l'Histoire, s'interprète en tant que faillite à cette obligation. Jung, dans Aspects du drame contempo- 
dre Césaire: «Quand je tourne le bouton de ma radio, que j'entends qu'en Amérique des nègres sont lynchés, je dis qu'on nous a menti : Hitler n'est pas mort: quand je tourne le bouton de ma radio, que j'apprends que des Juifs sont insultés, méprisés, pogromisés, je dis qu'on nous a menti : Hitler n'est pas mort; que je tourne enfin le bouton de ma radio et que j'apprenne qu'en Afrique le travail forcé est institué, légalisé, je dis que, véritablement, on nous a menti : Hitler n'est pas mort 87 . "

Oui, la civilisation européenne et ses représentants les plus qualifiés sont responsables du racisme colonial 88 ; et nous faisons encore appel à Césaire: «Et alors, un [93] beau jour, la bourgeoisie est réveillée par un formidable choc en retour: les gestapos s'affairent, les prisons s'emplissent, les tortionnaires inventent, raffinent, discutent autour des chevalets.

»On s'étonne, on s'indigne. On dit: « Comme c'est curieux! Mais, bah! c'est le nazisme, ça passera! » Et on attend, et on espère; et on se tait à soi-même la vérité, que c'est une barbarie, mais la barbarie suprême, celle qui couronne, celle qui résume la quotidienneté des barbaries: que c'est du nazisme, oui, mais qu'avant d'en être la victime on en a été le complice ; que ce nazisme-là, on l'a supporté avant de le subir, on l'a absout, on a fermé l'œeil là-dessus, on l'a légitimé, parce que, jusque-là, il ne s'était appliqué qu'à des peuples non européens ; que ce nazisme-là, on l'a cultivé, on en est responsable, et qu'il sourd, qu'il

rain, dit que tout Européen doit être à même de répondre des crimes commis par la barbarie nazie, devant un Asiatique ou un Hindou. Un autre auteur, Madame Maryse Choisy, dans L'Anneau de Polycrate, a pu décrire la culpabilité qui fut le lot des «neutres» pendant l'occupation. Ils se sentaient confusément responsables de tous ces morts et de tous les Büchenwald.

87 Cité de mémoire. - Discours politiques, Campagne électorale 1945, Fort-deFrance.

88 «La civilisation européenne et ses représentants les plus qualifiés ne sont pas responsables du racisme colonial; mais celui-ci est l'œuvre de subalternes et de petits commerçants, de colons qui ont beaucoup trimé sans grand succès. » (Mannoni, p. 16). 
perce, qu'il goutte, avant de l'engloutir dans ses eaux rougies, de toutes les fissures de la civilisation occidentale et chrétienne ${ }^{89}$. »

Chaque fois que nous voyons des Arabes, l'allure traquée, méfiants, fuyants, drapés de ces longues vestes déchirées qui semblent être fabriquées à leur intention, nous nous disons: M. Mannoni s'est trompé. Souvente-fois, nous nous sommes fait arrêter en plein jour par les inspecteurs de police qui nous prenaient pour un Arabe, et quand ils découvraient notre origine, ils s'empressaient de s'excuser - «Nous savons bien qu'un Martiniquais est différent d'un Arabe. "Véhémentement nous protestions, mais, nous disait-on, « vous ne les connaissez pas ». En vérité, M. Mannoni, vous vous êtes trompé. Car que signifie cette expression: «La civilisation européenne et ses représentants les plus qualifiés ne sont pas responsables du racisme colonial »? Que signifie-t-elle sinon que le colonialisme est l'œuvre d'aventuriers et de politiciens, les « représentants les plus qualifiés» se tenant en effet au-dessus de la mêlée. Mais, dit Francis Jeanson, tout ressortissant d'une nation est responsable des agissements perpétrés au nom de cette nation: «Jour après jour, ce système développe autour de vous ses conséquences pernicieuses, jour après jour ses promoteurs vous trahissent, [94] poursuivant au nom de la France une politique aussi étrangère que possible, non seulement à vos véritables intérêts, mais aussi à vos exigences les plus profondes... Vous vous faites gloire de vous maintenir à distance d'un certain ordre de réalités : ainsi laissezvous les mains libres à ceux que les atmosphères malsaines ne sauraient point rebuter, puisqu'ils les créent eux-mêmes par leur propre comportement. Et si vous parvenez, apparemment, à ne pas vous salir, c'est que d'autres se salissent à votre place. Vous avez des hommes de main, et tout compte fait, c'est vous les vrais coupables: car sans vous, sans votre négligente cécité, de tels hommes ne pourraient poursuivre une action qui vous condamne autant qu'elle les déshonore 90. »

89 Aimé Césaire, Discours sur le colonialisme, pp. 14-15.

90 Francis Jeanson, Cette Algérie conquise et pacifiée... (Esprit, avril 1950, p. 624). 
Nous disions tout à l'heure que l'Afrique du Sud avait une structure raciste. Nous allons plus loin et nous disons que l'Europe a une structure raciste. On voit bien que $M$. Mannoni n'est pas intéressé à ce problème, puisqu'il dit : «La France est le pays le moins raciste du monde 91 . " Beaux nègres, réjouissez-vous d'être français, même si c'est un peu dur, car en Amérique vos congénères sont plus malheureux que vous... La France est un pays raciste, car le mythe du nègre-mauvais fait partie de l'inconscient de la collectivité. Nous le montrerons plus loin (ch. VI).

Continuons avec M. Mannoni: «Un complexe d'infériorité lié à la couleur de la peau ne s'observe en effet que chez les individus qui vivent en minorité dans un milieu d'une autre couleur; dans une collectivité assez homogène comme la collectivité malgache, où les structures sociales sont encore assez solides, on ne rencontre de complexe d'infériorité que dans des cas exceptionnels ${ }^{92}$. "

Encore une fois, nous demandons à l'auteur quelque circonspection. Un Blanc aux colonies ne s'est jamais senti inférieur en quoi que ce soit ; comme le dit si bien M. Mannoni : "Il sera fait dieu ou dévoré. » Le colonisateur, [95] bien qu' « en minorité », ne se sent pas infériorisé. Il $y$ a en Martinique 200 Blancs qui s'estiment supérieurs à 300000 éléments de couleur. En Afrique australe, il y a 2000000 de Blancs pour près de 13000000 d'indigènes, et il n'est venu à l'idée d'aucun indigène de se sentir supérieur à un minoritaire blanc.

Si les découvertes d'Adler et celles, non moins intéressantes, de Kuenkel expliquent certains comportements névrotiques, il ne faut pas en inférer des lois qui s'appliqueraient à des problèmes infiniment complexes. L'infériorisation est le corrélatif indigène de la supériorisation européenne. Ayons le courage de le dire: c'est le raciste qui crée l'infériorisé.

\footnotetext{
91 Mannoni, op. cit., p. 31.

92 Ibid., p. 108.
} 
Par cette conclusion, nous rejoignons Sartre: «Le Juif est un homme que les autres hommes tiennent pour Juif : voilà la vérité simple d'où il faut partir... C'est l'antisémite qui faitle Juif 93. »

Que deviennent les cas exceptionnels dont nous parle M. Mannoni? Ce sont tout simplement ceux où l'évolué se découvre soudain rejeté par une civilisation qu'il a cependant assimilée. En sorte que la conclusion serait la suivante: dans la mesure où le véritable Malgache-type de l'auteur assume ses «conduites dépendantes», tout est pour le mieux : toutefois, s'il oublie sa place, s'il se met en tête d'égaler l'Européen, alors le dit Européen se fâche et rejette l'impudent, - qui, à cette occasion et dans ce «cas exceptionnel», paye d'un complexe d'infériorité son refus de la dépendance.

Nous décelions précédemment, dans certaines allégations de $M$. Mannoni, un quiproquo pour le moins dangereux. En effet, il laisse au Malgache le choix entre l'infériorité et la dépendance. Hormis ces deux solutions, point de salut. «Quand il (le Malgache) réussit à établir de telles relations (de dépendance) dans la vie avec des supérieurs, son infériorité ne le gêne plus, tout va bien. Quand il ne réussit pas, quand sa position d'insécurité ne se régularise pas de cette manière, il éprouve un échec ${ }^{94}$.

Le premier souci de M. Mannoni avait été de critiquer [96] les méthodes jusqu'ici employées par les différents ethnographes qui se sont penchés sur les populations primitives. Mais on voit le reproche qu'il nous faut adresser à son ouvrage.

Après avoir enfermé le Malgache dans ses coutumes, après avoir réalisé une analyse unilatérale de sa vision du monde, après avoir décrit le Malgache en cercle fermé, après avoir dit que le Malgache entretient des relations de dépendance avec les ancêtres, caractéristiques hautement tribales, l'auteur, au mépris de toute objectivité, ap-

94 Mannoni, op. cit., p. 61. 
plique ses conclusions à une compréhension bilatérale, - ignorant volontairement que depuis Galliéni le Malgache n'existe plus.

Ce que nous demandions à M. Mannoni, c'était de nous expliquer la situation coloniale. Il oublie singulièrement de le faire. Rien ne se perd, rien ne se crée, nous sommes d'accord. Parodiant Hegel, Georges Balandier, dans une étude 95 qu'il a consacrée à Kardiner et Linton, écrit à propos de la dynamique de la personnalité : «Le dernier de ses états est le résultat de tous les états antécédents et doit en contenir tous les principes. » Boutade, mais qui demeure la règle de nombreux chercheurs. Les réactions, les comportements qui sont nés de l'arrivée européenne à Madagascar ne sont pas venus s'additionner aux préexistants. Il n'y a pas eu augmentation du bloc psychique antérieur. Si par exemple des Martiens se mettaient en quête de coloniser les Terriens, non pas de les initier à la culture martienne, mais littéralement de les coloniser, nous douterions de la pérennité d'une quelconque personnalité. Kardiner redresse beaucoup de jugements en écrivant : «Enseigner le christianisme aux gens d'Alor, c'est une entreprise à la Don Quichotte... (Ça) n'a aucun sens tant que la personnalité reste construite avec des éléments qui sont en complète désharmonie avec la doctrine chrétienne : c'est assurément commencer par le mauvais bout 96 » et si les nègres sont imperméables à l'enseignement du Christ, ce n'est point parce qu'ils sont incapables de l'assimiler. Comprendre quelque chose de nouveau nous [97] demande de nous disposer à, de nous préparer à, exige une nouvelle mise en forme. Il est utopique d'attendre du Nègre ou de l'Arabe qu'ils accomplissent l'effort d'insérer des valeurs abstraites dans leur Weltanschauung alors qu'ils mangent à peine à leur faim. Demander à un nègre du haut-Niger de se chausser, dire de lui qu'il est incapable de devenir un Schubert, n'est pas moins absurde que de s'étonner qu'un ouvrier de chez Berliet ne consacre pas

95 Où l'ethnologie retrouve l'unité de l'homme (Esprit, avril 1950).

96 Cité par Georges Balandier, ibid., p. 610. 
ses soirées à l'étude du lyrisme dans la littérature hindoue ou de déclarer qu'il ne sera jamais un Einstein.

En effet, dans l'absolu, rien ne s'oppose à de pareilles choses. Rien, - sauf que les intéressés n'en ont pas la possibilité.

Mais ils ne se plaignent pas! La preuve: " Au bout du petit matin, au-delà de mon père, de ma mère, la case gerçant d'ampoules, comme un péché tourmenté de la cloque et le toit aminci, rapiécé de morceaux de bidons de pétrole, et ça fait des marais de rouillure dans la pâte grise sordide empuantie de la paille, et quand le vent siffle, ces disparates font bizarre le bruit, comme un crépitement de friture d'abord, puis comme un tison que l'on plonge dans l'eau avec la fumée des brindilles qui s'envole. Et le lit de planches d'où s'est levée ma race, tout entière ma race de ce lit de planches, avec ses pattes de caisses de Kérosine, comme s'il avait l'éléphantiasis le lit, et sa peau de cabri, et ses feuilles de banane séchées, et ses haillons, une nostalgie de matelas le lit de ma grand-mère (au-dessus du lit dans un pot plein d'huile un lumignon dont la flamme danse comme un gros navet... sur le pot, en lettres d'or: MERCI) 97. » Malheureusement, « cette attitude, ce comportement, cette vie trébuchée prise au lasso de la honte et du désastre, s'insurge, se conteste, conteste, aboie, et comme ma foi on lui demande:

«-Qu'y pouvez-vous?

«-Commencer!

$\ll-$ Commencer quoi?

«- La seule chose au monde qui vaille la peine de commencer: la fin du monde, parbleu ${ }^{98}$.

[98] 
Ce que M. Mannoni a oublié, c'est que le Malgache n'existe plus; il a oublié que le Malgache existe avec l'Européen. Le Blanc arrivant à Madagascar a bouleversé les horizons et les mécanismes psychologiques. Tout le monde l'a dit, l'altérité pour le Noir, ce n'est pas le Noir, mais le Blanc. Une île comme Madagascar, envahie du jour au lendemain par les «pionniers de la civilisation», même si ces pionniers se comportèrent du mieux qu'ils purent, connut une destructuration. C'est d'ailleurs M. Mannoni qui le dit : «Au début de la colonisation, chaque tribu voulait avoir son Blanc ${ }^{99}$. "Que l'on explique cela par des mécanismes magico-totémiques, par un besoin de contact avec le Dieu terrible, par l'illustration d'un système de dépendance, il n'en demeure pas moins que du nouveau s'était produit dans cette île, et qu'on en devait tenir compte - sous peine de rendre l'analyse fausse, absurde, caduque. Un apport nouveau étant intervenu, il fallait tenter la compréhension des nouveaux rapports.

Le Blanc débarquant à Madagascar provoquait une blessure absolue. Les conséquences de cette irruption européenne à Madagascar ne sont pas seulement psychologiques, puisque, tout le monde l'a dit, il y a des rapports internes entre la conscience et le contexte social.

Les conséquences économiques? mais c'est le procès de la colonisation qu'il faudrait faire!

Poursuivons notre étude.

«En termes abstraits, le Malgache peut supporter de ne pas être un homme blanc. Ce qui est cruel, c'est d'avoir découvert d'abord qu'on est un homme (par l'identification) et ensuite que cette unité se rompt en blancs et noirs. Si le Malgache « abandonné » ou «trahi » maintient son identification, elle devient alors revendicatrice; et il exigera des égalités dont il n'éprouvait nullement le besoin. Ces égalités lui auraient été avantageuses avant qu'il ne les réclamât, mais ensuite elles sont un remède insuffisant à ses maux: car tout progrès dans les 
égalités possibles rendra encore plus insupportables les différences qui tout à coup apparaissent comme douloureusement ineffaçables. C'est de cette manière qu'il passe (le Malgache) [99] de la dépendance à l'infériorité psychologique ${ }^{100}$. »

Ici encore, nous retrouvons le même malentendu. Il est en effet évident que le Malgache peut parfaitement supporter de ne pas être un Blanc. Un Malgache est un Malgache: ou plutôt non, un Malgache n'est pas un Malgache: il existe absolument sa «malgacherie ». S'il est Malgache, c'est parce que le Blanc arrive, et si, à un moment donné de son histoire, il a été amené à se poser la question de savoir s'il était un homme ou pas, c'est parce qu'on lui contestait cette réalité d'homme. Autrement dit, je commence à souffrir de ne pas être un Blanc dans la mesure où l'homme blanc m'impose une discrimination, fait de moi un colonisé, m'extorque toute valeur, toute originalité, me dit que je parasite le monde, qu'il faut que je me mette le plus rapidement possible au pas du monde blanc, «que je suis une bête brute, que mon peuple et moi sommes comme un fumier ambulant hideusement prometteur de canne tendre et de coton soyeux, que je n'ai rien à faire au monde 101 ». Alors j'essaierai tout simplement de me faire blanc, c'est-àdire j'obligerai le Blanc à reconnaître mon humanité. Mais, nous dira $M$. Mannoni, vous ne pouvez pas, car il existe au profond de vous un complexe de dépendance.

«Tous les peuples ne sont pas aptes à être colonisés, seuls le sont ceux qui possèdent ce besoin. » Et, plus loin: «Presque partout où les Européens ont fondé des colonies du type qui est actuellement « en question », on peut dire qu'ils étaient attendus, et même désirés dans l'inconscient de leurs sujets. Des légendes, partout, les préfiguraient sous la forme d'étrangers venus de la mer et destinés à apporter des bienfaits 102. " Comme on le voit, le Blanc obéit à un complexe

100 Mannoni, op. cit., p. 85.

101 Aimé Césaire, Cahier d'un retour.

102

Mannoni, op. cit., pp. 87-88. 
d'autorité, à un complexe de chef, cependant que le Malgache obéit à un complexe de dépendance. Tout le monde est satisfait.

Quand il s'agit de comprendre pourquoi l'Européen, l'étranger, fut appelé vazaha, c'est-à-dire « honorable étranger»; quand il s'agit de comprendre pourquoi les [100] Européens naufragés furent accueillis à bras ouverts, pourquoi l'Européen, l'étranger, n'est jamais conçu comme ennemi ; au lieu de le faire en partant de l'humanité, de la bienveillance, de la politesse, traits fondamentaux de ce que Césaire appelle les "vieilles civilisations courtoises», on nous dit que c'est tout simplement parce qu'il y avait, inscrit dans les « hiéroglyphes fatidiques», l'inconscient, en particulier, - quelque chose qui du Blanc faisait le maître attendu. L'inconscient, oui, nous y voilà. Mais il ne faut pas extrapoler. Quand un nègre me raconte le rêve suivant: "Je marche depuis longtemps, je suis très fatigué, j'ai l'impression que quelque chose mattend, je franchis des barrières et des murs, j'arrive dans une salle vide, et derrière une porte j'entends du bruit, j'hésite avant d'entrer, enfin je me décide, j'entre, il y a dans cette deuxième chambre des Blancs, je constate que moi aussi je suis blanc», et quand j'essaie de comprendre ce rêve, de l'analyser, sachant que cet ami a des difficultés d'avancement, je conclus que ce rêve réalise un désir inconscient. Mais quand il s'agira pour moi, en dehors de mon laboratoire de psychanalyste, d'intégrer mes conclusions au contexte du monde, je dirai :

$1^{\circ}$ Mon patient souffre d'un complexe d'infériorité. Sa structure psychique risque de se dissoudre. Il s'agit de l'en préserver et, peu à peu, de le libérer de ce désir inconscient.

$2^{\circ} \mathrm{S}^{\prime} i l$ se trouve à ce point submergé par le désir d'être blanc, c'est qu'il vit dans une société qui rend possible son complexe d'infériorité, dans une société qui tire sa consistance du maintien de ce complexe, dans une société qui affirme la supériorité d'une race: c'est dans l'exacte mesure où cette société lui fait des difficultés, qu'il se trouve placé dans une situation névrotique. 
Ce qui apparaît alors, c'est la nécessité d'une action couplée sur l'individu et sur le groupe. En tant que psychanalyste, je dois aider mon client à conscienciser son inconscient, à ne plus tenter une lactification hallucinatoire, mais bien à agir dans le sens d'un changement des structures sociales.

Autrement dit, le Noir ne doit plus se trouver placé devant ce dilemme: se blanchir ou disparaître, mais il [101] doit pouvoir prendre conscience d'une possibilité d'exister: autrement dit encore, si la société lui fait des difficultés à cause de sa couleur, si je constate dans ses rêves l'expression d'un désir inconscient de changer de couleur, mon but ne sera pas de l'en dissuader en lui conseillant de " garder ses distances » : mon but, au contraire, sera, une fois les mobiles éclairés, de le mettre en mesure de choisir l'action (ou la passivité) à l'égard de la véritable source conflictuelle - c'est-à-dire à l'égard des structures sociales.

M. Mannoni, soucieux d'envisager le problème sous tous les angles, n'a pas manqué d'interroger l'inconscient du Malgache.

Il analyse pour cela sept rêves: sept récits qui nous livrent l'inconscient, et parmi lesquels on en trouve six qui manifestent une dominante de terreur. Des enfants et un adulte nous communiquent leurs songes, et nous les voyons tremblants, fuyants, malheureux.

"Rêve du cuisinier:

« Je suis poursuivi par un taureau noir 103 furieux. Plein de terreur, je monte dans un arbre, où je reste jusqu'à ce que le danger soit passé. Je redescends tout tremblant. »...

103 Souligné par nous. 


\section{»Rêve de Rahevi, garçon de treize ans :}

«En me promenant dans le bois, je rencontre deux hommes noirs ${ }^{104}$. Ah! dis-je, je suis perdu! Je vais (veux) m'enfuir, mais c'est impossible. Ils m'encerclent et bredouillent à leur façon. Je crois qu'ils disent: "Tu vas voir ce que c'est que la mort. » Je tremble de peur et leur dit: «Laissez-moi, messieurs, j'ai tellement peur! » Un de ces hommes connaît le français, mais malgré tout ils me disent : «Viens à notre chef. » En s'acheminant, ils me font marcher devant eux et me font voir leurs fusils. Ma peur [se] redouble, mais avant d'arriver à leur camp, on doit traverser un cours d'eau. Je (me) plonge au fond [102] de l'eau. Grâce à mon sang-froid, je gagne une grotte de pierre et me cache dedans. Lorsque les deux hommes s'en vont, je m'enfuis et retrouve la maison de mes parents $» . .$.

\section{"Rêve de Josette:}

Le sujet (une jeune fille) s'est perdu et s'assied sur un tronc d'arbre couché. Une femme vêtue d'une robe blanche lui apprend qu'elle est au milieu des brigands. Le récit continue ainsi : "Je suis écolière, répondis-je en tremblant, et lorsque je revenais de l'école, je me suis perdue ici. » Elle me dit: «Suis ce chemin, et vous arriverez chez vous »...

"Rêve de Razafi, garçon de treize à quatorze ans :

Il est poursuivi par des tirailleurs (sénégalais) qui en courant «font un bruit de cheval au galop», « ils montrent leurs fusils devant eux. " Le sujet échappe en devenant invisible. Il monte un escalier et trouve la porte de la maison... 
"Rêve d'Elphine, fille de treize à quatorze ans :

"Je rêve d'un bøuf noir 105 qui me poursuit avec force. Le bouf est vigoureux. Sa tête, presque tachetée de blanc (sic), porte ses deux longues cornes bien pointues. Ah! quel malheur! me dis-je. Le sentier se rétrécit, que puis-je faire? Je me penche sur un manguier. Hélas! je suis tombée par les buissons. Alors il [s']appuie les cornes contre moi. Mon intestin sort et il le mange... »...

\section{»Rêve de Raza :}

Dans son rêve, le sujet entend dire à l'école que les Sénégalais viennent. "Je suis sorti de la cour de l'école pour voir. » Les Sénégalais viennent, en effet. Il s'enfuit, prend le chemin de la maison. « Mais notre maison est aussi dispersée par eux... » ...

Rêve de Si, garçon de quatorze ans:

"Je me promenais dans le jardin, je sentais quelque chose qui forme une ombre derrière moi. Les feuilles choquaient tout autour de moi, en tombant comme (si) il y avait un brigand qui voulait me prendre. Quand je marchais dans toutes les allées, l'ombre me suivait encore. Alors la peur me prit et je me mettais en fuite, mais l'ombre faisait de grandes enjambées [qu'] il tendait sa grosse main pour me prendre [avec] (par) mes habits. Je sentais ma chemise déchirée et je criais. En entendant ce 
cri, mon père sursautait du lit et me regardait, mais le grand ombre disparaissait et je ne sentais plus ma grande peur ${ }^{106}$. »

Il y a de cela une dizaine d'années, nous fûmes étonné de constater que les Nord-Africains détestaient les hommes de couleur. Il nous était vraiment impossible d'entrer en contact avec les indigènes. Nous avons laissé l'Afrique à destination de la France, sans avoir compris la raison de cette animosité. Cependant, quelques faits nous avaient amené à réfléchir. Le Français n'aime pas le Juif qui n'aime pas l'Arabe, qui n'aime pas le nègre... À l'Arabe, on dit: « Si vous êtes pauvres, c'est parce que le Juif vous a roulés, vous a tout pris»; au Juif, on dit: "Vous n'êtes pas sur le même pied que les Arabes parce qu'en fait vous êtes blancs et que vous, avez Bergson et Einstein »; au nègre, on dit : « Vous êtes les meilleurs soldats de l'Empire français, les Arabes se croient supérieurs à vous, mais ils se trompent. " D'ailleurs, ce n'est pas vrai, on ne dit rien au nègre, on n'a, rien à lui dire, le tirailleur sénégalais est un tirailleur, le bon-tirailleur-à-son-capitaine, le brave qui ne-connaît-que-la-consigne.

- Toi pas passer.

- Pourquoi?

- Moi y en a pas savoir. Toi pas passer.

Le Blanc, incapable de faire face à toutes les revendications, se décharge des responsabilités. Moi j'appelle ce processus : la répartition raciale de la culpabilité.

[104]

Nous avons dit que quelques faits nous avaient surpris. Chaque fois qu'il y avait un mouvement insurrectionnel, l'autorité militaire ne met-

106 Mannoni, op. cit., ch. I (Les rêves, pp. 55 à 59). 
tait en ligne que des soldats de couleur. Ce sont des « peuples de couleur » qui réduisaient à néant les tentatives de libération d'autres «peuples de couleur», preuve qu'il n'y avait pas lieu d'universaliser le processus : si les Arabes, ces feignants, se mettaient en tête de révolter, ce n'était pas au nom de principes avouables, mais tout simplement dans le but de défouler leur inconscient de «bicots».

Au point de vue africain, disait un étudiant de couleur au vingtcinquième congrès des Etudiants catholiques, au cours du débat sur Madagascar, «je m'élève contre l'envoi de tirailleurs sénégalais et l'abus qu'on en fait là-bas. » Nous savons par ailleurs que l'un des tortionnaires du bureau de police de Tananarive était un Sénégalais. Aussi, sachant tout cela, sachant ce que peut être pour un Malgache l'archétype sénégalais, les découvertes de Freud ne nous sont d'aucune utilité. Il s'agit de replacer ce rêve en son temps, et ce temps c'est la période pendant laquelle quatre-vingt mille indigènes ont été tués, c'est-à-dire un habitant sur cinquante; et dans son lieu, et ce lieu c'est une île de quatre millions d'habitants, au sein de laquelle aucune véritable relation ne peut s'instaurer, où les dissensions éclatent de tous côtés, où le mensonge et la démagogie sont les seuls maîtres ${ }^{107}$. Faut-

107 Nous relevons ces dépositions faites au procès de Tananarive.

Audience du 9 août. Rakotovao déclare:

«M. Baron me dit: «Puisque tu n'as pas voulu accepter ce que je viens de dire, je vais te faire passer à la salle des réflexions (...) » Je passai dans la pièce attenante. La salle des réflexions en question était déjà remplie d'eau et, de plus, il y avait aussi un bidon rempli d'eau sale, pour ne pas dire plus. $\mathrm{M}$. Baron me dit : «Voilà le moyen qui t'apprendra à accepter ce que je viens de te dire de déclarer. » Un Sénégalais reçut de M. Baron l'ordre de me « faire passer comme les autres». Il me fit mettre à genoux, les poignets écartés, puis il prit une tenaille en bois et pressa mes deux mains, puis, à genoux et mes deux mains pressées, il a mis ses pieds sur ma nuque et m'a plongé la tête dans le bidon. Voyant que j'allais m'évanouir, il a relevé son pied pour me laisser reprendre de l'air. Et ceci s'est répété jusqu'à ce que je sois complètement exténué. Il a alors dit: «Emmenez-le et donnez-lui des coups. " Le Sénégalais s'est donc servi du nerf de bœuf, mais $M$. Baron est entré dans la salle de torture et il a participé personnellement à la flagellation. Cela a duré, je crois, quinze minutes, au bout desquelles j'ai déclaré que je ne pouvais plus supporter, car, 
malgré ma jeunesse c'était insupportable. Alors il a dit : « Il faut donc admettre ce que je viens de te dire! »

«Non, monsieur le directeur, ce n'est pas vrai. »

« À ce moment-là, il m'a fait passer dans la chambre de torture, a appelé un autre Sénégalais, puisqu'un seul ne suffisait pas, et il donné l'ordre de me pendre les pieds en l'air et de jeter mon corps dans le bidon jusqu'à la poitrine. Et ils recommencèrent ainsi plusieurs fois. À la fin j'ai dit : «C'est trop même! laissez-moi m'adresser à $M$. Baron», et j'ai dit à celui-ci : « Je demande au moins des traitements dignes de la France, monsieur le directeur», et il me répondit : «Voici les traitements de la France! »

«N'en pouvant plus je lui dis: «J'accepte donc la première partie de votre déclaration. » $M$. Baron me répondit «Non, je ne veux pas la première partie, mais tout. - Je mentirai donc? - Mensonge ou non mensonge il faut que tu acceptes ce que je te dis... »

La déposition continue:

«Immédiatement M. Baron dit : « Faites-lui subir un autre genre de torture. » À ce moment on m'amène dans la salle attenante, où il y avait un petit escalier en ciment. Mes deux bras liés derrière, les deux Sénégalais ont tiré en l'air mes deux pieds et me firent monter et descendre de telle façon le petit escalier. Cela commençait à devenir insupportable et, même si j'avais eu assez de force, c'était intenable. J'ai dit aux Sénégalais: «Dites donc à votre chef que j'accepte ce qu'il va me faire dire. »

Audience du 11 août. L'accusé Robert raconte :

«Le gendarme me prit par le col de ma veste et me donna des coups de pied par derrière et des coups de poing dans la figure. Puis il me fit mettre à genoux, et $M$. Baron recommença à me frapper.

«Sans savoir comment, il est passé par derrière moi et je sentis des pointes de feu appliquées à ma nuque. En essayant de me protéger par mes mains celles-ci ont eu aussi des brûlures...

« Une troisième fois à terre j'ai perdu connaissance et je ne me rappelle plus ce qui s'est passé. M. Baron m'a dit de signer un papier tout préparé ; d'un signe j'ai dit: «Non»; alors le directeur rappela le Sénégalais et ce dernier me conduisit en me soutenant dans une autre salle de torture : «Il faut accepter sans quoi tu seras mort, dit le Sénégalais. - Tant pis pour lui, il faut commencer l'opération, jean », disait le directeur. On m'a lié les deux bras derrière, on me fit mettre à genoux et on me plongea la tête dans un bidon plein d'eau. Juste au moment où j'allais être asphyxié on me retirait. Et on a ainsi recommencé plusieurs fois jusqu'à mon épuisement complet... »

Rappelons, afin que nul n'en ignore, que le témoin Rakotovao fut condamné à mort.

Alors, quand on lit de telles choses, il semble bien que M. Mannoni ait laissé échapper une dimension des phénomènes qu'il analyse : le taureau noir, les hommes noirs, ce ne sont ni plus ni moins que les Sénégalais du bureau de la Sûreté. 
il le dire, à certains [105] moments le socius est plus important que I'homme. Je pense à P. Naville écrivant : «Parler des rêves de la société comme des rêves de l'individu, des volontés de puissance collectives comme de l'instinct sexuel personnel, [106] c'est retourner encore une fois l'ordre naturel des choses, puisque, au contraire, ce sont les conditions économiques et sociales des luttes de classes qui expliquent et déterminent les conditions réelles dans lesquelles s'exprime la sexualité individuelle, et que le contenu des rêves d'un être humain dépend aussi, en fin de compte, des conditions générales de la civilisation dans laquelle il vit 108 . »

Le taureau noir furieux, ce n'est pas le phallus. Les deux hommes noirs, ce ne sont pas les deux pères - l'un représentant le père réel, l'autre l'ancêtre. Voici ce qu'une analyse poussée aurait pu donner, sur la base même des conclusions de M. Mannoni au paragraphe précédent, «Le culte des morts et la famille».

Le fusil du tirailleur sénégalais n'est pas un pénis, mais véritablement un fusil Lebel 1916. Le bøuf noir et le brigand, ce ne sont pas les lolos, «âmes substantielles», mais véritablement l'irruption, pendant le sommeil, de phantasmes réels. Que représente cette stéréotypie, ce thème central des rêves, sinon une remise dans le droit chemin? Tantôt ce sont des tirailleurs noirs, tantôt ce sont des taureaux noirs tachetés de blanc à la tête, tantôt c'est carrément une Blanche, fort gentille. Que retrouvons-nous dans tous ces rêves, sinon cette idée centrale: "S'écarter de la routine, c'est se promener dans les bois : on y rencontre le taureau qui vous ramène dare-dare à la maison ${ }^{109}$. »

Malgaches, restez tranquilles, demeurez à votre place.

Après avoir décrit la psychologie malgache, M. Mannoni se propose d'expliquer la raison d'être du colonialisme. Ce faisant, il ajoute un nouveau complexe à la liste pré-existante: le «complexe de Prospéro», - défini comme l'ensemble des dispositions névrotiques inconscientes

108 Pierre Naville, Psychologie, Marxisme, Matérialisme, $2^{e}$ édit., Marcel Rivière et $C^{\text {ie }}$, éd., p. 151.

109 Mannoni, op. cit., p. 71. 
qui dessinent tout à la fois « la figure du paternalisme colonial » et « le portrait du raciste dont la fille a été l'objet d'une tentative de viol (imaginaire) de la part d'un être inférieur $110 »$.

[107]

Prospéro est, comme on le voit, le personnage principal de la pièce de Shakespeare, La Tempête. En face, se trouvent Miranda, sa fille, et Caliban. Vis-à-vis de Caliban, Prospéro adopte une attitude que les Américains du Sud connaissent bien. Ne disent-ils pas que les nègres attendent l'occasion de se jeter sur les femmes blanches? Ce qu'il y a d'intéressant, en tout cas, dans cette partie de l'ouvrage, c'est l'intensité avec laquelle $M$. Mannoni nous fait saisir les conflits mal liquidés qui semblent être à la base de la vocation coloniale. En effet, nous dit-il, « ce qui manque au colonial comme à Prospéro, ce dont il est déchu, c'est le monde des Autres, où les autres se font respecter. Ce monde, le colonial-type l'a quitté, chassé par la difficulté d'admettre les hommes tels qu'ils sont. Cette fuite est liée à un besoin de domination d'origine infantile, que l'adaptation au social n'a pas réussi à discipliner. Peu importe que le colonial ait cédé au « seul souci de voyager», au désir de fuir «l'horreur de son berceau» ou les « anciens parapets», ou qu'il désire, plus grossièrement, une «vie plus large »... Il s'agit toujours d'un compromis avec la tentation d'un monde sans hommes $111 »$.

Si l'on ajoute que beaucoup d'Européens vont aux colonies parce que là-bas il leur devient possible de s'enrichir en peu de temps, que, sauf de rares exceptions, le colonialiste est un commerçant ou plutôt un trafiquant, on aura saisi la psychologie de l'homme qui provoque chez l'autochtone «le sentiment d'infériorité». Quant au «complexe de dépendance » malgache, du moins sous la seule forme où il nous soit accessible et analysable, il procède, lui aussi, de l'arrivée dans liîle des

110 Ibid., p. 108.

111 Mannoni, op. cit., p. 106. 
colonisateurs blancs. De son autre forme, de ce complexe originel, à l'état pur, qui aurait caractérisé la mentalité malgache durant toute la période antérieure, M. Mannoni ne nous paraît nullement fondé à tirer la moindre conclusion concernant la situation, les problèmes ou les possibilités des autochtones dans la période actuelle. 
[108]

PEAU NOIRE. MASQUES BLANCS.

\section{Chapitre V}

\section{L'EXPÉRIENCE VÉCUE DU NOIR}

\section{Retour à la table des matières}

«Sale nègre! » ou simplement : « Tiens, un nègre! » J'arrivais dans le monde, soucieux de faire lever un sens aux choses, mon âme pleine du désir d'être à l'origine du monde, et voici que je me découvrais objet au milieu d'autres objets.

Enfermé dans cette objectivité écrasante, j'implorai autrui. Son regard libérateur, glissant sur mon corps devenu soudain nul d'aspérités, me rend une légèreté que je croyais perdue et, mabsentant du monde, me rend au monde. Mais là-bas, juste à contrepente, je bute, et l'autre, par gestes, attitudes, regards, me fixe, dans le sens où l'on fixe une préparation par un colorant. Je m'emportai, exigeai une explication... Rien n'y fit. J'explosai. Voici les menus morceaux par un autre moi réunis.

Tant que le Noir sera chez lui, il n'aura pas, sauf à l'occasion de petites luttes intestines, à éprouver son être pour autrui. Il y a bien le moment de «l'être pour l'autre», dont parle Hegel, mais toute ontologie est rendue irréalisable dans une société colonisée et civilisée. Il 
semble que cela n'ait pas suffisamment retenu l'attention de ceux qui ont écrit sur la question. Il y a, dans la Weltanschauung d'un peuple colonisé, une impureté, une tare qui interdit toute explication ontologique. Peut-être nous objectera-t-on qu'il en est ainsi de tout individu, mais c'est se masquer un problème fondamental. L'ontologie, quand on a admis une fois pour toutes qu'elle laisse de côté l'existence, ne nous permet pas de comprendre l'être du Noir. Car le Noir n'a plus à être noir, mais à l'être en face du Blanc. Certains se mettront en tête de nous rappeler que la situation est à double sens. Nous [109] répondons que c'est faux. Le Noir n'a pas de résistance ontologique aux yeux du Blanc. Les nègres, du jour au lendemain, ont eu deux systèmes de référence par rapport auxquels il leur a fallu se situer. Leur métaphysique, ou moins prétentieusement leurs coutumes et les instances auxquelles elles renvoyaient, étaient abolies parce qu'elles se trouvaient en contradiction avec une civilisation qu'ils ignoraient et qui leur en imposait.

Le Noir chez lui, au XXe siècle, ignore le moment où son infériorité passe par l'autre... Sans nul doute, il nous est arrivé de discuter du problème noir avec des amis, ou plus rarement avec des Noirs américains. Ensemble nous protestions et affirmions l'égalité des hommes devant le monde. Il y avait aussi aux Antilles ce petit hiatus qui existe entre la békaille, la mulâtraille et la négraille. Mais nous nous contentions d'une compréhension intellectuelle de ces divergences. En fait, ça n'était pas dramatique. Et puis...

Et puis il nous fut donné d'affronter le regard blanc. Une lourdeur inaccoutumée nous oppressa. Le véritable monde nous disputait notre part. Dans le monde blanc, l'homme de couleur rencontre des difficultés dans l'élaboration de son schéma corporel. La connaissance du corps est une activité uniquement négatrice. C'est une connaissance en troisième personne. Tout autour du corps règne une atmosphère d'incertitude certaine. Je sais que si je veux fumer, il me faudra étendre le bras droit et saisir le paquet de cigarettes qui se trouve à l'autre bout de la table. Les allumettes, elles, sont dans le tiroir de gauche, il faudra que je me recule légèrement. Et tous ces gestes, je 
les fais non par habitude, mais par une connaissance implicite. Lente construction de mon moi en tant que corps au sein d'un monde spatial et temporel, tel semble être le schéma. Il ne s'impose pas à moi, c'est plutôt une structuration définitive du moi et du monde - définitive, car il s'installe entre mon corps et le monde une dialectique effective.

Depuis quelques années, des laboratoires ont projeté de découvrir un sérum de dénégrification; des laboratoires, le plus sérieusement du monde, ont rincé leurs éprouvettes, réglé leurs balances et entamé des recherches [110] qui permettront aux malheureux nègres de se blanchir, et ainsi de ne plus supporter le poids de cette malédiction corporelle. J'avais créé au-dessous du schéma corporel un schéma historicoracial. Les éléments que j'avais utilisés ne mavaient pas été fournis par « des résidus de sensations et perceptions d'ordre surtout tactile, vestibulaire, cinesthésique et visuel $112 »$, mais par l'autre, le Blanc, qui mavait tissé de mille détails, anecdotes, récits. Je croyais avoir à construire un moi physiologique, à équilibrer l'espace, à localiser des sensations, et voici que l'on me réclamait un supplément.

«Tiens, un nègre! » C'était un stimulus extérieur qui me chiquenaudait en passant. J'esquissai un sourire.

«Tiens, un nègre! » C'était vrai. Je m'amusai.

« Tiens, un nègre! » Le cercle peu à peu se resserrait. Je m'amusai ouvertement.

« Maman, regarde le nègre, j'ai peur!» Peur! Peur! Voilà qu'on se mettait à me craindre. Je voulus mamuser jusqu'à m'étouffer, mais cela m'était devenu impossible.

Je ne pouvais plus, car je savais déjà qu'existaient des légendes, des histoires, l'histoire, et surtout l'historicité, que m'avait enseignée

112 Jean Lhermitte, L'Image de notre corps, Ed. de la Nouvelle Revue critique, p. 17. 
Jaspers. Alors le schéma corporel, attaqué en plusieurs points, s'écroula, cédant la place à un schéma épidermique racial. Dans le train, il ne s'agissait plus d'une connaissance de mon corps en troisième personne, mais en triple personne. Dans le train, au lieu d'une, on me laissait deux, trois places. Déjà je ne m'amusais plus. Je ne découvrais point de coordonnées fébriles du monde. J'existais en triple: j'occupais de la place. J'allais à l'autre... et l'autre évanescent, hostile mais non opaque, transparent, absent, disparaissait. La nausée...

J'étais tout à la fois responsable de mon corps, responsable de ma race, de mes ancêtres. Je promenai sur moi un regard objectif, découvris ma noirceur, mes caractères ethniques, - et me défoncèrent le tympan l'anthropophagie, l'arriération mentale, le fétichisme, les tares raciales, les négriers, et surtout, et surtout : «Y a bon banania. »

[111]

Ce jour-là, désorienté, incapable d'être dehors avec l'autre, le Blanc, qui, impitoyable, m'emprisonnait, je me portai loin de mon êtrelà, très loin, me constituant objet. Qu'était-ce pour moi, sinon un décollement, un arrachement, une hémorragie qui caillait du sang noir sur tout mon corps? Pourtant, je ne voulais pas cette reconsidération, cette thématisation. Je voulais tout simplement être un homme parmi d'autres hommes. J'aurais voulu arriver lisse et jeune dans un monde nôtre et ensemble édifier.

Mais je refusai toute tétanisation affective. Je voulais être homme, rien qu'homme. D'aucuns me reliaient aux ancêtres miens, esclavagisés, lynchés: je décidai d'assumer. C'est à travers le plan universel de l'intellect que je comprenais cette parenté interne, - j'étais petitfils d'esclaves au même titre que le président Lebrun l'était de paysans corvéables et taillables. Au fond, l'alerte se dissipait assez rapidement.

En Amérique, des nègres sont mis à part. En Amérique du Sud, on fouette dans les rues et l'on mitraille les grévistes nègres. En Afrique occidentale, le nègre est une bête. Et là, tout près de moi, juste à côté, ce camarade de Faculté, originaire d'Algérie, qui me dit: «Tant 
qu'on fera de l'Arabe un homme comme nous, aucune solution ne sera viable. »

- Vois-tu, mon cher, le préjugé de couleur, je ne connais pas cela... Mais comment donc, entrez, monsieur, chez nous le préjugé de couleur n'existe pas... Parfaitement, le nègre est un homme comme nous... Ce n'est pas parce qu'il est noir qu'il est moins intelligent que nous... J'ai eu un camarade sénégalais au régiment, il était très fin...

Où me situer? Ou, si vous préférez : où me fourrer?

- Martiniquais, originaire de « nos » vieilles colonies.

Où me cacher?

- Regarde le nègre !... Maman, un nègre !... Chut! Il va se fâcher... Ne faites pas attention, monsieur, il ne sait pas que vous êtes aussi civilisé que nous...

Mon corps me revenait étalé, disjoint, rétamé, tout endeuillé dans ce jour blanc d'hiver. Le nègre est une bête, le nègre est mauvais, le nègre est méchant, le nègre [112] est laid: tiens, un nègre, il fait froid, le nègre tremble, le nègre tremble parce qu'il a froid, le petit garçon tremble parce qu'il a peur du nègre, le nègre tremble de froid, ce froid qui vous tord les os, le beau petit garçon tremble parce qu'il croit que le nègre tremble de rage, le petit garçon blanc se jette dans les bras de sa mère: maman, le nègre va me manger.

Alentour le Blanc, en haut le ciel s'arrache le nombril, la terre crisse sous mes pieds et un chant blanc, blanc. Toute cette blancheur qui me calcine...

Je massieds au coin du feu, et je découvre ma livrée. Je ne l'avais pas vue. Elle est effectivement laide. Je marrête, car qui me dira ce qu'est la beauté?

Où me fourrer désormais? Je sentais monter des innombrables dispersions de mon être un afflux aisément reconnaissable. J'allais me 
mettre en colère. Depuis longtemps le feu était mort, et de nouveau le nègre tremblait.

- Regarde, il est beau, ce nègre...

- Le beau nègre vous emmerde, madame!

La honte lui orna le visage. Enfin j'étais libéré de ma rumination. Du même coup, je réalisais deux choses: j'identifiais mes ennemis et je créais du scandale. Comblé. On allait pouvoir s'amuser.

Le champ de bataille délimité, j'entrai en lice.

Comment? Alors que j'oubliais, pardonnais et ne désirais qu'aimer, on me renvoyait comme une gifle, en plein visage, mon message. Le monde blanc, seul honnête, me refusait toute participation. D'un homme on exigeait une conduite d'homme. De moi, une conduite d'homme noir - ou du moins une conduite de nègre. Je hélais le monde et le monde mamputait de mon enthousiasme. On me demandait de me confiner, de me rétrécir.

Ils allaient voir! Je les avais pourtant mis en garde. L'esclavage? On n'en parlait plus, un mauvais souvenir. Ma prétendue infériorité ? Une galéjade dont il valait mieux rire. J'oubliais tout, mais à condition que le monde ne me dérobât plus son flanc. J'avais à essayer mes incisives. Je les sentais robustes. Et puis...

Comment? Alors que moi j'avais toutes les raisons de hair, détester, on me rejetait? Alors que j'aurais dû être supplié, sollicité, on me refusait toute reconnaissance? [113] Je décidai, puisqu'il m'était impossible de partir d'un complexe inné, de m'affirmer en tant que NOIR. Puisque l'autre hésitait à me reconnaître, il ne restait qu'une solution: me faire connaître.

Jean-Paul Sartre, dans Réflexions sur la question juive, écrit : «Ils (les Juifs) se sont laissé empoisonner par une certaine représentation que les autres ont d'eux et ils vivent dans la crainte que leurs actes ne 
s'y conforment, ainsi pourrions-nous dire que leurs conduites sont perpétuellement sur-déterminées de l'intérieur » (p. 123).

Toutefois, le Juif peut être ignoré dans sa juiverie. Il n'est pas intégralement ce qu'il est. On espère, on attend. Ses actes, son comportement décident en dernier ressort. C'est un Blanc, et, hormis quelques traits assez discutables, il lui arrive de passer inaperçu. Il appartient à la race de ceux qui de tout temps ont ignoré l'anthropophagie. Quelle idée aussi de dévorer son père! C'est bien fait, on n'a qu'à ne pas être nègre. Bien entendu, les Juifs sont brimés, que dis-je, ils sont pourchassés, exterminés, enfournés, mais ce sont là petites histoires familiales. Le Juif n'est pas aimé à partir du moment où il est dépisté. Mais avec moi tout prend un visage nouveau. Aucune chance ne m'est permise. Je suis sur-déterminé de l'extérieur. Je ne suis pas l'esclave de "l'idée » que les autres ont de moi, mais de mon apparaître.

J'arrive lentement dans le monde, habitué à ne plus prétendre au surgissement. Je machemine par reptation. Déjà les regards blancs, les seuls vrais, me dissèquent. Je suis fixé. Ayant accommodé leur microtome, ils réalisent objectivement des coupes de ma réalité. Je suis trahi. Je sens, je vois dans ces regards blancs que ce n'est pas un nouvel homme qui entre, mais un nouveau type d'homme, un nouveau genre. Un nègre, quoi!

Je me glisse dans les coins, rencontrant de mes longues antennes les axiomes épars à la surface des choses, - le linge du nègre sent le nègre - les dents du nègre sont blanches - les pieds du nègre sont grands - la large poitrine du nègre, - je me glisse dans les coins, je demeure silencieux, j'aspire à l'anonymat, à l'oubli. Tenez, j'accepte tout, mais que l'on ne m'aperçoive plus!

- Tiens, viens que je te présente à mon camarade [114] noir... Aimé Césaire, homme noir, agrégé de l'Université... Marian Anderson, la plus grande chanteuse noire... Le $D^{r}$ Cobb, l'inventeur du sang blanc, est un nègre... Tiens, dis bonjour à mon ami Martiniquais (fais attention, il est très susceptible)... 
La honte. La honte et le mépris de moi-même. La nausée. Quand on maime, on me dit que c'est malgré ma couleur. Quand on me déteste, on ajoute que ce n'est pas à cause de ma couleur... Ici ou là, je suis prisonnier du cercle infernal.

Je me détourne de ces scrutateurs de l'avant-déluge et je magrippe à mes frères, nègres comme moi. Horreur, ils me rejettent. Eux sont presque blancs. Et puis ils vont épouser une Blanche. Ils auront des enfants légèrement bruns... Qui sait, petit à petit, peutêtre...

J'avais rêvé.

- Voyez-vous, monsieur, je suis l'un des plus négrophiles de Lyon.

L'évidence était là, implacable. Ma noirceur était là, dense et indiscutable. Et elle me tourmentait, elle me pourchassait, m'inquiétait, m'exaspérait.

Les nègres sont des sauvages, des abrutis, des analphabètes. Mais moi, je savais que dans mon cas ces propositions étaient fausses. Il y avait un mythe du nègre qu'il fallait démolir coûte que coûte. On n'était plus au temps où l'on s'émerveillait devant un nègre curé. Nous avions des médecins, des professeurs, des hommes d'État... Oui, mais dans ces cas persistait quelque chose d'insolite. "Nous avons un professeur d'histoire sénégalais. Il est très intelligent... Notre médecin est un Noir. Il est très doux. »

C'était le professeur nègre, le médecin nègre: moi qui commençais à me fragiliser, je frémissais à la moindre alarme. Je savais, par exemple, que si le médecin commettait une erreur, c'en était fini de lui et de tous ceux qui le suivraient. Qu'attendre, en effet, d'un médecin nègre? Tant que tout allait bien, on le portait aux nues, mais gare, pas de bêtises, à aucun prix! Le médecin noir ne saura jamais à quel point sa position avoisine le discrédit. Je vous le dis, j'étais emmuré : ni mes 
attitudes policées, ni mes connaissances littéraires, ni ma compréhension de la théorie des quanta ne trouvaient grâce.

[115]

Je réclamai, j'exigeai des explications. Doucement, comme on parle à un enfant, on me révéla l'existence d'une certaine opinion qu'adoptaient certaines personnes, mais, ajoutait-on, « il fallait en espérer la rapide disparition ». Qu'était-ce? Le préjugé de couleur.

«Le préjugé de couleur n'est rien d'autre qu'une haine irraisonnée d'une race pour une autre, le mépris des peuples forts et riches pour ceux qu'ils considèrent comme inférieurs à euxmêmes, puis l'amer ressentiment de ceux contraints à la sujétion et auxquels il est souvent fait injure. Comme la couleur est le signe extérieur le mieux visible de la race, elle est devenue le critère sous l'angle duquel on juge les hommes sans tenir compte de leurs acquis éducatifs et sociaux. Les races à peau claire en sont venues à mépriser les races à peau sombre, et celles-ci se refusent à consentir plus longtemps à la condition effacée quion entend leur imposer 113 . »

J'avais bien lu. C'était de la haine: j'étais haï, détesté, méprisé, non pas par le voisin d'en face ou le cousin maternel, mais par toute une race. J'étais en butte à quelque chose d'irraisonné. Les psychanalystes disent que pour le jeune enfant il n'y a rien de plus traumatisant que le contact du rationnel. Je dirai personnellement que, pour un homme qui n'a comme arme que la raison, il n'y a rien de plus névrotique que le contact de l'irrationnel.

Je sentis naître en moi des lames de couteau. Je pris la décision de me défendre. En bon tacticien, je voulus rationaliser le monde, montrer au Blanc qu'il était dans l'erreur.

113 Sir Alan Burns, Le préjugé de race et de couleur, Payot, p. 14. 
Chez le Juif, dit Jean-Paul Sartre, il y a « une sorte d'impérialisme passionné de la raison : car il ne veut pas seulement convaincre qu'il est dans le vrai, son but est de persuader ses interlocuteurs qu'il y a une valeur absolue et inconditionnée du rationalisme. Il se considère comme un missionnaire de l'universel; en face de l'universalité de la religion catholique, dont il est exclu, il veut établir la «catholicité » du rationnel, instrument pour atteindre le vrai et lien spirituel entre les hommes $114 »$.

[116]

Et, ajoute l'auteur, s'il s'est trouvé des Juifs pour faire de l'intuition la catégorie fondamentale de leur philosophie, leur intuition « ne ressemble en rien à l'esprit de finesse pascalien : et c'est cet esprit de finesse, incontestable et mouvant, fondé sur mille perceptions imperceptibles, qui paraît au Juif son pire ennemi. Quant à Bergson, sa philosophie offre l'aspect curieux d'une doctrine anti-intellectualiste entièrement bâtie par l'intelligence la plus raisonneuse et la plus critique. C'est en argumentant qu'il établit l'existence d'une durée pure, d'une intuition philosophique; et cette intuition même qui découvre la durée ou la vie, elle est universelle en ce que chacun peut la pratiquer et elle porte sur l'universel puisque ses objets peuvent être nommés et conçus $115 »$.

Avec ardeur, je me mis à inventorier, à sonder l'entourage. Au gré des temps, on avait vu la religion catholique justifier puis condamner l'esclavage et les discriminations. Mais en ramenant le tout à la notion de dignité humaine, on éventrait le préjugé. Les scientifiques, après beaucoup de réticences, avaient admis que le nègre était un être humain: in vivo et in vitro le nègre s'était révélé analogue au Blanc; même morphologie, même histologie. La raison s'assurait la victoire sur tous les plans. Je réintégrai les assemblées. Mais je dus déchanter.

\footnotetext{
114 Réflexions sur la question juive, pp. 146-147.

115 Sartre, Réflexions sur la question juive, pp. 149-150.
} 
La victoire jouait au chat et à la souris; elle me narguait. Comme disait l'autre, quand je suis là, elle n'y est pas, quand elle est là je n'y suis plus. Sur le plan de l'idée, on était d'accord: le nègre est un être humain. C'est-à-dire, ajoutaient les moins convaincus, qu'il a comme nous le cour à gauche. Mais le Blanc, sur certaines questions, demeurait intraitable. A aucun prix, il ne voulait d'intimité entre les races, car, on le sait, « les croisements entre races différentes abaissent le niveau physique et mental... Jusqu'à ce que nous ayons une connaissance mieux fondée des effets du croisements des races, nous ferions mieux d'éviter les croisements entre races très éloignées 116 ».

Quant à moi, je saurais bien comment réagir. Et en un [117] sens, si j'avais à me définir, je dirais que j'attends: j'interroge les alentours, j'interprète tout à partir de mes découvertes, je suis devenu sensitif.

Au début de l'histoire que les autres m'ont faite, on avait placé bien en évidence le socle de l'anthropophagie, pour que je m'en souvienne. On décrivait sur mes chromosomes quelques gènes plus ou moins épais représentant le cannibalisme. À côté des sex linked, on découvrait des racial linked. Une honte, cette science!

Mais je comprends ce «mécanisme psychologique». Car, tout le monde le sait, il n'est que psychologique, ce mécanisme. Il y a deux siècles, j'étais perdu pour l'humanité, esclave à jamais. Et puis des hommes sont venus, déclarant que tout cela n'avait que trop duré. Ma ténacité a fait le reste: j'étais sauvé du déluge civilisateur. Je me suis avancé...

Trop tard. Tout est prévu, trouvé, prouvé, exploité. Mes mains nerveuses ne ramènent rien; le gisement est épuisé. Trop tard! Mais là aussi je veux comprendre.

Depuis le temps que certain se plaignit de venir trop tard et que tout était dit, il semble exister une nostalgie du passé. Serait-ce ce paradis perdu des origines, dont parle Otto Rank? Combien de ceux-là, fixés, semble-t-il, à l'utérus du monde, ont consacré leur vie à

116 J.-A. Mocin, II ${ }^{e}$ Congrès international d'eugénisme, cité par sir Alan Burns. 
l'intellection des Oracles de Delphes ou se sont efforcés de retrouver le périple d'Ulysse! Les pan-spiritualistes, voulant prouver l'existence d'une âme chez les animaux, emploient l'argument suivant : un chien se couche sur la tombe de son maître et y meurt de faim. Il revient à Janet d'avoir montré que le dit chien, contrairement à l'homme, n'était tout simplement pas capable de liquider le passé. On parle de grandeur grecque, dit Artaud: mais, ajoute-t-il, si le peuple d'aujourd'hui ne comprend plus les Choéphores d'Eschyle, c'est Eschyle qui a tort. C'est au nom de la tradition que les antisémites valorisent leur «point de vue ». C'est au nom de la tradition, de ce long passé d'histoire, de cette parenté sanguine avec Pascal et Descartes, qu'on dit aux Juifs: vous ne sauriez trouver place dans la communauté. Dernièrement, un de ces bons Français déclarait, dans un train où j'avais pris place:

«Que les vertus vraiment françaises subsistent, et la [118] race est sauvée! À l'heure actuelle, il faut réaliser l'Union nationale. Plus de luttes intestines! Face aux étrangers (et, se tournant vers mon coin :) quels qu'ils soient. »

Il faut dire à sa décharge qu'il puait le gros rouge: s'il l'avait pu, il maurait dit que mon sang d'esclave libéré n'était pas capable de s'affoler au nom de Villon ou de Taine.

Une honte!

Le Juif et moi : non content de me racialiser, par un coup heureux du sort, je m'humanisais. Je rejoignais le Juif, frères de malheur.

Une honte!

De prime abord, il peut sembler étonnant que l'attitude de l'antisémite s'apparente à celle du négrophobe. C'est mon professeur de philosophie, d'origine antillaise, qui me le rappelait un jour : «Quand vous entendez dire du mal des Juifs, dressez l'oreille, on parle de vous. » Et je pensais qu'il avait raison universellement, entendant parlà que j'étais responsable, dans mon corps et dans mon âme, du sort réservé à mon frère. Depuis lors, j'ai compris qu'il voulait tout simplement dire: un antisémite est forcément négrophobe. 
Vous arrivez trop tard, beaucoup trop tard. Il y aura toujours un monde - blanc - entre vous et nous... Cette impossibilité pour l'autre de liquider une fois pour toutes le passé. On comprend que, devant cette ankylose affective du Blanc, j'aie pu décider de pousser mon cri nègre. Petit à petit, lançant çà et là des pseudopodes, je sécrétai une race. Et cette race tituba sous le poids d'un élément fondamental. Quel est-il ? Le rythme! Écoutez Senghor, notre chantre:

"C'est la chose la plus sensible et la moins matérielle. C'est l'élément vital par excellence. Il est la condition première et le signe de l'Art, comme la respiration de la vie; la respiration qui se précipite ou ralentit, devient régulière ou spasmodique suivant la tension de l'être, le degré et la qualité de l'émotion. Tel est le rythme primitivement dans sa pureté, tel il est dans les chefs-d'œuvre de l'Art nègre, particulièrement de la sculpture. Il est fait d'un thème - forme sculpturale - qui s'oppose à un thème frère comme l'inspiration à l'expiration, et qui se reprend. [118] Ce n'est pas la symétrie qui engendre la monotonie: le rythme est vivant, il est libre... C'est ainsi que le rythme agit sur ce qu'il y a de moins intellectuel en nous, despotiquement, pour nous faire pénétrer dans la spiritualité de l'objet; et cette attitude d'abandon qui est nôtre est elle-même rythmique ${ }^{117}$. »

Avais-je bien lu? Je relus à coups redoublés. De l'autre côté du monde blanc, une féerique culture nègre me saluait. Sculpture nègre! Je commençai à rougir d'orgueil. Etait-ce là le salut?

J'avais rationalisé le monde et le monde m'avait rejeté au nom du préjugé de couleur. Puisque, sur le plan de la raison, l'accord n'était pas possible, je me rejetais vers l'irrationalité. À charge au Blanc d'être plus irrationnel que moi. J'avais, pour les besoins de la cause, adopté le processus régressif, mais il restait que c'était une arme étrangère ; ici

117 « Ce que l'homme noir apporte», L'Homme de couleur, pp. 309-310. 
je suis chez moi: je suis bâti d'irrationnel: je patauge dans l'irrationnel. Irrationnel jusqu'au cou. Et maintenant, vibre ma voix!

«Ceux qui n'ont inventé ni la poudre ni la boussole Ceux qui n'ont jamais su dompter la vapeur ni l'électricité Ceux qui n'ont exploré ni les mers ni le ciel mais ils savent en ses moindres recoins le pays de souffrance Ceux qui n'ont connu de voyages que de déracinements Ceux qui se sont assouplis aux agenouillements Ceux qu'on domestiqua et christianisa Ceux qu'on inocula d'abâtardissement... »

Oui, tous ceux-là sont mes frères - une "fraternité âpre » nous agrippe pareillement. - Après avoir affirmé la thèse mineure, pardessus bord je hèle autre chose.

«... Mais ceux sans qui la terre ne serait pas la terre Gibbosité d'autant plus bienfaisante

que

[120]

la terre déserte davantage la terre

Silo où se préserve et mûrit ce que la terre a de plus terre

Ma négritude n'est pas une pierre, sa surdité ruée contre la clameur du jour

Ma négritude n'est pas une taie d'eau morte sur l'œil mort de la terre

Ma négritude n'est ni une tour ni une cathédrale Elle plonge dans la chair rouge du sol Elle plonge dans la chair ardente du ciel 
Elle troue l'accablement opaque de sa droite patience ${ }^{118}$. »

Eia! le tam-tam baragouine le message cosmique. Seul le nègre est capable de le transmettre, d'en déchiffrer le sens, la portée. A cheval sur le monde, les talons vigoureux contre les flancs du monde, je lustre l'encolure du monde, tel le sacrificateur l'entre-deux yeux de la victime.

« Mais ils s'abandonnent, saisis, à l'essence de toute chose, ignorants des surfaces mais saisis par le mouvement de toute chose

insoucieux de dompter mais jouant le jeu du monde véritablement les fils aînés du monde

poreux à tous les souffles du monde

aire fraternelle de tous les souffles du monde

lit sans drain de toutes les eaux du monde

étincelle du feu sacré du Monde

chair de la chair du monde palpitant du mouvement même du monde 119 ! »

Sang! Sang !... Naissance! Vertige du devenir! Aux trois quarts abîmé dans l'ahurissement du jour, je me sentis rougir de sang. Les artères du monde, bouleversées, arrachées, déracinées, se sont tournées vers moi et elles m'ont fécondé.

[121]

«Sang! Sang! Tout notre sang ému par le cœur mâle du soleil 120 . »

118 A. Césaire, Cahier d'un retour au pays natal, pp. 77-78.

119 Ibid., p. 78.

120 A. Césaire, op. cit., p. 79. 
Le sacrifice avait servi de moyen terme entre la création et moi je retrouvais non plus les origines, mais l'Origine. Toutefois, il fallait se méfier du rythme, de l'amitié Terre-Mère, ce mariage mystique, charnel, du groupe et du cosmos.

Dans La Vie sexuelle en Afrique noire, travail riche en observations, De Pédrals laisse entendre qu'il y a toujours en Afrique, quel que soit le domaine considéré, une certaine structure magico-sociale. Et, ajoute-t-il, « tous ces éléments sont ceux que l'on retrouve à une échelle plus vaste encore en matière de sociétés secrètes. Dans la mesure, d'ailleurs, où les circoncis, les excisées, opérés à l'adolescence, ne doivent, sous peine de mort, divulguer aux non-initiés ce qu'ils ont subi, et dans la mesure où l'initiation à une société secrète fait toujours appel à des actes d'amour sacré, il y a lieu de terminer en considérant la circoncision, l'excision et les rites qu'ils illustrent comme constitutifs de sociétés secrètes mineures $121 »$.

Je marche sur des chardons blancs. Des nappes d'eau menacent mon âme de feu. Face à ces rites, je redouble d'attention. Magie noire! Orgies, sabbat, cérémonies paiennes, gris-gris. Le coït est l'occasion d'invoquer les dieux de la fratrie. C'est un acte sacré, pur, absolu, favorisant l'intervention de forces invisibles. Que penser de toutes ces manifestations, de toutes ces initiations, de toutes ces opérations? De partout me revient l'obscénité de danses, de propositions. Tout près de moi retentit un chant :

« Avant nos cœurs étaient très chauds

Maintenant ils sont froids

Nous ne songeons plus qu'à l'Amour

De retour au village

Quand nous rencontrerons un gros phallus

121 De Pédrals, La vie sexuelle en Afrique noire, Payot, p. 83. 
[121]

Ah! que nous ferons bien l'Amour

Car notre sexe sera sec et propre ${ }^{122}$. »

Le sol, tout à l'heure encore coursier maîtrisé, se met à rigoler. Sont-ces des vierges, ces nymphomanes? Magie Noire, mentalité primitive, animisme, érotisme animal, tout cela reflue vers moi. Tout cela caractérise des peuples n'ayant pas suivi l'évolution de l'humanité. Il s'agit là, si l'on préfère, d'humanité au rabais. Parvenu à ce point, j'hésitai longtemps avant de m'engager. Les étoiles se firent agressives. Il me fallait choisir. Que dis-je, je n'avais pas le choix...

Oui, nous sommes (les nègres) arriérés, simples, libres dans nos manifestations. C'est que le corps pour nous n'est pas opposé à ce que vous appelez l'esprit. Nous sommes dans le monde. Et vive le couple Homme-Terre! D'ailleurs, nos hommes de lettres maidaient à vous convaincre: votre civilisation blanche néglige les richesses fines, la sensibilité. Écoutez:

"Sensibilité émotive. L'émotion est nègre comme la raison hellène ${ }^{123}$. Eau que rident tous les souffles? Ame de plein air battue des vents et d'où le fruit souvent tombe avant maturité? Oui, en un sens, le nègre aujourd'hui est plus riche de dons que d'ceuvres ${ }^{124}$. Mais l'arbre plonge ses racines dans la terre. Le fleuve coule profond, charriant des paillettes précieuses. Et, chante le poète afroaméricain Langston Hugues:

« J'ai connu des fleuves, d'antiques de sombres fleuves mon âme est devenue profonde comme les fleuves profonds. »

122 Versiat, Les rites secrets de l'Oubangui, p. 113.

123

Souligné par nous.

124 Souligné par nous. 
»La nature même de l'émotion, de la sensibilité du nègre, d'autre part, explique l'attitude de celui-ci devant l'objet perçu avec une telle violence essentielle. C'est un abandon qui devient besoin, attitude active de communion, [123] voire d'identification, pour peu que soit forte l'action, j'allais dire la personnalité de l'objet. Attitude rythmique, que l'on retienne le mot 125 . »

Et voici le nègre réhabilité, « debout à la barre», gouvernant le monde de son intuition, le nègre retrouvé, ramassé, revendiqué, assumé, et c'est un nègre, non pas, ce n'est point un nègre, mais le nègre, alertant les antennes fécondes du monde, planté dans l'avant-scène du monde, aspergeant le monde de sa puissance poétique, " poreux à tous les souffles du monde». J'épouse le monde! Je suis le monde! Le Blanc n'a jamais compris cette substitution magique. Le Blanc veut le monde; il le veut pour lui tout seul. Il se découvre le maître prédestiné de ce monde. Il l'asservit. Il s'établit entre le monde et lui un rapport appropriatif. Mais il existe des valeurs qui ne s'accommodent qu'à ma sauce. En magicien, je vole au Blanc « un certain monde», pour lui et les siens perdu. Ce jour-là, le Blanc dut ressentir un choc en retour qu'il ne put identifier, étant tellement peu habitué à ces réactions. C'est que, au-dessus du monde objectif des terres et des bananiers ou hévéas, j'avais délicatement institué le véritable monde. L'essence du monde était mon bien. Entre le monde et moi s'établissait un rapport de co-existence. J'avais retrouvé l'Un primordial. Mes «mains sonores» dévoraient la gorge hystérique du monde. Le Blanc eut l'impression pénible que je lui échappais, et que j'emmenais quelque chose avec moi. Il me fouilla les poches. Passa la sonde dans la moins dessinée de mes circonvolutions. Partout, c'était du connu. Or, c'était évident, je possédais un secret. On m'interrogea; me détournant d'un air mystérieux, je murmurai :

125 Senghor, Ce que l'homme noir apporte, p. 295. 
« Tokowaly, mon oncle, te souviens-tu des nuits de jadis

Quand s'appesantissait ma tête sur ton dos de patience ou que

Me tenant par la main ta main me guidait par ténèbres et signes

[124]

Les champs sont fleurs de vers luisants, des étoiles se posent sur les herbes, sur les arbres

C'est le silence alentour

Seuls bourdonnent les parfums de brousse, ruches d'abeilles rousses qui dominent la vibration grêle des grillons,

Et tam-tam voilé, la respiration au loin de la nuit,

Toi Tokowaly, tu écoutes l'inaudible, et tu m'expliques ce que disent les ancêtres dans la sérénité marine des constellations,

Le taureau, le scorpion, le léopard, l'éléphant et les poissons familiers,

Et la pompe lactée des Esprits par le tan céleste qui ne finit point,

Mais voici l'intelligence de la déesse Lune et que tombent les voiles des ténèbres.

Nuit d'Afrique, ma nuit noire, mystique et claire, noire et brillante ${ }^{126}$. »

Je me faisais le poète du monde. Le Blanc avait découvert une poésie qui n'avait rien de poétique. L'âme du Blanc était corrompue et, comme me le disait un ami qui enseigna aux Etats-Unis: "Les nègres en face des Blancs constituent en quelque sorte l'assurance sur l'humanité. Quand les Blancs se sentent par trop mécanisés, ils se

126 Senghor, Chants d'ombre. Éditions du Seuil, 1945. 
tournent vers les hommes de couleur et leur demandent un peu de nourriture humaine. » Enfin j'étais reconnu, je n'étais plus un néant.

Je devais vite déchanter. Le Blanc, un instant interloqué, m'exposa que génétiquement, je représentais un stade: «Vos qualités ont été épuisées par nous. Nous avons eu des mystiques de la terre comme vous n'en connaîtrez jamais. Penchez-vous sur notre histoire, vous comprendrez jusqu'où est allée cette fusion. " J'eus alors l'impression de répéter un cycle. Mon originalité m'était extorquée. Je restai longtemps à pleurer, et puis je me remis à vivre. Mais j'étais hanté par une série de formules dissolvantes : l'odeur sui generis du nègre... la bonhomie sui generis du nègre... la naïveté sui generis du nègre...

[125]

J'avais essayé de m'évader par la bande, mais les Blancs m'étaient tombés dessus et m'avaient coupé le jarret gauche. J'arpentai les limites de mon essence ; à n'en pas douter, c'était assez maigre. C'est à ce niveau que se situe ma découverte la plus extraordinaire. Cette découverte est à proprement parler une redécouverte.

Je fouillai vertigineusement l'antiquité noire. Ce que j'y découvris me laissa pantelant. Dans son livre sur L'abolition de l'esclavage, Schoelcher nous apportait des arguments péremptoires. Depuis lors, Frobenius, Westermann, Delafosse, tous blancs, firent chorus: Ségou, Djenné, villes de plus de cent mille habitants. On parla de docteurs noirs (docteurs en théologie qui allaient à La Mecque discuter du Coran). Tout cela exhumé, étalé, viscères au vent, me permit de retrouver une catégorie historique valable. Le Blanc s'était trompé, je n'étais pas un primitif, pas davantage un demi-homme, j'appartenais à une race qui, il y a de cela deux mille ans, travaillait déjà l'or et l'argent. Et puis, il y avait autre chose, autre chose que ne pouvait comprendre le Blanc. Ecoutez:

«Quels étaient donc ces hommes qu'une sauvagerie insurpassée au cours des siècles arrachait ainsi à leur pays, à leurs dieux, à leurs familles? 
»Des hommes doux, polis, courtois, supérieurs assurément à leurs bourreaux, ce ramassis d'aventuriers qui brisaient, violaient, insultaient l'Afrique pour mieux la dépouiller.

»Ils savaient bâtir des maisons, administrer des empires, construire des villes, cultiver les champs, fondre le minerai, tisser le coton, forger le fer.

»Leur religion était belle, faite de mystérieux contacts avec le fondateur de la cité. Leurs mœurs agréables, fondées sur la solidarité, la bienveillance, le respect de l'âge.

» Aucune coercition, mais l'entraide, la joie de vivre, la discipline librement consentie.

»Ordre - Intensité - Poésie et liberté.

»De l'individu sans angoisse au chef presque fabuleux, une chaîne continue de compréhension et de confiance. Pas de science? Certes, mais ils avaient, pour les protéger de la peur, de grands mythes où l'observation la plus [125] fine et l'imagination la plus hardie s'équilibraient et se fondaient. Pas d'art? Ils avaient leur magnifique statuaire, où l'émotion humaine n'explose jamais si farouchement qu'elle n'organise selon les obsédantes lois du rythme les grands plans d'une matière sommée de capter pour les redistribuer les forces les plus secrètes de l'univers $127 \ldots$ »

127 Victor Schœlcher, Esclavage et colonisation, Introduction par Aimé Césaire, p. 7. 
«... Des monuments en plein cœur de l'Afrique? Des écoles? Des hôpitaux? Pas un bourgeois du $X X^{e}$ siècle, pas un Durand, un Smith ou un Brown qui en soupçonne l'existence dans l'Afrique d'avant les Européens...

»... Mais Schœlcher en signale l'existence d'après Caillé, Mollien, les frères Cander. Et s'il ne signale nulle part que lorsque les Portugais débarquèrent sur les rives du Congo en 1498, ils y découvrirent un Etat riche et florissant et qu'à la Cour d'Ambasse les grands étaient vêtus de soie et de brocart, il sait du moins que l'Afrique s'est élevée d'elle-même à une conception juridique de l'Etat et il soupçonne en plein siècle d'impérialisme qu'après tout la civilisation européenne n'est qu'une civilisation parmi les autres - et pas la plus tendre ${ }^{128}$. »

Je remettais le Blanc à sa place: enhardi, je le bousculai et lui jetai à la face: accommodez-vous de moi, je ne maccommode de personne. Je ricanais à pleines étoiles. Le Blanc, c'était visible, grondait. Son temps de réaction s'allongeait indéfiniment... J'avais gagné. J'exultais.

«Laissez là votre histoire, vos recherches sur le passé et essayez de vous mettre à notre rythme. Dans une société comme la nôtre, industrialisée à l'extrême, scienticisée, il n'y a plus de place pour votre sensibilité. Il faut être dur pour être admis à vivre. Il ne s'agit plus de jouer le jeu du monde, mais bien de l'asservir à coups d'intégrales et d'atomes. Bien sûr, me disaiton, de temps à autre, quand nous serons fatigués de la vie de nos buildings, nous irons à vous comme à nos enfants... vierges... étonnés... spontanés. Nous irons à vous comme à l'enfance [127] du monde. Vous êtes si vrais dans votre vie, c'est-à-dire si badins. Abandonnons pour quelques instants notre civilisation cérémonieuse et polie et penchons-nous sur ces têtes, sur ces vi-

Ibid., p. 8. 
sages adorablement expressifs. En un sens, vous nous réconciliez avec nous-mêmes. »

Ainsi, à mon irrationnel, on opposait le rationnel. À mon rationnel, le «véritable rationnel». $\grave{A}$ tous les coups, je jouais perdant. J'expérimentai mon hérédité. Je fis un bilan complet de ma maladie. Je voulais être typiquement nègre, - ce n'était plus possible. Je voulais être blanc, - il valait mieux en rire. Et quand j'essayais, sur le plan de l'idée et de l'activité intellectuelle, de revendiquer ma négritude, on me l'arrachait. On me démontrait que ma démarche n'était qu'un terme dans la dialectique:

"Mais il y a plus grave: le nègre, nous l'avons dit, se crée un racisme antiraciste. Il ne souhaite nullement dominer le monde: il veut l'abolition des privilèges ethniques d'où qu'ils viennent; il affirme sa solidarité avec les opprimés de toute couleur. Du coup la notion subjective, existentielle, ethnique de négritude "passe », comme dit Hegel, dans celle - objective, positive, exacte - de prolétariat. "Pour Césaire, dit Senghor, le «Blanc » symbolise le capital, comme le nègre le travail... À travers les hommes à peau noire de sa race, c'est la lutte du prolétariat mondial qu'il chante. »

»C'est facile à dire, moins facile à penser. Et, sans doute, ce n'est pas par hasard que les chantres les plus ardents de la négritude sont en même temps des militants marxistes.

» Mais cela n'empêche que la notion de race ne se recoupe pas avec celle de classe: celle-là est concrète et particulière, celle-ci universelle et abstraite; l'une ressortit à ce que Jaspers nomme compréhension et l'autre à l'intellection; la première est le produit d'un syncrétisme psycho-biologique et l'autre est une construction méthodique à partir de l'expérience. En fait, la négritude apparaît comme le temps faible d'une progression dialectique: l'affirmation théorique et pratique de la suprématie du Blanc est la thèse; la position de la négritude com- 
me valeur antithétique est le moment de la négativité. Mais [128] ce moment négatif n'a pas de suffisance par lui-même et les Noirs qui en usent le savent fort bien; ils savent qu'il vise à préparer la synthèse ou réalisation de l'humain dans une société sans races. Ainsi la Négritude est pour se détruire, elle est passage et non aboutissement, moyen et non fin dernière ${ }^{129}$. »

Quand je lus cette page, je sentis qu'on me volait ma dernière chance. Je déclarai à mes amis: "La génération des jeunes poètes noirs vient de recevoir un coup qui ne pardonne pas. » On avait fait appel à un ami des peuples de couleur, et cet ami n'avait rien trouvé de mieux que montrer la relativité de leur action. Pour une fois, cet hégélien-né avait oublié que la conscience a besoin de se perdre dans la nuit de l'absolu, seule condition pour parvenir à la conscience de soi. Contre le rationalisme, il rappelait le côté négatif, mais en oubliant que cette négativité tire sa valeur d'une absoluité quasi substantielle. La conscience engagée dans l'expérience ignore, doit ignorer les essences et les déterminations de son être.

Orphée Noir est une date dans l'intellectualisation de l'exister noir. Et l'erreur de Sartre a été non seulement de vouloir aller à la source de la source, mais en quelque façon de tarir cette source:

«La source de la Poésie tarira-t-elle? Ou bien le grand fleuve noir colorera-t-il malgré tout la mer dans laquelle il se jette? Il n'importe: à chaque époque sa poésie: à chaque époque, les circonstances de l'histoire élisent une nation, une race, une classe pour reprendre le flambeau, en créant des situations qui ne peuvent s'exprimer ou se dépasser que par la Poésie; et tantôt l'élan poétique coïncide avec l'élan révolutionnaire et tantôt ils divergent. Saluons aujourd'hui la chance historique qui permet-

129 Jean-Paul Sartre, Orphée Noir, Préface à l'Anthologie de la poésie nègre et malgache, Pp. XL et suiv. 
tra aux Noirs de pousser "d'une telle raideur le grand cri nègre que les assises du monde en seront ébranlées » (Césaire) ${ }^{130 . »}$

[129]

Et voilà, ce n'est pas moi qui me crée un sens, mais c'est le sens qui était là, pré-existant, mattendant. Ce n'est pas avec ma misère de mauvais nègre, mes dents de mauvais nègre, ma faim de mauvais nègre, que je modèle un flambeau pour y foutre le feu afin d'incendier ce monde, mais c'est le flambeau qui était là, attendant cette chance historique.

En termes de conscience, la conscience noire se donne comme densité absolue, comme pleine d'elle-même, étape préexistante à toute fente, à toute abolition de soi par le désir. Jean-Paul Sartre, dans cette étude, a détruit l'enthousiasme noir. Contre le devenir historique, il y avait à opposer l'imprévisibilité. J'avais besoin de me perdre dans la négritude absolument. Peut-être qu'un jour, au sein de ce romantisme malheureux...

En tout cas j'avais besoin d'ignorer. Cette lutte, cette redescente devaient revêtir un aspect achevé. Rien de plus désagréable que cette phrase: «Tu changeras, mon petit ; quand j'étais jeune, moi aussi... tu verras, tout passe. »

La dialectique qui introduit la nécessité au point d'appui de ma liberté m'expulse de moi-même. Elle rompt ma position irréfléchie. Toujours en termes de conscience, la conscience noire est immanente à elle-même. Je ne suis pas une potentialité de quelque chose, je suis pleinement ce que je suis. Je n'ai pas à rechercher l'universel. En mon sein nulle probabilité ne prend place. Ma conscience nègre ne se donne pas comme manque. Elle est. Elle est adhérente à elle-même.

Mais, nous dira-t-on, il y a dans vos affirmations méconnaissance du processus historique. Ecoutez donc: 
«Afrique j'ai gardé ta mémoire Afrique

tu es en moi

Comme l'écharde dans la blessure

comme un fétiche tutélaire au centre du village

fais de moi la pierre de ta fronde

de ma bouche les lèvres de ta plaie

de mes genoux les colonnes brisées de ton abaissement

[130]

\section{POURTANT}

je ne veux être que de votre race

ouvriers paysans de tous les pays

... ouvrier blanc de Detroit péon noir d'Alabama

peuple innombrable des galères capitalistes

le destin nous dresse épaule contre épaule

et reniant l'antique maléfice des tabous du sang

nous foulons les décombres de nos solitudes

Si le torrent est frontière

nous arracherons au ravin sa chevelure

intarissable

Si la Sierra est frontière

nous briserons la mâchoire des volcans

affirmant les Cordillères

et la plaine sera l'esplanade d'aurore

où rassembler nos forces écartelées

par la ruse de nos maîtres

Comme la contradiction des traits

se résout en l'harmonie du visage

nous proclamons l'unité de la souffrance

et de la révolte

de tous les peuples sur toute la surface de la terre 
et nous brassons le mortier des temps fraternels dans la poussière des idoles ${ }^{131}$. »

Justement, répondrons-nous, l'expérience nègre est ambiguë, car il n'y a pas un nègre, mais des nègres. Quelle différence, par exemple, avec cet autre poème:

«Le Blanc a tué mon père

Car mon père était fier

Le Blanc a violé ma mère

Car ma mère était belle

Le Blanc a courbé mon frère sous le soleil des routes Car mon frère était fort

Puis le Blanc a tourné vers moi

Ses mains rouges de sang

M'a craché Noir son mépris au visage

Et de sa voix de maître:

[130]

« Hé boy, un berger, une serviette, de l'eau » 132. »

Et cet autre :

«Mon frère aux dents qui brillent sous le compliment hypocrite

Mon frère aux lunettes d'or

Sur tes yeux rendus bleus par la parole du Maître Mon pauvre frère au smoking à revers de soie

Piaillant et susurrant et plastronnant dans les salons de la Condescendance

131 Jacques Roumain, Bois d'ébène, prélude.

132 David Diop, Trois poèmes, Le temps du martyre. 
Tu nous fais pitié

Le soleil de ton pays n'est plus qu'une ombre

Sur ton front serein de civilisé

Et la case de ta grand-mère

Fait rougir un visage blanchi par des années d'humiliation et de Mea Culpa

Mais lorsque repu de mots sonores et vides

Comme la caisse qui surmonte tes épaules

Tu fouleras la terre amère et rouge d'Afrique

Ces mots angoissés rythmeront alors ta marche inquiète Je me sens si seul, si seul ici 133 ! »

De temps à autre, on a envie de s'arrêter. Exprimer le réel est chose ardue. Mais quand on se met en tête de vouloir exprimer l'existence, on risque de ne rencontrer que l'inexistant. Ce qui est certain, c'est qu'au moment où je tente une saisie de mon être, Sartre, qui demeure l'Autre, en me nommant m'enlève toute illusion. Alors que je lui dis:

«Ma Négritude n'est ni une tour, ni une cathédrale, elle plonge dans la chair rouge du sol, elle plonge dans la chair ardente du ciel, elle troue l'accablement opaque de sa droite patience... »

[131]

alors que moi, au paroxysme du vécu et de la fureur, je proclame cela, il me rappelle que ma négritude n'est qu'un temps faible. En vérité, en vérité je vous le dis, mes épaules ont glissé de la structure du monde, mes pieds n'ont plus senti la caresse du sol. Sans passé nègre, sans

133 David Diop, Le Renégat. 
avenir nègre, il m'était impossible d'exister ma nègrerie. Pas encore blanc, plus tout à fait noir, j'étais un damné. Jean-Paul Sartre a oublié que le nègre souffre dans son corps autrement que le Blanc ${ }^{134}$. Entre le Blanc et moi, il y a irrémédiablement un rapport de transcendance 135 .

Mais on a oublié la constance de mon amour. Je me définis comme tension absolue d'ouverture. Et je prends cette négritude et, les larmes aux yeux, j'en reconstitue le mécanisme. Ce qui avait été mis en pièces est par mes mains, lianes intuitives, rebâti, édifié.

Plus violente retentit ma clameur: je suis un nègre, je suis un nègre, je suis un nègre...

Et c'est mon pauvre frère, - vivant à l'extrême sa névrose, et qui se découvre paralysé :

«LE NÈGRE : Je ne peux pas, madame.

LIZZIE : Quoi?

LE NĖGRE : Je ne peux pas tirer sur les Blancs,

LIZZIE : Vraiment! Ils vont se gêner, eux!

LE NĖGRE : Ce sont des Blancs, madame.

LIZZIE : Et alors? Parce qu'ils sont Blancs, ils ont le droit de te saigner comme un cochon?

LE NÈGRE : Ce sont des Blancs. »

Sentiment d'infériorité? Non, sentiment d'inexistence. Le péché est nègre comme la vertu est blanche. Tous ces Blancs réunis, le revol-

134 Si les études de Sartre sur l'existence d'autrui demeurent exactes (dans la mesure, nous le rappelons, où l'Etre et le Néant décrit une conscience aliénée), leur application à une conscience nègre se révèle fausse. C'est que le Blanc n'est pas seulement l'Autre, mais le maître, réel ou imaginaire d'ailleurs.

135 Dans le sens où l'entend Jean Wahl, Existence humaine et transcendance, Etre et Penser. 
ver au poing, ne peuvent pas avoir tort. Je suis coupable. Je ne sais pas de quoi, mais je sens que je suis un misérable.

«LE NĖGRE : C'est comme ça, madame, c'est toujours comme ça avec les Blancs.

LIZZIE - Toi aussi tu te sens coupable?

LE NÈGRE : Oui, madame ${ }^{136}$. »

C'est Bigger Thomas, - qui a peur, une peur affreuse. Il a peur, mais de quoi a-t-il peur? De lui-même. On ne sais pas encore qui il est, mais il sait que la peur habitera le monde quand le monde saura. Et quand le monde sait, le monde attend toujours quelque chose du nègre. Il a peur que le monde sache il a peur de la peur qui serait celle du monde si le monde savait. Comme cette vieille femme, qui nous supplie à genoux de l'attacher à son lit :

«- Je sens, docteur, à tout instant cette chose qui me prend.

- Quelle chose?

- L'envie de me suicider. Attachez-moi, j'ai peur.»

À la fin, Bigger Thomas agit. Pour mettre fin à la tension, il agit, il répond à l'attente du monde 137.

C'est le personnage de If he hollers, let him go 138, qui fait justement ce qu'il ne voulait pas faire. Cette grosse blonde qui lui barre la

136 J.-P. Sartre, La Putain respectueuse. - Voir aussi : Je suis un nègre, « Home of the brave », film de Mark Robson.

137 Richard Wright, Native Son.

138 Chester Rimes. 
route à tout moment, défaillante, sensuelle, offerte, ouverte, craignant (souhaitant) le viol, à la fin devient sa maîtresse.

Le nègre est un jouet entre les mains du Blanc; alors, pour rompre ce cercle infernal, il explose. Impossible d'aller au cinéma sans me rencontrer. Je mattends. A l'entracte, juste avant le film, je m'attends. Ceux qui sont devant moi me regardent, m'épient, mattendent. Un nègre-groom va apparaître. Le cœur me tourne la tête.

L'estropié de la guerre du Pacifique dit à mon frère « Accommodetoi de ta couleur comme moi de mon moignon: nous sommes tous deux des accidentés ${ }^{139}$.

[134]

Pourtant, de tout mon être, je refuse cette amputation. Je me sens une âme aussi vaste que le monde, véritablement une âme profonde comme la plus profonde des rivières, ma poitrine a une puissance d'expansion infinie. Je suis don et l'on me conseille l'humilité de l'infirme... Hier, en ouvrant les yeux sur le monde, je vis le ciel de part en part se révulser. Je voulus me lever, mais le silence éviscéré reflua vers moi, ses ailes paralysées. Irresponsable, à cheval entre le Néant et l'Infini, je me mis à pleurer.

139 Je suis un nègre. 
[135]

PEAU NOIRE. MASQUES BLANCS.

\author{
Chapitre VI \\ LE NĖGRE \\ ETLA PSYCHOPATHOLOGIE
}

\title{
Retour à la table des matières
}

Les écoles psychanalytiques ont étudié les réactions névrotiques qui prennent naissance dans certains milieux, dans certains secteurs de civilisation. On devrait, pour obéir à une exigence dialectique, se demander dans quelle mesure les conclusions de Freud ou d'Adler peuvent être utilisées dans une tentative d'explication de la vision du monde de l'homme de couleur.

La psychanalyse, on ne le soulignera jamais assez, se propose de comprendre des comportements donnés - au sein du groupe spécifique que représente la famille. Et quand il s'agit d'une névrose vécue par un adulte, la tâche de l'analyste est de retrouver, dans la nouvelle structure psychique, une analogie avec de tels éléments infantiles, une répétition, une copie de conflits éclos au sein de la constellation familia- 
le. Dans tous les cas, on s'attache à considérer la famille « comme objet et circonstance psychiques 140 ».

Ici, toutefois, les phénomènes vont se compliquer singulièrement. La famille, en Europe, représente en effet une certaine façon qu'a le monde de s'offrir à l'enfant. La structure familiale et la structure nationale entretiennent des rapports étroits. La militarisation et la centralisation de l'autorité dans un pays entraînent automatiquement une recrudescence de l'autorité paternelle. En Europe et dans tous les pays dits civilisés ou civilisateurs, la famille est un morceau de nation. L'enfant qui sort du [136] milieu parental retrouve les mêmes lois, les mêmes principes, les mêmes valeurs. Un enfant normal ayant grandi dans une famille normale sera un homme normal ${ }^{141}$. Il n'y a pas de disproportion entre la vie familiale et la vie nationale. Inversement, si l'on considère une société fermée, c'est-à-dire ayant été protégée du flux civilisateur, on retrouve les mêmes structures décrites ci-dessus. L'âme du Pygmée d'Afrique, du R. P. Trilles, par exemple, nous convainc de la chose: on y sent bien à tout instant le besoin de catholiciser l'âme négrille, mais la description qu'on y trouve de la culture - schèmes cultuels, persistance de rites, survivance de mythes - ne donne pas l'impression artificielle de La philosophie bantoue.

Dans un cas comme dans l'autre, il y a projection sur le milieu social des caractères du milieu familial. Il est vrai que des enfants de voleurs ou de bandits, habitués à une certaine législation de clan, seront surpris de constater que le reste du monde se comporte différemment, mais une nouvelle éducation - à moins de perversion ou

140 «Le complexe, facteur concret de la psychologie familiale », J. Lacan, Encyclopédie française, 8-40-5.

141 Nous voulons croire qu'on ne nous fera pas un procès de cette dernière phrase. Les sceptiques ont beau jeu de demander: «Qu'appelez-vous normal ? » Pour l'instant, il n'est pas dans notre propos de répondre à cette question. Afin de parer au plus pressé, citons l'ouvrage très instructif, bien qu'axé uniquement sur le problème biologique, de $G$. Canguilhem, Le normal et le pathologique. Ajoutons seulement que, dans le domaine mental, est anormal celui qui demande, appelle, implore. 
d'arriération (Heuyer) 142 - doit pouvoir les amener à moraliser leur vision, à la socialiser.

On s'aperçoit, dans tous ces cas, que la morbidité se situe dans le milieu familial. "L'autorité dans l'Etat est pour l'individu la reproduction de l'autorité familiale par laquelle il a été modelé dans son enfance. L'individu assimile les autorités rencontrées ultérieurement à l'autorité parentale: il perçoit le présent en termes du passé. Comme tous les autres comportements humains, le comportement devant l'autorité est appris. Et il est appris [137] au sein d'une famille que l'on peut distinguer du point de vue psychologique par son organisation particulière, c'est-à-dire par la façon dont l'autorité y est répartie et exercée ${ }^{143}$. 》

Or, et c'est là un point très important, nous constatons l'inverse chez l'homme de couleur. Un enfant noir normal, ayant grandi au sein d'une famille normale, s'anormalisera au moindre contact avec le monde blanc. On ne comprendra pas immédiatement cette proposition. Aussi avancerons-nous à reculons. Rendant justice au $D^{r}$ Breuer, Freud écrit: «Dans presque chaque cas, nous constations que les symptômes étaient comme des résidus, pour ainsi dire, d'expériences émotives, que pour cette raison nous avons appelées plus tard traumas psychiques. Leur caractère particulier s'apparentait à la scène traumatique qui les avait provoqués. Selon l'expression consacrée, les symptômes étaient déterminés par des «scènes » dont ils formaient les résidus mnésiques, et il n'était plus nécessaire de voir en eux des effets arbitraires et énigmatiques de la névrose. Cependant, contrairement à ce

142 Encore que cette réserve soit elle-même discutable. Voir par exemple la communication de Mademoiselle Juliette Boutonnier : « La perversion ne serait-elle pas une profonde arriération affective entretenue ou engendrée par les conditions dans lesquelles a vécu l'enfant, au moins autant que par des dispositions constitutionnelles qui restent évidemment en cause, mais qui ne sont probablement pas seules responsables ? » (Revue Française de Psychanalyse, $n^{\circ} 3,1949$, pp. 403-404).

143 Joachim Marcus, «Structure familiale et comportements politiques», L'autorité dans la famille et dans l'Etat (Revue Française de Psychanalyse, avril-juin 1949). 
que l'on attendait, ce n'était pas toujours d'un seul événement que le symptôme résultait, mais la plupart du temps de multiples traumas souvent analogues et répétés. Par conséquent, il fallait reproduire chronologiquement toute cette chaîne de souvenirs pathogènes, mais dans l'ordre inverse, le dernier d'abord et le premier à la fin ; impossible de pénétrer jusqu'au premier trauma, souvent le plus efficace, si l'on sautait les intermédiaires. »

On ne saurait être plus affirmatif ; il y a des Erlebnis déterminées, à l'origine des névroses. Plus loin, Freud ajoute: « Ce trauma, les malades l'ont bien, il est vrai, chassé de leur conscience et de leur mémoire et se sont épargné en apparence une grande somme de souffrances, mais le désir refoulé continue à subsister dans l'inconscient ; il guette une occasion de se manifester et réapparaît bientôt à la lumière, mais sous un déguisement qui le rend méconnaissable; en d'autres termes, la pensée [138] refoulée est remplacée dans la conscience par une autre qui lui sert de substitut, d'ersatz, et à laquelle viennent s'attacher toutes les impressions de malaise que l'on croyait écartées par le refoulement. »Ces Erlebnis sont refoulées dans l'inconscient.

Dans le cas du Noir, que voyons-nous? À moins d'utiliser cette donnée vertigineuse - tant elle nous désaxe - de l'inconscient collectif de Jung, on ne comprend absolument rien. Un drame chaque jour se joue dans les pays colonisés. Comment expliquer, par exemple, qu'un bachelier nègre, arrivant en Sorbonne afin d'y préparer une licence de philosophie, avant toute organisation conflictuelle autour de lui, soit sur ses gardes? René Ménil rendait compte de cette réaction en termes hégéliens. Il en faisait « la conséquence de l'instauration dans la conscience des esclaves, à la place de l'esprit «africain» refoulé, d'une instance représentative du Maître, instance instituée au tréfonds de la collectivité et qui doit la surveiller comme une garnison la ville conquise $144 »$.

144 Citation empruntée à Michel Leiris, « Martinique, Guadeloupe, Haïti » (Temps Modernes, février 1950). 
Nous verrons, dans notre chapitre sur Hegel, que René Ménil ne s'est pas trompé. Cependant, nous avons le droit de nous poser la question: comment en expliquer la persistance au XXe siècle, quand il y a par ailleurs identification intégrale au Blanc? Fréquemment, le nègre qui s'anormalise n'a jamais eu de relations avec le Blanc. Y a-t-il eu expérience ancienne et refoulement dans l'inconscient? Le jeune enfant noir a-t-il vu son père frappé ou lynché par le Blanc? Y a-t-il eu traumatisme effectif ? À tout cela, nous répondons: non. Alors?

Si nous voulons répondre correctement, nous sommes obligé de faire appel à la notion de catharsis collective. Dans toute société, dans toute collectivité, existe, doit exister un canal, une porte de sortie par où les énergies accumulées sous forme d'agressivité, puissent être libérées. C'est ce à quoi tendent les jeux dans les Institutions d'enfants, les psychodrames dans les cures collectives et, d'une façon plus générale, les hebdomadaires illustrés [139] pour les jeunes, chaque type de société exigeant, naturellement, une forme de catharsis déterminée. Les histoires de Tarzan, d'explorateurs de douze ans, de Mickey, et tous les journaux illustrés, tendent à un véritable défoulement d'agressivité collective. Ce sont des journaux écrits par des Blancs, destinés à de petits Blancs. Or le drame se situe ici. Aux Antilles, et nous avons tout lieu de penser que la situation est analogue dans les autres colonies, ce sont ces mêmes illustrés qui sont dévorés par les jeunes indigènes. Et le Loup, le Diable, le Mauvais Génie, le Mal, le Sauvage sont toujours représentés par un nègre ou un Indien, et comme il y a toujours identification avec le vainqueur, le petit nègre se fait explorateur, aventurier, missionnaire «qui risque d'être mangé par les méchants nègres » aussi facilement que le petit Blanc. On nous dira que cela n'est pas très important: mais c'est qu'on n'aura point réfléchi sur le rôle de ces illustrés. Voici ce qu'en dit G. Legman : « de rares exceptions près, chaque enfant américain âgé en 1938 de six ans a donc maintenant absorbé un strict minimum de dix-huit mille scènes de tortures féroces et de violences sanguinaires... Les Américains sont le seul peuple moderne, à l'exception des Boers, qui, de mémoire d'homme, ont totalement balayé du sol où ils se sont installés la 
population autochtone ${ }^{145}$. Seule l'Amérique pouvait donc avoir une mauvaise conscience nationale à apaiser en forgeant le mythe du « Bad Injun $146 »$, pour pouvoir ensuite réintroduire la figure historique de l'honorable Peau-Rouge défendant sans succès son sol contre les envahisseurs armés de bibles et de fusils; le châtiment que nous méritons ne peut être détourné qu'en niant la responsabilité du mal, en rejetant le blâme sur la victime; en prouvant - du moins à nos propres yeux qu'en frappant le premier et l'unique coup nous agissions simplement en état de légitime défense... » Envisageant les répercussions de ces illustrés sur la culture américaine, l'auteur écrit encore: « La question reste ouverte de [140] savoir si cette fixation maniaque à la violence et à la mort est le substitut d'une sexualité censurée, ou si elle n'aurait pas plutôt pour fonction de canaliser dans la voie laissée libre par la censure sexuelle le désir d'agression des enfants et des adultes contre la structure économique et sociale, qui, avec leur propre consentement pourtant, les pervertit. Dans les deux cas, la cause de la perversion, qu'elle soit d'ordre sexuel ou économique, est essentielle: c'est pourquoi, tant que nous ne serons pas capables de nous en prendre à ces refoulements fondamentaux, toute attaque dirigée contre de simples procédés d'évasion tels que les comic books restera futile 147. »

Aux Antilles, le jeune Noir, qui à l'école ne cesse de répéter «nos pères, les Gaulois 148 », s'identifie à l'explorateur, au civilisateur, au Blanc qui apporte la vérité aux sauvages, une vérité toute blanche. Il y a identification, c'est-à-dire que le jeune Noir adopte subjectivement

145 En passant, signalons que les Caraïbes ont subi le même sort, de la part des aventuriers espagnols et français.

146 Déformation péjorative de « Bad Indian ».

147 G. Legman, «Psychopathologie des Comics», traduit par H. Robillot (Temps Modernes, $n^{\circ} 43$, pp. 916 et suiv.).

148 Comme dans beaucoup de circonstances, c'est le sourire que l'on provoque, quand en rapporte ce trait de l'enseignement en Martinique. On veut bien constater le caractère comique de la chose, mais on ne parle pas de ses conséquences lointaines. Or ce sont elles qui importent, puisque c'est à partir de trois ou quatre de ces phrases que s'élabore la vision du monde chez le jeune Antillais. 
une attitude de Blanc. Il charge le héros, qui est Blanc, de toute son agressivité, - laquelle, à cet âge, s'apparente étroitement à l'oblativité : une oblativité chargée de sadisme. Un enfant de huit ans offrant quelque chose, même à une grande personne, ne saurait tolérer de refus. Peu à peu, on voit se former et cristalliser chez le jeune Antillais une attitude, une habitude de penser et de voir, qui sont essentiellement blanches. Quand, à l'école, il lui arrive de lire des histoires de sauvages, dans des ouvrages blancs, il pense toujours aux Sénégalais. Etant écolier, nous avons pu discuter pendant des heures entières sur les prétendues coutumes des sauvages sénégalais. Il y avait dans nos propos une inconscience pour le moins paradoxale. Mais c'est que l'Antillais ne se pense pas Noir; il se pense Antillais. Le nègre vit en Afrique. Subjectivement, intellectuellement, l'Antillais se comporte comme un Blanc. Or, c'est un nègre. Cela, il s'en apercevra [141] une fois en Europe, et quand on parlera de nègres il saura qu'il s'agit de lui aussi bien que du Sénégalais. Sur ce point, que pouvons-nous conclure?

Imposer les mêmes « Mauvais Génies » au Blanc et au Noir constitue une grave erreur d'éducation. Si l'on veut bien entendre le «Mauvais Génie » comme une tentative d'humanisation du «ça», on saisira notre point de vue. En toute rigueur, nous dirons que les comptines subissent la même critique. On s'aperçoit déjà que nous voulons, ni plus ni moins, créer des illustrés destinés spécialement aux Noirs, des chansons pour enfants noirs et, à l'extrême, des ouvrages d'histoire, tout au moins jusqu'au certificat d'études. Car, jusqu'à preuve du contraire, nous estimons que s'il y a traumatisme, il se situe à cette date. Le jeune Antillais est un Français appelé à tout instant à vivre avec des compatriotes blancs. On l'oublie un peu trop souvent.

La famille blanche est le dépositiaire d'une certaine structure. La société est véritablement l'ensemble des familles. La famille est une institution, qui annonce une institution plus vaste: le groupe social ou national. Les axes de référence demeurent les mêmes. La famille blanche est le lieu de préparation et de formation à une vie sociale. «La structure familiale est intériorisée dans le surmoi et projetée dans le comportement politique [social, dirons-nous] » (Marcus). 
Le Noir, dans la mesure où il reste chez lui, réalise à peu de choses près le destin du petit Blanc. Mais qu'il aille en Europe, il aura à repenser son sort. Car le nègre en France, dans son pays, se sentira différent des autres. On a vite dit: le nègre s'infériorise. La vérité est qu'on l'infériorise. Le jeune Antillais est un Français appelé à tout instant à vivre avec des compatriotes blancs. Or la famille antillaise n'entretient pratiquement aucun rapport avec la structure nationale, c'est-à-dire française, européenne. L'Antillais doit alors choisir entre sa famille et la société européenne: autrement dit, l'individu qui monte vers la société - la Blanche, la civilisée - tend à rejeter la famille la Noire, la sauvage - sur le plan de l'imaginaire, en rapport avec les Erlebnis infantiles que nous avons décrites précédemment.

Et le schéma de Marcus devient dans ce cas:

$$
\text { Famille } \leftarrow \text { Individu } \rightarrow \text { Société }
$$

la structure familiale étant rejetée dans le «ça».

Le nègre s'aperçoit de l'irréalité de beaucoup de propositions qu'il avait faites siennes, en référence à l'attitude subjective du Blanc. Il commence alors son véritable apprentissage. Et la réalité se révèle extrêmement résistante... Mais, nous dira-t-on, vous ne faites que décrire un phénomène universel, - le critère de la virilité étant justement l'adaptation au social. Nous répondrons alors que cette critique porte à faux, car nous avons justement montré que, pour le nègre, il y a un mythe à affronter. Un mythe solidement ancré. Le nègre l'ignore, aussi longtemps que son existence se déroule au milieu des siens; mais au premier regard blanc, il ressent le poids de sa mélanine ${ }^{149}$.

149 Rappelons à ce propos ce qu'écrivait Sartre: « Certains enfants ont fait, dès l'âge de six ans, le coup de poing contre des camarades d'école qui les appelaient «youpins». D'autres ont été tenus longtemps dans l'ignorance de leur race. Une jeune fille israélite, dans une famille que je connais, ignora jusqu'à 
Ensuite, il y a l'inconscient. Le drame racial se déroulant en plein air, le Noir n'a pas le temps de l'« inconscienciser». Le Blanc, lui, y parvient dans une certaine mesure; c'est qu'il y a apparition d'un nouvel élément : la culpabilité. Le complexe de supériorité des nègres, leur complexe d'infériorité ou leur sentiment égalitaire sont conscients. $\grave{A}$ tout instant, ils les transitent. Ils existent leur drame. Il n'y a pas, chez eux, cette amnésie affective qui caractérise la névrose-type.

Chaque fois que nous avons lu un ouvrage de psychanalyse, discuté avec nos professeurs, conversé avec des malades européens, nous avons été frappé par l'inadéquation entre les schémas correspondants et la réalité que [143] nous offrait le nègre. Nous en avons progressivement conclu qu'il y a substitution de dialectique quand on passe de la psychologie du Blanc à celle du Noir.

Les valeurs premières, dont parle Charles Odier 150, sont différentes chez le Blanc et chez le Noir. L'effort de socialisation ne renvoie pas aux mêmes intentions. Véritablement, nous changeons de monde. Une étude rigoureuse devrait se présenter ainsi :

- interprétation psychanalytique de l'expérience vécue du Noir :

- interprétation psychanalytique du mythe nègre.

Mais le réel, qui est notre unique recours, nous interdit pareilles opérations. Les faits sont beaucoup plus compliqués. Quels sont-ils?

quinze ans le sens même du mot de Juif. Pendant l'occupation, un docteur juif de Fontainebleau, qui vivait enfermé dans sa maison, élevait ses petits-enfants sans leur dire un mot de leur origine. Mais, de quelque façon que ce soit, il faut bien qu'ils apprennent un jour la vérité : quelquefois c'est par les sourires des gens qui les entourent, d'autres fois par une rumeur ou par des insultes. Plus tardive est la découverte, plus violente est la secousse: tout d'un coup ils s'aperçoivent que les autres savaient sur eux quelque chose qu'ils ignoraient, qu'on leur appliquait ce qualificatif louche et inquiétant qui n'est pas employé dans leur famille. » (Réflexions sur la question juive, pp. 96-97.)

150 Les deux sources consciente et inconsciente de la vie morale. [Livre disponible dans Les Classiques des sciences sociales. JMT.] 
Le nègre est un objet phobogène, anxiogène. Depuis la malade de Sérieux et Capgras 151 jusqu'à cette fille qui nous avoue que coucher avec un nègre représente pour elle quelque chose de terrifiant, on rencontre tous les degrés de ce que nous appellerons la négrophobogénèse. À propos du nègre, on a beaucoup parlé de psychanalyse. Nous méfiant des applications qu'on pouvait en faire ${ }^{152}$, nous avons préféré intituler ce chapitre: «Le nègre et la psychopathologie», attendu que ni Freud, ni Adler, ni même le cosmique Jung n'ont pensé aux Noirs, dans le cours de leurs recherches. En quoi ils avaient bien raison. On oublie trop souvent que la névrose n'est pas constitutive de la réalité humaine. Qu'on le veuille ou non, le complexe d'Oedipe n'est pas près de voir le jour chez les nègres. On pourrait nous objecter, avec Malinowski, que le régime matriarcal est seul responsable de cette absence. Mais, outre que nous pourrions nous demander si les ethnologues, imbus de complexes de leur civilisation, ne se sont pas efforcés d'en retrouver la copie chez les peuples par eux étudiés, il nous serait relativement facile de montrer qu'aux Antilles françaises, 97\% des familles sont incapables de donner [144] naissance à une névrose œdipienne. Incapacité dont nous nous félicitons hautement 153.

Indépendamment de quelques ratés apparus en milieu clos, nous pouvons dire que toute névrose, tout comportement anormal, tout éréthisme affectif chez un Antillais, est la résultante de la situation culturelle. Autrement dit, il y a une constellation de données, une série

151 Les folies raisonnantes, - cité par Hesnard, L'univers morbide de la faute, p. 97.

152 Nous pensons spécialement à l'Amérique; voir, par exemple, Je suis un nègre.

153 Les psychanalystes hésiteront, sur ce point, à partager notre opinion. Le $D^{r}$ Lacan, par exemple, parle de la « fécondité » du complexe d'Oedipe. Mais si le jeune enfant doit tuer son père, encore est-il nécessaire que ce dernier accepte de mourir. Nous pensons à Hegel disant: «Le berceau de l'enfant est le tombeau des parents. » À Nicolas Calas (Foyer d'incendie) ; à Jean Lacroix (Force et faiblesses de la famille).

Le fait qu'il y ait eu un effondrement des valeurs morales en France, après la guerre, résulte peut-être de la défaite de cette personne morale que représente la nation. On sait ce que de tels traumatismes à l'échelle familiale peuvent déterminer. 
de propositions qui, lentement, sournoisement, à la faveur des écrits, des journaux, de l'éducation, des livres scolaires, des affiches, du cinéma, de la radio, pénètrent un individu - en constituant la vision du monde de la collectivité à laquelle il appartient ${ }^{154}$. Aux Antilles, cette vision du monde est blanche parce qu'aucune expression noire n'existe. Le folklore martiniquais est pauvre et, à Fort-de-France, nombreux sont les jeunes qui ignorent les histoires de "Compè Lapin », répliques de l'Oncle Rémus de la Louisiane. Un Européen, par exemple, au courant des manifestations poétiques noires actuelles, serait étonné d'apprendre que jusqu'en 1940 aucun Antillais n'était capable de se penser nègre. C'est seulement avec l'apparition d'Aimé Césaire qu'on a pu voir naître [145] une revendication, une assomption de la négritude. La preuve la plus concrète, d'ailleurs, en est cette impression que ressentent les jeunes générations d'étudiants débarquant à Paris: il leur faut quelques semaines pour comprendre que le contact de l'Europe les oblige à poser un certain nombre de problèmes qui jusqu'alors ne les avaient pas effleurés. Et pourtant ces problèmes ne manquent pas d'être visibles 155 .

154 Nous conseillons l'expérience suivante à ceux qui ne seraient pas convaincus: assister à la projection d'un film de Tarzan aux Antilles et en Europe. Aux Antilles, le jeune Noir s'identifie de facto à Tarzan contre les nègres. Dans une salle d'Europe, la chose est beaucoup plus difficile, car l'assistance, qui est blanche, l'apparente automatiquement aux sauvages de l'écran. Cette expérience est décisive. Le nègre sent qu'on n'est pas noir impunément. Un documentaire sur l'Afrique, projeté dans une ville française et à Fort-de-France, provoque des réactions analogues. Mieux : nous affirmons que les Boschimans et les Zoulous déclenchent davantage l'hilarité des jeunes Antillais. Il serait intéressant de montrer que dans ce cas cette exagération réactionnelle laisse deviner un soupçon de reconnaissance. En France, le Noir qui voit ce documentaire est littéralement pétrifié. Là il n'y a plus de fuite : il est à la fois Antillais, Boschiman et Zoulou.

155 Plus spécialement ils s'aperçoivent que la ligne d'auto-valorisation qui était la leur doit s'inverser. Nous avons vu en effet que l'Antillais qui vient en France conçoit ce voyage comme la dernière étape de sa personnalité. Littéralement nous pouvons dire sans crainte de nous tromper que l'Antillais qui va en France afin de se persuader de sa blancheur y trouve son véritable visage. 
Chaque fois que nous avons discuté avec nos professeurs ou conversé avec des malades européens, nous nous sommes aperçu des différences qui pouvaient exister entre les deux mondes. Nous entretenant dernièrement avec un médecin qui a toujours exercé à Fort-de-France, nous lui fîmes part de nos conclusions; il surenchérit en nous disant que cela était vrai, non seulement en psychopathologie, mais encore en médecine générale. Ainsi, ajouta-t-il, vous n'avez jamais une typhoïde pure telle que vous l'étudiez dans les traités de médecine; il y a toujours, greffé là-dessus, un paludisme plus ou moins manifeste. Il serait intéressant d'envisager, par exemple, une description de la schizophrénie vécue par une conscience noire, - si tant est que cette sorte de trouble se retrouve là-bas.

Quel est notre propos? Tout simplement ceci : quand les nègres abordent le monde blanc, il y a une certaine action sensibilisante. Si la structure psychique se révèle fragile, on assiste à un écroulement du Moi. Le Noir cesse de se comporter en individu actionnel. Le but de son action sera Autrui (sous la forme du Blanc), car Autrui seul peut le valoriser. Cela sur le plan éthique : valorisation de soi. Mais il y a autre chose.

Nous avons dit que le nègre était phobogène. Qu'est-ce que la phobie? Nous répondrons à cette question en nous appuyant sur le dernier ouvrage de Hesnard: «La phobie est une névrose caractérisée par la crainte anxieuse [146] d'un objet (au sens le plus large de toute chose extérieure à l'individu) ou, par extension, d'une situation 156. » Naturellement, cet objet devra revêtir certains aspects. Il faut, dit Hesnard, qu'il éveille la crainte et le dégoût. Mais là nous rencontrons une difficulté. Appliquant à la compréhension de la phobie la méthode génétique, Charles Odier écrit : « Toute angoisse provient d'une certaine insécurité subjective liée à l'absence de la mère ${ }^{157}$. " Cela se passe, dit l'auteur, aux environs de la deuxième année.

156 L'univers morbide de la faute, P.U.F., 1949, p. 37.

157 L'angoisse et la pensée magique, p. 38. 
Recherchant la structure psychique du phobique, il en arrive à cette conclusion: «Avant de s'en prendre directement aux croyances des adultes, il importe d'analyser dans tous ses éléments la structure infantile dont elles émanent et qu'elles impliquent 158. " Le choix de l'objet phobogène est donc surdéterminé. Cet objet ne sort pas de la nuit du Néant, il $a$, en une certaine circonstance, provoqué un affect chez le sujet. La phobie est la présence latente de cet affect sur le fond de monde du sujet; il y a organisation, mise en forme. Car naturellement l'objet n'a pas besoin d'être là, il suffit qu'il soit : c'est un possible. Cet objet est doté d'intentions méchantes et de tous les attributs d'une force maléfique ${ }^{159}$. Chez le phobique, il y a priorité de l'affect au mépris de toute pensée rationnelle. Comme on le voit, un phobique est un individu qui obéit aux lois de la prélogique rationnelle et de la prélogique affective : processus de penser et de sentir rappelant l'âge où s'est produit l'accident désécurisant. La difficulté annoncée est la suivante: y a-t-il eu traumatisme désecurisant chez cette jeune femme dont nous parlions tout à l'heure? Chez la plupart des négrophobes masculins, y a-t-il eu tentative de rapt? Tentative de fellation? En toute rigueur, voici ce que nous obtiendrions en appliquant les conclusions analytiques: si un objet très effrayant, comme un agresseur plus ou moins imaginaire, éveille la terreur, c'est aussi par exemple, - car il s'agit le plus souvent d'une femme, - et c'est surtout, une peur mêlée d'horreur sexuelle. Le: «J'ai peur des [147] hommes » veut dire, lorsqu'on élucide le mobile de l'effroi : parce qu'ils pourraient me faire toutes sortes de choses, mais pas des sévices vulgaires : des sévices sexuels, c'est-à-dire immoraux, déshonorants ${ }^{160}$.

"Le simple contact suffit à provoquer l'angoisse. Car le contact est en même temps le type schématique même de l'action sexuelle initiale (toucher, attouchements - sexualité) ${ }^{161}$. „ Comme nous sommes habi-

\footnotetext{
158 Ibid., p. 65.

159 Ibid., pp. 58 et 78.

160 Hesnard, op. cit., p. 38.

161 Ibid., p. 40.
} 
tués à tous les artifices qu'emploie le moi pour se défendre, nous savons qu'il faut éviter de prendre à la lettre ses dénégations. Ne sommes-nous pas en présence d'un transitivisme intégral ? Au fond, cette peur du viol n'appelle-t-elle pas, justement, le viol ? De même qu'il y a des têtes à claques, ne pourrait-on pas décrire des femmes à viol? Dans S'il braille, lâche-le, Chester Himes décrit bien ce mécanisme. La grosse blonde défaille chaque fois que le nègre approche. Pourtant elle ne craint rien, l'usine étant remplie de Blancs... En conclusion, ils couchent ensemble.

Nous avons pu voir, alors que nous étions militaire, le comportement de femmes blanches, dont trois ou quatre pays d'Europe, en face de Noirs, au cours de soirées dansantes. La plupart du temps, les femmes esquissaient un mouvement de fuite, de retrait, le visage rempli d'une frayeur non feinte. Pourtant les nègres qui les invitaient auraient été incapables, l'eussent-ils voulu, d'entreprendre contre elles quoi que ce soit. Le comportement des femmes en question se comprend nettement sur le plan de l'imaginaire. C'est que la négrophobe n'est en réalité qu'une partenaire sexuelle putative, - tout comme le négrophobe est un homosexuel refoulé.

Vis-à-vis du nègre, en effet, tout se passe sur le plan génital. Il y a quelques années, nous laissions entendre aux amis avec lesquels nous discutions que, d'une façon générale, le Blanc se comporte vis-à-vis du Noir comme un aîné réagit à la naissance d'un frère. Depuis, nous savons qu'en Amérique Richard Sterba le comprend de même. Sur le plan phénoménologique, il y aurait à étudier une double réalité. On a peur du Juif à cause de son [148] potentiel appropriatif. «Ils» sont partout. Les banques, les bourses, le gouvernement en sont infestés. Ils règnent sur tout. Bientôt le pays leur appartiendra. Ils sont reçus aux concours avant les «vrais» Français. Bientôt ils feront la loi chez nous. Dernièrement, un camarade qui prépare l'Ecole d'Administration nous disait : « Tu as beau dire, ils se soutiennent. Par exemple, quand Moch était au pouvoir, le nombre de youpins qui ont été nommés est effarant. » Dans le domaine médical, la situation n'est pas différente. Tout étudiant juif qui est reçu à un concours est un «pistonnée. - 
Les nègres, eux, ont la puissance sexuelle. Pensez donc! avec la liberté qu'ils ont, en pleine brousse! Il paraît qu'ils couchent partout, et à tout moment. Ce sont des génitaux. Ils ont tellement d'enfants qu'ils ne les comptent plus. Méfions-nous, car il nous inonderaient de petits métis.

Décidément, tout va mal...

Le gouvernement et l'Administration assiégés par les Juifs.

Nos femmes par les nègres.

Car le nègre a une puissance sexuelle hallucinante. C'est bien le terme : il faut que cette puissance soit hallucinante. Les psychanalystes qui réfléchissent sur la question retrouvent assez rapidement les rouages de toute névrose. L'inquiétude sexuelle est prédominante ici. Toutes les femmes négrophobes que nous avons connues avaient une vie sexuelle anormale. Leur mari les délaissait; elles étaient veuves, et elles n'osaient pas remplacer le défunt; divorcées, et elles hésitaient devant un nouvel investissement objectal. Toutes dotaient le nègre de pouvoirs que d'autres (mari, amants épisodiques) ne possédaient pas. Et puis, il intervient un élément de perversité, persistance de la structure infantile: Dieu sait comment il font l'amour! Ce doit être terrifiant 162 .

[149]

Il y a une expression qui à la longue s'est singulièrement érotisée: un athlète noir. Il y a là, nous confiait une jeune femme, quelque chose

162 Nous retrouvons dans le travail de J. Marcus l'opinion selon laquelle la névrose sociale, ou si l'on préfère le comportement anormal en face de l'Autre quel qu'il soit, entretient des rapports étroits avec la situation individuelle: «Le dépouillement des questionnaires montra que les individus le plus fortement antisémites appartenaient aux structures familiales les plus conflictuelles. Leur antisémitisme était une réaction à des frustrations subies au sein du milieu familial. Ce qui montre bien que les Juifs sont des objets de substitution dans l'antisémitisme, c'est le fait que les mêmes situations familiales engendrent, suivant les circonstances locales, la haine des Noirs, l'anticatholicisme ou l'antisémitisme. On peut donc dire que, contrairement à l'opinion courante, c'est l'attitude qui trouve un contenu et non ce dernier qui crée une attitude. » (Op. cit., p. 282.) 
qui vous soulève le cœur. Une prostituée nous disait qu'au début l'idée de coucher avec un nègre lui procurait l'orgasme. Elle les cherchait, évitant de leur réclamer de l'argent. Mais, ajoutait-elle, « coucher avec eux n'était pas plus extraordinaire qu'avec des Blancs. C'est avant l'acte que je parvenais à l'orgasme. Je pensais (imaginais) tout ce qu'ils pourraient me faire : et c'est cela qui était formidable. »

Toujours sur le plan génital, le Blanc qui déteste le Noir n'obéit-il pas à un sentiment d'impuissance ou d'infériorité sexuelle? L'idéal étant une virilité absolue, n'y aurait-il pas un phénomène de diminution par rapport au Noir, ce dernier perçu comme symbole pénien? Le lynchage du nègre, ne serait-ce pas une vengeance sexuelle? Nous savons tout ce que les sévices, les tortures, les coups comportent de sexuel. Qu'on relise quelques pages du marquis de Sade et l'on s'en convaincra aisément. La supériorité du nègre est-elle réelle? Tout le monde sait que non. Mais l'important n'est pas là. La pensée prélogique du phobique a décidé qu'il en était ainsi 163 . Une autre femme avait la phobie du nègre depuis la lecture de J'irai cracher sur vos tombes. Nous avons essayé de lui montrer l'irrationalité de sa position en lui faisant remarquer que les victimes blanches étaient aussi morbides que le nègre. De plus avions-nous ajouté, il ne s'agit pas de revendications noires comme le laisserait entendre le titre, puisque Boris Vian en était l'auteur. Nous dûmes constater la vanité de nos efforts. Cette jeune femme ne voulait rien entendre. Quiconque a lu ce livre comprendra aisément quelle ambivalence exprime cette [150] phobie. - Nous avons connu un étudiant en médecine noir qui n'osait pas faire un toucher vaginal aux malades qui venaient en consultation au service de gynécologie. Il nous avoua un jour avoir entendu cette réflexion d'une consultante: «Il y a un nègre là-dedans. S'il me touche je le gifle. Avec eux, on ne sait jamais. Il doit avoir de grandes mains et puis il est certainement brutal. »

163 Pour demeurer dans l'optique de Ch. Odier, il serait plus exact de dire : « paralogique »: «On pourrait proposer le terme de «paralogique » lorsqu'il s'agit de régression, c'est-à-dire de processus propres à l'adulte. » (L'angoisse et la pensée magique, p. 95.) 
Si l'on veut comprendre psychanalytiquement la situation raciale, conçue non pas globalement, mais ressentie par des consciences particulières, il faut attacher une grande importance aux phénomènes sexuels. Pour le Juif, on pense à l'argent et à ses dérivés. Pour le nègre, au sexe. L'antisémitisme est susceptible de rationalisation sur le plan foncier. C'est parce que les Juifs s'annexent le pays qu'ils sont dangereux. Récemment, un camarade nous disait que, sans être antisémite, il était obligé de constater que la plupart des Juifs qu'il avait connus pendant la guerre s'étaient comportés en salauds. Nous avons vainement essayé de lui faire admettre qu'il y avait dans cette conclusion la conséquence d'une volonté déterminée de détecter l'essence de Juif partout où elle pouvait se trouver.

Sur le plan clinique, il nous revient l'histoire de cette jeune femme qui présentait un délire du toucher, se lavant sans cesse les mains et les bras depuis le jour où on lui avait présenté un Israélite.

Jean-Paul Sartre ayant étudié magistralement le problème de l'antisémitisme, essayons de voir ce qu'il en est de la négrophobie. Cette phobie se situe sur le plan instinctuel, biologique. À l'extrême, nous dirons que le nègre par son corps gêne la fermeture du schéma postural du Blanc, au moment naturellement où le Noir fait son apparition dans le monde phénoménal du Blanc. Le lieu n'est pas ici de rapporter les conclusions auxquelles nous sommes parvenu en réfléchissant à l'influence sur le corps de l'irruption d'un autre corps. (Supposons, par exemple, un groupe de quatre garçons de quinze ans, sportifs plus ou moins déclarés. Pour le saut en hauteur, l'un d'eux l'emporte avec $1 \mathrm{~m}$ 48. Surgisse un cinquième qui franchit $1 \mathrm{~m} 52$, et les quatre corps subissent une déstructuration.) [151] Ce qui nous importe, c'est de montrer qu'avec le nègre commence le cycle du biologique 164 .

164 Il y aurait certainement intérêt, en s'appuyant sur la notion lacanienne du stade du miroir, à se demander dans quelle mesure l'imago du semblable édifiée chez le jeune Blanc à l'âge que l'on sait ne subirait pas une agression imaginaire à l'apparition du Noir. Quand on a compris ce processus décrit par Lacan, il ne fait plus de doute que le véritable Autrui du Blanc est et demeure le Noir. Et inversement. Seulement, pour le Blanc, Autrui est perçu sur le plan de l'image 
corporelle, absolument comme le non-moi, c'est-à-dire le non-identifiable, le non-assimilable. Pour le Noir, nous avons montré que les réalités historiques et économiques entraient en ligne de compte. «La reconnaissance par le sujet de son image dans le miroir, dit Lacan, est un phénomène qui pour l'analyse de ce stade est deux fois significatif : le phénomène apparaît après six mois, et son étude à ce moment révèle de façon démonstrative les tendances qui constituent alors la réalité du sujet : l'image spéculaire, en raison même de ces affinités, donne un bon symbole de cette réalité : de sa valeur affective, illusoire comme l'image, et de sa structure, comme elle reflet de la forme humaine. » (Encyclopédie française, 8-40, 9 et 10.)

Nous verrons que cette découverte est fondamentale: chaque fois que le sujet apercevra son image et qu'il la saluera, c'est toujours en quelque sorte «l'unité mentale qui lui est inhérente » qui est acclamée. En pathologie mentale, par exemple, si l'on considère les délires hallucinatoires ou d'interprétation, on constate que toujours il y a respect de cette image de soi. Autrement dit il y a une certaine harmonie structurale, une totalité de l'individu et des constructions qu'il transite, à tous les stades du comportement délirant. Outre qu'on pourrait attribuer cette fidélité aux contenus affectifs, il n'en demeure pas moins une évidence qu'il serait a-scientifique de méconnaître. Chaque fois qu'il y a conviction délirante il y a reproduction de soi. C'est surtout dans la période d'inquiétude et de méfiance qu'ont décrite Dide et Guiraud que l'autre intervient. Alors il n'est pas étonnant de retrouver le Noir sous forme de satyre ou d'assassin. Mais à la période de systématisation, quand s'élabore la certitude, il n'y a plus place pour l'étranger. A l'extrême, d'ailleurs, nous n'hésiterons pas à dire que le thème du nègre dans certains délires (quand il n'est pas central) prend place à côté d'autres phénomènes tels que les zoopsies. Lhermitte a décrit l'émancipation de l'image corporelle. C'est ce qu'en clinique on désigne par le terme d'héautoscopie. La soudaineté d'apparition de ce phénomène est, dit Lhermitte, excessivement curieuse. Il se produit même chez les normaux (Goethe, Taine, etc.). Nous affirmons que pour l'Antillais l'hallucination spéculaire est toujours neutre. À ceux qui nous ont dit l'avoir observée chez eux, nous avons posé régulièrement la question: «De quelle couleur étais-tu? J'étais sans couleur. » Mieux, dans les visions hypnagogiques et surtout dans ce que, depuis Duhamel, on appelle « salavinisations», le même processus se répète. Ce n'est pas moi en tant que Noir qui agit, pense ou est acclamé sous des voûtes.

D'ailleurs nous conseillons à ceux que ces conclusions intéressent de lire quelques compositions françaises d'enfants antillais de dix à quatorze ans. Au sujet posé : «Impressions avant de partir en vacances», ils répondent comme de véritables petits Parisiens et l'on retrouve les thèmes suivants:

«J'aime les vacances, car je pourrai courir à travers les champs, respirer un bon air et je reviendrai les joues roses. " On voit que nous ne nous trompions guère en laissant entendre qu'il y a de la part de l'Antillais méconnaissance de sa qualité de nègre. Nous avions peut-être treize ans lorsqu'il nous fut 
donné de voir pour la première fois des Sénégalais. Nous savions à leur sujet ce que racontaient les vieux de 1914 : «Ils attaquent à la baïonnette et, quand ça ne va pas, coupe-coupe au poing, foncent au travers des rafales de mitrailleuses... Ils coupent les « cabèches » et font provision d'oreilles. »Ils étaient de passage à la Martinique, venant de Guyane. Avides nous cherchions dans les rues leur uniforme, dont on nous avait parlé : chéchia et ceinturon rouges. Notre père alla jusqu'à en racoler deux qu'il emmena à la maison, où ils firent les délices de la famille. A l'école la même situation était entretenue : notre professeur de mathématiques, lieutenant de réserve, et qui commandait en 1914 une unité de tirailleurs sénégalais, nous faisait frémir en nous rappelant: «Quand ils prient il ne faut pas les troubler, car alors il n'y a plus de lieutenant. Des lions à la bagarre, mais respectez leurs coutumes. "Que l'on ne s'étonne plus si Mayotte Capécia se voit blanche et rose dans ses rêves: nous dirons que la chose est normale.

On nous objectera peut-être que si pour le Blanc il y a élaboration de l'imago du semblable, un phénomène analogue devrait se produire chez l'Antillais, la perception visuelle étant le canevas de cette élaboration. Mais ce serait oublier qu'aux Antilles la perception se situe toujours sur le plan de l'imaginaire. C'est en termes de Blanc que l'on y perçoit son semblable. On dira par exemple d'un tel qu'il est « très noir »; il n'y a rien d'étonnant, au sein d'une famille, à entendre la mère déclarer : «X... est le plus noir de mes enfants. » C'est-à-dire le moins blanc... Nous ne pouvons que répéter la réflexion d'une camarade européenne à qui nous parlions de cela : sur le plan humain, c'est une véritable mystification. Disons-le encore une fois, c'est en référence à l'essence du Blanc que tout Antillais est appelé à être perçu par son congénère. Aux Antilles tout comme en France, on rencontre le même mythe; à Paris on dit : il est noir mais très intelligent : en Martinique on ne s'exprime pas autrement. Pendant la guerre, des professeurs guadeloupéens venaient à Fort-deFrance corriger les épreuves du baccalauréat et, poussés par notre curiosité, nous allions voir, jusque dans l'hôtel où il était descendu, M. B.... professeur de philosophie, qui avait la réputation d'être excessivement noir ; comme on dit en Martinique, non sans quelque ironie, il était «bleu». Telle famille est très bien vue : «Ils sont très noirs, mais ils sont tous bien. » Il y a en effet un professeur de piano, ancien élève du Conservatoire, un professeur de sciences naturelles au lycée de jeunes filles, etc. Quant au père, qui tous les jours à la nuit tombante se promenait sur son balcon, à partir d'un certain moment, disait-on, on ne le voit plus. On racontait que dans une autre famille, à la campagne, lorsque la nuit venue l'électricité parfois manquait, les enfants devaient rire pour qu'on pût s'apercevoir de leur présence. Le lundi, très propres dans leur costume de toile blanche, certains fonctionnaires martiniquais ressemblent, selon la symbolique locale, « à un pruneau dans un bol de lait». 
Il ne viendrait par exemple à l'idée d'aucun antisémite de castrer le Juif. On le tue ou on le stérilise. Le nègre, [153] lui, est castré. Le pénis, symbole de virilité, est anéanti, c'est-à-dire qu'il est nié. On aperçoit la différence entre les deux attitudes. Le Juif est atteint dans sa personnalité confessionnelle, dans son histoire, dans sa race, dans les rapports qu'il entretient avec ses ancêtres et ses descendants; dans le Juif qu'on stérilise, on tue la souche: chaque fois qu'un Juif est persécuté, c'est toute la race qu'on persécute à travers lui. Mais c'est dans sa corporéité que l'on atteint le nègre. C'est en tant que personnalité concrète qu'on le lynche. C'est en tant qu'être actuel qu'il est dangereux. Le péril juif est remplacé par la peur de la puissance sexuelle du nègre. O. Mannoni, dans Psychologie de la Colonisation, écrit : « Un argument utilisé partout dans le monde, de la part des racistes contre ceux qui ne partagent pas leurs convictions, mérite d'être mentionné à cause de son caractère révélateur. «Quoi ? disent ces racistes, si vous aviez une fille à marier, la donneriez-vous à un nègre? "J'ai vu des gens qui n'étaient aucunement racistes en apparence, interloqués par ce genre d'argument, perdre tout sens critique. C'est qu'un tel argument touche en eux des sentiments très troubles (exactement incestueux), qui poussent au racisme par une réaction de défense 165. » Avant de continuer, il nous semble important de faire la remarque suivante : en admettant qu'il y ait tendances inconscientes à l'inceste, pourquoi ces tendances se manifesteraient-elles plus spécialement à l'égard du Noir? En quoi, dans l'absolu, un gendre noir diffère-t-il d'un gendre blanc? Dans les deux cas, n'y a-t-il pas affleurement des tendances inconscientes? Pourquoi ne pas penser, par exemple, que le père s'insurge parce que, selon lui, le nègre introduira sa fille dans un univers sexuel dont il ne possède pas la clef, les armes, les attributs?

Toute acquisition intellectuelle réclame une perte du potentiel sexuel. Le Blanc civilisé garde la nostalgie irrationnelle d'époques extraordinaires de licence sexuelle, de scènes orgiaques, de viols non 
sanctionnés, d'incestes non réprimés. Ces phantasmes, en un sens, répondent à l'instinct de vie de Freud. Projetant ses intentions chez [154] le nègre, le Blanc se comporte «comme si » le nègre les avait réellement. Quand il s'agit du Juif, le problème est net : on s'en méfie, car il veut posséder les richesses ou s'installer aux postes de commande. Le nègre, lui, est fixé au génital; ou du moins on l'y a fixé. Deux domaines : l'intellect et le sexuel. Le penseur de Rodin en érection, voilà une image qui choque. On ne peut décemment pas «faire le dur» partout. Le nègre représente le danger biologique. Le Juif, le danger intellectuel.

Avoir la phobie du nègre, c'est avoir peur du biologique. Car le nègre n'est que biologique. Ce sont des bêtes. Ils vivent nus. Et Dieu seul sait... O. Mannoni écrit encore : «Ce besoin de retrouver chez les singes anthropoïdes, chez Caliban ou chez les Noirs, et même chez les Juifs, la figure mythologique des satyres, touche dans l'âme humaine, à une profondeur 166 où la pensée est confuse et où l'excitation sexuelle est étrangement liée à l'agressivité et à la violence, des ressorts d'une grande puissance 167 . » L'auteur intègre le Juif dans la gamme. Nous n'y voyons pas d'inconvénient. Mais ici le nègre est maître. C'est le spécialiste de la question : qui dit viol dit nègre.

Pendant trois ou quatre ans, nous avons interrogé environ cinq cents individus de race blanche: Français, Allemands, Anglais, Italiens. Nous profitions d'un certain ton de confidence, d'un laisser-aller, en tout cas nous attendions que nos interlocuteurs n'aient point à craindre de s'ouvrir à nous, c'est-à-dire soient persuadés de ne pas nous vexer. Ou bien, au cours d'associations libres, nous insérions le mot nègre parmi une vingtaine d'autres. Près de six dixièmes des réponses se présentaient ainsi :

166 Nous verrons, en considérant les réponses fournies par le rêve éveillé, que ces figures mythologiques, « archétypes », sont en effet très profondes dans l'âme humaine. Chaque fois que l'individu descend, on rencontre le nègre, soit concrètement, soit symboliquement. 
Nègre = biologique, sexe, fort, sportif, puissant, boxeur, Joe Louis, Jess Owen, tirailleurs sénégalais, sauvage, animal, diable, péché.

Le mot de tirailleur sénégalais évoque ceux de : terrible, sanguinaire, costaud, fort.

Il est intéressant de constater qu'au mot nègre, un sur [155] cinquante répondait - nazi, S.S. : quand on sait la valeur affective de l'image du S.S., on voit que la différence avec les réponses précédentes est minime. Ajoutons que quelques Européens nous ont aidé et ont posé la question à des camarades: la proportion augmenta sensiblement. Il faut $y$ voir la conséquence de notre qualité de nègre: inconsciemment, il y avait une certaine retenue.

Le nègre symbolise le biologique. D'abord, chez eux, la puberté commence à neuf ans, ils ont des enfant à dix; ils sont chauds, ils ont le sang fort; ils sont robustes. Comme nous disait un Blanc dernièrement, avec un peu d'amertume dans la voix: «Vous êtes de forts tempéraments. »C'est une belle race, regardez les tirailleurs... Pendant la guerre, ne les a-t-on pas appelés nos Diables Noirs?... Mais ils doivent être brutaux... Je ne les vois pas touchant mes épaules de leurs grandes mains. J'en frissonne d'horreur. Sachant bien que dans certains cas il convient de lire à contresens, nous comprenons cette femme si délicate : au fond, ce qu'elle voit fort bien, c'est le robuste nègre martyrisant ses frêles épaules. Il y $a$, dit Sartre, quand on prononce l'expression « jeune Juive», un fumet imaginaire de viol, de pillage... Inversement, nous pourrions dire qu'il y a dans l'expression «beau Noir » une allusion « possible » à de semblables phénomènes. J'ai toujours été frappé par la rapidité avec laquelle on passe de «beau jeune Noir » à « jeune poulain, étalon». Dans un film: Le deuil sied à Electre, une bonne partie de l'intrigue est basée sur la rivalité sexuelle. 
Orin reproche à sa sœur Vinnie d'avoir admiré les splendides indigènes nus de lîle d'Amour. Il ne le lui pardonne pas ${ }^{168}$.

L'analyse du réel est délicate. Un chercheur peut adopter deux attitudes en face de son sujet. Ou bien il se contente de décrire, à la façon des anatomistes qui sont tous étonnés quand, au milieu d'une description du tibia, on leur demande le nombre de dépressions antépéronnières qu'ils possèdent. C'est que dans leur recherche il n'est jamais question d'eux, mais des autres ; au début de nos études médicales, après quelques séances nauséeuses de dissection, nous priâmes un endurci de nous donner le moyen d'éviter ces malaises. Il nous répondit fort simplement : "Mon cher, fais comme si tu disséquais un chat, et tout ira bien... »-Ou bien, après avoir décrit le réel, il se propose de le changer. En principe, d'ailleurs, l'intention de décrire semble bien impliquer un souci critique et par-là une exigence de dépassement vers quelque solution. La littérature officielle ou anecdotique a créé trop d'histoires de nègres pour qu'on les taise. Mais à les réunir, on n'avance pas dans la véritable tâche qui est d'en montrer le mécanisme. L'essentiel pour nous n'est pas d'accumuler des faits, des comportements, mais de dégager leur sens. Nous pourrions en cela nous récla-

168 Remarquons toutefois que la situation est ambiguë. Orin jalouse aussi le fiancé de sa soeur. Sur le plan psychanalytique, voici comment se présente l'action: Orin est un abandonnique fixé à la mère et qui est incapable de réaliser un véritable investissement objectal de sa libido. Voir par exemple son comportement vis-à-vis de sa prétendue fiancée. Vinnie, qui, elle, est fixée au père, démontre à Orin que sa mère le trahit. Mais que l'on ne s'y trompe point. C'est en tant qu'instance réquisitoriale (processus introjectionnel) qu'elle agit. Devant l'évidence de la trahison, Orin tue le rival. La mère, réactionnellement, se suicide. La libido d'orin, qui a besoin d'être investie sur le même mode, s'infléchit vers Vinnie. Vinnie en effet, dans son comportement et même dans son apparaître, se substitue à la mère. De sorte que, et c'est là une très belle réalisation du film, c'est un OEdipe incestueux qui est vécu par Orin. Aussi comprend-on qu'Orin ébranle l'air de ses lamentations et de ses reproches à l'annonce du mariage de sa sœur. Mais dans la lutte avec le fiancé c'est le sentiment, l'affectivité qu'il rencontre; avec le nègre, les splendides indigènes, le conflit se situe sur le plan génital, biologique. 
mer de Jaspers, lorsqu'il écrit : « La compréhension approfondie d'un seul cas nous permet souvent, phénoménologiquement, une application générale à des cas innombrables. Souvent ce qu'on a saisi une fois se retrouve bientôt. Ce qui importe en phénoménologie, c'est moins l'étude de cas innombrables que la compréhension intuitive et profonde de quelques cas particuliers ${ }^{169}$. "La question qui se pose est la suivante: le Blanc peut-il se comporter sainement vis-à-vis du Noir, le Noir peut-il se comporter sainement vis-à-vis du Blanc?

Pseudo-question, diront certains. Mais quand nous disons que la culture européenne possède une imago du [157] nègre responsable de tous les conflits qui peuvent naître, nous ne dépassons pas le réel. Dans le chapitre sur le langage, nous avons montré qu'à l'écran les nègres reproduisaient fidèlement cette imago. Même des écrivains sérieux s'en font les chantres. C'est ainsi que Michel Cournot écrit: «L'épée du Noir est une épée. Quand il a passé ta femme à son fil, elle a senti quelque chose. C'est une révélation. Dans le gouffre qu'ils ont laissé, ta breloque est perdue. À force de ramer, mettrais-tu la chambre en nage, c'est comme si tu chantais. On se dit Adieu... Quatre Noirs membre au clair combleraient une cathédrale. Pour sortir, ils devront attendre le retour à la normale; et dans cet entrelacis, ce n'est pas une sinécure.

»Pour se mettre à l'aise sans complications, il leur reste le plein air. Mais un dur affront les y guette : celui du palmier, de l'arbre à pain et de tant de fiers tempéraments qui ne débanderaient pas pour un empire, dressés comme ils sont pour l'éternité et à des hauteurs malgré tout malaisément accessibles 170 . »

Quand on lit ce passage une dizaine de fois et qu'on se laisse aller, c'est-à-dire quand on s'abandonne au mouvement des images, on n'aperçoit plus le nègre, mais un membre: le nègre est éclipsé. Il est fait membre. Il est pénis. On imagine facilement ce que de pareilles

169 Karl Jaspers, Psychopathologie générale, traduction Kastler et Mendousse, p. 49.

170 Martinique, Collection Métamorphoses, Gallimard, pp. 13-14. 
descriptions peuvent provoquer chez une jeune Lyonnaise. De l'horreur? Du désir? En tout cas, pas de l'indifférence. Or, quelle est la vérité ? La longueur moyenne du pénis chez le Noir d'Afrique, dit le $D^{r}$ Palès, dépasse rarement cent vingt millimètres. Testut, dans son Traité d'anatomie humaine, indique les mêmes chiffres pour l'Européen. Mais ce sont là des faits qui ne convainquent personne. Le Blanc est persuadé que le nègre est une bête; si ce n'est pas la longueur du pénis, c'est la puissance sexuelle qui le frappe. Il a besoin, en face de ce «différent de lui », de se défendre. C'est-à-dire de caractériser l'Autre. L'Autre sera le support de ses préoccupations et de ses désirs ${ }^{171}$. La prostituée que nous citions plus haut [158] nous rapportait que sa recherche des nègres datait du jour où on lui avait raconté l'histoire suivante: une femme, un soir qu'elle couchait avec un nègre,

171 Certains auteurs ont essayé, acceptant par-là les préjugés (au sens étymologique), de montrer pourquoi le Blanc comprend mal la vie sexuelle du Noir. C'est ainsi qu'on peut lire dans De Pédrals ce passage qui, exprimant pourtant la vérité, ne laisse pas moins de côté les causes profondes de «l'opinion» blanche: «L'enfant noir n'éprouve ni surprise ni honte des manifestations génésiques, parce qu'on lui livre ce qu'il tient à en savoir. Il est assez évident, et sans faire davantage appel aux subtilités de la psychanalyse, que cette différence ne peut manquer d'avoir des effets sur la manière de penser, donc d'agir. L'acte sexuel lui étant présenté comme la chose la plus naturelle, la plus recommandable même, en considération du but qu'elle poursuit: la fécondation, l'Africain continuera toujours, sa vie durant, à avoir présente à l'esprit cette notion tandis que l'Européen sa vie durant conservera inconsciemment un complexe de culpabilité que ni la raison ni l'expérience ne parviendront jamais à faire disparaître tout à fait. De la sorte l'Africain est disposé à ne considérer sa vie sexuelle que comme une branche de sa vie physiologique tout comme le manger, le boire et le dormir... Une conception de cet ordre est exclusive, on l'imagine, des détours auxquels se sont entraînés les esprits européens pour concilier les tendances d'une conscience torturée, d'une raison vacillante et d'un instinct entravé. D'où une différence foncière non point de nature, de constitution, mais de conception, d'où également le fait que l'instinct génésique, privé de l'auréole dont l'entourent les monuments de notre littérature, n'est point du tout dans la vie de l'Africain l'élément dominant qu'il constitue dans la nôtre propre, au contraire des affirmations de trop d'observateurs disposés à expliquer ce qu'ils ont vu par le seul moyen de l'analyse de soi-même (a) » (La vie sexuelle en Afrique noire, pp. 28-29).

(a) Souligné par nous. 
perdit la raison ; elle resta folle pendant deux ans, mais, guérie, refusa de coucher avec un autre homme. Elle ne savait pas ce qui avait rendu folle cette femme. Mais, rageusement, elle essayait de reproduire la situation, de retrouver ce secret qui participait de l'ineffable. Il faut comprendre que ce qu'elle voulait c'était une rupture, une dissolution de son être sur le plan sexuel. Chaque expérience qu'elle tentait avec un nègre consolidait ses limites. Ce délire orgasmique lui échappait. Elle ne pouvait le vivre, aussi se vengeait-elle en se jetant dans la spéculation.

À ce propos, il faut mentionner un fait: une Blanche qui a couché avec un nègre accepte difficilement un amant blanc. Du moins est-ce une croyance que nous avons rencontrée surtout chez les hommes: «Qui sait ce qu'« ils » leur donnent? » En effet, qui le sait? Certainement pas eux. Nous ne pouvons à ce sujet passer sous silence cette remarque d'Etiemble: «La jalousie [159] raciale incite aux crimes du racisme : pour beaucoup d'hommes blancs, le Noir est justement cette épée merveilleuse dont transfixées leurs femmes à jamais seraient transfigurées. Mes services de statistiques ne m'ont point donné de documents à ce propos. J'ai pourtant connu des nègres. Des Blanches qui ont connu des Noirs. Des négresses enfin qui ont connu des Blancs. J'en ai reçu assez de confidences pour regretter que M. Cournot revigore de son talent une fable où le Blanc saura toujours trouver un spécieux argument : inavouable, douteux, deux fois donc efficace ${ }^{172}$. »

Une tâche colossale que l'inventaire du réel. Nous amassons des faits, nous les commentons, mais à chaque ligne écrite, à chaque proposition énoncée, nous ressentons une impression d'inachèvement. Dénonçant J.-P. Sartre, Gabriel d'Arbousier écrit: « Cette anthologie qui met sur le même pied Antillais, Guyannais, Sénégalais et Malgaches crée une regrettable confusion. Elle pose de ce fait le problème culturel des pays d'outre-mer en le détachant de la réalité historique et sociale de chaque pays, des caractéristiques nationales et des conditions différentes imposées à chacun d'eux par l'exploitation et

172 « Sur le Martinique de M. Michel Cournot», Temps Modernes, février 1950. 
l'oppression impérialistes. Ainsi lorsque Sartre écrit : « Le Noir, par le simple approfondissement de sa mémoire d'ancien esclave, affirme que la douleur est le lot des hommes et qu'elle n'en est pas moins imméritée», se rend-il compte de ce que cela peut signifier pour un Hova, un Maure, un Targui, un Peulh ou un Bantou du Congo ou de la Côted'Ivoire 173 ? »

Cette objection est valable. Elle nous atteint aussi. Au début, nous voulions nous cantonner aux Antilles. Mais la dialectique, coûte que coûte, reprend le dessus et nous avons été obligé de voir que l'Antillais est avant tout un Noir. Toutefois, nous ne saurions oublier qu'il y a des Noirs de nationalité belge, française, anglaise; il existe des républiques nègres. Comment prétendre à la saisie d'une essence quand de tels faits nous requièrent? La [160] vérité est que la race nègre est dispersée, qu'elle ne possède plus d'unité. Lors de l'invasion de l'Ethiopie par les forces du Duce, un mouvement de solidarité s'amorça chez les hommes de couleur. Mais si, d'Amérique, un ou deux avions furent envoyés à l'agressé, aucun Noir ne bougea effectivement. Le nègre possède une patrie, prend place dans une Union ou un Commonwealth. Toute description doit se situer sur le plan du phénomène, mais là encore nous sommes renvoyé à des perspectives infinies. Il y a une ambiguiité dans la situation universelle du nègre, qui se résout toutefois dans son existence concrète. Par-là il rejoint en quelque sorte le Juif. Contre les obstacles allégués ci-dessus, nous ferons appel à une évidence : où qu'il aille, un nègre demeure un nègre.

Dans certains pays, le Noir a pénétré la culture. Comme nous le laissons entendre ci-dessus, on ne saurait attacher trop d'importance à la façon selon laquelle les enfants blancs prennent contact avec la réalité du nègre. En Amérique, par exemple, le jeune Blanc, même s'il n'habite pas le Sud où il a l'occasion de voir des nègres concrètement, les connaît à travers le mythe de l'oncle Rémus. - En France, on pourrait évoquer La Case de l'Oncle Tom. Le petit garçon de Miss Sally et

173 Gabriel d'Arbousier, « Une dangereuse mystification : la théorie de la négritude», La Nouvelle Critique, juin 1949. 
Mars John écoute avec un mélange de crainte et d'admiration les histoires de Brer Rabbitt. Bernard Wolfe fait de cette ambivalence chez le Blanc la dominante de la psychologie blanche américaine. Il va même, en s'appuyant sur la biographie de Joel Chandler Harris, jusqu'à montrer que l'admiration correspond à une certaine identification du Blanc avec le Noir. On sait de quoi il est question dans ces histoires. Frère Lapin entre en lutte avec presque tous les autres animaux de la création et naturellement il est toujours vainqueur. Ces histoires appartiennent à la tradition orale des nègres des plantations. Aussi a-t-on reconnu assez facilement le Noir sous sa livrée extraordinairement ironique et méfiante du lapin. Les Blancs, pour se défendre de leur masochisme inconscient, qui voulait qu'ils s'extasient devant les prouesses du lapin - noir - ont essayé d'enlever à ces histoires leur potentiel agressif. C'est ainsi qu'ils ont pu se dire que «le Noir fait agir des animaux comme un ordre inférieur de l'intelligence humaine, celui que le [161] Noir lui-même peut comprendre. Le Noir se sent naturellement en contact plus étroit avec les "animaux inférieurs qu'avec l'homme blanc qui lui est tellement supérieur à tous égards. D'autres ont, ni plus ni moins, avancé que ces histoires n'étaient pas des réactions à la condition faite aux Noirs en Amérique, mais simplement des survivances africaines. - Wolfe nous donne la clef de ces interprétations: «De toute évidence, dit-il, Frère Lapin est un animal parce que le Noir doit être un animal ; le Lapin est un étranger parce que le Noir doit être marqué comme étranger jusques aux chromosomes. Depuis le début de l'esclavage, sa culpabilité démocratique et chrétienne en tant que propriétaire d'esclaves, conduisait le Sudiste à définir le Noir comme une bête, un Africain inaltérable dont le caractère était fixé dans le protoplasma par des gènes «africains». Si le Noir se voyait assigner les limbes humains, ce n'était pas par l'Amérique mais par l'infériorité constitutionnelle de ses ancêtres de la jungle. » Ainsi le Sudiste refusait de voir dans ces histoires l'agressivité qu'y mettait le Noir. Mais, dit Wolfe, Harris le compilateur était un psychopathe: «Il était particulièrement apte à ce travail, car il était bourré à craquer d'obsessions raciales pathologiques en sus de celles qui rongeaient le Sud et, à un degré moindre, toute l'Amérique blanche... En vérité, pour 
Harris aussi bien que pour beaucoup d'autres Américains blancs, le Noir semblait à tous égards un négatif de son propre moi anxieux: insouciant, sociable, éloquent, musculairement détendu, jamais en proie à l'ennui, ou passif, exhibitionniste sans honte, dégagé de l'apitoiement sur soi-même dans sa situation de souffrance concentrée, exubérant... » Mais Harris eut toujours l'impression d'être handicapé. Aussi Wolfe voit-il en lui un frustré, - mais non pas selon le schéma classique: c'est en son essence que réside l'impossibilité d'exister sur le mode «naturel » du Noir. On ne le lui interdit pas : cela lui est impossible. Pas interdit, mais irréalisable. Et c'est parce que le Blanc se sent frustré par le Noir, qu'il va lui aussi le frustrer, l'enserrant dans des interdictions de toutes sortes. Et, là encore, le Blanc est la proie de son inconscient. Ecoutons toujours Wolfe: «Les histoires de Rémus sont un monument à l'ambivalence [162] du Sud. Harris, l'archétype du Sudiste, recherchait l'amour du Noir et prétendait qu'il l'avait obtenu (le grin de Rémus) ${ }^{174}$. Mais il recherchait en même temps la haine du Noir (Frère Lapin), en faisait ses délices, dans une orgie inconsciente de masochisme, - se punissant peut-être bien de n'être pas le Noir, le stéréotype du Noir, le « donateur » prodigue. Ne se peut-il que le Sud blanc, et peut-être la plus grande partie de l'Amérique blanche, agisse souvent de même dans ses rapports avec le Noir?»

Il y a une quête du Noir, on réclame le Noir, on ne peut pas se passer du Noir, on l'exige, mais on le veut assaisonné d'une certaine façon. Malheureusement, le nègre démonte le système et viole les traités. Le Blanc va-t-il s'insurger? Non, il s'en accommode. Ce fait, dit Wolfe, explique pourquoi beaucoup d'ouvrages traitant des questions raciales sont des best sellers ${ }^{175}$. "Personne certainement n'est obligé de consommer des histoires de Noirs faisant l'amour aux Blanches (Deep are the roots, Strange fruit, Uncle Remus), de Blancs découvrant qu'ils

174 Le personnage de l'Oncle Rémus est une création de Harris. L'introduction de ce vieil esclave doucereux et mélancolique, avec son éternel grin, est une des images les plus typiques du Noir américain.

175 Voir aussi les nombreux films noirs des dix dernières années. Pourtant, les producteurs sont tous blancs. 
sont des Noirs (Kingsblood royal, Lost boundary, Uncle Remus), de Blancs étranglés par des Noirs (Native son; If he hollers, let him go, Uncle Remus)... Nous pouvons empaqueter et exposer sur une grande échelle le grin du Noir dans notre culture populaire comme un manteau pour ce masochisme: la caresse sucre l'attaque. Et, comme le montre l'oncle Remus, le jeu des races est ici, pour une grande part, inconscient. Le Blanc n'est pas plus conscient de son masochisme lorsqu'il est émoustillé par le contenu subtil du grin stéréotypé que le Noir ne l'est de son sadisme quand il convertit le stéréotype en gourdin culturel. Peut-être moins ${ }^{176}$. »

En Amérique, comme on le voit, le nègre crée des histoires où il lui devient possible d'exercer son agressivité : l'inconscient du Blanc justifie et valorise cette agressivité [163] en l'infléchissant vers lui, reproduisant ainsi le schéma classique du masochisme 177.

Nous pouvons maintenant poser un jalon. Pour la majorité des Blancs, le Noir représente l'instinct sexuel (non éduqué). Le nègre incarne la puissance génitale au-dessus des morales et des interdictions. Les Blanches, elles, par une véritable induction, aperçoivent régulièrement le nègre à la porte impalpable qui donne sur le royaume des Sabbats, des Bacchanales, des sensations sexuelles hallucinantes... Nous avons montré que le réel infirme toutes ces croyances. Mais cela se place sur le plan de l'imaginaire, en tout cas sur celui d'une paralogique. Le Blanc qui attribue au Noir une influence maléfique régresse sur le plan intellectuel, puisque nous avons montré qu'il percevait à un âge mental de huit ans (illustrés... ). N'y a-t-il pas concurremment régression et fixation à des phases prégénitales de l'évolution sexuelle?

176 Bernard Wolfe, «L'oncle Rémus et son lapin», Temps Modernes, $n^{\circ} 43$, mai 1949.

177 Il est habituel en Amérique de s'entendre dire, quand on réclame l'émancipation des Noirs: ils n'attendent que cette occasion pour se jeter sur nos femmes. Comme le Blanc se comporte d'une façon insultante envers le Noir, il se rend compte qu'à la place du Noir il n'aurait aucune pitié pour ses oppresseurs. Aussi n'est-il pas étonnant de le voir s'identifier au nègre: orchestres hot blancs, chanteurs de blues, de spirituals, écrivains blancs rédigeant des romans où le héros nègre formule ses doléances, Blancs se barbouillant de noir. 
Auto-castration? (Le nègre est appréhendé avec un membre effarant.) Passivité s'expliquant par la reconnaissance de la supériorité du Noir en termes de virilité sexuelle? On voit le nombre des questions qu'il serait intéressant de poser. Il y a des hommes, par exemple, qui vont dans des « maisons » se faire fouetter par des Noirs; des homosexuels passifs, qui exigent des partenaires noirs.

Une autre solution serait la suivante: il y a d'abord agressivité sadique vis-à-vis du Noir, puis complexe de culpabilité à cause de la sanction que fait peser sur ce comportement la culture démocratique du pays considéré. Cette agressivité est alors supportée par le Noir, d'où masochisme. Mais, nous dira-t-on, votre schéma est faux: on n'y retrouve pas les éléments du masochisme classique. Peut-être, en effet, cette situation n'est-elle pas classique. En tout cas, c'est la seule façon d'expliquer le comportement masochiste du Blanc.

[164]

D'un point de vue heuristique, sans présumer de la réalité, nous aimerions proposer une explication du phantasme: un nègre me viole. Depuis les études d'Hélène Deutsch 178 et de Marie Bonaparte ${ }^{179}$, qui ont toutes deux repris et en quelque sorte porté à leur terme ultime les idées de Freud sur la sexualité féminine, nous savons que, alternativement clitoridienne, clitorido-vaginale, puis vaginale pure, la femme - conservant plus ou moins intriquées sa libido conçue comme passive et son agressivité, ayant franchi son double complexe d'Oedipe - arrive, au terme de sa progression biologique et psychologique, à l'assomption de son rôle que réalise l'intégration neuropsychique. Pourtant, nous ne saurions passer sous silence certains ratés ou certaines fixations.

$\grave{A}$ la phase clitoridienne correspond un complexe d'Oedipe actif, bien que, selon Marie Bonaparte, il n'y ait pont succession mais coexistence de l'actif et du passif. La désexualisation de l'agressivité chez la

178 Psychology of women.

179 De la sexualité de la femme. 
fille est moins réussie que chez le garçon ${ }^{180}$. Le clitoris est perçu comme pénis en raccourci, mais, dépassant le concret, la fille ne retient que la qualité. C'est en termes qualitatifs qu'elle appréhende le réel. Comme chez le petit garçon existeront en elle des pulsions dirigées vers la mère; elle aussi voudrait éventrer la mère.

Or nous nous demandons si, à côté de la réalisation définitive de la féminité, il n'y aurait pas persistance de ce fantasme infantile. "Une trop vive aversion des jeux brutaux de l'homme, chez une femme, est d'ailleurs suspect stigmate de protestation mâle et de bi-sexualité excessive. Une telle femme a des chances d'être une clitoridienne ${ }^{181}$. » Voici ce que nous en pensons. D'abord la petite fille voit battre un enfant rival par le père, libidinal agressif. À ce stade (cinq à neuf ans), le père, maintenant le pôle libidinal, refuse en quelque sorte d'assumer l'agressivité que l'inconscient de la petite fille exige de lui. À ce moment, cette agressivité libérée, sans support, réclame [165] un investissement. Comme c'est à cet âge que l'enfant pénètre le folklore et la culture sous la forme que l'on sait, le nègre devient le dépositaire prédestiné de cette agressivité. Si nous pénétrons davantage dans le labyrinthe, nous constatons: quand la femme vit le phantasme de viol par un nègre, c'est en quelque sorte la réalisation d'un rêve personnel, d'un souhait intime. Réalisant le phénomène du retournement contre soi, c'est la femme qui se viole. Nous en trouvons la preuve certaine dans le fait qu'il n'est pas étonnant que les femmes, au cours du coït, disent au partenaire: «Fais-moi mal. » Elles ne font qu'exprimer cette idée: fais-moi mal comme je me (le) ferais si j'étais à ta place. Le phantasme du viol par le nègre est une variante de cette représentation: «Je souhaite que le nègre m'éventre comme moi je l'aurais fait d'une femme. »Admettant nos conclusions sur la psychosexualité de la femme blanche, on pourrait nous demander celles que nous proposerions pour la femme de couleur. Nous n'en savons rien. Ce que nous pouvons avancer tout au moins, c'est que, pour beaucoup d'Antillaises,

180 Marie Bonaparte, «De la sexualité de la femme», Revue française de Psychanalyse, avril-juin 1949.

181 Ibid., p. 180. 
que nous appellerons les juxta-Blanches, l'agresseur est représenté par le Sénégalais-type, ou en tout cas par un inférieur (considéré comme tel).

Le nègre est le génital. Toute l'histoire est-elle là? Malheureusement non. Le nègre est autre chose. Ici encore, nous rencontrons le Juif. Le sexe nous départage, mais nous avons un point commun. Tous deux nous représentons le Mal. Le Noir davantage, pour la bonne raison qu'il est noir. Ne dit-on pas, dans la symbolique, la Blanche Justice, la Blanche Vérité, la Blanche Vierge? Nous avons connu un Antillais qui, parlant d'un autre, disait: "Son corps est noir, sa langue est noire, son âme aussi doit être noire. » Cette logique, le Blanc la réalise quotidiennement. Le Noir est le symbole du Mal et du Laid.

M. Henri Baruk, dans son nouveau précis de psychiatrie 182, décrit ce qu'il appelle les psychoses antisémites.

«Chez un de nos malades, la grossièreté et l'obscénité du délire dépassait tout ce que la langue française peut contenir et présentait par sa forme des allusions évidentes [166] et pédérastiques 183 dont le sujet détournait la honte intime en la transférant sur le bouc émissaire des Juifs sur qui il appelait le massacre. Un autre malade, atteint d'une bouffée délirante favorisée par les événements de 1940, présente un brusque délire d'interprétation antisémite si violent que se trouvant un jour

182 Masson, 1950, p. 371.

183 Mentionnons rapidement quil ne nous a pas été donné de constater la présence manifeste de pédérastie en Martinique. Il faut y voir la conséquence de l'absence de l'OEdipe aux Antilles. On connaît en effet le schéma de I'homosexualité. Rappelons toutefois l'existence de ce qu'on appelle là-bas « des hommes habillés en dames » ou "Ma Commère ». Ils ont la plupart du temps une veste et une jupe. Mais nous restons persuadé qu'ils ont une vie sexuelle normale. Ils prennent le punch comme n'importe quel gaillard et ne sont pas insensibles aux charmes des femmes, - marchandes de poissons, de légumes. Par contre en Europe nous avons trouvé quelques camarades qui sont devenus pédérastes, toujours passifs. Mais ce n'était point là homosexualité névrotique, c'était pour eux un expédient comme pour d'autres celui de souteneur. 
dans un hôtel, et soupçonnant que le voyageur de la chambre voisine était un Juif, il se précipita la nuit dans sa chambre pour l'assommer...

» Un autre malade, de constitution physique souffreteuse, atteint de colite chronique, était humilié de sa mauvaise santé et finalement l'avait attribuée à un empoisonnement par un «bouillon bactérien » qui lui aurait été donné par des infirmiers d'un établissement où il était précédemment, - infirmiers anticléricaux et communistes, disait-il, qui avaient voulu le punir pour ses opinions et ses convictions catholiques. Arrivé dans notre service, échappé à un «personnel syndicaliste», il se crut tombé de Charybde en Scylla, puisqu'il se trouvait entre les mains d'un Juif. Ce Juif ne pouvait être que, par définition, un bandit, un monstre, un homme capable de tous les crimes. »

Ce Juif, en face de cette montée d'agressivité, devra prendre position. C'est toute l'ambiguiité que décrit Sartre. Certaines pages de Réflexions sur la question juive sont les plus belles que nous ayons jamais lues. Les plus belles, parce que le problème qu'elles expriment nous prend aux entrailles 184 .

184 Nous pensons plus spécialement à ce passage: « Tel est donc cet homme, traqué, condamné à se choisir sur la base de faux problèmes et dans une situation fausse, privé du sens métaphysique par l'hostilité menaçante de la Société qui l'entoure, acculé à un rationalisme de désespoir. Sa vie n'est qu'une longue fuite devant les autres et devant lui-même, on lui a aliéné jusqu'à son propre corps, on a coupé en deux sa vie affective, on l'a réduit à poursuivre dans un monde qui le rejette le rêve impossible d'une fraternité universelle. A qui la faute? $\mathrm{Ce}$ sont nos yeux qui lui renvoient l'image inacceptable qu'il veut se dissimuler. Ce sont nos paroles et nos gestes - toutes nos paroles et tous nos gestes, notre antisémitisme, mais tout aussi bien notre libéralisme condescendant - qui l'ont empoisonné jusqu'aux moelles ; c'est nous qui le contraignons à se choisir juif, soit qu'il se fuie, soit qu'il se revendique, c'est nous qui l'avons acculé au dilemme de l'inauthenticité ou de l'authenticité... Cette espèce d'hommes, qui témoigne de l'homme plus que toutes les autres, parce qu'elle est née de réactions secondaires à l'intérieur de l'humanité, cette quintessence d'homme disgraciée, déracinée, originellement vouée à l'inauthenticité ou au martyre. Il 
[167]

Le Juif, authentique ou inauthentique, tombe sous le coup du « salaud». La situation est telle que tout ce qu'il fait est appelé à se retourner contre lui. Car naturellement le Juif se choisit, et il lui arrive d'oublier sa juiverie, ou de la cacher, de s'en cacher. C'est qu'il admet alors pour valable le système de l'aryen. Il y a le Bien et le Mal. Le Mal est juif. Tout ce qui est juif est laid. Ne soyons plus juifs. Je ne suis plus juif. À bas les Juifs. - En l'occurrence, ce sont les plus agressifs. Tel ce malade de Baruk atteint de délire de persécution, qui, l'apercevant un jour porteur de l'étoile jaune, le toisa en s'écriant avec mépris : «Eh bien! moi, monsieur, je suis français.» Et celle-ci : «En traitement dans le service de notre collègue, le $D^{r}$ Daday, se trouvant dans un pavillon où une de ses coreligionnaires a été l'objet de moqueries et de réflexions désagréables de la part d'autres malades. Une malade non juive a pris sa défense. La première malade traite alors celle qui a pris la défense des Juifs avec mépris et lui lance à la tête toutes les calomnies antisémites en demandant qu'on la débarrasse de cette Juive ${ }^{185}$. »

On a ici un bel exemple de phénomène réactionnel. Le Juif, pour réagir contre l'antisémitisme, se fait antisémite. C'est ce que montre Sartre dans Le Sursis, où Birnenschatz arrive à vivre son reniement avec une intensité [168] qui frise le délire. Nous verrons que le mot n'est pas trop fort. Les Américains qui viennent à Paris s'étonnent d'y voir tant de Blanches en compagnie de Noirs. À New York, Simone de Beauvoir, se promenant avec Richard Wright, se fait rappeler à l'ordre par une vieille dame. Sartre disait : ici c'est le Juif, ailleurs c'est le nègre. Ce qu'il faut, c'est un bouc émissaire. Baruk ne dit pas autre chose: "La délivrance des complexes de haine ne sera obtenue que si I'humanité sait renoncer au complexe du bouc émissaire. »

n'est pas un de nous qui ne soit, en cette circonstance, totalement coupable et même criminel ; le sang juif que les nazis ont versé retombe sur toutes nos têtes » (pp. 177-178).

Baruk, op. cit., pp. 372-373. 
La Faute, la Culpabilité, le refus de cette culpabilité, la paranoïa, on se retrouve en terrain homosexuel. En résumé, ce que d'autres ont décrit dans le cas des Juifs s'applique parfaitement au nègre 186.

Bien-Mal, Beau-Laid, Blanc-Noir : tels sont les couples caractéristiques du phénomène que, reprenant une expression de Dide et Guiraud, nous appellerons « manichéisme délirant 187 ».

Ne voir qu'un type de nègre, assimiler l'antisémitisme à la négrophobie, telles semblent être les erreurs d'analyse commises ici. Quelqu'un à qui nous parlions de notre travail nous demanda ce que nous en attendions. Depuis l'étude décisive de Sartre, Qu'est-ce que la littérature? (Situations II), la littérature s'engage de plus en plus dans sa seule tâche vraiment actuelle, qui est de faire passer la collectivité à la réflexion et à la médiation : ce travail voudrait être un miroir à infra-structure progressive, où pourrait se retrouver le nègre en voie de désaliénation.

Quand il n'y a plus le « minimum humain», il n'y a pas de culture. Il m'importe peu de savoir que le «Muntu est Force» chez les Bantous 188, - ou du moins cela aurait pu m'intéresser, n'étaient certains détails qui me gênent. Que signifient les méditations sur l'ontologie bantoue, [169] quand on lit par ailleurs: « Lorsque soixante-quinze mille mineurs noirs se sont mis en grève en 1946, la police d'Etat les a contraints à coups de fusil et à coups de baïonnette à reprendre le travail. Il y a eu vingt-cinq morts, des milliers de blessés.

186 C'est ainsi que Marie Bonaparte écrit : « Les antisémites projettent sur le juif, attribuent au juif tous leurs mauvais instincts plus ou moins inconscients... Ainsi, en s'en déchargeant sur son dos, ils s'en lavent eux-mêmes et apparaissent à leurs propres yeux tout rayonnants de pureté. Le juif se prête ainsi à merveille à être une projection du Diable... Les nègres en Amérique assument aussi une telle fonction de fixation... » (Mythes de guerre, p. 145, $n^{\circ} \mathrm{I}$ ).

187 Psychiatrie du médecin praticien, Masson, 1922, p. 164.

188 R. P. Tempels, La philosophie bantoue. 
»Smuts était à cette époque à la tête du gouvernement et délégué à la Conférence de la Paix. Dans les fermes blanches, les travailleurs noirs vivent presque comme des serfs. Ils peuvent emmener leurs familles, mais aucun homme ne peut quitter la ferme sans l'autorisation de son maître. S'il le fait, la police en est avertie, il est ramené de force et fouetté...

»En vertu de l'Acte sur l'Administration indigène, le gouverneur général, en tant que chef suprême, a des pouvoirs autocratiques sur les Africains. Il peut, par proclamation, arrêter et détenir tout Africain jugé dangereux pour la tranquillité publique. Il peut interdire dans n'importe quel secteur indigène les rassemblements de plus de dix personnes. Il n'y a pas d'Habeas Corpus pour les Africains. A n'importe quel moment sont opérées des arrestations en masse sans mandat.

» Les populations non blanches de l'Afrique du Sud sont dans une impasse. Toutes les formes modernes de l'esclavage les empêchent d'échapper à ce fléau. Pour l'Africain en particulier, la société blanche a brisé son ancien monde sans lui en donner un nouveau. Elle a détruit les bases tribales traditionnelles de son existence et barre la route de l'avenir après avoir fermé la route du passé...

» L'apartheid prétend lui interdire (au nègre) de participer à I'histoire moderne en tant que force indépendante et libre ${ }^{189}$.»

Nous nous excusons de ce long extrait, mais il permet de rendre évidentes quelques possibilités d'erreurs noires. Alioune Diop, par exemple, dans son introduction à La philosophie bantoue, remarque que l'ontologie bantoue ne connaît pas cette misère métaphysique de l'Europe. L'inférence qu'il en tire est toutefois dangereuse: « La double [170] question qui se pose est de savoir si le génie noir doit cultiver ce qui fait son originalité, cette jeunesse de l'âme, ce respect inné

189 I. R. Skine, « Apartheid en Afrique du Sud », Temps Modernes, juillet 1950. 
de l'homme et du créé, cette joie de vivre, cette paix qui est non point défiguration de l'homme imposée et subie par hygiène morale, mais harmonie naturelle avec la majesté heureuse de la vie... On se demande aussi ce que le Noir peut apporter au monde moderne... Ce que nous pouvons dire, c'est que la notion même de culture conçue comme volonté révolutionnaire est contraire à notre génie comme la notion même de progrès. Le progrès n'eût hanté notre conscience que si nous avions quelques griefs contre la vie, donnée naturelle. "Attention! Il ne s'agit pas de retrouver l'Etre dans la pensée bantoue, quand l'existence des Bantous se situe sur le plan du non-être, de l'impondérable 190. Bien sûr, la philosophie bantoue ne se laisse pas comprendre à partir d'une volonté révolutionnaire: mais c'est justement dans la mesure où, la société bantoue étant fermée, on n'y trouve pas cette substitution de l'exploitant aux relations ontologiques des Forces. Or, nous savons que la société bantoue n'existe plus. Et la ségrégation n'a rien d'ontologique. Assez de ce scandale.

Depuis quelque temps, on parle beaucoup du nègre. Un peu trop. Le nègre voudrait qu'on l'oublie, afin de regrouper ses forces, ses authentiques forces.

Un jour il a dit : « Ma négritude n'est ni une tour... »

Et l'on est venu l'helléniser, l'orphéiser... ce nègre qui recherche l'universel. Il recherche l'universel! Mais en juin 1950, les hôtels parisiens refusaient de loger des pèlerins noirs. Pourquoi? Tout simplement parce que les clients anglo-saxons (qui sont riches et négrophobes, comme chacun sait) risquaient de déménager.

Le nègre vise l'universel, mais, à l'écran, on maintient intacte son essence nègre, sa « nature » nègre :

190 Voir par exemple : Pleure, ô pays bien-aimé, de Alan Paton. 


\author{
« toujours serviteur \\ toujours obséquieux et souriant \\ moi, jamais voler, jamais mentir \\ éternellement y a bon banania... »
}

[171]

Le nègre s'universalise, mais au lycée Saint-Louis, à Paris, on en balance un : a eu l'impudence de lire Engels.

Il y a là un drame, et les intellectuels noirs risquent de s'y engluer.

Comment? J'ai à peine ouvert les yeux qu'on avait bâillonnés, et déjà l'on veut me noyer dans l'universel ? Et les autres? Ceux qui n'ont «point de bouche», ceux qui n'ont «point de voix "... J'ai besoin de me perdre dans ma négritude, de voir les cendres, les ségrégations, les répressions, les viols, les discriminations, les boycottages. Nous avons besoin de toucher du doigt toutes les plaies qui zèbrent la livrée noire.

L'on voit déjà Alioune Diop se demander quelle sera la position du génie noir dans le chœur universel. Or, nous disons qu'une véritable culture ne peut naître dans les conditions actuelles. On parlera de génie noir quand l'homme aura retrouvé sa véritable place.

Encore une fois, nous ferons appel à Césaire: nous voudrions que beaucoup d'intellectuels noirs s'en inspirent. Il faut qu'à moi aussi je me répète : «Et surtout, mon corps, aussi bien que mon âme, gardezvous de vous croiser les bras en l'attitude stérile du spectateur, car la vie n'est pas un spectacle, car une mer de douleurs n'est pas un proscénium, car un homme qui crie n'est pas un ours qui danse... »

Continuant à inventorier le réel, m'efforçant de déterminer le moment de la cristallisation symbolique, je me suis trouvé tout naturellement aux portes de la psychologie jungienne. La civilisation européenne se caractérise par la présence, au sein de ce que Jung appelle l'Inconscient collectif, d'un archétype: expression des mauvais instincts, de l'obscur inhérent à tout Moi, du sauvage non civilisé, du nè- 
gre qui sommeille chez tout Blanc. Et Jung affirme avoir constaté chez les peuples non civilisés la même structure psychique que reproduit son diagramme. Personnellement, je pense que Jung s'est abusé. D'ailleurs, tous les peuples qu'il a connus - Indiens Pueblos de l'Arizona ou nègres du Kenya en A.O. britannique - ont eu des contacts plus ou moins traumatiques avec les Blancs. Nous avons dit, plus haut, que, dans ses salavinisations, [172] le jeune Antillais n'est jamais noir ; et nous avons tenté de montrer à quoi correspond ce phénomène. Jung situe l'inconscient collectif dans la substance cérébrale héritée. Mais l'inconscient collectif, sans qu'il soit besoin de recourir aux gènes, est tout simplement l'ensemble de préjugés, de mythes, d'attitudes collectives d'un groupe déterminé. Il est entendu, par exemple, que les Juifs qui se sont installés en Israël donneront naissance en moins de cent ans à un inconscient collectif différent de celui qui était le leur en 1945 dans les pays d'où ils ont été expulsés.

Sur le plan de la discussion philosophique, on soulèverait ici le vieux problème de l'instinct et de l'habitude : l'instinct, qui est inné (on sait ce qu'il faut penser de cette «innéite»), invariable, spécifique: l'habitude, qui est acquise. Il y aurait sur ce plan tout simplement à démontrer que Jung confond instinct et habitude. Selon lui, en effet, l'inconscient collectif est solidaire de la structure cérébrale, les mythes et archétypes sont des engrammes permanents de l'espèce. Nous espérons avoir montré qu'il n'en est rien et qu'en fait cet inconscient collectif est culturel, c'est-à-dire acquis. De même qu'un jeune campagnard des Carpathes, dans les conditions physico-chimiques de la région, verra apparaître chez lui un myxœdème, de même un nègre comme René Maran, ayant vécu en France, respiré, ingéré les mythes et préjugés de l'Europe raciste, assimilé l'inconscient collectif de cette Europe, ne pourra, s'il se dédouble, que constater sa haine du nègre. Il faut aller doucement, et c'est un drame que de devoir exposer petit à petit des mécanismes qui s'offrent dans leur totalité. Pourra-t-on comprendre cette proposition? En Europe, le Mal est représenté par le Noir. Il faut aller doucement, nous le savons, mais c'est difficile. Le bourreau c'est l'homme noir, Satan est noir, on parle de ténèbres, 
quand on est sale on est noir, - que cela s'applique à la saleté physique ou à la saleté morale. On serait surpris, si on prenait la peine de les réunir, du très grand nombre d'expressions qui font du Noir le péché. En Europe, le nègre, soit concrètement, soit symboliquement, représente le côté mauvais de la personnalité. Tant qu'on n'aura pas compris cette proposition, on se condamnera [173] à parler vainement sur le «problème noir». Le noir, l'obscur, l'ombre, les ténèbres, la nuit, les labyrinthes de la terre, les profondeurs abyssales, noircir la réputation de quelqu'un; et de l'autre côté : le regard clair de l'innocence, la blanche colombe de la paix, la lumière féerique, paradisiaque. Un magnifique enfant blond, que de paix dans cette expression, que de joie et surtout que d'espoir! Rien de comparable avec un magnifique enfant noir: littéralement, c'est une chose tout à fait insolite. Je ne vais tout de même pas revenir sur les histoires d'anges noirs. En Europe, c'està-dire dans tous les pays civilisés et civilisateurs, le nègre symbolise le péché. L'archétype des valeurs inférieures est représenté par le nègre. Et c'est précisément la même antinomie qu'on retrouve dans le rêve éveillé de Desoille. Comment expliquer, par exemple, que l'inconscient représentant les qualités basses et inférieures soit coloré en noir? Chez Desoille, où, sans jeu de mots, la situation est plus claire, il s'agit toujours de descendre ou de monter. Quand je descends, je vois des cavernes, des grottes où dansent des sauvages. Surtout, que l'on ne s'y trompe pas. Par exemple, dans l'une des séances de rêve éveillé que nous communique Desoille, nous rencontrons des Gaulois dans une caverne. Mais, faut-il le dire, le Gaulois est bonasse... Un Gaulois dans une caverne, ça a comme un air de famille, - conséquence, peut-être, de «nos pères les Gaulois »... Je crois qu'il faut redevenir enfant pour comprendre certaines réalités psychiques. C'est en quoi Jung est un novateur : il veut aller à la jeunesse du monde. Mais il se trompe singulièrement : il ne va qu'à la jeunesse de l'Europe.

Il s'est élaboré au plus profond de l'inconscient européen un croissant excessivement noir, où sommeillent les pulsions les plus immorales, les désirs les moins avouables. Et comme tout homme monte vers la blancheur et la lumière, l'Européen a voulu rejeter ce non-civilisé qui 
tentait de se défendre. Quand la civilisation européenne se trouva en contact avec le monde noir, avec ces peuples de sauvages, tout le monde fut d'accord : ces nègres étaient le principe du mal.

Jung assimile régulièrement étranger à obscurité, à mauvais penchant : il a parfaitement raison. Ce mécanisme [174] de projection, ou, si l'on préfère, de transitivisme, a été décrit par la psychanalyse classique. Dans la mesure où je découvre en moi quelque chose d'insolite, de répréhensible, je n'ai plus qu'une solution: m'en débarrasser, en attribuer la paternité à l'autre. Ainsi je mets fin à un circuit tensionnel qui risquait de compromettre mon équilibre. Dans le rêve éveillé, il faut faire attention, lors des premières séances, car il n'est pas bon que la descente s'amorce trop vite. Il faut que les rouages de sublimation soient connus du sujet avant tout contact avec l'inconscient. Si, à la première séance, il apparaît un nègre, il faut tout de suite s'en débarrasser: pour cela, proposez à votre sujet un escalier, une corde, ou invitez-le à se laisser emporter sur une hélice. Le nègre, immanquablement, reste dans son trou. En Europe, le nègre a une fonction : celle de représenter les sentiments inférieurs, les mauvais penchants, le côté obscur de l'âme. Dans l'inconscient collectif de l'homo occidentalis, le nègre, ou, si l'on préfère, la couleur noire, symbolise le mal, le péché, la misère, la mort, la guerre, la famine. Tous les oiseaux de proie sont noirs. En Martinique, qui est un pays européen par son inconscient collectif, on dit, quand un nègre «bleu» vous fait une visite : «Quel malheur amène-t-il ? »

L'inconscient collectif n'est pas dépendant d'un héritage cérébral : il est la conséquence de ce que j'appellerai l'imposition culturelle irréfléchie. Rien d'étonnant, donc, à ce qu'un Antillais, soumis à la méthode du rêve éveillé, revive les mêmes phantasmes qu'un Européen. C'est que l'Antillais a le même inconscient collectif que l'Européen.

Si l'on a compris ce qui précède, on est à même d'énoncer la conclusion suivante: il est normal que l'Antillais soit négrophobe. Par l'inconscient collectif, l'Antillais a fait siens tous les archétypes de l'Européen. L'anima du nègre antillais est presque toujours une Blanche. De même, l'animus des Antillais est toujours un Blanc. C'est que chez 
Anatole France, Balzac, Bazin ou tel autre de «nos» romanciers, il n'est fait mention ni de cette femme noire vaporeuse et pourtant présente ni du sombre Apollon aux yeux étincelants... Mais je suis trahi, j'ai parlé d'Apollon! Rien à faire: je suis un Blanc. Or, inconsciemment, j[175] e me méfie de ce qui est noir en moi, c'est-à-dire de la totalité de mon être.

Je suis un nègre - mais naturellement je ne le sais pas, puisque je le suis. À la maison ma mère me chante, en français, des romances françaises où il n'est jamais question de nègres. Quand je désobéis, quand je fais trop de bruit, on me dit de ne pas « faire le nègre».

Un peu plus tard, nous lisons des livres blancs et nous assimilons petit à petit les préjugés, les mythes, le folklore qui nous viennent d'Europe. Mais nous n'accepterons pas tout, certains préjugés n'étant pas applicables aux Antilles. L'antisémitisme, par exemple, n'existe pas, car il n'y a pas de Juifs, ou si peu. Sans faire appel à la notion de catharsis collective, il me serait facile de montrer que le nègre, irréflexivement, se choisit objet susceptible de porter le péché originel. Pour ce rôle, le Blanc choisit le Noir, et le Noir qui est un Blanc choisit aussi le Noir. Le Noir antillais est esclave de cette imposition culturelle. Après avoir été esclave du Blanc, il s'autoesclavagise. Le nègre est, dans toute l'acception du terme, une victime de la civilisation blanche. Rien d'étonnant à ce que les créations artistiques des poètes antillais ne portent pas d'empreinte spécifique : ce sont des Blancs. Pour revenir à la psychopathologie, disons que le nègre vit une ambiguïté qui est extraordinairement névrotique. À vingt ans, c'est-à-dire au moment ou l'inconscient collectif est plus ou moins perdu, ou du moins difficile à ramener au niveau du conscient, l'Antillais s'aperçoit qu'il vit dans l'erreur. Pourquoi cela? Tout simplement parce que, et ceci est très important, l'Antillais s'est connu comme nègre, mais, par un glissement éthique, il s'est aperçu (inconscient collectif) qu'on était nègre dans la mesure où l'on était mauvais, veule, méchant, instinctif. Tout ce qui s'opposait à ces manières d'être nègre était blanc. Il faut voir là l'origine de la négrophobie de l'Antillais. Dans l'inconscient collectif, noir = laid, péché, ténèbres, immoral. Autrement dit : est nègre celui 
qui est immoral. Si dans ma vie je me comporte en homme moral, je ne suis point un nègre. D'où, en Martinique, l'habitude de dire d'un mauvais Blanc qu'il a une âme de nègre. La couleur n'est rien, je ne la vois même pas, je ne connais [176] qu'une chose, c'est la pureté de ma conscience et la blancheur de mon âme. "Moi blanc comme neige », disait l'autre.

L'imposition culturelle s'exerce facilement en Martinique. Le glissement éthique ne rencontre pas d'obstacle. Mais le véritable Blanc mattend. Il me dira à la première occasion qu'il ne suffit pas que l'intention soit blanche, mais qu'il faut réaliser une totalité blanche. C'est à ce moment seulement que je prendrai conscience de la trahison. - Concluons. Un Antillais est blanc par l'inconscient collectif, par une grande partie de l'inconscient personnel et par la presque totalité de son processus d'individuation. La couleur de sa peau, dont il n'est pas fait mention chez Jung, est noire. Toutes les incompréhensions procèdent de ce quiproquo.

Alors qu'il était en France, préparant sa licence de lettres, Césaire « retrouva sa lâcheté ». Il sut que c'était une lâcheté, mais il ne put jamais dire pourquoi. Il sentit que c'était absurde, idiot, je dirai même malsain, mais dans aucun de ses écrits on ne trouve les mécanismes de cette lâcheté. C'est qu'il fallait néantiser la situation présente et tenter d'appréhender le réel avec une âme d'enfant. Le nègre du tramway était comique et laid. Pour sûr, Césaire s'amusa. C'est qu'il n'y avait rien de commun entre ce véritable nègre et lui. Dans un cercle de Blancs en France, on présente un beau Noir. Si c'est un cercle d'intellectuels, soyez certains que le Noir essaiera de s'imposer. Il demande qu'on ne fasse pas attention à sa peau, mais à sa puissance intellectuelle. Nombreux sont, en Martinique, ceux qui à vingt ou trente ans se mettent à travailler Montesquieu ou Claudel dans le seul but de les citer. C'est que, par la connaissance de ces auteurs, ils comptent faire oublier leur noirceur.

La conscience morale implique une sorte de scission, une rupture de la conscience, avec une partie claire qui s'oppose à la partie sombre. Pour qu'il y ait morale, il faut que disparaisse de la conscience le noir, l'obscur, le nègre. Donc, un nègre à tout instant combat son image. 
Si pareillement l'on accorde à M. Hesnard sa conception scientifique de la vie morale et si l'univers morbide se comprend à partir de la Faute, de la Culpabilité, un [177] individu normal sera celui qui se sera déchargé de cette culpabilité, qui aura réussi en tout cas à ne pas la subir. Plus directement, tout individu doit rejeter ses instances inférieures, ses pulsions, sur le compte d'un mauvais génie qui sera celui de la culture à laquelle il appartient (nous avons vu que c'était le nègre). Cette culpabilité collective est supportée par ce qu'il est convenu d'appeler le bouc émissaire. Or le bouc émissaire pour la société blanche - basée sur les mythes: progrès, civilisation, libéralisme, éducation, lumière, finesse - sera précisément la force qui s'oppose à l'expansion, à la victoire de ces mythes. Cette force brutale, oppositionnelle, c'est le nègre qui la fournit.

Dans la société antillaise, où les mythes sont les mêmes que ceux de la société dijonnaise ou niçoise, le jeune Noir, s'identifiant au civilisateur, fera du nègre le bouc émissaire de sa vie morale.

C'est à l'âge de quatorze ans que je compris la valeur de ce que j'appelle maintenant l'imposition culturelle. J'avais un camarade, mort depuis, dont le père, italien, avait épousé une Martiniquaise. Cet homme était installé à Fort-de-France depuis plus de vingt ans. On le considérait comme un Antillais, mais, par en dessous, on se souvenait de son origine. Or, en France, I'Italien, militairement, ne vaut rien; un Français vaut dix Italiens; les Italiens ne sont pas courageux... Mon camarade était né en Martinique et ne fréquentait que des Martiniquais. Certain jour où Montgomery bouscula l'armée italienne a Bengazi, je voulus constater sur la carte l'avance alliée. Devant le gain considérable de terrain, je m'écriai, enthousiaste: «Qu'est-ce que vous prenez !... » Mon camarade, qui ne pouvait ignorer l'origine de son père, fut extrêmement gêné. Moi aussi, d'ailleurs. Tous deux, nous avions été victimes de l'imposition culturelle. Je suis convaincu que celui qui aura compris ce phénomène et toutes ses conséquences saura exactement dans quel sens chercher la solution. Écoutez le Rebelle: 
«Il monte... il monte des profondeurs de la terre... le flot noir monte... des vagues de hurlements... des marais de senteurs animales... l'orage écumant de pieds nus... et il en grouille toujours d'autres dévalant les sentiers des [178] mornes, gravissant l'escarpement des ravins torrents obscènes et sauvages grossisseurs de fleuves chaotiques, de mers pourries, d'océans convulsifs, dans le rire charbonneux du coutelas et de l'alcool mauvais... »

A-t-on compris? Césaire est descendu. Il a accepté de voir ce qui se passait tout au fond, et maintenant il peut monter. Il est mûr pour l'aube. Mais il ne laisse pas le Noir en bas. Il le prend sur ses épaules et le hisse aux nues. Déjà, dans Cahier d'un retour au pays natal, il nous avait prévenus. C'est le psychisme ascensionnel, pour reprendre le terme de Bachelard 191, qu'il a choisi :

« et pour ce, Seigneur aux dents blanches, les hommes au cou frêle

reçois et perçois fatal calme triangulaire et à moi mes danses

mes danses de mauvais nègre

à moi mes danses

la danse brise-carcan

la danse saute-prison

la danse il-est-beau-et-bon-et-légitime-d'être-nègre

À moi mes danses et saute le soleil sur la raquette de mes mains

mais non l'inégal soleil ne me suffit plus

enroule-toi, vent, autour de ma nouvelle croissance

pose-toi sur mes doigts mesurés 
je te livre ma conscience et son rythme de chair je te livre les feux où brasille ma faiblesse je te livre le chain-Gang je te livre le marais je te livre l'intourist du circuit triangulaire dévore vent je te livre mes paroles abruptes dévore et enroule-toi et t'enroulant embrasse-moi d'un plus vaste frisson embrasse-moi jusqu'au nous furieux embrasse, embrasse NOUS mais nous ayant également mordus [178]

jusqu'au sang de notre sang mordus embrasse, ma pureté ne se lie qu'à ta pureté mais alors embrasse comme un champ de justes filaos le soir nos multicolores puretés et lie, lie-moi sans remords lie-moi de tes vastes bras à l'argile lumineuse lie ma noire vibration au nombril même du monde lie, lie-moi fraternité âpre puis, m'étranglant de ton lasso d'étoiles monte, Colombe monte monte monte Je te suis, imprimée en mon ancestrale cornée blanche monte lécheur de ciel et le grand trou noir où je voulais me noyer l'autre lune c'est là que je veux pêcher maintenant la langue maléfique 
de la nuit en son immobile verrition 192 ! »

On comprend pourquoi Sartre voit dans la prise de position marxiste des poètes noirs la fin logique de la négritude. Voici en effet ce qui se passe. Comme je m'aperçois que le nègre est le symbole du péché, je me prends à haïr le nègre. Mais je constate que je suis un nègre. Pour échapper à ce conflit, deux solutions. Ou bien je demande aux autres de ne pas faire attention à ma peau; ou bien, au contraire, je veux qu'on s'en aperçoive. J'essaie alors de valoriser ce qui est mauvais puisque, irréflexivement, j'ai admis que le Noir était la couleur du mal. Pour mettre fin à cette situation névrotique, où je suis obligé de choisir une solution malsaine, conflictuelle, nourrie de phantasmes, antagoniste, inhumaine, enfin, - [180] je n'ai qu'une solution: survoler ce drame absurde que les autres ont monté autour de moi, écarter ces deux termes qui sont pareillement inacceptables et, à travers un particulier humain, tendre vers l'universel. Quand le nègre plonge, autrement dit descend, il se produit quelque chose d'extraordinaire.

\section{Écoutez encore Césaire}

« Ho ho

Leur puissance est bien ancrée

Acquis

Requis

Mes mains baignent dans des bruyères de clairin Dans des rizières de roucou

Et j'ai ma calebasse d'étoiles grosse

Mais je suis faible. Oh je suis faible.

Aidez-moi.

Et voici je me retrouve au fil de la métamorphose Noyé aveuglé

192 Aimé Césaire, Cahier d'un retour au pays natal, pp. 94-96. 
Apeuré de moi-même, effrayé de moi-même

Des dieux... vous n'êtes pas des dieux. Je suis libre. »

«LE REBELLE. - J'ai pacte avec cette nuit, depuis vingt ans je la sens qui vers moi doucement hèle 193 ... »

Ayant retrouvé cette nuit, c'est-à-dire le sens de son identité, Césaire constate d'abord que:

«On a beau peindre blanc le pied de l'arbre, la force de l'écorce en dessous crie... »

Puis, une fois le Blanc découvert en lui, il le tue:

«Nous forçâmes les portes. La chambre du maître était grande ouverte. La chambre du maître était brillamment éclairée, et le maître était là très calme... et les nôtres s'arrêtèrent... C'était le maître... J'entrai. C'est toi, me dit-il, très calme... C'était moi. C'était bien moi, lui disais-je, le bon esclave, le fidèle esclave, l'esclave esclave, et soudain ses yeux furent deux ravets apeurés les jours [181] de pluie... je frappai, le sang gicla: c'est le seul baptême dont je me souvienne aujourd'hui ${ }^{194}$.»

«Par une inattendue et bienfaisante révolution intérieure, il honorait maintenant ses laideurs repoussantes 195 . »

193 Et les chiens se taisaient, tragédie (Les armes miraculeuses, pp. 144 et 122).

194 A. Césaire, op. cit., p. 136.

195 P. 65. 
Qu'ajouter de plus? Après s'être porté aux limites de l'autodestruction, le nègre, méticuleusement ou éruptivement, va sauter dans le «trou noir » d'où fusera « d'une telle raideur le grand cri nègre que les assises du monde en seront ébranlées ».

L'Européen sait et ne sait pas. Sur le plan réflexif, un nègre est un nègre: mais dans l'inconscient il y $a$, bien fichée, l'image du nègresauvage. Je pourrais donner non pas dix, mais des milliers d'exemples. Georges Mounin dit dans Présence africaine: «J'ai eu la chance de ne pas découvrir les Noirs à travers la Mentalité primitive de Lévy-Bruhl, au cours de sociologie: plus généralement, la chance de découvrir les Noirs autrement que par les lectures - et je m'en félicite tous les jours 196 ... »

Mounin, que l'on ne saurait tenir pour un Français moyen, ajoute, et par cela il saute à pieds joints dans nos vues: "J'y ai peut-être gagné d'apprendre, au temps où on a l'esprit non prévenu, que les Noirs sont des hommes comme nous... J'y ai peut-être gagné, moi Blanc, la possibilité d'être naturel pour toujours avec un Noir - et de ne jamais être en face de lui bêtement et subtilement dans cette position d'enquêteur ethnographique qui reste trop souvent notre insupportable façon de les remettre à leur place... »

Dans le même numéro de Présence africaine, Emile Dermenghem, qui ne peut être suspecté de négrophobie, écrit : « Un de mes souvenirs d'enfance est une visite à l'Exposition Universelle de 1900, au cours de laquelle ma principale préoccupation était de voir un nègre. Mon imagination était naturellement excitée par des lectures: Capitaine de quinze ans, Les Aventures de Robert, Les Voyages de Livingstone. 》

[182]

Emile Dermenghem nous dit que cela exprimait chez lui un goût de l'exotisme. Si je suis prêt, les deux mains perdues dans les siennes, à

196 Premières réponses à l'enquête sur le « Mythe du nègre », Présence Africaine, $n^{0} 2$. 
croire le Dermenghem qui a écrit l'article, je lui demande la permission de douter du Dermenghem de l'Exposition de 1900.

Je m'en voudrais de reprendre les thèmes que l'on agite depuis cinquante ans. Ecrire sur les possibilités d'une amitié noire est une entreprise généreuse, mais malheureusement les négrophobes et autres princes consorts sont imperméables à la générosité. Quand nous lisons : « Un nègre est un sauvage, et pour conduire des sauvages il n'y a qu'une seule méthode : le coup de pied aux fesses», nous pensons, de notre table de travail, que "toutes ces imbécillités doivent disparaître ». Mais là-dessus tout le monde est d'accord. Jacques Howlett, toujours dans Présence africaine ( $\left.n^{\circ} 5\right)$, écrit : «Deux choses, en outre, contribuèrent, semble-t-il, à cet éloignement du nègre dans le monde de l'autre, sans commune mesure avec moi : la couleur de sa peau et sa nudité, car j'imaginais le nègre nu. - Certes, des éléments superficiels (encore qu'on ne saurait dire jusqu'à quel point ils ne continuent pas à hanter nos idées neuves, nos conceptions révisées) ont pu recouvrir parfois cet être lointain, noir et nu, quasi inexistant: tel est le bon Noir à chéchia et au vaste sourire fernandelesque, symbole de quelque déjeuner chocolaté, tel encore le brave pioupiou sénégalais « esclave de la consigne», Don Quichotte sans grandeur, « héros bon enfant» de tout ce qui ressortit à «l'épopée coloniale», tel enfin le Noir «homme-à-convertir», «fils soumis » du missionnaire à barbe. »

Jasques Howlett, dans la suite de sa communication, nous dit avoir, par réaction, fait du nègre le symbole de l'innocence. Il nous en donne la raison, mais nous sommes obligé de penser qu'il n'avait plus huit ans, car il nous parle de "mauvaise conscience de la sexualité » et de " solipsisme». Je suis d'ailleurs persuadé que cette «innocence pour grand adulte », Jacques Howlett l'a laissée loin, loin derrière lui.

Sans nul doute, le plus intéressant témoignage est celui de Michel Salomon. Quoiqu'il s'en défende, il pue le raciste. Il est Juif, il a une «expérience millénaire de [183] l'antisémitisme», et pourtant il est raciste. Ecoutez-le: "Mais nier que, du fait de sa peau et de sa chevelure, de cette aura de sensualité qu'il (le nègre) dégage, il n'y a pas, 
spontanément, une certaine gêne, attractive ou répulsive, c'est se refuser à l'évidence au nom d'une pruderie absurde qui n'a jamais rien résolu... » Plus loin, il va jusqu'à nous parler de la «prodigieuse vitalité du Noir».

L'étude de M. Salomon nous apprend qu'il est médecin. Il devra se méfier de ces perspectives littéraires qui sont a-scientifiques. Le Japonais et le Chinois sont dix fois plus prolifiques que le Noir : sont-ils pour cela sensuels? Et puis, M. Salomon, je m'en vais vous faire un aveu: je n'ai jamais pu entendre sans nausée un homme dire d'un autre homme: «Comme il est sensuel! » Je ne sais pas ce que c'est que la sensualité d'un homme. Imaginez une femme disant d'une autre: «Elle est effroyablement désirable, cette poupée... »M. Salomon, le nègre ne dégage d'aura de sensualité ni par sa peau, ni par sa chevelure. Simplement, depuis de longs jours et de longues nuits, l'image du nègrebiologique-sexuel-sensuel-et-génital s'est imposée à vous, et vous n'avez pas su vous en dégager. L'ceil n'est pas seulement miroir, mais miroir redresseur. L'ceil doit nous permettre de corriger les erreurs culturelles. Je ne dis pas les yeux, je dis l'ceil, et l'on sait à quoi cet œil renvoie: pas à la scissure calcarine, mais à cette très égale lueur qui sourd du rouge de Van Gogh, qui glisse d'un concerto de Tchaïkowsky, qui s'agrippe désespérément à l'Ode à la Joie de Schiller, qui se laisse porter par la gueulée vermiculaire de Césaire.

Le problème noir ne se résout pas en celui des Noirs vivant parmi les Blancs, mais bien des Noirs exploités, esclavagisés, méprisés par une société capitaliste, colonialiste, accidentellement blanche. Vous vous demandez, M. Salomon, ce que vous feriez « si vous aviez huit cent mille nègres en France »; parce que pour vous il y a un problème, le problème de la montée des Noirs, le problème du péril noir. Le Martiniquais est un Français, il veut rester au sein de l'Union Française, il ne demande qu'une chose, le Martiniquais, c'est que les imbéciles et les exploitants lui laissent la possibilité de vivre humainement. Je me vois fort bien perdu, submergé par le flot [184] blanc que constitueraient des hommes comme Sartre ou Aragon, je ne demanderais que cela. M. Salomon, vous dites qu'on ne gagne rien à être prude, et nous sommes 
de votre avis. Mais je n'ai pas l'impression d'abdiquer ma personnalité en épousant une Européenne quelconque: je vous affirme que je ne fais pas un "marché de dupes». Si l'on flaire mes enfants, si l'on examine la lunule de leurs ongles, c'est tout simplement parce que la société n'aura pas changé, qu'elle aura, comme vous le dites si bien, gardé intacte sa mythologie. Pour notre part, nous refusons de considérer le problème sur le mode : ou bien, ou bien...

Qu'est-ce que cette histoire de peuple noir, de nationalité nègre? Je suis Français. Je suis intéressé à la culture française, à la civilisation française, au peuple français. Nous refusons de nous considérer comme « à-côté », nous sommes en plein dans le drame français. Quand des hommes, non pas fondamentalement mauvais, mais mystifiés, ont envahi la France pour l'asservir, mon métier de Français m'indiqua que ma place n'était pas à côté, mais au cœur du problème. Je suis intéressé personnellement au destin français, aux valeurs françaises, à la nation française. Qu'ai-je à faire, moi, d'un Empire noir?

Georges Mounin, Dermenghem, Howlett, Salomon ont bien voulu répondre à l'enquête sur la genèse du mythe du nègre. Tous nous ont convaincu d'une chose. C'est qu'une authentique saisie de la réalité du nègre devait se faire au détriment de la cristallisation culturelle.

Dernièrement je lisais dans un journal pour enfants cette phrase, qu'illustrait une image où un jeune scout noir présentait un village nègre à trois ou quatre scouts blancs : «Voici la chaudière où mes ancêtres faisaient cuire les vôtres. " On veut bien admettre qu'il n'existe plus de nègres anthropophages, mais souvenons-nous-en... En toute rigueur d'ailleurs, je pense que l'auteur a, sans le savoir, rendu service aux nègres. Car le jeune Blanc qui le lira ne se représentera pas le nègre comme mangeant le Blanc, mais comme l'ayant mangé. Incontestablement, il y a progrès.

Avant de terminer ce chapitre, nous voudrions communiquer une observation que nous devons à l'obligeance du [185] médecin-chef du service des femmes de l'hôpital psychiatrique de Saint-Ylie. Cette observation éclaire le point de vue que nous défendons ici. Elle montre 
qu'à l'extrême le mythe du nègre, l'idée du nègre arrive à déterminer une authentique aliénation.

Mlle B... est âgée de dix-neuf ans quand elle entre dans le service au mois de mars 19... Le certificat est libellé comme suit : « Je soussi-

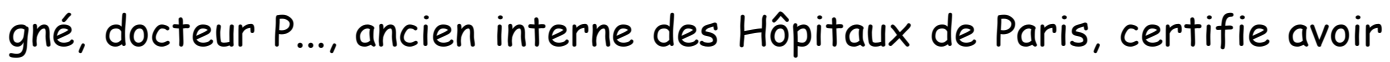
examiné Mlle B..., qui est atteinte de troubles nerveux consistant en crises d'agitation, instabilité motrice, tics, spasmes conscients, mais qu'elle ne peut empêcher. Ces troubles vont en croissant et l'empêchent de mener une vie sociale normale. Son placement en observation est nécessaire dans un établissement régi par la loi de 1838 par voie de placement volontaire. »

Le certificat de vingt-quatre heures établi par le médecin-chef: "Atteinte d'une névrose des tics survenue depuis l'âge de dix ans et s'aggravant avec la puberté et les premiers travaux hors de la maison. Dépression passagère avec anxiété s'accompagnant d'une recrudescence des symptômes. Obésité. Demande à être soignée. Se trouve rassurée en compagnie. Malade de service ouvert. À maintenir. »

Dans les antécédents personnels, on ne retrouve aucun processus pathologique. On ne retient qu'une puberté à seize ans. L'examen somatique ne révèle rien, sinon une adiposité, une infiltration minime des téguments qui fait penser à une insuffisance endocrinienne légère. Périodes menstruelles régulières.

Un entretien permet de préciser les points suivants: «C'est surtout quand je travaille que les tics apparaissent» (la malade était placée, et vivait par conséquent hors du milieu parental).

Tic des yeux, du front; souffle, aboie. Dort très bien, sans cauchemars, s'alimente bien. N'est pas énervée les jours de règles. Dans son lit, avant de s'endormir, nombreux tics faciaux.

Avis de la surveillante: c'est surtout quand elle est seule. Lorsqu'elle est avec les autres ou en conversation, c'est moins marqué. Le tic dépend de ce qu'elle fait. Elle [186] commence par taper des deux pieds, s'en va en soulevant les pieds, les jambes, les bras, les épaules symétriquement. 
Articule des sons. On n'a jamais pu comprendre ce qu'elle disait. Puis cela se termine par des cris très forts, inarticulés. Dès qu'on l'appelle, cela cesse.

Le médecin-chef commence des séances de rêve éveillé. Un entretien préalable ayant mis en évidence l'existence d'hallucinoses sous la forme de cercles effrayants, on demande à la malade d'évoquer ces cercles.

Voici un extrait du compte rendu de la première séance :

«Profonds, concentriques, ils grandissent et diminuent au rythme d'un tam-tam nègre. Ce tam-tam évoque le danger de perdre ses parents, sa mère surtout.

»Alors je lui demande de faire un signe de croix sur ces cercles, ils ne s'effacent pas. Je lui dis de prendre un chiffon et de les effacer, ils disparaissent.

»Se tourne du côté du tam-tam. Elle est entourée d'hommes et de femmes à demi nus, qui dansent de façon effrayante. Je lui dis de ne pas avoir peur d'entrer dans cette danse. Elle le fait. Immédiatement, les danseurs changent d'aspect. C'est une réunion brillante. Les hommes et les femmes sont bien habillés et ils dansent une valse: Etoile des Neiges.

" Je lui dis de s'approcher des cercles : elle ne les voit plus. Je lui dis de les évoquer: les voici, mais ils sont brisés. Je lui dis d'entrer par l'ouverture. Je ne suis plus entourée entièrement, dit-elle spontanément, je pourrai ressortir. Le cercle se brise en deux, puis en plusieurs morceaux. Il ne reste plus que deux morceaux qui disparaissent. Nombreux tics de gorge et d'yeux pendant qu'elle raconte.

» Une série de séances amène la sédation de l'agitation motrice. » 
Voici le résumé d'une autre séance

« Je lui dis de rappeler les cercles. Ne les voit pas. Puis les voilà. Ils sont brisés. Entre dedans. Ils se cassent, s'élèvent, puis tombent doucement les uns après les autres dans le vide. Je lui dis d'écouter le tam-tam. Ne l'entend pas. L'appelle. L'entend sur la gauche.

[186]

» Je lui propose un ange qui l'accompagnerait vers le tamtam : elle veut y aller toute seule. Pourtant quelqu'un descend du ciel. C'est un ange. Il est souriant ; il l'emmène près du tam-tam. Il n'y a que des hommes noirs qui dansent autour d'un grand feu et ont l'air méchant. L'ange lui demande ce qu'ils vont faire: ils vont brûler un Blanc. Le cherche de tous les côtés. Ne le voit pas.

»Ah! je le vois. C'est un Blanc d'une cinquantaine d'années. Il est à demi déshabillé.

» L'ange parlemente avec le chef noir (car elle a peur). Le chef noir dit que cet homme blanc n'est pas de la région, aussi vont-ils le brûler. Mais il n'a pas fait de mal.

» Ils le libèrent et se remettent à danser de joie. Elle refuse de se mêler à la danse.

» Je l'envoie parlementer avec le chef. Celui-ci danse seul. Le Blanc a disparu. Elle veut partir et n'a pas l'air de tenir à connaître les Noirs. Elle veut partir avec son ange quelque part où elle sera bien chez elle, avec sa mère, ses frères et sceurs. »

Les tics ayant disparu, on arrête le traitement. Quelques jours après on revoit la malade, qui a rechuté. Compte rendu de la séance: 
« Toujours les cercles rapprochés. Elle prend un bâton. Ils se cassent en morceaux. C'est la baguette magique. Transforme ces morceaux de fer en une matière brillante très belle.

»Se dirige vers un feu : c'est le feu des Noirs qui dansent. Veut connaître le chef. Va vers lui.

» Le nègre qui s'était arrêté de danser reprend la danse, mais sur un autre rythme. Elle danse autour du feu en donnant la main.

» Les séances ont nettement amélioré la malade. Elle écrit à ses parents, reçoit des visites, va aux séances de cinéma de l'établissement. Elle prend part aux jeux de groupe. Une malade jouant une valse au piano du Pavillon, invite une camarade et danse. Ses camarades l'estiment bien. »

Nous extrayons ce passage d'une autre séance

«Repense aux cercles. Ils sont cassés en une seule pièce, mais il manque un morceau à droite. Les plus petits sont entiers. Elle voudrait casser les petits. Elle [188] les prend dans ses mains, les tord; ils se cassent. Pourtant, reste un petit. Passe à travers. De l'autre côté se trouve dans le noir. N'a pas peur. Appelle quelqu'un, son ange gardien vient du haut, gentil, souriant. Il va l'emmener au jour, à droite. »

Le rêve éveillé donna dans le cas présent des résultats appréciables. Mais dès que la malade se trouvait seule, les tics réapparaissaient.

Nous ne voulons pas nous étendre sur l'infrastructure de cette psycho-névrose. L'interrogatoire du médecin-chef avait mis en évidence une peur de nègres imaginaires, - peur vécue à douze ans.

Nous avons eu un grand nombre d'entretiens avec la malade. 
Alors qu'elle avait dix ou douze ans, son père, « ancien de la Coloniale », aimait prendre des programmes de musique nègre. Le tam-tam résonnait à la maison tous les soirs. Elle était alors au lit.

D'autre part, nous l'avons dit, c'est à cet âge qu'apparaissent les nègres-sauvages-cannibales.

La liaison est aisément reconnaissable.

De plus, ses frères et sceurs, qui avaient trouvé son point faible, s'amusaient à l'effrayer.

Dans son lit, le tam-tam aux oreilles, elle voyait effectivement des nègres. Elle se réfugiait sous les draps en tremblant.

Puis des cercles de plus en plus petits apparaissaient et scotomisaient les nègres.

On retrouve donc les cercles comme mécanismes de défense contre les hallucinoses.

Aujourd'hui, les cercles apparaissent sans le Noir, - le mécanisme de défense s'impose en ignorant son déterminisme.

Nous avons vu la mère. Elle confirma les dires de sa fille. Elle était très émotive et, à douze ans, dans son lit, tremblait souvent. Notre présence dans le service ne provoqua aucune modification visible de l'état mental.

Aujourd'hui, les cercles seuls déclenchent les phénomènes moteurs : cris, tics faciaux, gesticulations désordonnées.

Même si l'on réserve une part à la constitution, il est [189] évident que cette aliénation est la conséquence d'une peur du nègre, peur favorisée par des circonstances déterminées. Bien que la malade soit nettement améliorée, on doute qu'elle puisse de sitôt reprendre une vie sociale. 
[190]

PEAU NOIRE. MASQUES BLANCS.

\section{Chapitre VII \\ LE NĖGRE \\ ET LA RECONNAISSANCE}

\section{A. LE NÉGRE ET ADLER}

\section{Retour à la table des matières}

«Par quelque côté qu'on aborde l'analyse des états morbides psychogènes, on ne tarde pas à se trouver en présence du phénomène suivant : tout le tableau de la névrose, ainsi que tous ses symptômes, apparaissent comme influencés par un but final, voire comme des projections de ce but. Aussi peut-on attribuer à ce but final la valeur d'une cause formative, celle d'un principe d'orientation, d'arrangement, de coordination. Essayez de comprendre le «sens» et la direction des phénomènes morbides, sans tenir compte de ce but final, et vous vous trouverez aussitôt en présence d'une multitude chaotique de tendances, d'impulsions, de faiblesses et d'anomalies, faite pour décourager les uns et pour susciter chez les autres le désir téméraire de percer coûte que coûte les ténèbres, au risque d'en revenir les mains vides ou avec un butin illusoire. Si, au contraire, on admet l'hypothèse du but final ou d'une finalité causale, cachée derrière les phénomènes, on voit 
aussitôt les ténèbres se dissiper et nous lisons dans l'âme du malade comme dans un livre ouvert 197 . »

C'est à partir de positions théoriques analogues que s'édifient en général les mystifications les plus ahurissantes de notre époque. En effet, appliquons la psychologie caractérielle aux Antillais.

Les nègres sont comparaison. Première vérité. Ils sont comparaison, c'est-à-dire qu'à tout instant ils se préoccuperont [191] d'autovalorisation et d'idéal du moi. Chaque fois qu'ils se trouvent en contact avec un autre, il est question de valeur, de mérite. Les Antillais n'ont pas de valeur propre, ils sont toujours tributaires de l'apparition de l'Autre. Il est toujours question de moins intelligent que moi, de plus noir que moi, de moins bien que moi. Toute position de soi, tout ancrage de soi entretient des rapports de dépendance avec l'effondrement de l'autre. C'est sur les ruines de l'entourage que je bâtis ma virilité.

Je propose au Martiniquais qui me lit l'expérience suivante. Déterminer la plus «comparaison» des rues de Fort-de-France. La rue Schoelcher, la rue Victor-Hugo... certainement pas la rue FrançoisArago. Le Martiniquais qui accepte de réaliser cette expérience sera de mon avis dans l'exacte mesure où il ne se crispera pas de se voir mis à nu. Un Antillais qui retrouve un camarade après cinq ou six ans l'aborde agressivement. C'est que dans le temps l'un et l'autre avaient une position déterminée. L'infériorisé croit se valoriser... et le supérieur tient à la hiérarchie.

« Tu n'as pas changé... aussi bête. »

J'en connais, cependant, médecins et dentistes, qui continuent à se jeter à la tête des erreurs de jugement vieilles de quinze ans. Mieux que des erreurs conceptuelles, ce sont des «créolismes» qu'on lance au dangereux. On l'a maîtrisé une fois pour toutes: rien à faire.

197 Alfred Adler, Le tempérament nerveux, p. 12. 
L'Antillais se caractérise par son désir de dominer l'autre. Sa ligne d'orientation passe par l'autre. Il est toujours question du sujet et l'on ne se préoccupe nullement de l'objet. J'essaie de lire dans les yeux de l'autre l'admiration, et si par malheur l'autre me renvoie une image désagréable, je dévalorise ce miroir : décidément cet autre est un imbécile. Je ne cherche pas à être nu en face de l'objet. L'objet est nié en tant qu'individualité et liberté. L'objet est un instrument. Il doit me permettre de réaliser ma sécurité subjective. Je me donne comme plein (désir de plénitude) et n'admets aucune scission. L'Autre entre sur la scène pour la meubler. Le Héros, c'est moi. Applaudissez ou critiquez, que m'importe, c'est moi le centre. Si l'autre veut m'inquiéter par son désir de valorisation (sa fiction), je l'expulse sans autre forme de procès. [192] Il n'existe plus. Ne me parlez pas de ce type. Je ne veux pas subir le choc de l'objet. Le contact de l'objet est conflictuel. Je suis Narcisse et je veux lire dans les yeux de l'autre une image de moi qui me satisfasse. Aussi en Martinique, dans un cercle donné (milieu), y a-t-il le « pélé », la cour du «pélé », les indifférents (qui attendent) et les humiliés. Ceux-là sont impitoyablement massacrés. On devine la température qui règne dans cette jungle. Pas moyen de s'en sortir.

Moi, rien que moi.

Les Martiniquais sont avides de sécurité. Ils veulent faire admettre leur fiction. Ils veulent être reconnus dans leur désir de virilité. Ils veulent paraître. Chacun d'eux constitue un atome isolé, aride, tranchant, aux trottoirs bien délimités, chacun d'eux est. Chacun d'eux veut être, veut paraître. Toute action de l'Antillais passe par l'Autre. Non parce que l'Autre demeure le but final de son action dans la perspective de la communion humaine que décrit Adler 198, mais plus simplement parce que c'est l'Autre qui l'affirme dans son besoin de valorisation.

198 A. Adler, Connaissance de l'Homme. [Livre disponible dans Les Classiques des sciences sociales. JMT.] 
Maintenant que nous avons retrouvé la ligne d'orientation adlérienne de l'Antillais, il nous reste à en rechercher l'origine.

Ici apparaissent les difficultés. En effet, Adler a créé une psychologie individuelle. Or nous venons de voir que le sentiment d'infériorité est antillais. Ce n'est pas tel Antillais qui présente la structure du nerveux, mais tous les Antillais. La société antillaise est une société nerveuse, une société «comparaison». Donc nous sommes renvoyés de l'individu à la structure sociale. S'il y a un vice, il ne réside pas dans «l'âme » de l'individu, mais bien dans celle du milieu.

Le Martiniquais est un nerveux, et n'en est pas un. Si nous appliquions rigoureusement les conclusions de l'école adlérienne, nous dirions que le nègre essaie de protester contre l'infériorité qu'il ressent historiquement. Comme le nègre, de tout temps, a été un inférieur, il essaie de réagir par un complexe de supériorité. Et c'est bien ce qui ressort du livre de Brachfeld. Parlant du sentiment [192] d'infériorité raciale, l'auteur cite une pièce espagnole d'André de Claramunte, El valiente negro de Flandres. On y peut voir que l'infériorité du nègre ne date pas de ce siècle, puisque de Claramunte est contemporain de Lope de Vega.

« La couleur seule lui fait défaut

pour qu'il soit un vrai caballero... »

Et le nègre Juan de Mérida s'exprime ainsi :

«Quelle infamie c'est d'être noir dans ce monde!

Les Noirs ne sont-ils pas des hommes?

Ont-ils pour cela une âme plus vile, plus maladroite, plus laide?

Et pour cela on leur donne des surnoms

Je me lève lourd de l'infamie de ma couleur 
Et j'affirme mon courage au monde...

Est-il si vil d'être noir?»

Le pauvre Juan ne sait plus à quel saint se vouer. Normalement, le Noir est un esclave. Rien de pareil dans sa position :

«Car malgré que je sois noir

Je ne suis pas un esclave. »

Il voudrait cependant échapper à cette noirceur. Il a une attitude éthique dans la vie. Axiologiquement, c'est un Blanc:

« Je suis plus blanc que la neige. »

Car en définitive, sur le plan symbolique,

«Qu'est-ce donc, être noir?

Est-ce être de cette couleur?

De cette offense je me plaindrai au Destin, [193]

au temps, au ciel

et à tous ceux qui me firent noir!

O malédiction de la couleur!»

Enfermé, Juan s'aperçoit que l'intention ne peut le sauver. Son apparaître mine, infirme toutes ses actions:

«Qu'importent les âmes?

Je suis fou.

Que faire sinon être désespéré? 
O ciel quelle affreuse chose

d'être noir. »

Au paroxysme de la douleur, il ne reste qu'une solution au malheureux nègre: donner les preuves de sa blancheur aux autres et surtout à lui-même.

«Si je ne peux pas changer de couleur, je veux l'Aventure ${ }^{199}$. »

Comme on le voit, il faut comprendre Juan de Mérida dans la perspective de la surcompensation. C'est parce que le nègre appartient à une race « inférieure » qu'il essaie de ressembler à la race supérieure.

Mais nous savons nous dégager de la ventouse adlérienne. De Man et Eastman ont, en Amérique, appliqué la méthode d'Adler d'une façon quelque peu abusive. Tous les faits que j'ai relevés sont réels, mais, faut-il le dire, ils n'entretiennent avec la psychologie adlérienne que des rapports externes. Le Martiniquais ne se compare pas au Blanc, considéré comme le père, le chef, Dieu, mais se compare à son semblable sous le patronage du Blanc. Une comparaison adlérienne se schématise de la manière suivante:

« Moi plus grand que l'Autre.»

La comparaison antillaise, par contre, se présente ainsi :

Blanc

Moi différent de l'Autre 
La comparaison adlérienne comporte deux termes; elle est polarisée par le moi.

La comparaison antillaise est coiffée par un troisième terme: la fiction dirigeante n'y est pas personnelle, mais sociale.

Le Martiniquais est un crucifié. Le milieu qui l'a fait (mais qu'il n'a pas fait) l'a épouvantablement écartelé ; et ce milieu de culture, il l'entretient de son sang et de ses humeurs. Or le sang du nègre est un engrais estimé des connaisseurs.

Adlériennement, après avoir constaté que mon camarade, dans son rêve, réalise le désir de se blanchir, c'est-à-dire d'être viril, je lui révélerai donc que sa névrose, son instabilité psychique, la brisure de son moi proviennent de cette fiction dirigeante et je lui dirai : « M. Mannoni a très bien décrit ce phénomène chez le Malgache. Vois-tu, il faudrait, je crois, que tu acceptes de rester à la place qu'on t'a faite. »

Eh bien non! Je ne dirai point cela! Je lui dirai : c'est le milieu, la société qui sont responsables de ta mystification. Ceci dit, le reste viendra tout seul, et l'on sait de quoi il s'agit.

De la fin du monde, parbleu.

Je me demande parfois si les inspecteurs d'enseignement et les chefs de service sont conscients de leur rôle aux colonies. Pendant vingt ans, ils s'acharnent par leurs programmes à faire du nègre un Blanc. À la fin, ils le lâchent et lui disent : vous avez incontestablement un complexe de dépendance vis-à-vis du Blanc. 


\section{B. LE NĖGRE ET HEGEL}

La conscience de soi est en soi et pour soi quand et parce qu'elle est en soi et pour soi pour une autre conscience de soi ; c'est-à-dire qu'elle n'est qu'en tant qu'être reconnu 200.

L'homme n'est humain que dans la mesure où il veut s'imposer à un autre homme, afin de se faire reconnaître [196] par lui. Tant qu'il n'est pas effectivement reconnu par l'autre, c'est cet autre qui demeure le thème de son action. C'est de cet autre, c'est de la reconnaissance par cet autre, que dépendent sa valeur et sa réalité humaines. C'est dans cet autre que se condense le sens de sa vie.

Il n'y a pas de lutte ouverte entre le Blanc et le Noir.

Un jour le Maître Blanc a reconnu sans lutte le nègre esclave.

Mais l'ancien esclave veut se faire reconnaître.

Il y a, à la base de la dialectique hégélienne, une réciprocité absolue qu'il faut mettre en évidence.

C'est en tant que je dépasse mon être-là immédiat que je réalise l'être de l'autre comme réalité naturelle et plus que naturelle. Si je ferme le circuit, si je rends irréalisable le mouvement à double sens, je maintiens l'autre à l'intérieur de soi. A l'extrême, je lui enlève même cet être-pour-soi.

Le seul moyen de rompre ce cercle infernal qui me renvoie à moimême est de restituer à l'autre, par la médiation et la reconnaissance, sa réalité humaine, différente de la réalité naturelle. Or l'autre doit effectuer semblable opération. "L'opération unilatérale serait inutile parce que ce qui doit arriver peut seulement se produire par

200 Hegel, Phénoménologie de l'Esprit, trad. Hippolyte, p. 155. 
l'opération des deux... »; «...ils se reconnaissent comme se reconnaissant réciproquement ${ }^{201}$. »

Dans son immédiateté, la conscience de soi est être-pour-soisimple. Pour obtenir la certitude de soi-même, il faut l'intégration du concept de reconnaissance. L'autre, pareillement, attend notre reconnaissance, afin de s'épanouir dans la conscience de soi universelle. Chaque conscience de soi recherche l'absoluité. Elle veut être reconnue en tant que valeur primordiale désinsérée de la vie, comme transformation, de la certitude subjective (Gewisheit) en vérité objective (Wahrheit).

Rencontrant l'opposition de l'autre, la conscience de soi fait l'expérience du Désir ; première étape sur la route qui conduit à la dignité de l'esprit. Elle accepte de risquer sa vie, et par conséquent menace l'autre dans [197] sa présence corporelle. «C'est seulement par le risque de sa vie qu'on conserve la liberté, qu'on prouve que l'essence de la conscience de soi n'est pas l'être, n'est pas le mode immédiat dans lequel la conscience de soi surgit d'abord, n'est pas enfoncement dans l'expansion de la vie 202. »

Ainsi la réalité humaine en-soi-pour-soi ne parvient à s'accomplir que dans la lutte et par le risque qu'elle implique. Ce risque signifie que je dépasse la vie vers un bien suprême qui est la transformation en vérité objective universellement valable de la certitude subjective que j'ai de ma propre valeur.

Je demande qu'on me considère à partir de mon Désir. Je ne suis pas seulement ici-maintenant, enfermé dans la choséité. Je suis pour ailleurs et pour autre chose. Je réclame qu'on tienne compte de mon activité négatrice en tant que je poursuis autre chose que la vie; en tant que je lutte pour la naissance d'un monde humain, c'est-à-dire d'un monde de reconnaissances réciproques.

201 Hegel, Phénoménologie de l'Esprit, p. 157.

202 Hegel, op. cit., p. 159. 
Celui qui hésite à me reconnaître s'oppose à moi. Dans une lutte farouche, j'accepte de ressentir l'ébranlement de la mort, la dissolution irréversible, mais aussi la possibilité de l'impossibilité 203.

L'autre, cependant, peut me reconnaître sans lutte:

«L'individu qui n'a pas mis sa vie en jeu peut bien être reconnu comme personne, mais il n'a pas atteint la vérité [198] de cette reconnaissance d'une conscience de soi indépendante 204 . »

Historiquement, le nègre, plongé dans l'inessentialité de la servitude, a été libéré par le maître. Il n'a pas soutenu la lutte pour la liberté.

D'esclave, le nègre a fait irruption dans la lice où se trouvaient les maîtres. Pareil à ces domestiques à qui une fois l'an on permet de danser au salon, le nègre cherche un support. Le nègre n'est pas devenu un maître. Quand il n'y a plus d'esclaves, il n'y a pas de maîtres.

Le nègre est un esclave à qui on a permis d'adopter une attitude de maître.

Quand nous avons commencé ce travail nous voulions consacrer une étude à l'être du nègre pour-la-mort. Nous la jugions nécessaire, car on ne cesse de répéter : le nègre ne se suicide pas.

M. Achille dans une conférence n'hésite pas à le soutenir, et Richard Wright dans une de ses nouvelles fait dire à un Blanc: "Si j'étais un nègre je me suiciderais... », entendant par là que seul un nègre peut accepter semblable traitement sans ressentir l'appel du suicide.

Depuis, M. Deshaies a consacré sa thèse à la question du suicide. Il montre que les travaux de Jaensch, qui opposent le type désintégré (yeux bleus, peau blanche) au type intégré (yeux et peau bruns), sont pour le moins spécieux.

Pour Durkheim les Juifs ne se suicidaient pas. Aujourd'hui ce sont les nègres. Or, «l'hôpital de Detroit reçut parmi les suicidants $16,6 \%$ de nègres, alors que la proportion de ceux-ci dans la population n'est que de $7,6 \%$. À Cincinnati, il y a plus du double de suicides que chez les Blancs, surenchère due à l'étonnante proportion de négresses: 358 contre 76 nègres » (Gabriel Deshaies, Psychologie du suicide, n. 23). 
Le Blanc est un maître qui a permis à ses esclaves de manger à sa table.

Un jour, un bon maître blanc qui avait de l'influence a dit à ses copains :

« Soyons gentils avec les nègres... »

Alors les maîtres blancs, en rouspétant, car c'était quand même dur, ont décidé d'élever des hommes-machines-bêtes au rang suprême d'hommes.

Nulle terre française ne doit plus porter d'esclaves.

Le bouleversement a atteint le Noir de l'extérieur. Le Noir a été agi. Des valeurs qui n'ont pas pris naissance de son action, des valeurs qui ne résultent pas de la montée systolique de son sang, sont venues danser leur ronde colorée autour de lui. Le bouleversement n'a pas différencié le nègre. Il est passé d'un mode de vie à un autre, mais pas d'une vie à une autre. De même que, lorsqu'on annonce à un malade amélioré qu'il sortira dans peu de jours de l'asile, il arrive qu'il rechute, de même la nouvelle de la libération des esclaves noirs détermina des psychoses et des morts subites.

Dans une vie, on n'apprend pas deux fois cette même nouvelle. Le Noir s'est contenté de remercier le Blanc, et la preuve la plus brutale de ce fait se trouve dans le nombre imposant de statues disséminées en France et aux colonies, représentant la France blanche caressant la chevelure crépue de ce brave nègre dont on vient de briser les chaînes. 
"Dis merci à monsieur», dit la mère à son fils... mais nous savons que souvent le petit garçon rêve de crier quelque autre mot - plus retentissant...

Le Blanc en tant que maître 205 a dit au nègre:

«Désormais tu es libre. »

Mais le nègre ignore le prix de la liberté, car il ne s'est pas battu pour elle. De temps à autre, il se bat pour la Liberté et la Justice, mais il s'agit toujours de liberté blanche et de justice blanche, c'est-à-dire de valeurs sécrétées par les maîtres. L'ancien esclave, qui ne retrouve dans sa mémoire ni la lutte pour la liberté ni l'angoisse de la liberté dont parle Kierkegaard, se tient la gorge sèche en face de ce jeune Blanc qui joue et chante sur la corde raide de l'existence.

Quand il arrive au nègre de regarder le Blanc farouchement, le Blanc lui dit: "Mon frère, il n'y a pas de différence entre nous.» Pourtant le nègre sait qu'il y a une différence. Il la souhaite. Il voudrait que le Blanc lui dise tout à coup: «Sale nègre. » Alors, il aurait cette unique chance - de «leur montrer... ».

Mais le plus souvent il n'y a rien, rien que l'indifférence, ou la curiosité paternaliste.

L'ancien esclave exige qu'on lui conteste son humanité, il souhaite une lutte, une bagarre. Mais trop tard: le nègre français est condam-

205 Nous espérons avoir montré que le maître ici diffère essentiellement de celui décrit par Hegel. Chez Hegel il y a réciprocité, ici le maître se moque de la conscience de l'esclave. Il ne réclame pas la reconnaissance de ce dernier, mais son travail.

De même l'esclave ici n'est nullement assimilable à celui qui, se perdant dans l'objet, trouve dans le travail la source de sa libération.

Le nègre veut être comme le maître.

Aussi est-il moins indépendant que l'esclave hégélien.

chez Hegel, l'esclave se détourne du maître et se tourne vers l'objet.

Ici, l'esclave se tourne vers le maître et abandonne l'objet. 
né à se mordre et à mordre. Nous disons le Français, car les Noirs américains vivent un autre drame. En Amérique, le nègre lutte et il est combattu. Il y a des lois qui, petit à petit, disparaissent de la constitution. Il y a des décrets qui interdisent certaines discriminations. Et nous sommes assurés qu'il ne s'agit pas alors de dons.

Il y a bataille, il y a défaites, trêves, victoires.

[200]

"The twelve millions black voices» ont gueulé contre le rideau du ciel. Et le rideau, traversé de part en part, les empreintes dentales bien en place, logées dans son ventre d'interdiction, est tombé tel un balafon crevé.

Sur le champ de bataille, limité aux quatre coins par des vingtaines de nègres pendus par les testicules, se dresse peu à peu un monument qui promet d'être grandiose.

Et au sommet de ce monument, j'aperçois déjà un Blanc et un Nègre qui se donnent la main.

Pour le Noir français, la situation est intolérable. N'étant jamais sûr que le Blanc le considère comme conscience en-soi pour-soi, sans cesse il va se préoccuper de déceler la résistance, l'opposition, la contestation.

C'est ce qui ressort de quelques passages du livre que Mounier a consacré à l'Afrique 206. Les jeunes Noirs qu'il a connus là-bas voulaient conserver leur altérité. Altérité de rupture, de lutte, de combat.

Le moi se pose en s'opposant, disait Fichte. Oui et non.

Nous avons dit dans notre introduction que l'homme était un oui. Nous ne cesserons de le répéter.

Oui à la vie. Oui à l'amour. Oui à la générosité.

206 Emmanuel Mounier, L'éveil de l'Afrique noire. Editions du Seuil, 1948. [Livre disponible dans Les Classiques des sciences sociales. JMT.] 
Mais l'homme est aussi un non. Non au mépris de l'homme. Non à l'indignité de l'homme. À l'exploitation de l'homme. Au meurtre de ce qu'il y a de plus humain dans l'homme: la liberté.

Le comportement de l'homme n'est pas seulement réactionnel. Et il y a toujours du ressentiment dans une réaction. Nietzsche, dans La Volonté de Puissance, l'avait déjà signalé.

Amener l'homme à être actionnel, en maintenant dans sa circularité le respect des valeurs fondamentales qui font un monde humain, telle est la première urgence de celui qui, après avoir réfléchi, s'apprête à agir. 
PEAU NOIRE. MASQUES BLANCS.

\section{EN GUISE DE CONCLUSION}

La révolution sociale ne peut tirer sa poésie du passé, mais seulement du futur. Elle ne peut commencer avec ellemême avant de s'être dépouillée de toutes les superstitions concernant le passé. Les révolutions précédentes faisaient appel à des souvenirs de l'histoire mondiale afin de se droguer quant à leur propre contenu. Pour atteindre leur propre contenu, les révolutions du XIXe siècle doivent laisser les morts enterrer les morts. Là, l'expression dépassait le contenu ; ici le contenu dépasse l'expression.

(K. Marx, Le dix-huit Brumaire.)

Retour à la table des matières

J'aperçois déjà le visage de tous ceux qui me demanderont de préciser tel ou tel point, de condamner telle ou telle conduite.

Il est évident, je ne cesserai de le répéter, que l'effort de désaliénation du docteur en médecine d'origine guadeloupéenne se laisse comprendre à partir de motivations essentiellement différentes de celui du nègre qui travaille à la construction du port d'Abidjan. Pour le premier, l'aliénation est de nature presque intellectuelle. C'est en tant qu'il conçoit la culture européenne comme moyen de se déprendre de sa race, qu'il se pose comme aliéné. Pour le second, c'est en tant que victime d'un régime basé sur l'exploitation d'une certaine race par une 
autre, sur le mépris d'une certaine humanité par une forme de civilisation tenue pour supérieure.

Nous ne poussons pas la naïveté jusqu'à croire que les appels à la raison ou au respect de l'homme puissent changer le réel. Pour le nègre qui travaille dans les plantations de canne du Robert 207, il n'y a qu'une solution: la lutte. Et cette lutte, il l'entreprendra et la mènera non pas après une analyse marxiste ou idéaliste, mais parce que, tout simplement, il ne pourra concevoir son existence [202] que sous les espèces d'un combat mené contre l'exploitation, la misère et la faim.

Il ne nous viendrait pas à l'idée de demander à ces nègres de corriger la conception qu'ils se font de l'histoire. D'ailleurs, nous sommes persuadé que, sans le savoir, ils entrent dans nos vues, habitués qu'ils sont à parler et à penser en termes de présent. Les quelques camarades ouvriers que j'ai eu l'occasion de rencontrer à Paris ne se sont jamais posé le problème de la découverte d'un passé nègre. Ils savaient qu'ils étaient noirs, mais, me disaient-ils, cela ne change rien à rien.

En quoi ils avaient fichtrement raison.

$\grave{A}$ ce sujet, je formulerai une remarque que j'ai pu retrouver chez beaucoup d'auteurs: l'aliénation intellectuelle est une création de la société bourgeoise. Et j'appelle société bourgeoise toute société qui se sclérose dans des formes déterminées, interdisant toute évolution, toute marche, tout progrès, toute découverte. J'appelle société bourgeoise une société close où il ne fait pas bon vivre, où l'air est pourri, les idées et les gens en putréfaction. Et je crois qu'un homme qui prend position contre cette mort est en un sens un révolutionnaire.

La découverte de l'existence d'une civilisation nègre au $X V^{e}$ siècle ne me décerne pas un brevet d'humanité. Qu'on le veuille ou non, le passé ne peut en aucune façon me guider dans l'actualité.

La situation que j'ait étudiée, on s'en est aperçu, n'est pas classique. L'objectivité scientifique m'était interdite, car l'aliéné, le névrosé, était mon frère, était ma sœur, était mon père. J'ai constamment es-

207 Commune de la Martinique. 
sayé de révéler au Noir qu'en un sens il s'anormalise : au Blanc, qu'il est à la fois mystificateur et mystifié.

Le Noir, à certains moments, est enfermé dans son corps. Or, «pour un être qui a acquis la conscience de soi et de son corps, qui est parvenu à la dialectique du sujet et de l'objet, le corps n'est plus cause de la structure de la conscience, il est devenu objet de conscience 208 . »

Le Noir, même sincère, est esclave du passé. Cependant, je suis un homme, et en ce sens la guerre du Péloponèse [203] est aussi mienne que la découverte de la boussole. En face du Blanc, le Noir a un passé à valoriser, une revanche à prendre; en face du Noir, le Blanc contemporain ressent la nécessité de rappeler la période anthropophagique. Il y a quelques années, I'Association lyonnaise des Etudiants de la France d'outre-mer me demandait de répondre à un article qui littéralement faisait de la musique de jazz une irruption du cannibalisme dans le monde moderne. Sachant où j'allais, je refusai les prémices de l'interlocuteur et je demandai au défenseur de la pureté européenne de se défaire d'un spasme qui n'avait rien de culturel. Certains hommes veulent enfler le monde de leur être. Un philosophe allemand avait décrit ce processus sous le nom de pathologie de la liberté. En l'occurrence, je n'avais pas à prendre position pour la musique noire contre la musique blanche, mais à aider mon frère à abandonner une attitude qui n'avait rien de bénéfique.

Le problème envisagé ici se situe dans la temporalité. Seront désaliénés Nègres et Blancs qui auront refusé de se laisser enfermer dans la Tour substantialisée du Passé. Pour beaucoup d'autres nègres, la désaliénation naîtra, par ailleurs, du refus de tenir l'actualité pour définitive.

Je suis un homme, et c'est tout le passé du monde que j'ai à reprendre. Je ne suis pas seulement responsable de la révolte de SaintDomingue.

208 Merleau-Ponty, Phénoménologie de la perception, p. 277. [Livre en préparation dans Les Classiques des sciences sociales. JMT.] 
Chaque fois qu'un homme a fait triompher la dignité de l'esprit, chaque fois qu'un homme a dit non à une tentative d'asservissement de son semblable, je me suis senti solidaire de son acte.

En aucune façon je ne dois tirer du passé des peuples de couleur ma vocation originelle.

En aucune façon je ne dois m'attacher à faire revivre une civilisation nègre injustement méconnue. Je ne me fais l'homme d'aucun passé. Je ne veux pas chanter le passé aux dépens de mon présent et de mon avenir.

Ce n'est pas parce que l'Indochinois a découvert une culture propre qu'il s'est révolté. C'est parce que « tout simplement» il lui devenait, à plus d'un titre, impossible de respirer.

Quand on se rappelle les récits des sergents de carrière [204] qui, en 1938, décrivaient le pays des piastres et des pousse-pousse, des boys et des femmes à bon marché, on ne comprend que trop la fureur avec laquelle se battent les hommes du Viet-Minh.

Un camarade, aux côtés duquel je m'étais trouvé durant la dernière guerre, est revenu d'Indochine. Il m'a mis au courant de beaucoup de choses. Par exemple de la sérénité avec laquelle de jeunes Vietnamiens de seize ou dix-sept ans tombaient devant un peloton d'exécution. Une fois, me dit-il, nous fûmes obligés de tirer dans la position du tireur à genoux: les soldats tremblaient devant ces jeunes «fanatiques». En conclusion, il ajoutait: "La guerre que nous avons faite ensemble n'était qu'un jeu à côté de ce qui se passe là-bas. »

Vues d'Europe, ces choses sont incompréhensibles. Certains arguent d'une prétendue attitude asiatique devant la mort. Mais ces philosophes de bas étage ne convainquent personne. Cette sérénité asiatique, les « voyous» du Vercors et les « terroristes» de la Résistance l'ont manifestée pour leur compte il n'y a pas si longtemps.

Les Vietnamiens qui meurent devant le peloton d'exécution n'espèrent pas que leur sacrifice permettra la réapparition d'un passé. C'est au nom du présent et de l'avenir qu'ils acceptent de mourir. 
Si à un moment la question s'est posée pour moi d'être effectivement solidaire d'un passé déterminé, c'est dans la mesure où je me suis engagé envers moi-même et envers mon prochain à combattre de toute mon existence, de toute ma force pour que plus jamais il n'y ait, sur la terre, de peuples asservis.

Ce n'est pas le monde noir qui me dicte ma conduite. Ma peau noire n'est pas dépositaire de valeurs spécifiques. Depuis longtemps, le ciel étoilé qui laissait Kant pantelant nous a livré ses secrets. Et la loi morale doute d'elle-même.

En tant qu'homme, je m'engage à affronter le risque de l'anéantissement pour que deux ou trois vérités jettent sur le monde leur essentielle clarté.

Sartre a montré que le passé, dans la ligne d'une attitude inauthentique, «prend» en masse et, solidement charpenté, informe alors l'individu. C'est le passé transmué [205] en valeur. Mais je peux aussi reprendre mon passé, le valoriser ou le condamner par mes choix successifs.

Le Noir veut être comme le Blanc. Pour le Noir, il n'y a qu'un destin. Et il est blanc. Il y a de cela longtemps, le Noir a admis la supériorité indiscutable du Blanc, et tous ses efforts tendent à réaliser une existence blanche.

N'ai-je donc pas sur cette terre autre chose à faire qu'à venger les Noirs du XVIIe siècle?

Dois-je sur cette terre, qui déjà tente de se dérober, me poser le problème de la vérité noire?

Dois-je me confiner dans la justification d'un angle facial?

Je n'ai pas le droit, moi homme de couleur, de rechercher en quoi ma race est supérieure ou inférieure à une autre race.

Je n'ai pas le droit, moi homme de couleur, de souhaiter la cristallisation chez le Blanc d'une culpabilité envers le passé de ma race. 
Je n'ai pas le droit, moi homme de couleur, de me préoccuper des moyens qui me permettraient de piétiner la fierté de l'ancien maître.

Je n'ai ni le droit ni le devoir d'exiger réparation pour mes ancêtres domestiqués.

Il n'y a pas de mission nègre: il n'y a pas de fardeau blanc.

Je me découvre un jour dans un monde où les choses font mal ; un monde où l'on me réclame de me battre; un monde où il est toujours question d'anéantissement ou de victoire.

Je me découvre, moi homme, dans un monde où les mots se frangent de silence; dans un monde où l'autre, interminablement, se durcit.

Non, je n'ai pas le droit de venir et de crier ma haine au Blanc. Je n'ai pas le devoir de murmurer ma reconnaissance au Blanc.

Il y a ma vie prise au lasso de l'existence. Il y a ma liberté qui me renvoie à moi-même. Non, je n'ai pas le droit d'être un Noir.

Je n'ai pas le devoir d'être ceci ou cela...

Si le Blanc me conteste mon humanité, je lui montrerai, en faisant peser sur sa vie tout mon poids d'homme, [206] que je ne suis pas ce «Y a bon banania » qu'il persiste à imaginer.

Je me découvre un jour dans le monde et je me reconnais un seul droit : celui d'exiger de l'autre un comportement humain.

Un seul devoir. Celui de ne pas renier ma liberté au travers de mes choix.

Je ne veux pas être la victime de la Ruse d'un monde noir.

Ma vie ne doit pas être consacrée à faire le bilan des valeurs nègres.

Il n'y a pas de monde blanc, il n'y a pas d'éthique blanche, pas davantage d'intelligence blanche.

Il y a de part et d'autre du monde des hommes qui cherchent.

Je ne suis pas prisonnier de l'Histoire. Je ne dois pas y chercher le sens de ma destinée. 
Je dois me rappeler à tout instant que le véritable saut consiste à introduire l'invention dans l'existence.

Dans le monde où je machemine, je me crée interminablement.

Je suis solidaire de l'Etre dans la mesure où je le dépasse.

Et nous voyons, à travers un problème particulier, se profiler celui de l'Action. Placé dans ce monde, en situation, « embarqué » comme le voulait Pascal, vais-je accumuler des armes?

Vais-je demander à l'homme blanc d'aujourd'hui d'être responsable des négriers du XVII siècle?

Vais-je essayer par tous les moyens de faire naître la Culpabilité dans les âmes?

La douleur morale devant la densité du Passé ? Je suis nègre et des tonnes de chaînes, des orages de coups, des fleuves de crachats ruissellent sur mes épaules.

Mais je n'ai pas le droit de me laisser ancrer. Je n'ai pas le droit d'admettre la moindre parcelle d'être dans mon existence. Je n'ai pas le droit de me laisser engluer par les déterminations du passé.

Je ne suis pas esclave de l'Esclavage qui déshumanisa mes pères.

Pour beaucoup d'intellectuels de couleur, la culture [207] européenne présente un caractère d'extériorité. De plus, dans les rapports humains, le Noir peut se sentir étranger au monde occidental. Ne voulant pas faire figure de parent pauvre, de fils adoptif, de rejeton bâtard, va-t-il tenter fébrilement de découvrir une civilisation nègre?

Que surtout l'on nous comprenne. Nous sommes convaincu qu'il y aurait un grand intérêt à entrer en contact avec une littérature ou une architecture nègres du III siècle avant Jésus-Christ. Nous serions très heureux de savoir qu'il exista une correspondance entre tel philosophe nègre et Platon. Mais nous ne voyons absolument pas ce que ce fait pourrait changer dans la situation des petits gamins de huit ans qui travaillent dans les champs de canne en Martinique ou en Guadeloupe. 
Il ne faut pas essayer de fixer l'homme, puisque son destin est d'être lâché.

La densité de l'Histoire ne détermine aucun de mes actes.

Je suis mon propre fondement.

Et c'est en dépassant la donnée historique, instrumentale, que j'introduis le cycle de ma liberté.

Le malheur de l'homme de couleur est d'avoir été esclavagisé.

Le malheur et l'inhumanité du Blanc sont d'avoir tué l'homme quelque part.

Sont, encore aujourd'hui, d'organiser rationnellement cette déshumanisation. Mais moi, l'homme de couleur, dans la mesure où il me devient possible d'exister absolument, je n'ai pas le droit de me cantonner dans un monde de réparations rétroactives.

Moi, l'homme de couleur, je ne veux qu'une chose:

Que jamais l'instrument ne domine l'homme. Que cesse à jamais l'asservissement de l'homme par l'homme. C'est-à-dire de moi par un autre. Qu'il me soit permis de découvrir et de vouloir l'homme, où qu'il se trouve.

Le nègre n'est pas. Pas plus que le Blanc.

Tous deux ont à s'écarter des voix inhumaines qui furent celles de leurs ancêtres respectifs afin que naisse une authentique communication. Avant de s'engager dans la voix positive, il y a pour la liberté un effort de désaliénation. Un homme, au début de son existence, est toujours [208] congestionné, est noyé dans la contingence. Le malheur de l'homme est d'avoir été enfant.

C'est par un effort de reprise sur soi et de dépouillement, c'est par une tension permanente de leur liberté que les hommes peuvent créer les conditions d'existence idéales d'un monde humain.

Supériorité ? Infériorité? 
Pourquoi tout simplement ne pas essayer de toucher l'autre, de sentir l'autre, de me révéler l'autre?

Ma liberté ne m'est-elle donc pas donnée pour édifier le monde du Toi?

À la fin de cet ouvrage, nous aimerions que l'on sente comme nous la dimension ouverte de toute conscience.

Mon ultime prière :

O mon corps, fais de moi toujours un homme qui interroge! 
[209]

PEAU NOIRE. MASQUES BLANCS.

POSTFACE

RECONNAISSANCE DE FANON

«... Et véritablement il s'agit de lâcher l'homme.»

\section{Retour à la table des matières}

Il y a plus de trois ans qu'il est mort, il n'y a pas treize ans que son premier livre a paru; mais sa pensée retentit aujourd'hui sur des continents entiers avec une force telle qu'il est devenu impossible (ou extrêmement suspect), traitant des problèmes du Tiers-Monde, de n'y pas faire au moins quelque allusion. Un aussi prodigieux destin, c'est à peine s'il a nécessité, pour s'accomplir, ce moment de la vie à travers lequel un homme a généralement besoin de passer pour acquérir la maîtrise de ses moyens : à 18 ans, un étudiant en médecine de Fort-deFrance s'engage dans l'armée française et lutte contre le nazisme sous les ordres du général De Lattre de Tassigny: à 25 ans, il est interne des hôpitaux et se spécialise en psychiatrie ; à 27 ans, il publie à Paris Peau noire, masques blancs ; à 36 ans il meurt dans un hôpital de New York, en léguant le fanonisme à tous les colonisés du monde. 
Que s'est-il donc passé, pour cet homme, durant ces dix années que nous avons tous vécues (de 1952 à 1961, de Ridgway-les-pigeonsvoyageurs aux hélicoptères des rencontres de Lugrin)? Dans quelle étoffe a-t-il bien pu tailler son existence, avec quelle puissance a-t-il bandé son arc, quand nous nous sentions chaque jour un peu plus défaits, un peu moins efficaces, et qu'au bout de nos faibles bras pendaient en vain nos armes dérisoires? Du bulletin de vote à la valise, de l'action légale à l'action clandestine, du meeting à la désertion, toutes ont été brandies, toutes ont fait long feu: certains objectifs, il est vrai, furent tout de même atteints (ceux qui réclamaient la paix ont fini par [210]

l'avoir, ceux qui souffraient d'une mauvaise conscience ont pu s'imaginer guéris, ceux qui n'avaient rien tenté en ont paru justifiés, et peut-être même ceux qui avaient prétendu aider le peuple algérien y étaient-ils plus ou moins parvenus), mais nous ne nous en sommes pas moins retrouvés tous au même point, les uns privés de leurs droits civiques, les autres ne voyant plus ce qu'ils pourraient en faire, - cependant que déchirait le ciel de notre monde cette flèche intrépide dont le vol n'a pas fini d'ébranler des multitudes de consciences humaines. A croire que le monde, et jusque dans ses zones les plus familières, avait précisément cessé d'être « nôtre »...

Je ne suis pas un colonisé : j'avoue pourtant que cette flèche me touche, et beaucoup mieux qu'il y a treize ans, mais bien toujours aux mêmes points sensibles.

Ce qui d'abord mavait atteint, dans cette pensée, dès le moment où il me fut donné de lire le manuscrit de Peau noire et d'en rencontrer l'auteur, c'est sa démarche exceptionnellement incarnée, où je persiste à voir le plus sûr garant de sa dimension universelle et de son efficience révolutionnaire. Fanon argumentait à corps perdu, à cœur perdu, il s'avouait blessé dans sa chair même, il nous disait avoir crié, avoir explosé, avoir failli devenir fou («Il y a trois ans que ce livre aurait dû 
être écrit... Mais alors les vérités nous brûlaient... »): « au paroxysme du vécu et de la fureur », s'éprouvant « damné », prisonnier d'un « cercle infernal », Fanon n'avait pourtant pas cessé de parier sur l'homme, sur un homme qu'il concevait à sa mesure, «creusant dans sa chair pour y trouver un sens ».

Ainsi choisissait-il d'affronter d'emblée son vertige même (cette atroce tentation qui nous vient parfois de liquider à jamais dans notre tête les difficultés sur lesquelles nous butons chaque jour dans le monde), en prenant pour point d'ancrage et pour règle absolue de son rapport aux [211] autres cette "folle » exigence, qui le consumait, de les reconnaître et d'en être reconnu. Sombrer dans la folie, c'est préférer le salut personnel: Fanon s'y est refusé, ne pouvant concevoir qu'un salut collectif. Belle chimère, peut-être bien, mais la seule sans doute qui puisse équilibrer la mort en nos âmes mortelles. Sachons en tout cas de quelles profondeurs il est d'abord remonté vers nous, cet homme fier, cet intraitable camarade, ce frère rigoureux, qui eut un jour le courage d'écrire: « je me mis à pleurer».

$\mathrm{Ce}$ dont un Monsieur qui se disait critique eut le front de tirer, quant à lui, la leçon que voici : «M. Fanon a la maladie d'être noir comme on a la rougeole... Il a les nerfs à fleur de peau (noire) et le sang assez bouillonnant... Son livre est probablement un mauvais livre et sa névrose certainement une très mauvaise névrose... Et puisqu'il est médecin, qu'il se guérisse lui-même! » Fasse Hippocrate, avec l'aide des dieux, que nos blancs psychiatres parviennent - en cas de besoin - à se guérir entre eux comme ce psychiatre noir y est tout seul parvenu. Il reste, bien sûr, que cette peau n'était point rationnelle, que cette chair entravait de la plus obscène façon le libre exercice d'une pensée cartésienne: «O mon corps (s'écriait Fanon, en guise d' « ultime prière »), fais de moi toujours un homme qui interroge!»: «C'est dire, commentait un autre de ses critiques, le vague dans lequel nous nageons. »

Il nageait certes, ce docteur en médecine (hélas !) aux yeux de qui Fanon n'était alors qu'un « aliéné » (pour avoir voulu échapper à sa véritable condition, «médecin de campagne aux Antilles»); il nageait 
même assez mal pour prédire à son jeune « confrère ( «bien jeune pour écrire un livre de 222 pages ») qu'il finirait par regretter, « dans ses vieux jours », d'avoir été à ce point « incohérent et destructeur ». Pour les vieux jours, c'est raté ; pour la destruction, j'en connais les victimes et ne saurais les plaindre: pour l'incohérence, j'en dirai deux mots.

Parce qu'il est lui-même dans cette situation, et qu'il y dispose toutefois d'un équipement intellectuel dont elle [212] est généralement fort peu prodigue, un homme parvient à comprendre ce que c'est que de naître avec une peau noire dans un monde dominé par les Blancs. Il appelle névrose le phénomène dont souffrent ses semblables; il leur en fournit la description la plus concrète et la plus pénétrante; il tente enfin de les aider à s'en guérir, en leur proposant de dépasser leur noirceur, leurs rêves de blancheur aussi bien que leur choix négatif de la «négritude», vers un monde humain où Blancs et Noirs puissent enfin se reconnaître par la médiation d'une commune entreprise. Cet homme, il est vrai, n'a point de doctrine en poche: muni de sa seule exigence, il se contente de poser un diagnostic et de proposer une thérapeutique. On peut contester l'un, trouver que l'autre est insuffisamment définie: mais je ne crois pas qu'on puisse déceler, dans Peau noire, masques blancs, la moindre trace de contradiction dans l'analyse du mal, - non plus que la moindre incertitude quant au sens dans lequel la guérison peut être recherchée. Si toutefois quelque incohérence virtuelle risquait encore d'échapper à la lecture de cette seule étude, sans doute n'aurait-elle pas tardé à se manifester dans les prolongements de tous ordres que son auteur lui donna durant les dix années qui lui restaient à vivre. Or je tiens qu'en 1952 Fanon était un esprit authentiquement révolutionnaire, et qu'il l'est demeuré par la suite. Fanon l'Algérien a tenu les promesses de Fanon l'Antillais : Les damnés de la terre sont la confirmation de Peau noire, masques blancs, tout comme ils en reçoivent leur éclairage le plus sûr. 
Si j'admire profondément cet homme, c'est bien pour son humanité : je ne rêve pas d'en faire un saint laïque, ni quelque héros pour nos sinistres panthéons. Cette surabondante intelligence, si fréquemment souveraine jusque dans sa démesure, pouvait aussi s'abandonner parfois à de plus vains délires, - où transparaissait sous la violence des mots, sous la véhémence du ton, l'extrême vulnérabilité d'une conscience nue. En ce sens, bien sûr, on ne pouvait qu'en être bouleversé : en quelque autre sens, j'avoue que je ne l'étais guère. Je ne sais si Fanon a vécu [213] l'amitié : je sais seulement que nous n'avons pas été amis, qu'il ne semblait guère y tenir (malgré ce qui aurait pu nous rapprocher), et le fait est que je n'y tenais moi-même en aucune façon. Cherchant à comprendre d'où pouvait bien procéder, de ma part, une telle abstention, j'ai d'abord tenté de concevoir que la lutte même dans laquelle nous étions ensemble engagés - quoique à des niveaux différents - nous dépassait l'un et l'autre au point d'interdire entre nous le luxe, proprement bourgeois, d'un rapport d'amitié. Mais une aussi noble explication ne pouvait longtemps me convaincre: bourgeois ou pas, le luxe dont il s'agit est de ceux auxquels je n'ai jamais su renoncer. Si je ne craignais de leur porter tort, je pourrais nommer sur-le-champ trois hommes au moins, que cette lutte m'a fait connaître, et dont je compte bien demeurer l'ami jusqu'à la fin des temps. Ce sont des Algériens il est vrai, et sans doute se sentaient-ils à cet égard plus libres que ce Noir des Antilles qui avait choisi de s'identifier à eux.

Faut-il aller jusqu'à dire, sur cette lancée, que Fanon « en rajouta»? Quand le médecin-chef de l'hôpital psychiatrique de Blida nous revint à Paris pendant quelques jours, - en transit pour Tunis, où il allait rejoindre l'état-major politico-militaire de la Révolution algérienne, - je retrouvai en tout cas un homme d'un abord aussi difficile que celui que j'avais connu cinq ans auparavant, mais de façon apparemment fort différente: moins susceptible, sans doute, moins "écorché vif », il était à coup sûr devenu plus hautain.

En 1952, nous avions failli rompre, lui et moi, le jour même de notre première rencontre: ayant trouvé son manuscrit exceptionnellement intéressant, j'avais commis l'erreur de le lui dire, ce qui le fit me soup- 
çonner d'avoir pensé que « pour un nègre, ce n'était pas si mal »; sur quoi je lui avais, en lui montrant la porte, formulé ma propre réaction dans les termes les plus vifs, - qu'il eut le bon esprit de prendre positivement. Cette seconde rencontre me le fit voir sous un angle nouveau, qui me le rendit à la fois (si j'ose dire) d'autant plus attachant et d'autant plus lointain: tout en relatant avec une sincérité extrême la terreur qui pesait quotidiennement sur lui dans [214] cet enfer « hospitalier » de Blida, où ses jours et ses nuits se partageaient entre les vrais fous et les faux, entre les aliénés de la colonisation et les militants de l'insurrection venus chercher dans cet asile un camouflage provisoire, Fanon manifesta en effet le plus entier dédain à l'égard de ce qui se passait en France, de ce que nous tentions d'y faire et de l'organisation même qui le prenait en charge pour lui faciliter son passage. Il allait vers Tunis et nous n'existions pas. J'ai eu l'occasion de voir défiler par la suite un certain nombre de touristes, français ou étrangers, qui se glorifiaient de partir pour Tunis, ou bien d'en revenir, quand nous avions choisi de rester prisonniers de nos tâches obscures: le cas de Fanon n'avait assurément rien à voir avec celui de ces pèlerins satisfaits : s'il allait aux lieux saints, ce n'était point pour en ramener quelque précieuse relique. Une troisième fois pourtant, le fossé se creusa entre nous. Je revenais de Rome en passant par Madrid et je le rencontrai en descendant d'avion : nous passâmes ensemble une longue soirée, au terme de laquelle, sur un trottoir de la calle Montana, près de la Puerta del Sol, il m'expliqua sans ménagements que tous nos efforts de soutien étaient vains, qu'il savait, lui, comment le F.L.N. était organisé en France, et que nous étions dupes d'une façade politique derrière laquelle se tenait un chef militaire que nous ne connaîtrions jamais. J'avais, par chance, quelques raisons de demeurer sceptique, et la suite des événements me confirma qu'elles ne manquaient pas de force.

Peut-être entrevoit-on ce que ces trois moments signifièrent pour moi : si j'ai cru pouvoir en parler, c'est qu'en chacun d'eux Fanon n'en poursuivait pas moins son humaine entreprise, alors même qu'il en révélait le très humain revers. Dans le premier cas, c'est à vrai dire ma 
propre susceptibilité qui était surtout en cause: il en avait trop vu, quant à lui, pour pouvoir se fier au premier venu; et Dieu sait si mon attitude eût été finalement, à sa place, aussi vraie que la sienne... Dans le second, c'était son impatience de servir la cause concrète qu'il était enfin parvenu à faire sienne, et par rapport à laquelle ce qui l'appelait là-bas nous condamnait en effet à n'être que des intermédiaires. Dans le troisième, et ce fut le dernier, je [215] crois voir le terrible besoin des options le plus radicales et l'impatient rejet, par cet homme qui se savait déjà condamné, de toute forme d'action n'offrant pas une prise directe sur le cours même de la lutte.

Mais c'est un fait qu'il me fallut chaque fois un peu plus de temps pour comprendre ces choses. Et quand je dis qu'il n'y eut aucune amitié entre Fanon et moi, on entend bien, j'imagine, que je n'en suis pas fier: du moins cela me permet-il de lui rendre aujourd'hui, en toute liberté, le plus sincère hommage - de la tête et du cœur.

J'ai dit combien me frappa tout de suite l'allure incarnée de sa démarche intellectuelle. Depuis lors, je l'ai retrouvée partout : dans ses deux autres livres, dans son action, dans sa vie même et jusque dans sa façon de mourir.

Dans L'An V de la révolution algérienne ${ }^{209}$, parlant des déplacements de population, des regroupements imposés par un adversaire qui " taille dans la chair algérienne avec une violence inouiie», il montre qu'une mechta regroupée a d'abord été «brisée, abîmée », et qu'au sein des groupes humains où sont ainsi rassemblés des morceaux de familles préalablement dispersées, aucun geste, aucun rythme antérieur n'est conservé intact : ces membres séparés « ne mangent ni ne dorment comme avant ». Encore ne s'agit-il là que de transformations subies, entièrement passives : ce sont les bombardements, ratissages, prises d'otages et autres exactions de l'armée française qui ont rendu

209 Chez François Maspéro, Paris. 
nécessaires ces artificielles reconcentrations en provoquant d'abord une dispersion réelle, en perturbant d'emblée, de part en part, «le panorama social, le monde de la perception ». À ces facteurs destructifs, déstructurants, des actes ont en effet répondu, qui n'ont guère tardé à déclencher d'étonnants processus de restructuration.

Tel est le cas, par exemple, en ce qui concerne les rapports entre le peuple algérien et cet instrument technique, le poste de radio. En écoutant - même brouillée, [216] hachée, discontinue, presque inaudible - «la Voix de l'Algérie combattante», en réagissant contre le brouillage "de façon presque physique, musculaire», chaque Algérien éprouve, dès la fin 1956, le sentiment de «faire corps avec la Nation en lutte», de participer à sa «nouvelle respiration». À l'écoute de la Révolution (grâce à une technique qu'il rejetait auparavant pour ne point « donner voix à l'occupant»), il en « décide la relance..., existe avec elle, la fait exister ». Et c'est ainsi que l'on assiste, dans un sens cette fois positif, "à un bouleversement de fond en comble des moyens de perception, du monde même de la perception».

Si cette pensée incarnée me paraît efficace, c'est dans la mesure où elle ne néglige, sauf erreur, aucune des prises essentielles auxquelles son objet même peut tour à tour se prêter :

- «Accepter la technique radiophonique, acheter un poste, et vivre la Nation en lutte, coïncident. »

- «La voix de l'occupant se désacralise... La Parole de la Nation, le Verbe de la Nation, ordonnent le monde en le renouvelant. »

- « Incorporée dans ces conditions à la vie de la Nation, la radio aura, dans la phase de construction du pays, une importance exceptionnelle... À la pédagogie révolutionnaire de la lutte de Libération, doit normalement se substituer une pédagogie révolutionnaire de la construction de la Nation. » 
Les mêmes remarques s'imposent sur un autre plan, celui des rapports entre le peuple algérien et la technique médicale. Au point de départ, c'est le refus : «le colonisé perçoit dans une confusion presque organique le médecin, l'ingénieur, l'instituteur, le policier, le gardechampêtre » et bien entendu, le cas échéant, le parachutiste). C'est le drame de toute situation coloniale, celui de "la rencontre impossible »: en présence du médecin européen, le colonisé « est toujours un peu rigide», - et son corps l'est aussi, « les muscles sont contracturés, il n'y a pas de détente: c'est l'homme total, c'est le colonisé, qui affronte à la fois un technicien et un colonisateur ». Le médecin autochtone lui-même est perçu, avant le combat national, « comme un ambassadeur de l'occupant », - faisant [217] corps, à différents titres, avec la colonisation, avec la domination, avec l'exploitation. Mais voici que, " couchant sur la terre avec les hommes et les femmes des mechtas, vivant le drame du peuple», prenant ses responsabilités dans l'indispensable organisation nationale de la Santé, le médecin algérien « réintègre le groupe, ... devient un morceau de la chair algérienne »: «Il y a présence simultanée de la Révolution et de la médecine ». Conclusion pratique, et de portée plus générale: «Dès lors que le corps de la Nation se remet à vivre de façon cohérente et dynamique, tout devient possible... Le peuple qui prend son destin en mains assimile à une cadence presque insolite les formes les plus modernes de la technique. »

C'est pourtant à propos de la femme algérienne et de son propre corps (qu'il ose lui dévoiler à elle-même sous le regard de l'homme algérien), que la pensée de Fanon me semble accéder - par son incarnation - à la plus incontestable authenticité, du point de vue révolutionnaire. Le voile, explique-t-il, c'est la résistance à l'occupant: face à l'Algérienne, l'Européen « veut voir »; limiter sa perception c'est donc lui tenir tête, lui infliger un échec spectaculaire. Or il advint, au bout d'un an de lutte armée, qu'on entrevit «l'urgence d'une guerre totale » et que le problème se posa « d'engager les femmes comme éléments actifs», de décider leur entrée dans la Révolution. «La décision... ne fut pas prise à la légère,... les hésitations ne manquèrent pas, ... les oppositions intérieures se firent massives... » Mais enfin cela eut lieu : 
et ce fut, pour commencer, au niveau le plus radical : celui du terrorisme urbain. Voici donc notre jeune Algérienne, - que le voile, traditionnellement, «protège, rassure, isole», qui hier encore rasait les murs, évitait de tenir le milieu du trottoir, - appelée à circuler sans voile en pleine ville européenne; la voici devenue « femme-arsenal,... porteuse de revolvers, de grenades, de centaines de fausses cartes d'identité ou de bombes". L'absence du voile, nous dit Fanon, altère son « schéma corporel », perturbe son sens des distances, lui semble étirer ses propres membres indéfiniment, lui donne l'impression de " s'échapper», de "s'en aller en morceaux,... d'être mal habillée, voire d'être nue »: de sorte qu'il lui faut bientôt [218] réapprendre son corps, lui « inventer... de nouvelles dimensions,... de nouveaux moyens de contrôle musculaire». Nous avons quelque peine, sans doute, à mesurer la distance que ces femmes ont dû franchir d'un seul coup ; c'est pourquoi Fanon, qui n'est pas précisément l'homme des précautions oratoires, reprend un peu plus loin son implacable description: «La fille algérienne a honte de son corps, de ses seins, de ses menstrues. Elle a honte d'être femme devant les siens. Elle a honte de parler devant son père, de regarder son père. Et son père aussi a honte devant elle. En réalité, l'analyse en profondeur montre que le père voit la femme dans sa fille. Inversement, la fille voit l'homme chez son père. » Or cette fille-là va maintenant devoir, seule, dévoilée, maquillée, sortir n'importe quand, aller on ne sait où, et peut-être enfin vivre au maquis - parmi les hommes. Dès lors, l'attitude du père va se modifier de façon radicale, vis-à-vis même de n'importe quelle femme rencontrée dans la rue. "La fille militante, en adoptant de nouvelles conduites, échappe aux traditionnelles coordonnées... »: ainsi convie-t-elle son père « à une sorte de mutation, d'arrachement à lui-même ».

Suivez jusqu'au bout cette piste charnelle, vous y découvrirez ceci : «Les hommes cessent d'avoir raison. Les femmes cessent d'être silencieuses... La femme cesse d'être un complément pour l'homme. Littéralement elle arrache sa place à la force du poignet... La société algérienne, dans le combat libérateur, dans les sacrifices qu'elle consent pour se libérer du colonialisme, se renouvelle et fait exister des va- 
leurs inédites, de nouveaux rapports intersexuels. ... Le mariage en Algérie aura connu sa mutation radicale au cœur même du combat... C'est au milieu des dangers les plus graves que l'Algérien invente des formes modernes d'existence et confère à la personne son maximum de poids. »

Ces quelques passages, que j'épingle à regret parmi tant d'autres qu'il faudrait aussi relire, nous pouvons certes les juger contestables, - à la faveur, notamment, de ce léger recul dont il se trouve que nous disposons aujourd'hui. Du moins serait-il absurde, prétendant en apprécier aujourd'hui le contenu, d'ignorer de quel poids politique [219] se trouvait alors affectée la pensée même qui les sous-tend. En annexe du premier chapitre de L'An V, Fanon reproduisait un texte paru dans «Résistance Algérienne» (16 mai 1957), afin de montrer « la conscience que les responsables du F.L.N. ont toujours eue du rôle important de la femme algérienne dans la Révolution »: je laisse au lecteur le soin de procéder lui-même aux innombrables regroupements qui s'imposent (du triple point de vue du sens, du ton et du vocabulaire), entre le texte très officiellement anonyme des pages 46 à 49 et les chapitres I et III du texte même de Fanon. S'il nous semble aujourd'hui - à tort ou à raison, j'y reviendrai - que notre auteur se laissa plus ou moins entraîner à « forcer la note», constatons du moins qu'à cette époque, en d'aussi délicates matières et à de tels niveaux de responsabilités, ses convictions faisaient école.

Son troisième et dernier livre, Les damnés de la terre 210 est d'ailleurs venu confirmer - par l'accueil exceptionnellement positif que lui firent d'emblée les principaux intéressés - qu'il ne s'agissait pas, entre eux et Fanon, d'une rencontre de hasard : car c'est la même pensée qui s'y exprime, mais à ce point amplifiée que plus d'une fois je me suis pris à rougir, durant ces trois dernières années, d'en avoir si mal pressenti auparavant les véritables dimensions.

210 Chez François Maspéro, Paris 1961. [Livre disponible dans Les Classiques des sciences sociales. JMT] 
Il n'est guère possible de relever ici toutes les descriptions où des conduites signifiantes s'enracinent dans une attitude corporelle. A titre d'exemple, rappelons seulement ces quelques notations: « dans ses muscles, le colonisé est toujours en attente»; c'est « un persécuté qui rêve en permanence de devenir un persécuteur», ce qui entretient en lui « un tonus musculaire de tous les instants»; son affectivité est sans cesse "en érection..., maintenue à fleur de peau comme une plaie vive qui fuit l'agent caustique»: son psychisme «se rétracte, s'oblitère, se décharge dans des démonstrations musculaires qui ont fait dire à des hommes très savants que le colonisé est un hystérique »; de sorte qu'il se complaît « avec érotisme dans les dissolutions motrices de la crise», dans cette « orgie musculaire» [220] qui est sa « relaxation » et dont « le phénomène de la danse et de la possession » offre le parfait exemple, - le plus pacifique aussi... Or tout le prix de ces descriptions se situe à mes yeux dans le rapport même entre leur allure délibérément concrète et le souci pratique de restructuration qui les sous-tend: «L'objectif du colonisé qui se bat est de provoquer la fin de la domination. Mais il doit également veiller à la liquidation de toutes les non-vérités fichées dans son corps par l'oppression... La libération totale est celle qui concerne tous les secteurs de la personnalité... Quand la nation démarre en totalité, l'homme nouveau n'est pas une production a posteriori de cette nation mais coexiste avec elle, se développe avec elle, triomphe avec elle... »

J'arrête ici cette citation capitale, qui est sur le point de le devenir un peu trop : car tout Fanon est là, dans l'absurde et pourtant décisive exigence dont ces quelques lignes témoignent. Dans la préface quiil m'avait été donné d'écrire en 1952, je retenais surtout de Peau noire ce thème, qui m'y était apparu primordial, selon lequel une attitude réellement révolutionnaire consiste à vouloir à la fois la transformation des hommes et celle des structures : si cette évidence m'est demeurée chère, c'est qu'à force de considérer qu'elle «va de soi » nous sommes à peu près parvenus, les uns et les autres, à n'en plus jamais tenir compte. Ce sera pourtant tout à fait en vain que nous aborderons nos actuels problèmes, aussi longtemps que nous n'aurons pas rejeté, 
avec la même force, l'humanisme tricheur, qui s'en remet à la conscience pure, et les tentatives de mystification du cynisme politique. L'intention est nécessaire, le résultat l'est aussi : c'est ce que Fanon appelle une « exigence dialectique». Et si je note que cette expression même signale un relatif privilège accordé à l'intention (dans le cas contraire, l'exigence y eût été nommée "nécessité »), je n'en suis que plus à l'aise pour me déclarer en parfaite consonance avec l'attitude en cause : car il faut bien que l'objectif dépende du projet, que le résultat ait été profondément voulu pour pouvoir être atteint - c'est-àdire effectivement apprécié. Mais il faut qu'il puisse être atteint; et c'est bien ce que Fanon, qui s'adressait surtout aux Algériens, se tuait à [221] leur dire, leur criait en mourant - aux toutes dernières pages de son ultime effort de participation. Fin de la citation précédemment interrompue: «L'indépendance n'est pas un mot à exorciser mais une condition indispensable à l'existence des hommes et des femmes vraiment libérés, c'est-à-dire de tous les moyens matériels qui rendent possible la transformation radicale de la société. »

On voit ce qu'est ici devenue cette "dialectique du corps et du monde » dont il nous entretenait dans son précédent ouvrage, à propos de la femme algérienne. C'est bien toujours « la chair algérienne mise à nu » : mais c'est le corps même de la Nation qui est cette fois incité à tirer parti de ses épreuves régénératrices (parce qu'issues de sa propre entreprise), pour entrer enfin dans le monde. Pour adopter à son égard, - comme jadis femme algérienne entrant en ville européenne, ou fellagha blessé se confiant à une technique héritée de l'occupant, ou consciences « arabo-berbères » rejoignant le combat collectif à force de tendre l'oreille vers les émissions en langue française de l'Algérie combattante, - des conduites nouvelles, des conduites révolutionnaires.

Tel est bien, me semble-t-il, le cœur de cette pensée, le point central où se trouvent ensemble définis son équilibre et le principe même 
de son dynamisme. Fanon est un intellectuel et sa culture philosophique est considérable : mais il se souvient d'avoir dû, lui aussi, faire son entrée dans le monde, restructurer sa personnalité, accéder à l'existence en inventant son rapport aux autres, à partir de sa situation concrète de Noir colonisé. Sartre, Freud et Marx l'y ont aidé, c'est certain : dans l'exacte mesure où il s'en est lui-même aidé, pour affronter son problème et non pour le subtiliser. Si prestigieux qu'ils fussent à ses yeux, ces quelques esprits, et tant d'autres encore, n'avaient eu à surmonter ni un passé d'esclave ni la couleur de leur peau ; quand ils parlaient de société sans classe ou de reconnaissance de l'homme par l'homme, ils songeaient aux opprimés, bien sûr, mais ils n'en étaient point, - n'ayant en fait besoin d'être reconnus que par ces autres hommes, qui avaient tout ensemble besoin, [222] quant à eux, d'être reconnus par leurs oppresseurs, par leurs propres frères, et chacun d'eux par sa propre conscience. La philosophie blanche ne semble guère se soucier que de recomposer le monde (et de tendre la main à tous ceux qui, pour des raisons diverses, n'entrent point encore dans sa composition): son lecteur noir, en tout cas, ne peut accepter l'invitation qu'au prix de se recomposer lui-même. Or il va de soi que si nous sommes blancs nous avons nous aussi, corrélativement, à nous recomposer: convenons toutefois que nous n'en éprouvons pas le besoin au même titre que lui, et qu'un échec sur ce plan lui sera toujours plus cuisant qu'à nous-mêmes.

Pour nous, le schéma est en somme fort simple: la reconnaissance doit être réciproque, et nous pensons la réciprocité en termes d'égalités géométriques, en termes de symétrie. À la faveur d'une double rotation - accomplie de part et d'autre, et en sens inverse, autour de l'axe même qui nous sépare de nos homologues à peau noire - nous pensons pouvoir coïncider les uns avec les autres en nous identifiant ensemble à la véritable essence de l'homme, laquelle se trouve évidemment située par-delà le blanc et le noir. Dans les meilleurs cas, notre mauvaise conscience, notre esprit de finesse ou notre sens esthétique brouillent légèrement ce schéma, y ajoutant une discrète touche d'authenticité, un certain flou, - sorte d'hommage gracieuse- 
ment rendu par la connaissance rationnelle (du-Bien-du-Vrai-du-Beau) à la morale pratique, aux trop humaines réalités, à l'œuvre d'art dans sa concrète imperfection. Pour avoir été hégélianisé, notre platonisme ne saurait se désintéresser des malheureux qui sont restés dans la caverne. Ainsi allons-nous par exemple jusqu'à concevoir qu'il nous faudrait peut-être, à l'occasion, faire les premiers pas, dans la mesure où nous serions en somme plus évolués - donc plus «conscients», donc plus « responsables»-que ces frères humains situés de l'autre côté de l'axe de rotation: sur cette admirable pente, nous ne tardons pas à nous sentir tenus de prendre sur le monde, en plus de notre point de vue, celui-là même de nos partenaires. Nous le prenons même si bien qu'ils se hâtent, le plus souvent, de nous l'abandonner, [223] ne songeant guère à s'en réclamer, quant à eux, que dans les grandes occasions (colloques, rencontres culturelles, négociations de tous ordres), - afin sans joute de redonner quelque sens à ce que nous persistons à nommer, en France, la courtoisie française.

Or ce que Fanon, fort opportunément, nous montre et nous démontre, c'est que notre démarche et celle du colonisé ne sont pas symétriques, ne sont pas superposables, et que nous ne saurions en aucun cas déduire la sienne de la nôtre, ni l'inventer à sa place, ni même la comprendre s'il se bornait à la formuler.

J'en demande pardon à notre amour-propre: Fanon va même un peu plus loin. Il va jusqu'à nous dire qu'en matière d'humanisation c'est au colonisé de jouer, car lui seul peut accomplir, au plan collectif, des actes réels. Commandés par une simple « obligation » d'ordre moral, nos propres actes demeurent personnels et ne sont guère, en effet, que des gestes: dans la meilleure hypothèse, nous pratiquons nos idées, nous les «appliquons», nous les mettons en ceuvres (plus ou moins « bonnes »...), nous visons l'acte - nous nous efforçons d'agir - à partir de ce que nous pensons. Mais le colonisé, lui, il faut bien qu'il agisse d'abord, s'il veut conquérir le pouvoir de penser. De penser par luimême, bien entendu.

À l'époque de Peau noire, Fanon n'est à vrai dire colonisé qu'en tant que «nègre», sous l'angle du racisme: il n'est pas exploité, il a eu la 
chance d'échapper à l'oppression économique. C'est dire que son problème, s'il se trouve reproduit à des quantités d'exemplaires à travers le monde, n'en demeure pas moins individuel, - les conditions économico-sociales aux Antilles ne permettant guère d'escompter qu'il puisse être bientôt posé en termes collectifs. Le prix que doit payer, pour une pensée personnelle, cette conscience sur qui pèse sans relâche l'anthropophagique regard de l'homme blanc, ce n'est encore, à ce niveau, qu'une action sur soi. Mais le fait est, déjà, que les seules vérités qui trouveront grâce à ses yeux, sont celles qui lui seront passées par le corps, qui auront brûlé sa chair. Ainsi Jean Genet, cet autre paria qui dut lui aussi réinventer la morale pour répondre au mépris raciste de notre moralisme, dit-il volontiers ne pouvoir s'assurer [224] d'une pensée s'il n'en a pas été d'abord parcouru « des pieds jusqu'à la tête » : c'est qu'il eut d'abord à se concevoir méprisé, et que ces sortes d'enfantement n'ont rien à voir avec nos jongleries mentales, nos jeux de mots, nos maux de tête.

Avons-nous abandonné notre peau au dermatologue, notre chair au biologiste, notre colonne vertébrale au kinésithérapeute? Le fait est que nos idées manquent d'ossature, de réalité concrète et de sensibilité. Vivons-nous encore? Notre réflexion, du moins, ne semble pas s'en trouver affectée: ce que peut-être il nous arrive encore de vivre n'y figure plus que sous les espèces d'une certaine idée de la vie, d'une notion du « vécu q que nous nous sommes faite et ne cessons de subtiliser. "L'homme blanc, dit le proverbe noir, ne voit que ce qu'il sait»: il a perdu le contact avec le monde environnant; il n'a plus de dos (son corps n'est plus en prise sur ce qui se passe derrière lui); et s'il conserve une façade, il semble avoir depuis longtemps renoncé à rencontrer son semblable face à face. Je ne prétends pas faire ici l'éloge des effusions sentimentales: je dis seulement que nos tête-à-tête gagneraient sans doute à prendre un peu plus souvent l'allure du « cœur à cœur», sinon même, çà et là, celle du corps à corps... Car nous ne nous pensons nous-mêmes, en fin de compte, qu'au prix de nous quitter, comme l'indique assez bien ce thème de l'« incarnation » (ou de la «situation», ou de l'« engagement») selon lequel notre pensée 
s'invente une consistance, tente de «prendre corps» par ses propres moyens, - avouant ainsi qu'elle a cessé de se concevoir charnelle, déjà située à sa naissance même, engagée et comme enracinée dès l'instant même où elle prend conscience de soi. Mais l'idée de la chair ne saurait incarner quelque idée que ce soit (non plus que l'idée de la charité ne saurait redonner cœur, rendre courage, à quelque esprit que ce soit): «... L'esprit européen, dit Fanon, a eu de singuliers fondements. Toute la réflexion européenne s'est déroulée dans des lieux de plus en plus désertiques, de plus en plus escarpés. On prit ainsi l'habitude d'y rencontrer de moins en moins l'homme. - Un dialogue permanent avec soimême, un narcissisme de plus en plus obscène n'ont cessé de faire [225] le lit à un quasi-délire où le travail cérébral devient une souffrance, les réalités n'étant point celles de l'homme vivant, travaillant et se fabriquant, mais des mots, des assemblages divers de mots, les tensions nées des significations contenues dans les mots... »

Or ce n'est point ici un adversaire qui nous parle: «L'Europe a fait ce qu'elle devait faire et somme toute elle l'a bien fait; cessons de l'accuser mais disons-lui fermement qu'elle ne doit plus continuer à faire tant de bruit. Nous n'avons plus à la craindre, cessons donc de l'envier. » De Fanon-le-Nègre à Fanon-l'Africain, toute la distance est ici résumée, et ce qui s'est passé entre-temps c'est qu'il a rencontré le peuple algérien: une collectivité totalement opprimée, niée du point de vue racial et simultanément exploitée sur le plan économique. En soutenant la lutte armée déclenchée le $1^{\text {er }}$ novembre 1954, ce peuple engageait en effet une entreprise collective, dont la seule existence promettait une dimension nouvelle à l'effort solitaire d'une conscience méconnue, soucieuse de penser le monde en termes de reconnaissance. La marche à l'humain, l'invention, la conception de l'homme, cessait d'être une simple postulation morale: elle impliquait désormais une prise réelle sur le monde, dans la mesure où elle était cette fois vécue par une collectivité consciente d'elle-même. Ce corps-là, en effet, on pouvait être sûr qu'il ne se laisserait point traverser, transir jusqu'à la moelle, par le regard de tous ceux qui prétendaient encore maintenir le problème au seul niveau de la conscience pure, quand la moindre de 
leurs pensées n'en continuait pas moins à se fonder distraitement sur la puissance des armes ou sur celle du fric.

Fanon avait vécu à sa façon (plus douloureusement que nous sans doute, et peut-être aussi, déjà, plus positivement) la solitude d'une conscience morale, ce dérisoire sentiment d'« obligation » qui n'oblige à rien parce qu'il oblige à tout, - vis-à-vis de tant d'autres consciences qu'on ne saurait en fait rencontrer sur ces hauteurs, mais seulement en ayant la chance de pouvoir se joindre à elles au sein d'une commune entreprise. Il a eu cette chance; il l'avait bien cherchée.

Et s'il est vrai qu'on ne cherche jamais que ce qu'on a [226] déjà "trouvé », sans doute trouve-t-on toujours plus que ce que l'on cherchait: ainsi Fanon a-t-il rencontré la violence, qui n'était certes pas son idéal de vie. Cette positivité qu'il lui a alors reconnue, j'admire que Fanon-le-Nègre ait su auparavant la concevoir et tout ensemble la récuser, dans cette situation qui fut d'abord la sienne - où tout concourait en effet à rendre la violence inopérante. "Le nègre, disait-il, ignore le prix de la liberté, car il ne s'est pas battu pour elle »: version antillaise, à un siècle et demi de distance, de cette hégélienne intuition selon laquelle «l'individu qui n'a pas mis sa vie en jeu peut bien être reconnu comme personne, mais... n'a pas atteint la vérité de cette reconnaissance d'une conscience de soi indépendante ». Mais si le malheur du nègre français aux yeux de ce Fanon d'il y a douze ans est d'avoir « été libéré par le maître», d'avoir été «agi», de n'avoir pas été à la source du bouleversement de sa propre situation et d'être ainsi « condamné à se mordre et à mordre », si sa situation, enfin, peut être dite « intolérable » par rapport à celle du nègre américain (qui lutte parce qu'il est combattu, qui connaît la bagarre, les défaites, les trêves et les victoires), le même Fanon n'en persiste pas moins à préférer l'action à la réaction: «Nous avons dit dans notre introduction que l'homme était un oui. Nous ne cesserons de le répéter. - Oui à la vie. Oui à l'amour. Oui à la générosité. » Reconnaissant toutefois que l'homme « est aussi un non » (au mépris, à l'indignité, à l'exploitation, « au meurtre de ce qu'il y a de plus humain en l'homme: la liberté »), il conclut en demandant qu'on l'amène à se délivrer du ressentiment, à 
devenir « actionnel», et il fait de cette entreprise même « la première urgence de celui qui, après avoir réfléchi, s'apprête à agir».

Jamais je ne dirai assez combien ces quelques mots me touchent, sur lesquels s'achève le dernier chapitre de Peau noire. C'était en 1952 , et l'horizon, pour nous, était plutôt bouché : nous rencontrions assidûment les responsables vietnamiens mais n'avions à leur proposer que nos écrits pour soutenir leur guerre, nous savions que le peuple algérien réclamait la sienne mais ne pouvions en convaincre [227] personne, nous «nagions » en somme, et déplorablement, mais ce fut notre seule vertu de rester optimistes, - en persistant à prétendre, contre toute évidence, qu'il y avait quelque chose à faire, une action à mener, un travail à poursuivre. Et s'ils m'atteignent, ces mots, ce n'est pas seulement parce qu'ils évoquent pour moi une ancienne impuissance, sa douloureuse prolongation pendant trois ans, puis sa vive résolution dans un travail concret : c'est aussi parce qu'ils font de nouveau retentir en nous, dans l'espèce d'apathie sombre et bavarde où nous voici retombés, l'écho de l'humaine exigence - qui se moque pas mal de savoir si nous sommes ou non « en situation révolutionnaire ». J'y reviendrai tantôt. Je voudrais d'abord essayer de voir ce qu'il advint, pour cette conscience, de sa rencontre avec la violence d'un peuple.

Or il advint surtout, me semble-t-il, qu'elle en décela sur le champ la très concrète positivité. Comme Fanon, bien sûr, nous avions lu Hegel ; comme lui nous avions appris, avec Marx, à remettre la dialectique sur ses pieds : comme lui enfin, nous avions compris, Sartre nous y aidant, que cette folle maîtresse pouvait çà et là garder, de son ancien état, une certaine tendance à ne marcher que dans sa tête tout en pensant avec ses pieds, - d'où résultaient à l'occasion, entre elle et nous, des amours difficiles. En bref, nous étions affranchis et les éventuels travestis négatifs de la positivité n'avaient pas plus de se- 
crets pour nous que ceux, positifs, de la négativité : à l'instar des physiciens du noyau, qui inventèrent le neutron pour résoudre la différence de signes entre électrons et protons, nous étions même allés, du coup, jusqu'à découvrir les vertus de la neutralité. Entre thèse et antithèse, nous ne balancions certes pas, au niveau des idées; et si quelque antithèse venait à prendre corps dans une collectivité donnée, notre intelligence lui était d'emblée acquise, - dans la mesure où la situation échappait suffisamment à nos prises pour n'être plus en somme, de notre point de vue, qu'un objet de pensée. En Algérie, par contre, nous nous savions plus ou moins impliqués, et c'est ainsi que nous devînmes « objectifs». Fanon, quant à lui, ne le fut [228] jamais: ce qui lui permit de le devenir vraiment, et de mieux en mieux jusqu'à ses derniers jours.

Ce qu'il dit du nationalisme, gardons-nous de l'en absoudre aujourd'hui au nom d'une trop actuelle indifférence: car nous en avons été scandalisés, nous qui coquetions avec l'antithèse "F.L.N.», et peut-être n'en sommes-nous pas encore tout à fait remis, - soucieux que nous voilà d'opposer maintenant au « benbellisme » la parfaite négativité d'une idée, d'une «opposition» de principe. Ecoutons un instant cette apologie du « négatif», dans sa terrible nudité.

«Dans un pays colonisé, le nationalisme le plus élémentaire, le plus brutal, le plus indifférencié, est la forme la plus fervente et la plus efficace de défense de la culture nationale. " Je sais : le nationalisme n'est point à nos yeux « révolutionnaire », et la violence ne nous plaît que lorsqu'elle est mise au service d'une révolution «authentique», - pour y combattre cette autre violence (généralement plus sourde, plus feutrée, mais tout autant meurtrière) qu'exerce l'ordre établi sur ceux-là même qui font les frais de son établissement. Et je crois savoir aussi qu'en pareil domaine nous sommes plutôt avares de nos «appellations contrôlées». Combien de révolutions auront finalement trouvé grâce à nos yeux? La soviétique eut le tort d'être stalinienne, puis celui d'être anti-chinoise sous Krouchtchev; la chinoise commit l'erreur d'être anti-krouchtchévienne; la yougoslave, en- 
tre-temps, avait donné dans le titisme: la vietnamienne, un peu trop chinoise sur les bords, manquait d'envergure et se soldait par un partage aberrant; et voici qu'à son tour la cubaine nous préoccupe par ses aspects anarchiques après nous avoir inquiétés par son allure exagérément doctrinaire. La conscience du civilisé n'est jamais en sommeil... L'un de nos meilleurs spécialistes en matière de politique dans les pays du Tiers-Monde qui a su mettre le doigt sur des points essentiels de la pensée de Fanon (et dont les critiques l'atteignent çà et là de plein fouet) lui reproche notamment « d'avoir accrédité avec une certaine naïveté, une certaine complaisance, l'idée de la révolution algérienne, d'avoir ainsi qualifié aussi prématurément un mouvement qui n'avait pas encore, de toute évidence, le caractère [229] révolutionnaire et dont les développements ultérieurs devaient en effet inciter à analyser plus sérieusement le contenu 211 . »

Je n'ignore certes pas que ma connaissance de l'Algérie nouvelle est tout entière « de seconde main »: je ne puis pourtant pas m'empêcher d'opposer à cette perspective une contestation radicale. Car il mapparaît de plus en plus que nous passons notre temps, nous autres Européens, à jouer à cache-cache avec les réalités - au nom de notre idée de la Révolution: quand il s'agit de nous, ce n'est pas le moment : quand il s'agit des autres, ce n'est point ainsi qu'il eût fallu s'y prendre. Et pour nous en tenir au cas des Algériens, Dieu sait toutes les déceptions qu'ils nous ont procurées... J'en parle d'autant plus à l'aise que j'ai pour ma part ressenti la plus aiguë d'entre elles, - celle d'ailleurs dont on parle le moins, bien que peut-être elle ait conditionnné toutes les autres: j'avais en effet espéré, je l'avoue, que les responsables du déclenchement de la lutte nationale sauraient, le jour venu, rendre très concrètement responsables de la lutte sociale les masses mêmes qui les avaient si totalement suivis (après les avoir, sauf erreur, plus ou

211 D'après la sténographie d'une conférence de Jean Lacouture sur « l'ceuvre de Frantz Fanon», faite en 1963 à l'Ecole Nationale d'Administration, et qui fut complétée, la semaine suivante, par une seconde conférence intitulée « Frantz Fanon et notre temps». 
moins poussés) durant cette première phase. Ce n'est point ce qui s'est produit, et il faut essayer de comprendre pourquoi. Or il me semble que Fanon, sur cette énigme, a beaucoup à nous dire.

Mais sans doute faut-il observer tout d'abord que, par-delà une description étonnamment précise de sa situation colonisée, Les damnés de la terre proposent en somme au peuple algérien un véritable plan d'action pour le jour où il aura obtenu son indépendance nationale. Qu'il s'agisse du choix de la paysannerie comme base révolutionnaire, des nationalisations, du parti unique (de son rôle, de son fonctionnement démocratique et de l'importance décisive de la cellule de base), qu'il s'agisse de la jeunesse, des femmes, de l'attitude à adopter à l'égard de la bourgeoisie autochtone, de la place que doit [230] occuper l'armée au sein de la nation, du rapport des travailleurs aux tâches qu'ils effectuent, ou des motivations profondes d'une politique étrangère à l'égard de l'Europe et des pays socialistes, les solutions avancées par Fanon - si discutables soient-elles - ont au moins le mérite d'être suffisamment précises pour pouvoir être en effet discutées. Les tiendra-t-on d'emblée pour «utopiques», sous le prétexte que la plupart d'entre elles ne se sont point encore inscrites dans les faits?

Toute la question est là. Et je ne crois pas que nous devions à ce point nous hâter de stigmatiser les fanoniennes «chimères » au nom de la réalité benbelliste, ou d'en tirer argument pour condamner le régime que le peuple algérien s'est jusqu'ici donné. Du moins faudrait-il, avant d'en arriver là, s'être tout d'abord efforcé de comprendre l'une par l'autre ces deux séries d'aspects, ces deux points de vue pris tour à tour sur une même situation: a priori, rien ne prouve en effet que les descriptions proposées par Fanon soient incompatibles avec nos propres constats, dont on peut aussi bien supposer qu'ils en recevraient au contraire une dimension nouvelle, tout en remédiant sur différents points au manque de précision et de rigueur dont elles souffrent plus ou moins.

Je parle ici d'un effort difficile, auquel notre amour-propre répugne. Car nous avons tout pensé, bien sûr, jusqu'à la situation de nos propres esclaves (si nous ne les forcions pas nous-mêmes à travailler, 
nous n'en profitions pas moins de leur travail), et jusqu'aux normes de leur éventuelle libération : ayant enfin reçu du marxisme leur signification pratique, nos sciences parfaites et nos techniques sans rivales nous ont rendus capables de dire à tout moment tout ce qui peut être dit, dans le monde où nous sommes et en ce point de l'histoire, sur n'importe quel phénomène humain qui se propose à notre observation. Dans la mesure, sans doute, où j'ai mis bien du temps à m'en délivrer, où je ne suis même pas tout à fait

sûr d'y être parvenu, je voue à cette attitude une haine profonde. Il faut penser à tout, c'est vrai, dès lors qu'on est capable de penser: mais comment feindre d'oublier qu'on ne pense jamais, tous comptes faits, que ce qui s'est déjà produit? Côté face, notre plus grande mal [231] honnêteté à l'égard de Fanon est d'en faire un « prophète »; côté pile, c'est de revendiquer pour nous le privilège de l'objectivité. Personne ne prophétise, on le sait bien; et seule la compréhension du présent peut être favorisée, pour les individus comme pour les collectivités, par leur besoin de projeter tel ou tel avenir. Quand le projet aura été formulé, nous devrons certes nous efforcer de le comprendre: mais nous ne saurions en inventer le besoin avant qu'il ait été, ici ou là, concrètement vécu. Ainsi notre objectivité retarde-t-elle toujours d'une mesure ou deux, - le temps de nous assurer (statistiques en main) que le besoin en cause n'était point pur caprice, et d'essayer de tenir compte, ensuite, de ce que les intéressés peuvent avoir à en dire.

L'admirable, chez Fanon, c'est précisément qu'il ne se soucie pas d'être objectif, étant lui-même bien trop intéressé à la solution du problème. "Il ne m'a pas été possible d'être objectif», disait-il déjà dans Peau noire: "l'objectivité scientifique m'était interdite, car l'aliéné, le névrosé, était mon frère, était ma sœur, était mon père ». Et il rappelait, dans l'An V, cette « difficulté de situation à être objectif », cette espèce d'obligation vitale qui est faite au colonisé de rejeter tout à la fois la médecine et le système colonial, la langue et la "présence» française, la radio comme technique et la pensée de l'oppresseur. Le souci d'être exhaustif, de tenir compte de tous les aspects d'une situation, de nuancer à l'infini son jugement, est un luxe 
que ne saurait s'offrir celui qui est socialement nié : «pour le colonisé, l'objectivité est toujours dirigée contre lui ». Cette irritante formule se trouve dans le dernier livre de Fanon, et vise nos diverses théologies politiques, dans la mesure où elles tentent encore de refiler leur vaine casuistique à ceux que leur bras séculier a par avance damnés. Nous autres Occidentaux, nous avons de Dieu, c'est certain, ou du Sens de l'Histoire, ou de la Dialectique de la Nature, ou des Super-Lois Economiques de la Croissance et du Développement, - de la Vérité, pour tout dire, - la connaissance la plus intime qui se puisse concevoir: mais les difficultés mêmes que nous éprouvons à nous la communiquer, à en faire usage entre nous, ne devraient-elles pas [232] nous rendre un peu plus réservés quand le désir nous prend d'en évangéliser le monde? Du moins les avertissements ne nous auront-ils pas manqué : «Au sein du peuple, de tout temps, la vérité n'est due qu'aux nationaux. Aucune vérité absolue, aucun discours sur la transparence de l'âme ne peut effriter cette position. Au mensonge de la situation coloniale, le colonisé répond par un mensonge égal. La conduite est ouverte avec les nationaux, crispée et illisible avec les colons. Le vrai, c'est ce qui précipite la dislocation du régime colonial, c'est ce qui favorise l'émergence de la nation. Le vrai, c'est ce qui protège les indigènes et perd les étrangers. Dans le contexte colonial il n'y a pas de conduite de vérité. Et le bien est tout simplement ce qui leur fait du mal. »

J'aime la dure lucidité de ces quelques lignes. Je ne prétends certes pas qu'une telle situation doive se perpétuer après l'Indépendance, au point d'interdire indéfiniment tout vrai rapport entre l'ancien colonisé et son ancien colonisateur : je dis seulement que ni les «accords » d'Evian ni les jours fastes de juillet 62 n'ont tracé, dans l'histoire algérienne, cette rigoureuse ligne de démarcation que sous-entendent plus ou moins toutes nos expertises. Renonçons à nos douteux solstices, à nos journées historiques, à nos événements décisifs : la vie d'un peuple ne se lit pas sur un calendrier.

J'entends dire - esprit français pas mort - que le peuple algérien n'est pas encore sorti de l'auberge... C'est vrai : pour lui, tout reste à faire. Et c'est faux : car il a choisi d'en sortir, il y a dix ans, au point 
qu'il est déjà dehors, quels que soient les liens qui le retiennent encore à l'intérieur. Difficile pensée, j'en conviens, pour ces vrais prisonniers que nous sommes, bien trop aveuglés par les splendeurs de leur palace, par son confort et par les feux qu'il persiste à jeter sur lui-même, pour pouvoir déceler le travail de délabrement qui ne cesse de s'inscrire jusque dans ses fondations, ou le lent épaississement de ces ténèbres qui le cernent. En dépit (et sous le couvert) de nos très objectives techniques du radio-guidage et de la surcongélation, nous vivons dans l'imaginaire; et si notre puissance matérielle « fait » encore un petit peu, sans nous, ce que nous appelons l'histoire, nous n'en avons [233] pas moins perdu le sens de la durée - et dans tous les sens à la fois. Comme le voulait Spinoza, notre pensée se meut dans l'éternel, où ses aberrations mêmes ne sont plus que des modalités de la Substance, bien qu'elle puisse simultanément s'y donner le frisson de l'existence concrète en rêvant çà et là de quelque instant privilégié : à toute révolution réelle notre pensée objecte ses absolus critères; et notre bonne conscience n'en saurait être entamée, puisque nous ne cessons d'entrevoir, songe après songe, l'éventuelle et prestigieuse imminence d'une vraie révolution. Car il ne nous manque, en fin de compte, que d'être « en situation», quand tant d'autres le sont qui n'ont pas notre science...

Ces autres-là, je les crois pour ma part - s'il s'agit d'entreprise révolutionnaire - infiniment mieux placés que nous ne saurions l'être. Parce qu'ils en ont besoin et que nous nous contentons d'en avoir envie, leur objectivité est nécessairement supérieure à la nôtre. Parce qu'ils abordent les problèmes de tout leur être, pour avoir été opprimés corps et âme, leur pensée demeure concrètement dialectique, quand la nôtre n'est guère plus qu'une pensée de la dialectique. Parce qu'ils ont vécu dans leur chair, et trop souvent continuent de vivre, un malheur quotidien, c'est pour eux-mêmes qu'ils veulent le bonheur, quand il nous suffit, presque heureux que nous sommes, d'en attendre patiemment la venue au nom de nos petits-enfants. Parce que c'est leur misère réelle 
qui a compté les jours et mesuré les humiliations, c'est dans le temps réel qu'ils éprouvent le besoin de parcourir toute la dimension humaine: mais nous, qui pensons avoir déjà frayé la plus grande partie du chemin, nous admettons sans trop de peine qu'un temps indéfini puisse être désormais nécessaire pour parcourir le reste. Parce qu'ils n'ont jamais connu l'ennui, mais seulement le travail, la souffrance et la rage, parce qu'il leur a fallu sans relâche espérer, ils conçoivent la durée comme une effective maturation et peuvent dès lors en tirer parti pour y mûrir à tout moment leurs diverses libérations : d'une Histoire qui ne nous concerne plus que très indirectement, nous [234] tentons par contre de nous distraire en nous réfugiant dans l'instant, en imaginant quelque fête inouie, qui jamais n'est la nôtre et à laquelle nous ne pouvons guère que substituer, de proche en proche, les mornes plaisirs de nos petites évasions. J'exagère, je durcis les contrastes, je manque d'objectivité ? Le pense qui pourra. J'ai toujours eu une très mauvaise mémoire, mais ça ne m'empêche pas de réentendre dans ma tête, ou de relire à l'occasion, d'innombrables sceptiques qui n'avaient pas donné cher de tel ou tel peuple lorsqu'il entreprenait de se mettre debout, et qui n'hésitent pas aujourd'hui à saluer son relatif succès - en l'opposant au regrettable échec de tel autre qui tente à son tour d'avancer.

Revenons plutôt à Fanon, à son sens dialectique des phénomènes humains. Sur le nationalisme, sur la culture, sur la pratique révolutionnaire, on n'en finirait pas de citer les textes où il réclame qu'il soit tenu compte de tout et montre, dans le plus bouleversant des langages, comment on peut bien dire, en effet, que tout se tient: la violence libératrice et l'invention culturelle, la transformation des hommes et celle de l'Etat. D'un bout à l'autre on y retrouverait, irréductiblement liés, la description et l'appel, l'affirmation du progrès et l'exigence d'avancer, le mouvement réel et l'effort pour le susciter. Ces deux dimensions, je le sais bien, sont à nos yeux parfaitement hétérogènes, et nous mettons toute notre honnêteté à ne les point confondre: en quoi nous manquons les hommes réels (ceux qui sont encore capables d'agir et d'entreprendre) parce qu'il leur faut évidemment tenir pour au 
moins aussi vrai ce qu'ensemble ils s'efforcent de faire que ce qui a déjà pu en résulter. L'objectivité dont nous nous faisons un devoir et que nous tentons d'imposer à autrui, c'est la nôtre: celle d'une subjectivité plus ou moins satisfaite. Portée par un corps social en relatif équilibre, notre pensée, en effet, a tout loisir de balancer, de peser indéfiniment le pour et le contre. Ainsi les problèmes humains deviennent-ils, à nos yeux, de plus en plus théoriques: c'est vrai pour nos propres problèmes, et combien plus encore lorsqu'il s'agit de ceux des autres. Convenons en tout cas qu'il faut être soi-même dans une sacrée situation de conservatisme (« je sais ce qu'un changement [235] me ferait perdre, je ne suis pas sûr de ce que j'y pourrais gagner ») pour ne pas comprendre que dans la plupart des situations humaines toute description suppose une certaine incitation: les exigences de l'homme font partie de sa réalité, et seuls les esthètes que nous devenons peuvent avoir l'idée de la décrire sans avoir le souci de les stimuler. La vérité ne saurait être la même pour ceux qui se contentent d'en jouir rêveusement et pour ceux dont les besoins vitaux se confondent avec le besoin de la conquérir. Dès 1959, à la toute dernière page de L'An V, Fanon osait écrire: «La Révolution en profondeur, la vraie, parce que précisément elle change l'homme et renouvelle la société, est déjà très avancée... » Appelez ça propagande ou manque d'objectivité : j'y reconnaîtrai plutôt, je l'avoue, cette sorte de foi, - d'inévitable pari sur la mise en commun des ressources humaines, - en l'absence de laquelle, sans doute, aucune tentative d'objectivation n'eût jamais abouti parmi nous. Et si vous pensez pouvoir la déclarer aveugle, je vous renverrai par exemple à ces quelques lignes, qui me semblent la préciser assez bien « Il ne faut pas attendre que la nation produise de nouveaux hommes. Il ne faut pas attendre qu'en perpétuel renouvellement révolutionnaire les hommes insensiblement se transforment... Il faut aider la conscience.»

"Il s'agit de lâcher l'homme», avait écrit Fanon dans son premier livre: « il ne faut pas essayer de fixer l'homme, puisque son destin est d'être lâché ». Si j'essaie de comprendre aujourd'hui, à travers lui, la situation du peuple algérien, je dirai qu'il s'agit d'une aventure en 
cours, d'un mouvement profond, d'une histoire en train de se faire, et que les contradictions qui hantent cette histoire, la façon même dont elles la hantent, me rendent plus optimiste - en matière de «lendemains qui chantent » - pour cette Algérie maghrébine, et déjà si africaine, que pour notre France, si française encore. Le fait est, en tout cas, qu'il faudra bien l'aider jusqu'au bout, cette sceur nouveau-née que trop longtemps nous avons maintenue dans les limbes: car il se trouve aujourd'hui que nous ne pouvons plus nous passer d'elle... Aussi longtemps que nous ne ferons rien par nous-mêmes, c'est surtout par son intermédiaire (notre famille s'étant un peu [236] restreinte durant ces derniers temps) que nous serons tentés de maintenir notre « influence », sur tel ou tel secteur de ce monde qui tend de plus en plus à nous devenir étranger.

Sans doute le peuple algérien n'a-t-il pas encore été suffisamment lâché. Mais je parie volontiers qu'il obtiendra de l'être quand nous n'en serons encore, à force de civilisation, qu'à nous relâcher davantage. Peut-être alors l'idée nous viendra-t-elle de relire Fanon, et peut-être parviendrons-nous à reconnaître, au plus profond de nous-mêmes, cette exigence dont il parle, sa souterraine efficacité.

Mais quoi ? Sommes-nous vraiment condamnés à attendre, pour découvrir les vertus de l'action, que toute action soit, pour nous, devenue vaine? Plus ou moins nourris, plus ou moins respectés, nous sentons bien pourtant qu'il ne fait pas bon vivre dans cette société sur laquelle nous vivons. Très relativement actifs vis-à-vis d'elle (dans la mesure où nous la parasitons), nous lui laissons par ailleurs le soin de nous contaminer jusqu'à la moelle: la dénonçant au niveau des idées, nous en subissons la pernicieuse influence au cœur de notre vie; à chaque jour, à chaque heure nous lui rendons les armes, et tous nos rapports humains en sont constamment infectés. En chacun de nous les symptômes du mal sont déjà visibles : s'il est relativement aisé d'admettre que tout 
chrétien conscient s'efforce à l'athéisme, on aura sans doute un peu plus de peine à concevoir que tout communiste conscient...

Dieu me pardonne: ma remarque ne visait qu'à faire apparaître, chez ces privilégiés que nous sommes, l'équivalent d'un besoin : une nécessité non-matérielle, certes, mais qui devrait bien être tout aussi pressante, pour nous autres consciences, que le fait d'avoir faim pour un néocolonisé. Convenons avec Sartre que "la faim c'est beaucoup plus que la faim »; et convenons, corrélativement, que la pensée consciente est aussi bien autre chose qu'elle-même: Fanon ne s'y est pas trompé, parce que sa peau était noire. Si la nôtre est blanche, et si notre corps se porte en général assez bien, n'en profitons pas pour [237] oublier que ce nègre, arrière-petit-fils d'Africains, n'a finalement résolu son propre conflit qu'en assumant sa lointaine origine par la médiation d'un peuple, africain mais de race blanche: entre sa propre conscience (blanche) et son propre corps (noir), toute dialectique - si généreuse qu'elle fût - demeura vaine, jusqu'au jour où il parvint enfin à se donner un corps social. Pour facile que soit notre problème en comparaison du sien, n'espérons pas nous en tirer différemment : ou bien nous ferons corps avec ce prolétariat européen dont nous ne sommes pas (comme avec ces sous-développés qui vont bientôt choisir de nous ignorer), ou bien nous resterons captifs de nos mornes altitudes, que toute lumière humaine est sur le point de déserter.

Telle est, pour nous autres bâtards, l'unique voie de la reconnaissance. Pas plus que cet Antillais n'était algérien, nous ne sommes, bien sûr, prolétaires ou sous-développés. Et peu m'importe que Fanon soit réellement devenu ce qu'il prétendait être, qu'il ait ou n'ait pas été pleinement fondé à dire «nous » lorsqu'il parlait des Algériens : ce qui compte c'est qu'il les ait compris au point de s'en faire accepter. Ne pourrions-nous inventer, avec tout cet équipement culturel dont nous sommes si fiers, une forme de solidarité active qui soit suffisamment réelle, vis-à-vis de nos semblables différents et si longtemps défavorisés, pour que ces hommes - dont le destin concret commande notre destin « spirituel » - cessent de voir en nous, suivant les cas, des intellectuels de service ou des paternalistes d'élite? Car nous avons be- 
soin d'eux, c'est sûr, bien plus qu'ils n'ont besoin de nous, et nous nous flattons volontiers de «penser » bien mieux qu'ils ne sauraient le faire. Si nous tentions vraiment, pour une fois, d'affronter avec eux leurs problèmes concrets, de les aider à les poser comme leur lutte exige qu'ils le soient? Je ne me lance point ici à mettre Paris en bouteille: mais ce serait si bon, ça soignerait si bien nos diverses névroses, de parvenir un jour à travailler ensemble - avec ces travailleurs...

Fanon, tragiquement, nous a quittés avant qu'ait pu être officiellement proclamée cette Indépendance algérienne [238] qu'il offrait en exemple à l'Afrique entière (au point d'interpréter parfois en termes algériens telle ou telle situation qui ne s'y prêtait qu'assez peu) : je laisse aux croque-morts de toute appartenance le soin de décider s'il eût été déçu par l'Algérie nouvelle ou s'il eût persisté à combattre pour elle. Ce qu'on peut du moins retenir de lui, c'est l'exceptionnelle énergie qu'il a manifestée durant sa vie entière, c'est l'extraordinaire santé dont cette conscience a fait preuve alors même qu'un ignoble et incurable mal avait entrepris de lui ronger le sang.

Aux tout derniers moments, je le sais, ce mal engendra à son tour une pensée mauvaise, une fausse pensée: dans cet hôpital de New York où le tremblant espoir qu'on nourrissait encore de le sauver le condamnait à mourir loin de son peuple, définitivement exclu de cette humaine entreprise à laquelle il s'était donné, Fanon usa ses dernières forces à se débattre contre une médecine impuissante, qu'il soupçonnait de vouloir lui blanchir le sang... Car cette conscience noire fut emportée par une leucémie (en termes objectifs: augmentation, dans la composition sanguine, du nombre des globules blancs).

Que l'atroce ironie de notre langage ne nous fasse pourtant pas oublier que, si cette existence prit parfois à nos yeux des allures plus ou moins crispées, sa principale vertu fut de puiser - sans trêve et sans réserve - dans la force vitale dont elle disposait. «Le soleil que je transhume», disait-il. Nous qui faisons si volontiers des gueules d'enterrement, qui pour un oui ou pour un non prenons des airs « sinistres», nous qui semblons toujours porter sur nos épaules délicates toute la misère du monde et tout le poids de ses péchés, ne tenterons- 
nous donc jamais de tirer parti de nos privilèges autrement que pour emmerder le monde et nous compliquer la vie? Sommes-nous donc à jamais incapables d'aller aux autres, à nos propres problèmes, avec, dans nos têtes, un peu de ce soleil que brandissait vers nous ce camarade noir?

FRANCIS JEANSON. 